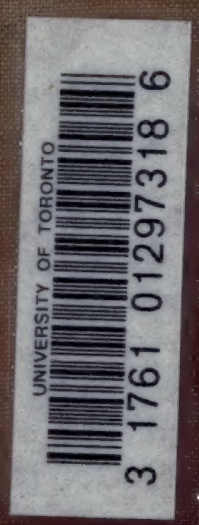

VIKIV. OI

TOROMTO

IIBRARY 


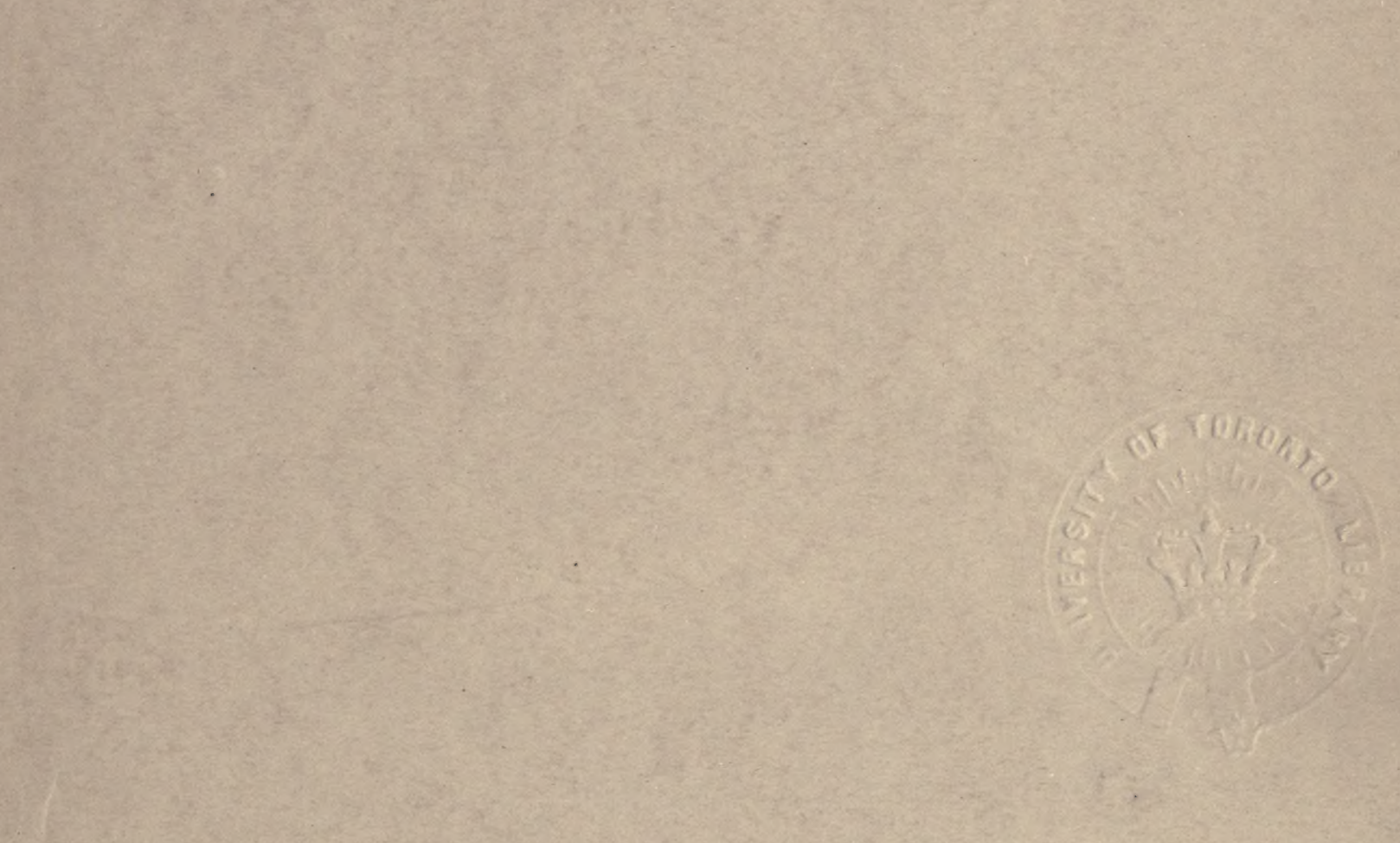


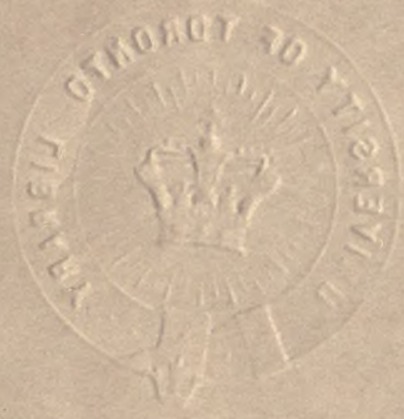




$$
\text { D i e }
$$

fossilen $Z$. Ihane und úndehen $\frac{1.83}{28}$

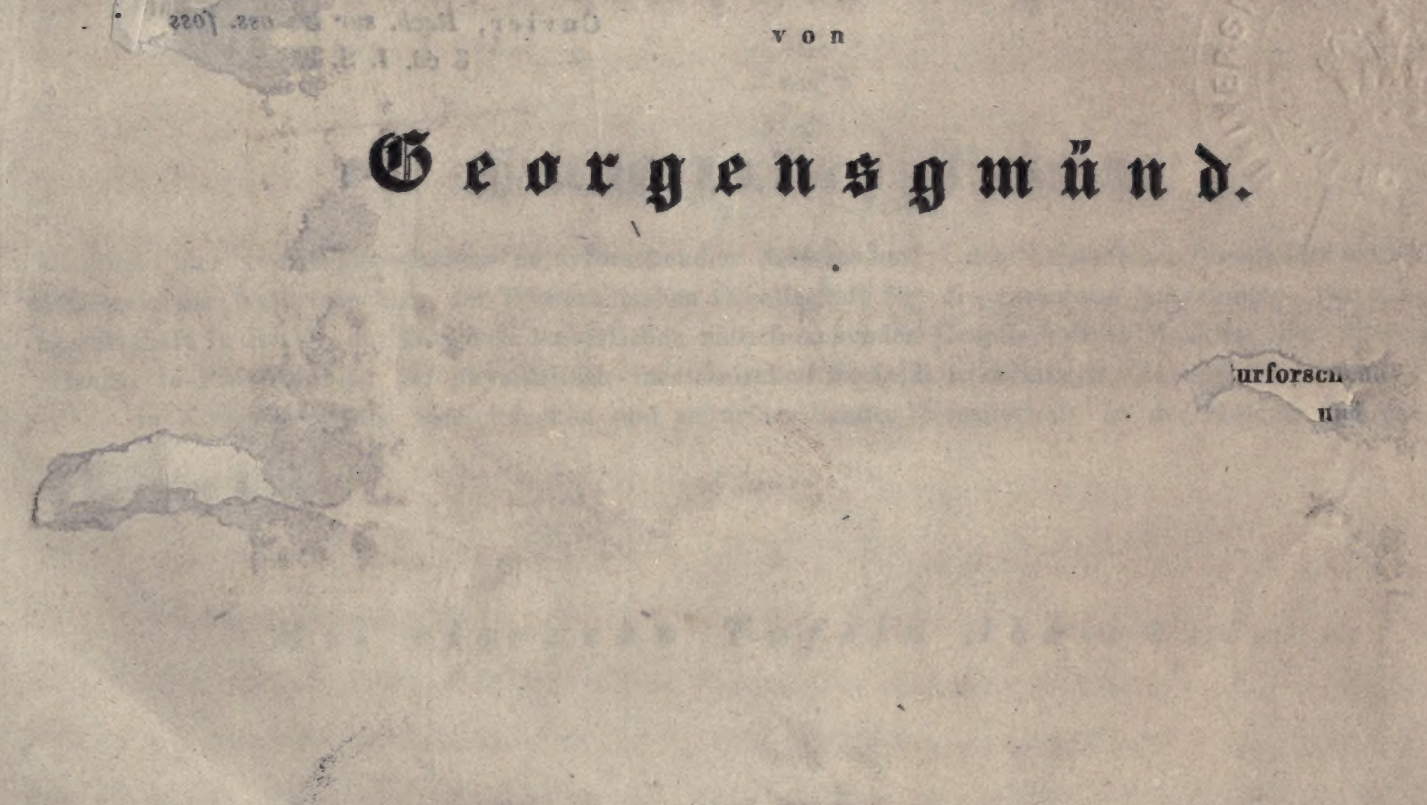


„Il est sensible, en effet, que les ossemens de quadrupèdes peuvent conduire par plusienrs raisons, à des résultats plus rigourenx qu'ancune autre dépouille de corps organisés.

Chvier, Rech. sur les oss. foss

3. éd. I. S. 30.

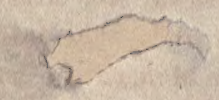


Dio

fossilen Zähne und Knochen

saco

\title{
ihre Ablagerung
}

in $\mathrm{der}$

\section{Gegend von Geoxgeng}

\author{
Untersucht und a b g e b i l d e t \\ 8)
}

Mitgliede der Senckenbergischen naturforschenden Gejellochaft, der kaiserlichen Leopoldinisch-Carolinischen Akademie der Naturforscher, der Wetterauischen Gesellschaft für die gesammte Naturkunde, der naturforschenden Gesellschaft in Berlin, der Russisch kaiserlichen naturforschenden Gesellschaft in Moskwa, der Academy of natural Sciences in Philadelphia, der physikalisch-medicinischen Societät in Erlangen, der uaturforschenden Gesellschaft in Strassburg, der medicinischen und naturforschenden Gesellschaft in der Moldau und anderer.

Mit vierzehn Tafeln Abbildungen.

\section{Frankfur am Main.}

Druck und Verlag von Johann David Sauerländer. 
"In der Naturbeschreibung, wie in historischen Untersuchungen, stehen die Thatsachen lange einzeln da, bis es gelingt, durch mühsames Nachforschen sie in Verbindung zu setzen."

Alex. r. Humboldt, Ansichten der Natur,

2. Auf. I. S. 65 .

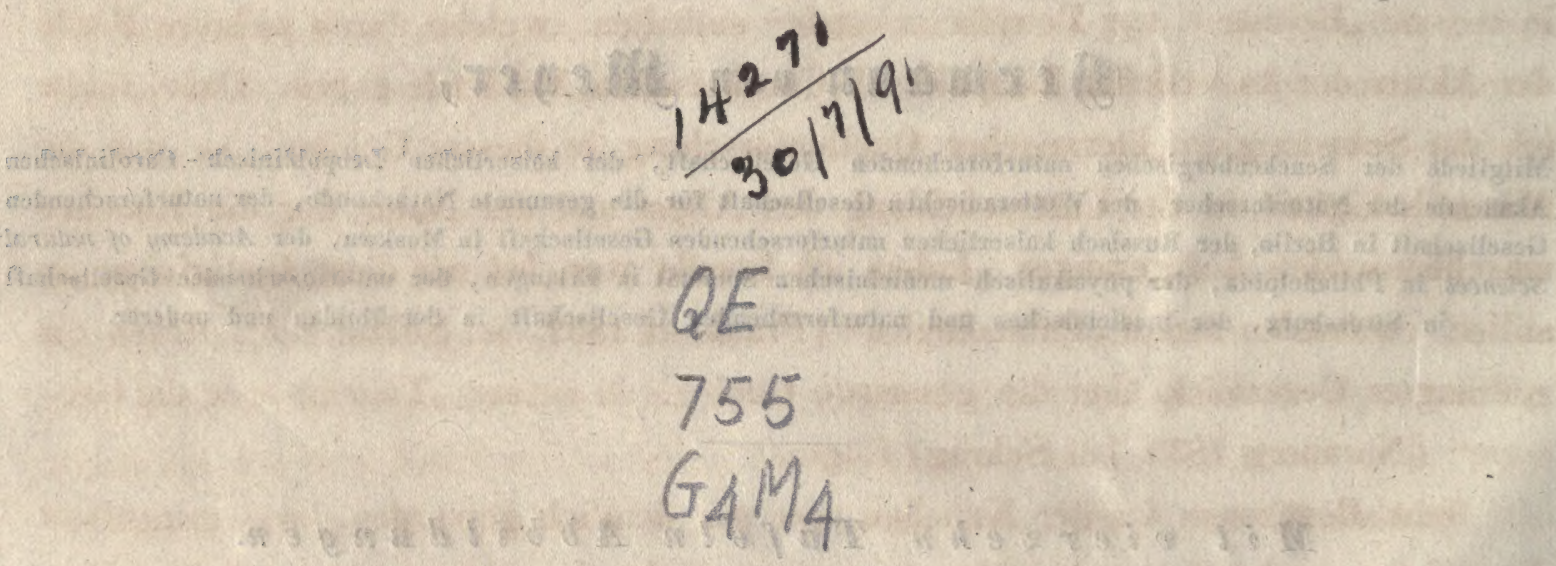




\section{$\begin{array}{lllllll}\mathbf{V} & \mathbf{r} & \mathbf{r} & \mathbf{r} & \mathrm{e} & \mathbf{d} & \mathbf{e}\end{array}$}

Manches Jahr ist über der Herausgabe dieser Schrift hingegangen. Ich kannte anfangs die Schwierigkeiten nicht, welche damit verknüpft waren. Liebe zur Sache hat mir diese beseitigen helfen, obgleich sie unter der Arbeit fühlbarer wurden. Von Naturwissenschaften war ich nur mit der Chemie und Mineralogie vertraut; auch die Geologie lag mir näher; hingegen die vergleichende Anatomie oder Osteologie war für mich ein ganz fremdes Feld. $\mathrm{Zu}$ ihr sah ich mich geführt durch die Ueberreste einer längst verstorbenen Thierwelt. Die erste Anregung dazu gab mir eigentlich die Auffindung eines vollständigen fossilen Ochsenschädels mit einer Knochenwunde auf der Stirne. Hierauf fand ich Gelegenheit, mich auch mit andern fossilen Knochen zu beschäftigen, und selbst welche zu entdecken. Die Versuche, sie zu bestimmen, sind in meinen „Beiträgen zur Petrefactenkunde“ enthalten, welche durch mehrere Bände der Akten der kaiserlichen Leopoldisch-Carolinischen Akademie gehen. Dabei fühlte ich die Schwierigkeit literarischer Quellenforschung in diesem Gebiete, so wie die Mangelhaftigkeit in der Unterscheidung des Alters und der Natur der die Knochen umschliessenden Ablagerungen. Indem ich bemüht war, bei mir diese Bedürfnisse zu stillen, entstanden meine „Palaeologica“ (Frankfurt 1832, bei Schmerber), denen ein gedrängter Ueberblick über die gesammte Geologie in meiner „Tabelle über die Geologie" (Nürnberg 1833, bei Schrag) folgte.

Beim Bestimmen fossiler Knochen war mir deutlich geworden, wie mangelhaft die meisten vorhandenen Abbildungen seyen, und wie schwer sich nach denselben bestimmen lasse. Nur wer den Gegenstand selbst untersucht, ist im Stande, davon ein in allen seinen Theilen getreues Bild zu entwerfen, das auch Andern nützt. Das Untersuchen muss mit dem Abbilden Hand in Hand gehen. Ich erkannte diess wohl, war aber in der Führung des Stiftes ungeübt, und in der Lehre von Licht und Schatten und deren belebenden Abstufungen unerfahren. Meine ersten Versuche hierin reichen nicht über die Darstellung der fossilen Ochsenschädel hinaus, welche meine Abhandlung uber die fossilen Ochsen und ihr Vorkommen in dem unter der Presse befind- 
lichen Bande der Akten der kaiserlichen Leopoldinisch-Corolinischen Akademie begleitet. Gerne denke ich nun zurück an die Stunden, in denen ich bemüht war, bei mir selbst zeichnen zu lernen, und die Gegenstände, so wie sie sich darstellen, aufzufassen und wiederzugeben. Die schwierigsten und verwickeltsten Falle dabei schienen mir nichts anders zu seyn, als Verbindungen der einzelnen einfachen Falle, auf die es hauptsächlich ankommt, und die zerlegt oder entwickelt werden müssen, um sie recht zu begreifen. Naturhistorische Abbildungen sollen den Umriss und die einzelnen Theile mit ganzer Genauigkeit und Schärfe enthalten. Dazu verhilft ein praktisches Mittelchen, welehes darin besteht, dass man den Sehpunkt etwas bewegt, und so das Verziehen, welches die Perspective den Formen verleiht, zu mildern sucht, doch ohne den malerisehen Effect zu beeinträchtigen. Auch wirkt da, wo viel Detail zusammenliegt, etwas Freiheit in Anbringung der Beleuchtung oft recht verdeutlichend; aber auch sie darf nie bis zum Stören missbraucht werden. Ich überzeugte mich nun auch erst, dass die beschreibende Naturgeschichte im engern Sinn wesentlich auf bildlicher Darstellung beruhe, dass eher die Darstellung in Worten dieser untergeordnet seyn könne, als umgekehrt, dass man den Gegenstand gleichsam in sich selbst müsse Gestalt gewinnen lassen, an der alles Bemerkenswerthe hervorleuchtet, dass diese Gestalt es sey, welche man wiederzugeben habe, dass sogar diese Darstellungen öfters dienlicher seyen, als der Gegenstand selbst; aber auch, dass zu solchen Darstellungen nur der Forscher selbst befähigt sey; weshalb ich es mir zur Pflicht machte, Jedem; der zu naturwissenschaftlichen Studien ernstlich hinneigt, anzurathen, zuerst weniger mit der Feder als mit dem Zeichenstifte seine Untersuchungen zu unterstützen.

Unter solchen Bestrebungen ward nun auch diese Schrift zur Mitheilung reif. Vieles darin ist nur vorbereitet; Alles aber war man so zu geben bemüht, dass es Verbesserung und Abänderung annimmt. Der odontologische Vorläufer schien mir Bedürfniss. Gerne hätte ich ihn weiter geführt, und unter anderer Gestalt gegeben; doch konnte diess vorerst nicht seyn. Die Abbildungen sind in natürlicher Grösse und alle von mir gezeichnet. Ich fand indess den Stein nicht immer geeignet, die Zeichnungen vollkommen wiederzugeben.

Herr Oberlieutenant von Gemming in Nürnberg und der königl. Bayerische Kämmerer Herr Graf zu Münster in Bayreuth hatten die Güte, mir Alles mitzutheilen, was 
ihre Sammlungen an Resten aus dieser Ablagerung enthalten. Sie setzten mich dadurch in den Stand, meinen Arbeiten uber diese interessante Gegend einen passenden Umfang einzuräumen. Thnen schulde ich dafür den aufrichtigsten Dank, den ich hiemit öffentlich aussprechen zu können mich freue. Damit verbinde ich auch den Dank für die von verschiedenen Seiten erhaltenen Mittheilungen uber das Vorkommen von fossilen Knochen, über die Natur und Lagerungsverhältnisse knochenführender Gebilde, über Werke, kleinere Schriften oder vereinzelt angefertigte Blätter, Abbildungen etc., die in meinen Palaeologicis noch nicht erwähnt sind; aber auch für Berichtigungen darin enthaltener Angaben danke ich; indem ich den Wunsch um fernere Mittheilungen beifüge. Es leitet mich dabei kein anderer Zweck, als der, fortzufahren, das so sehr verstreute Material über diese Gegenstande geeignet zusammen zu fassen, um das Studium der fossilen Knochen zu erleichtern und die wichtigen Ergebnisse aus denselben zu fördern. Jederzeit werde ich mir auch ein Vergnügen daraus machen, mir zugesandte fossile Ueberreste von Wirbelthieren, mit Ausnahme der fossilen Fische, denen sich Herr Dr. Agassiz mit so vielem Erfolg gewidmet hat, zu untersuchen.

Die ausführliche Bekanntmachung der einzelnen knochenführenden Ablagerungen oder Localitäten und ihrer fossilen Einschlüsse ist jetzt unerlässlich. Die „Description des environs de Paris" von Cuvier und Alex. Brongniart bleibt ein Muster solcher monographischen Arbeiten und ist unstreitig der wichtigste Theil in Cuvier's gefeierten, „Recherches sur les ossemens fossiles“6 (zuletzt 1825 herausgeben). Diesem Werke in Frankreich stehen Buckland's „Reliquiae Diluvianae“ (1823) gegenüber. Bedeutende Monographien über Sauugethierablagerungen sind auch Croizet's und Jobert's „Recherches sur les ossemens fossiles du Puy-de-Dôme“" (1824), von denen der zweite Band vergeblich erwartet wird; ferner Buckland's und Clift's Beschreibung der fossilen Knochen der Irawadiebene in den Geolog. Trans. 2. II., auch in Crawfurd's ,Journal of an Embassay of Ava“ (1829); Bravard's ,Monographie de la montagne de Perrier" (1828), Kaup's ,Description d'ossemens fossiles du Muséum de Darmstadt“ (1832) und Schmerling's „Ossemens fossiles de cavernes de Liège“ (1833). Manches ist noch rückstăndig und versprochen. Cuvier hat die Herausgabe des Supplementbandes zu seinen ",Recherches" etc. nicht erlebt. Sie wird nun durch Laurillard besorgt, und der im Frscheinen begriffenen vierten Ausgabe von Cuvier's „Recherches“, etc. beigegeben, 
einer Ausgabe, welche in Octav und mit hinterlassenen Noten des Verfassers, herauskömmt. Von Buckland's zweitem Bande seiner „Reliquiae Diluvianae“ ist es wieder still; auch verlautet von Bravard's und de Christol's „Ossemens fossiles de la France méridionale“", und von Marcel de Serres, Dubreuil's und Jean-Jean's „Recherches sur les ossemens fossiles de Lunel-Vieil“" nichts; Jäger's Werk über die fossilen Saugethiere Würtemberg's ist im Erscheinen begriffen; von Kaup's „Description“ etc. wird das dritte Heft erwartet; von Schmerling's Werk über die Höhlen Lüttich's ist das zweite Heft, was sehr zu loben, mit lebensgrossen Abbildungen reich an Zahl, erschienen; Partsch wird durch die Beschreibung der fossilen Knochen Oesterreich's eine längst empfundene Lucke ausfüllen; Morren will ein Werk uber die in den angeschwemmten und Tertiärgebilden Belgien's gefundenen Knochen herausgeben. Auch in der Bekanntmachung der fossilen Reste von Wirbelthieren anderer Klassen ist grosse Thatigkeit. Agassiz gibt bekanntlich ein unvergleichliches Werk über die fossilen Fische heraus; über die Saurier Würtemberg's hat Jäger, und über die der Normandie Geoffroy geschrieben und Deslongchamps ein Werk versprochen; Saurier habe auch ich in den Akten der kaiserl. Leopoldinisch-Carolinischen Akademie und im ,Museum Senckenbergianum" bereits bekannt gemacht, denen eine ăhnliche Arbeit in den ,Mémoires de la société d'histoire naturelle de Strasbourg“6 folgen wird; Mantell's „Geology of the South-East of England"6 (1833) ist hier auch zu nennen; des Thomas Hawkins Abhandlung über Ichthyosaurus und Plesiosaurus mit Abbildungen in Folio, soll so eben erschienen seyn; Otto wird die Saurier Schlesien's mit den fossilen Fischen in einem Hefte herausgeben; auch haben Goldfuss und Graf zu Münster Saurier beschrieben. So steht es jetzt um die Kunde von den fossilen Wirbelthieren; wobei das reiche Material, das Deutschland ausserdem zu einem Werk über dieselben bewahrt, noch länger unbenutzt bleiben zu sollen scheint.

Erfreulich ist es indess, zu sehen, wie man an so vielen Orten eifrig bemüht ist, eine Welt aufzuschliessen, über die nur seit unberechenbarer Zeit von Bergen bedeckte und von Schichten umschlossene Trummer das Zeugniss ablegen; dass sie bestanden habe. Möchte diese Thätigkeit nie erkalten!

Frankfurt a. M, im August 1834. 


\section{Zu r O d o n t o l o g i e.}

Die Odontologie oder Lehre von den Zälnen gehört, gleich der Osteologie und so mancher andern Lehre von der Beschaffenheit gewisser Theilganze oder Systeme in der Structur der Geschöpfe, der vergleichenden Anatomie an.

Früher, so lange man die Zähne für gewöhnliche Knochen gehalten, konnte man nicht wohl daran denken, sie von den Knochen, so weit als thunlich, getrennt zu betrachten, und einer gründlichen Behandlung zu unterwerfen. Die grossen Stossoder Eckzăhne wurden selbst für Hörner angesehen, wie diess z. B. Pa us a nia s mit den Stosszähnen des Elephanten gethan; ein Irrthum, den schon Philostratus zu widerlegen versuchte. Die Entstehungsweise der Zähne, ihre Substanzen und ihre Beziehungen zu den Knochen beweisen aber deutlich, dass sie weder Knochen noch Hörner sind, sondern zu einer eigenen Abtheilung von Organen oder Werkzeugen im Körperbaue des Geschöpfes gehören, und ihre nähere Betrachtung ergibt, dass es zu ihrem wie der vergleichenden Anatomie Nutzen ist, wenn man ihre Lehre als einen besondern Theil von letzterer betrachtet.

Die neuere Zeit hat viel zur Kenntniss der Zähne beigetragen, dabei aber auch fühlen lassen, welcher Ausdehnung dieses Studium noch fähig sey, und wie erwünscht und belohnend für die Wissenschaft eine gründliche Behandlung derselben komme. Die Andeutungen, welche ich darüber hier gebe, haben sich mir beim Studium der fossilen Knochen und Zähne aufgedrungen; sie gehören daher mehr zur Erläuterung meiner Arbeiten in letzterem Fache, denen sie sich nicht passend auf eine andere Weise unterordnen liessen, und sind also auch ohne allen Anspruch. Es sind, wie gesagt, nur Andeutungen, die leicht Abänderungen unterworfen seyn können; sie enthalten Bekanntes, sollen vor manchem Anerkannten warnen, durften aber auch Eigenes aufzuweisen haben. Dass dabei hie uud da Eingriffe in die vergleichende Anatomie uberhaupt geschahen, wird nicht zum Vorwurf sich eignen, da die in dieselbe einschlagenden Beschäftigungen nie ihre Richtung nach ihr verläuguen sollen. 
In der Wissenschaft von der Natur beruhen die Bestimmungen hauptsächlich auf Vergleichung. Das Vergleichen ist indess nicht so leicht, als es scheint. Die Schwierigkeiten wachsen mit den Aehnlichkeiten in gleichem Masse.

Was hier angedeutet wird, hat insonderheit Bezug auf das Bereich der Thiere, und wird bei der Bestimmung fossiler Knochen, wie wir glauben, einige Berücksichtigung verdienen. Aristoteles, dessen ausgezeichneter Geist den lebendigen Quell der Natur trank, war der Erste, der die Zoologie in ihrem Umfang und mit bewunderungswürdiger Gründlichkeit erfasste. Auch war er schon Physiolog, und mit besonderer Liebe führte er seine Untersuchungen weiter, indem er sie vergleichend zusammenstellte, und daraus allgemeinere Folgerungen zu ziehen versuchte. Unrichtiges läuft Jedem unter; daher konnte es auch nicht fehlen, dass dem scharfsinnigen Aristoteles in dem langen Zeitraume, welcher zwischen ihm und uns liegt, manches Irrthümliche nachgewiesen wurde. Er ist indess zu Ergebnissen gelangt, welche seitdem unbestritten dastehen, und kaum mehr als weiter ausgebildet worden sind. Zur Lieblingsbeschäftigung aber wählte sich Aristoteles die vergleichende Anatomie. Err würde als Schöpfer derselben zu bezeichnen seyn, hätte nicht De mokritus von Abdera, Lehrer des Hippokrates, dadurch dass er, so viel man weiss, der Erste war, welcher die verschiedenen Thiere mit Geschicklichkeit und Kunst zu zergliedern und zu vergleichen anfing, sich diesen Namen verdient. Von dieser Beschäftigung war indess Aristoteles so sehr durchdrungen, dass er nicht anders wusste, als dass zu Untersuchungen Zergliederung gehöre. Die umfassende Richtung, die er seinen Arbeiten gab, sicherte ihm daher auch den grossen Ruhm in der vergleichenden Anatomie, und die glückliche Anwendung derselben auf die Zoologie uberhaupt führte ihn zur Aufrichtung eines Gebäudes in der Zoologie, das ăhnliche Bewunderung verdient, als die wohlerhaltensten Denkmäler der Baukunst des classischen Alterthums; wiewohl man es gewagt hat, dem Aris to teles das Verdienst als Classificator oder Systematiker abzusprechen. Ich habe nicht die Absicht, hier eine Geschichte der vergleichenden Anatomie zu schreiben, und es wird daher Entschuldigung finden, wenn ich, in stillschweigender Anerkennung Aller, welche sich wirkliche Verdienste um dieselbe erworben, gleich des Vicq d'Azyr namentlich gedenke. Dieser fing nämlich an, nicht allein die analogen Theile in verschiedenen Thiergattungen, sondern auch verschiedene Theile 
an einem und demselben Individuum unter einander zu vergleichen, wobei er die Art und den Grad der Abweichungen derselben fand. Viel ist bereits verglichen, dabei auch nicht selten geirrt worden.

Eins der bewunderungswürdigsten Ergebnisse der Vergleichung ist die Existenz der Einheit des Planes in der unendlichen Mannichfaltigkeit geschaffener Formen. Welches Resultat bringt den Sterblichen dem nie zu erfassenden Geheimniss der Natur näher, als dieses! Einige Forscher unserer Zeit erlaubten sich, die Entdeckung dieser Einheit im Plane thierischer Bildungen sich anzueignen, während dieselbe doch weit alter ist. Was unsere Zeit sich rühmen darf ist, der Analogien. Werth und Bedeutung schärfer hervorgehoben und genauer durchgeführt zu haben; sie hat gezeigt, dass Analogien, wenn sie auch nicht gleich in die Augen fallen, nicht wegzuläugnen, sondern wirklich in der Weisheit begründet sind, welche die Natur allerwärts kund gibt, und dass sie in dem Thierreiche namentlich sich auf höchst befriedigende Weise durchführen lassen.

Die bestehenden Gesetze, Verhältnisse, Folgerungen etc. der vergleichenden Anatomie beruhen auf der Gesammtmasse von Beobachtungsthatsachen. Die Vermehrung letzterer kann jene vermehren, verringern, verändern, besonders aber läutern. Man weiss, dass die Organe, aus denen der Körper besteht, in den verschiedenen Geschöpfen nicht gleichmåssig verschieden entwickelt sind. Die vergleichende.Anatomie lehrt, dass, wenn gewisse Organe in manchen Geschöpfen mehr untergeordnet und selbst mangelhaft (wemn man so sagen darf) vorhanden sind, dafur andere und nicht selten gerade solche vorherrschend auftreten, die in Thieren, bei denen erstere Organe mehr vorwalten, zurlickgedrăngt, mangelhaft oder in Zahl verringert sind. Diess erinnert an ein von $G$ ö the in die vergleichende Anatomie eingeführtes Gesetz, welches sagt *): , dass keinem Theil etwas zugelegt werden könne, ohne dass einem andern dagegen etwas abgezogen werde, und umgekehrt." In manchen Fallen findet dieser Satz Anwendung, er lảsst aber keine Verallgemeinerung zu. Richtiger wăre gesagt worden: Wenn einem Theil etwas zugelegt ist, so konnte diess geschehen, indem dafur einem andern etwas abgezogen wurde, und umgekehrt. Denn man wird bei umsichtigerer Betrachtung gewahr werden, dass die Natur keineswegs in die Schranken gebannt ist, welche Gesetze der Art ihr anlegen, sondern dass sie dieselben eben so gewiss uberspringt, als sie in andern Fällen, ohne weniger gesetz-

(2) Göthe's Werke (120.), B. 55. S. 205. 
massig zu seyn, des ihr eingräumten Umfanges nicht einmal benothigt ist. So gibt es, um bei obigem Fall stehen zu bleiben, Thiere, in denen nicht bloss eins der Organe, sondern beide entweder zurückgedrängt sind oder vorwalten.

Gleichwie die Anatomie des Menschen sich durch Hinzuziehung der Anatomie der Thiere wichtiger Aufschlüsse erfreut, so wird es der vergleichenden Anatomie uberhaupt erst durch Würdigung der fossilen Knochen möglich, die Structurgesetze im gehörigen Umfang zu erforschen.

Gewöbnlich erstaunt man über die Formen der fossilen oder versteinerten Geschöpfe; allein mit Unrecht. Man denke sich nur einmal unsere jetzige Schöpfung statt jener in die Gräber von Erdschichten verschlossen, und dafur die, welche wir lebend nicht kennen, als Bevölkerung des Erdballs. Vor welchen Formen und Typen hätte man alsdann Ursache, in grösseres Staunen zu gerathen? In den fossilen Knochen sah die Unkenntniss Reste fabelhafter Geschöpfe; die überkluge Weisheit dagegen erkannte nicht, dass dem schöpferischen Willen eine so freie und allseitige Gesetzmässigkeit in der Hervorrufung von Bildungstypen zustehe, wie sie in mehreren fossilen, freilich uberraschend gegeben ist. Die Natur bildet nur Fin Ganzes; jedes Einzelne trägt das vollgültige Gepragge dieses Zusammenhanges. Nicht nur das gegenwärtig Bestehende, sondern auch Alles fruherer Epochen, worüber die Typen erloschen, bezeugt, dass es aus einer und derselben Natur hervorgegangen sey. Nichts wird aufgefunden, so sonderbar es wäre, dem die Natur nicht seine Stelle vorhergesehen hätte, auf der es dieselbe inniger verbindet.

Die Bestimmung der fossilen Knochen geschieht auf dieselbe Weise, wie die der nicht fossilen. Nur dadurch wird sie erschwert, dass man in der Regel darauf verzichten muss, das ganze Skelett zur Untersuchung dargeboten zu bekommen. Am besten und vollstăndigsten erhalten, auch häufig anzutreffen, sind die Zähne. Wenn sie schon bei den gewøßhnlichen osteologischen Untersuchungen besonders berüksichtigt werden, um wie viel mehr verdienen sie es bei der Untersuchung der fossilen Thiere? Der genaueren Beachtung der Zähne verdankte Cuvier die Möglichkeit, dem Studium der fossilen Knochen den Aufschwung zu geben, dessen es sich jetzt erfreut. Die Methode, der sich dieser Forscher bediente, besteht darin, dass man sich zuerst durch die Zähne eine Vorstellung vom Thier verschafft, und hierauf die vorgefundenen Theile vom Kopf, sodann von den Extremitäten und endlich vom übrigen Skelett damit zu vereinigen sucht. Hiedurch gelangt man am sichersten zur Kenntniss des Knochengerustes, aus dem weiter über die weiche Bekleidung dessel- 
ben und selbst über die Lebensweise des Thieres gegründete Vermuthungen aufgestellt werden können.

Hiebei wird voransgesetzt, dass bei Geschöpfen der Grad der Aehnlichkeit analoger Theile die Aehnlichkeit der ganzen Thiere angebe. Ein solches Gesetz ist indess eben so wenig in der vergleichenden Anatomie zulässig, als $\mathrm{H}$ a ü y's Fundamentallehre in der Mineralogie, wonach in den krystallisirten Körpern gleicher Grundform, auch gleiche Stoffzusammensetzung vorauszusetzen wäre, der entgegen aber jetzt der Isomorphismus, (Fuchs, Mitscherlich etc.) oder Plesiomorphismus (Miller) und der Dimorphismus (Mitscherlich, Weiss) gefunden ist, und überdiess das Bekenntniss steht, dass die äussere Körperform eines Krystalls durch ein Gesetz müsse bedingt werden, welches in keinem unmittelbaren Zusammenhang mit den Mischungsverhältnissen der Bestandtheile des Körpers sich befindet (Karsten). Cuvier scheint durch so viel treffliche Untersuchungen und durch kühne Vermuthungen, die sich bewährten, verleitet worden zu seyn, die Behauptung zu verallgemeinern: aus dem kleinsten fossilen Knöchelchen errathen zu können, wohin das Thier gehöre, von dem es herruhrt; und in seinem Ausspruche: ,une seule dent m'a, pour ainsi dire, tout annoncé", sollte man kaum den Forscher erkennen, der sich streng nur an das hielt, dessen Existenz durch Beobachtung dargethan war, und Allem misstraute, das diese nicht erprobt hatte. Die unberechenbare Allseitigkeit dessen, was seine Entstehung der lebendigen Natur verdankt, ergibt sich wieder recht auffallend aus dem Studium der fossilen Knochen. Hier ist es gewagt, Schlüsse aus einem Theil auf das Ganze, wie aus einer bekannten Grösse auf die unbekannte zu thun; die grössten Anatomen haben sich dadurch zu Trugschlüssen verleiten lassen. Wenn der Forscher glaubt, die Natur durch die Aufstellung eines Gesetzes sicher ergründet zu haben, da wird er von ihr oft plötzlich beschämt durch die seiner Vermuthung ganz entgegengesetzte Art, mit der sie sich von einer nicht geahnten Stufe gleichsam von Neuem erschliesst.

Zuerst führten mich meine Untersuchungen der fossilen Saurier zur Ueberzeugung, dass die Analogie eines oder mehrerer Theile, so gross sie auch sey, gänzlichen Mangel an Analogie in andern Theilen derselben Geschöpfe nicht ausschliesst, so dass Geschöpfe, welche in einzelnen Theilen die grösste Aehnlichkeit zeigen, im Uebrigen eine grosse, überraschende Unähnlichkeit besitzen kömnen. Daher ist es auch unmöglich, bei den fossilen Sauriern aus einem einzigen, selbst aus mehreren Skelettheilen, so wesentlich sie immer seyn mögen, im Wege der Analogie auf das 
ganze Thier zu schliessen; dazu wird vielmehr erfordert, zuvor vom Typus oder der Gesammtstructur des Thieres durch den Augenschein unterrichtet zu seyn.

Was ich an den fossilen Sauriern deutlich und öfter gefunden, das ist auch in anderen Klassen, nicht nur unter den fossilen, sondern auch unter den lebenden Formen vorhanden. Au letzteren făllt es gewöhnlich weniger auf, weil sie ganż der Untersuchung dargeboten werden, und man daher nicht nöthig hat, aus einem Theil auf's Ganze zu schliessen.

Nicht zu läugnen ist die bisweilen auffallende Aehnlichkeit oder das merkwürdige Hinuberspielen von Thieren der verschiedensten Structur in Betreff gewisser Theile, wahrend sie in andern Theilen nur um so mehr von einander abweichen. Es liessen sich Seiten mit den auffallendsten Beispielen fullen, welche diess beweisen. Doch gehören diese weniger hieher, als in das Bereich der vergleichenden Anatomie überhaupt.

Für Körpertheile, in denen das Typische am deutlichsten und sicherste ausgedrückt liegt, werden die Zähne gehalten. Sie sind wirklich ein eben so brauchbares als bequemes Mittel zu Bestimmungen und für die Classificirung. Da jedoch, wo nur sie allein geboten sind, würde es gewagt seyn, für die auf sie über die sonstige Structur des Geschöpfes gegründeten Folgerungen einstehen zu wollen. Es gibt Thiere mit grosser Verśchiedenheit im Zahnsystem, die einander doch sehr nahe gestellt werden, nach der Aehnlichkeit der allgemeinen Form ihres Körpers. Aus der Beschaffenheit der Zähne lässt sich mit einiger Sicherheit schliessen, ob und selbst in welchem Grad das Thier pflanzenoder fleischfressend ist. Schwieriger schon ist in gewissen Fällen daraus abzunehmen, ob das Thier ein Land-oder ein Wasserthier, selbst ob es überhaupt ein Săugethier sey, oder welch anderer Klasse es angehört habe. Es gibt z. B. Fische, welche durch ihre Zähne vorzugsweise sich als Fleischfresser, andere dagegen, welche aus demselben Grund sich als Pflanzenfresser charakterisiren, so wie Saurier, namentlich unter den fossilen, von denen Aehnliches gilt; so dass es bisweilen schwer fällt, aus vereinzelten Zähnen selbst nur über die Klasse zu entscheiden, der das Thier angehörte, von dem, sie herrühren. In den Zähnen liegt kaum ausgedrückt, auf welchem Weg das Thier seiner Nahrung nachgeht, und wie seine Gliedmassen beschaffen sind, was man doch nicht selten ersehen zu können vorgibt. Der Annahme, dass die Zähne der Sängethiere in den meisten Fällen einen zusammengesetzteren Bau haben und zu einem complicirteren Zahnsysteme geordnet stehen, lassen sich manche denkwürdige Ausnahmen unter den Säugethieren des Wassers, wie unter denen des Landes, entgegensetzen. Zudem 
wissen wir nicht, was noch Alles über die Zähne der Thiere anderer Klassen, welche fast gănzlich unbekannt sind, noch ermittelt wird.

Schlusse, welche bloss auf den Zähnen beruhen, haben sich wirklich öfter nicht bewahrt. Die Aehnlichkeit von Zahnen im Oberkiefer setzt nicht immer eine gleiche Aehnlichkeit im Unterkiefer voraus. Als Beweis diene ein Beispiel aus dem Bereiche der lebenden Thiere. Unter den Hasenmäusen gibt es die Geschlechter Chinchilla (Gray) und Lagostomus (Brookes), deren Backenzăhne sich im Oberkiefer fast ganz gleich sehen, dagegen im Unterkiefer sich sehr von einander unterscheiden *). Sogar die Schlusse aus der Analogie eines Theils der Zahnreihe auf die übrige Zahnreihe können falsch seyn. Den überraschendsten hieher gehörigen Fällen begegnet man unter den fossilen Thieren. Am Dinotherium z. B., von dem Cuvier nur die Backenzahne kannte, nach deren Beschaffenheit er dieses Thier für einen Riesentapir erklärte, hat sich später ausgewiesen, dass der vordere Theil seines Zahnsystems die grösste Verschiedenheit vom Tapir besitzt, und auch andere Theile, namentlich die Tastwerkzeuge, vom Tapir durchaus abweichen; es ist eins der merkwürdigsten Thiere. Ein anderes Beispiel liefern die fossilen Fleischfresser, deren Zahne Nesti, Cuvier, Croizet, Jobert und Bravard untersuchten, und die bald zu Ursus, bald zu Felis gezählt wurden. Die Anstände sind auf eigene Weise gehoben. Während dieses Streites stellt sich nun an vollständigeren Stücken heraus, dass diese Reste Fleischfressern angehören, deren Backenzähne Felis entsprechen, die aber in Betreff des Vorderendes der Schnauze von letzterem Thier uberraschend abweichen. Vor den untern Backenzähnen sitzt ein leerer Raum, damit der grosse, lange und flache Eckzahn des Oberkiefers unbehindert am Unterkiefer sich herunterbiegen könne. Diese grossen und sonderbar gebildeten Eckzahne sind dieselben, aus denen Cuvier seinen Ursus cultridens errichtete, die Bravard, sie zuerst zu Ursus, dann zu Felis zählend, richtig dem Oberkiefer einverleibte, und die Croizet und Jobert, mit der Bemerkung, Bravard habe, indem er einen Eckzahn vom Ursus in den Oberkiefer einer Felis gesteckt, eine wahre Missgeburt gebildet, Ursus beilegte. Letztlich erkannte nun Croizet, dass Bravard nicht so sehr geirrt habe, und dass die von ihm und von Jobert theils in Felis, theils in Ursus verlegten Reste, Theile eines neuen Typus seyen; das Thier, von dem diese Reste herruhren, nannte er Steneodon, und unterscheidet zwei Species: Steneodon megantereon und Ste-

*) Me y e., Nova Acta Acad. Leop. Carol. Nat. Cur. XVI. 2. S. 592. 
neodon cultridens *). Auch $\mathbf{K}$ a up ** hat aus dem grossen Eckzahn ein eigenes Thier gemacht, das er Machairodus nannte. Wie behutsam man bei Folgerungen aus vereinzelten Zähnen oder Kiefertheilen zu Werk zu gehen habe, ergibt sich ferner daraus, dass dem Kieferfragment, aus welchem Cuvier den Hippopotume moyen errichtete, ganz kurzlich durch vollständigere Stücke von de Christol seine richtige Stelle beim Dugong angewiesen wurde. Mir ist es indess unerklarlich, wie man bei der Kenntniss der Zahne vom Hippopotamus und Dugong einen solchen Irrthum begehen konnte. Endlich gehören auch die Zähne und Kieferfragmente, welche wegen Analogie der Backenzähne und der entsprechenden Kiefertheile in Mastodon angustidens vereinigt sind, wahrscheinlich zwei verschiedenen Genera an, dem Mastodon und dem Tetracaulodon, letzteres von Godmann errichtet wegen der Schneidezahne im Unterkiefer, die man am Mastodon nicht kennt. Einige erblickten darin Milchzähne junger Mastodonten, welche beim Aelterwerden des Thieres ausfallen, eine Ansicht, welche Hays wobei er die Verschiedenheit des Mastodon und Tetracaulodon nachweiset. Titian Peale hat nun noch die Ansicht aufgestellt, diese unteren Schneidezähne seyen nur Geschlechtsunterschied, was eben so schwer zu widerlegen, als zu beweisen seyn möchte.

Wenu nun diese Beispiele beweisen, dass selbst bei der grössten Analogie der Backenzahne die auffallendste Abweichung im Vorderende der Zahnreihe bestehen könne, so ist nun noch übrig, darauf aufmerksam zu machen, dass selbst aus einem Theil der Backenzahnreihe nicht immer sicher auf den andern Theil derselben zu schliessen sey. Dass die hinteren Backenzähne über die Beschaffenheit der vordern bisweilen nichts besagen, geht deutlich aus dem hervor, was Chäropotamus, das von mir weiter unten năher dargelegte schweinsartige Thier, das Anthracotherium, so wie noch andere Thiere ergeben.

Hinter der Aehnlichkeit von einzelnen Zahnen, von Kieferfragmenten und selbst von mehr oder weniger beträchtlichen Skelettheilen (oder andern Organen) liegen also

*) Vgl. Geoffroy in der Revue Encyclopédique. T. LIX (1833), S. 86.

*) K a u p, Description d'ossements fossiles du Museum de Darmstadt. 2d. Cah. S. 24. Darmst. 1838. *) Des Dr. Is a a Hays Beschreibung der Unterkiefer von Mastodon, welche das Museum der Amerikanischen philosophischen Gesellschaft besitzt, mit Bemerkungen über das Geschlecht Tetracaulodon, kenne ich noch nicht näher; es sollen sich 29 Tafeln Abbildungen dabei befinden. 
bisweilen unbekannte Typen verborgen, fur die es kein Mittel der Errathung gibt. Diess geht selbst so weit, dass man sagen kann: Je ahnlicher sich Thiere in einem Theile sind, desto unähnlicher können sie sich in andern Theilen seyn. Anatomen wie Camper, Cuvier und andere, eher vom Gegentheil hievon überzeugt, führten sich selbst irre, indem sie bei Folgerungen aus ihren tréfflichen Untersuchungen zu sehr der Unfehlbarkeit des Weges der Analogie vertrauten. Dieser Zustand der vergleichenden Anatomie lässt sich einigermassen dem der Optik unter $\mathbf{N}$ ew ton vergleichen, der zwar die Lehre von der Zusammensetzung des Lichtes und der verschiedenen Brechbarkeit der Strahlen, woraus es besteht, entdeckte, aber die Möglichkeit ubersah, dass verschiedene Körper, wenn gleich die Refraction des Mittelstrahls des Spectrums dieselbe bleibt, doch verschiedene Refractionskraft in Ansehung der übrigen Strahlen besitzen können, was gleich nach N ewton's Tod Chester More Hall fand, und die Construction achromatischer Fernrohre herbeiführte.

Unter Beachtung des bereits Erwähnten wird die vergleichende Osteologie bei vorsichtiger Anwendung das sicherste Mittel zur Bestimmung der fossilen Knochen bleiben.

Die Zähne sind Körpertheile, in denen das Typische des Thieres oft deutlicher ausgedrückt liegt, als in irgend einem andern. Sie sind daher auch am besten dazu geeignet, einen Aufschluss über die Natur der Thiere herbeizuführen, deren Reste gewöhnlich der verschiedensten Art und in grösster Unordnung untereinandergemengt, in den Erdschichten liegen. Dazu kommt nun noch, dass die Zähne sich häufiger und besser erhalten in den Erdschichten vorfinden, als andere Körpertheile, was sie der ausgezeichneten Härte ihrer Substanzen zu verdanken haben. Bei den fossilen Knochen nimmt man daher zuerst auf die Zähne Bedacht; und vielleicht liegt hierin der Grund, dass der Werth der Zähne bei Bestimmungen und für die Classification in letzter Zeit bisweilen etwas zu hoch gestellt wurde. Die Zühne sind indess von grösster Wichtigkeit, und verdienten, genauer ergründet zu werden, als es bisher geschehen ist.

Des Aristoteles grundlich umfassende Behandlungsweise der Zoologie erhellt auch daraus, dass er schon die Zähne zu würdigen gewusst, wenn auch das, was er darüber mittheilt, noch unvollkommen ist. Er zieht sie andern Merkmalen vor zur Unterscheidung gewisser Thiere in solche, deren Oberkiefer nach.vorn zahnlos, in solche, welche herausstehende Zăhne haben, etc. Aber schon Aris to teles gebrauchte die Vorsicht, nicht einem Unterscheidungsmerkmal allein zu trauen, und selbst das 
der Zähne mit andern in Anwendung zu bringen. Der Engländer Ray (1693), Gründer einer tief wissenschaftlich aufgefassten Classificationsmethode der Thiere, unterscheidet die Saugethiere nach den Hufen, Klauen, Zehen und Nägeln, und bedient sich zur weiteren Unterscheidung der Säugethiere mit Nageln der Zähne, hauptsăchlich der Schneidezähne. Bereits im ersten Entwurf seines Systems (1740) hebt Linné die Zähne als Anhaltspunkte für seine Säugethierordnungen hervor, und will gefunden haben, dass die Amphibien sich von den Säugethieren auch darin unterscheiden, dass die Zähne ersterer alle spitzig seyen, und dass sie keine Backenzähne haben. Die Vervollkommenung, welche er seinem Systeme mehrmal selbst angedeihen liess, war zum Theil auch Folge genauerer Beachtung der Zähne, von denen er hauptsächlich die Schneidezähne beachtete, wobei er Rücksicht nahm, ob dieselben fehlten, oder häufig, und in welcher Zahl sie vorhanden, ingleichen ob sie spitzig waren; auch der Eckzähne wird von ihm gedacht. Man kann indess sagen, dass Li nn é eigentlich doch die Verschiedenartigkeit der Zăhne und ihre Bedeutung übersah; es waren, genau genommen, nur die Schneidezähne, welche ihn leiteten, daher es auch geschah, dass die verschiedensten Thiere in eine und dieselbe Ordnung geriethen, und verwandte in verschiedene Ordnungen getrennt wurdeu. Die mangelhafte Anwendung von Linné's Prinzip erkennend, fasste Bris s o n dasselbe in ausgedehnterem Sinn auf. Fr bemültte sich, die ganze Zahnbildung der Saugethiere zu studiren, und bei dem Ordnen dieser Thiere alle Arten Zăhne zu beachten. Seine Săugethierordnungen eröffnet er mit der, worin den Thieren alle Zähne fehlen. Die zweite Ordnung besteht aus Thieren, welche nur Backenzahne besitzen, die dritte aus solchen mit Backen- und Eckzähnen, und die übrigen der von ihm aufgestellten achtzehn Ordnungen besitzen Backen-, Eck und Schneidezähne, und unterscheiden sich unter einander hauptsächlich durch den Mangel an oberen Schneidezahnen oder durch die Zahl derselben. Die Beachtung der Zähne allein war indess in diesen Ordnungen weit weniger zulänglich, als in den früheren, in denen schon bisweilen sehr verschiedene Thiere sich begegneten. B ris s on sah sich daher genöthigt, die meisten dieser Ordnungen auch nach der Beschaffenheit der Klauen, Nägel, Zehen, Haare, Stacheln, Schuppen, Hörner etc. festzusetzen.

Der neueste Versuch, die Zähne zum wichtigsten Unterscheidungskennzeichen der Säugethiere zu erheben, ging, durch G. Cuvier veranlasst, von dessen Bruder Fr. Cuvier *) aus. Er umfasst, was dazu das Pariser Museum darbot, und über-

") Fr. Cuvier, des dents des Mammifères, considérés comme caraetères zoologiques. Paris 1825. 
trifft an übersichtlicher Vollständigkeit und Bequemlichkeit die früheren Versuche. Aber anch diese Arbeit fuhrt, wie die des Brisson, der schon im Ganzen trefflich zu classificiren verstand, zur Ueberzeugung, dass die Zăhne so wenig, als jedes andere Organ, sich zur Grundlage einer angemessenen Classificationsmethode eignen, wenn man sich ihrer ausschliesslich bedient. Dadurch verlieren indess die Zähne nichts von ihrer Brauchbarkeil, die Nahrung, die Grösse des Wuchses und das Alter des Individuums annäherungsweise zu erkennen. Das Ordnen aber der verschiedenen Formen kann folgerecht nach einem Organ allein nicht durchgeführt werden; es wird nur möglichst erreicht dadurch, dass bald das eine bald das andere hervorgehoben oder zurückgesetzt wird, je nach Erforderniss der so vielseitigen und innigen Verknüpfung des Geschaffenen unter einander.

Diese Versuche, die Zåhne gleichsam als Symbol des Geschöpfes zu betrachten, gaben die Anregung zu einem genaueren Studium derselben, die durch die fossilen Knochen zu einem wahren Bedürfniss stieg. Viel ist bis jetzt hierin geschehen, und doch kaum mehr als der Anfang gemacht. Es ist bisher hauptsăchlich auf die Zähne der Säugethiere Rücksicht genommen worden; die Zähne der Reptilien und Fische sind kaum beachtet, nur einige fossile Zähne aus diesen Thierklassen sind es mehr. Die wissenschaftliche Behandlung der Zähne erheischt überdiess die Darlegung derselben oder der ihnen analogen Theile in den andern Thierklassen, wie denn auch die Zähne gewisser Infusorien von solcher Bedeutung sind, dass Ehrenberg die Räderthierchen allein nach ihren Kauorganen einzutheilen fur geeignet fand.

Bei den Säugethieren, von denen hier ausschliesslich die Rede ist, sind die Beobachtungen ubber die Zähne gewöhnlich nur an einem Individuum und zwar eines zufalligen Alters vorgenommen worden, wie es sich gerade darbot. Um aber über das Zahnsystem eines Thiers richtigen Aufschluss zu erhalten, ist erforderlich, die Verschie-

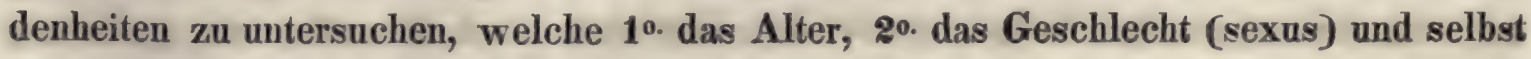
30. das Individuum bedingt.

Der Einfluss des Alters oder des periodischen Lebenszustandes des Geschöpfs auf die Beschaffenheit und das System der Zähne ist hinlänglich auffallend, aber eigentlich nur erst im Menschen genauer ermittelt. Vom Fötuszustand an gehen wichtige Verănderungen im Zahnsystem vor. Das Geschöpf bekommt seine Zähne nicht auf einmal. Die Zahnbildung beginnt gewöhnlich schon frühe im Fötus, und sollte von da an beobachtet, und nicht nur aus einer einzigen Altersperiode gekannt, sondern aus den verschiedenen dieser Perioden schematisch verzeichnet seyn, was allein richtige 
Anhaltspunkte der Vergleichung gewähren würde. Die Veränderungen im System und in der Reihe der Zähne bestehen in Vermehrung und Verminderung der Zahl bis zum ganzlichen Verluste, und im Wechseln der Zähne. Sie sind an verschiedene Lebenszeiten gebunden, die bei verschiedenen Geschöpfen verschieden seyn können. Gelegentlich nur bemerke ich hier, dass Spix *) drei Ruhepunkte der Zahnbildung annimmt, und danach die Säugethiere eintheilt in Reissende, bei welchen die Eckzăhne, in Nager, bei welchen die Schneidezähne, und in Wiederkäuer, bei welchen die Stok- (Backen-) Zähne vorherrschen. Dabei sagt er: ,Zahnlos und bloss vom Flüssigen lebend, tritt das neugeborene Kind in die Welt ein, nun erscheinen die unteren, dann die oberen Schneidezähne, und der neue Sprössling übt das Geschäft eines Nagthiers aus, später keimen die Eckzähne hervor, und jenes nimmt schon die Eigenschaft eines fleischfressenden Thieres an, endlich treten langsam auch die Stokzähne heraus, und mit ihnen zugleich das Geschäft des Kauens, bis zuletzt in ihm jene drei Arten von Zähnen sich in Symmetrie und wechselseitiges Gleichgewicht gestellt haben, und sich so im Menschen das, was an einzelnen Reihen von Säugethieren einzeln vertheilt ist, zugleich und mit einem Male wiederholt."

Bei einigen Geschöpfen fallen schon vor der Geburt Zahne aus, was bei den meisten erst spater, bei andern sehr spät zu geschehen pflegt. Diese werden entweder durch wiederholte Bildung ersetzt, und dieses kann vertical, indem der Ersatzzahn unter seinem Vorgainger heraufkommt, oder horizontal geschehen, indem die früher vorhandenen Zähne von später auftretenden allmählig von hinten nach vorn geschoben und endlich ausgestossen werden; oder die ausgefallenen Zähne werden gar nicht mehr ersetzt. Beginnt das Ausfallen frühzeitig, so kann es geschehen, dass dem Thier gewisse Zähne irriger Weise ganz abgesprochen werden. Wenn der Zahn nicht mehr wächst, bisweilen auch fruher, zehrt an ihm eine freiwillige Caries, was man das Aufsaugen der Zähne nennt. Bei Menschen wird bisweilen ein dreifacher Zahnwechsel beobachtet; nach dem Berichte Spanischer Journale war diess bei der Is abelle, der Gattin des Domingo Morelli, der'Fall, wo sich derselbe an einer und derselben Stelle in der Reihe innerhalb weniger Jahre einstellte. Oefter ist in höherem Alter ein solcher aussergewöhnlicher Zahnwechsel beobachtet worden. Hier drückt er gleichsam ein nochmaliges Aufkeimen des vegetativen Lebens aus, wie

\#) Johannes Spix, Geschichte und Beurtheilung aller Systeme in der Zoologie nach ihrer Kntwickelungsfolge von Aristoteles bis auf die gegenwärtige Zeit. S. 174. Nürnbg. 1811. 
auch die Pflanzen im Spätherbste bisweilen nochmals Blüthe treiben; und es liesse sich von manchem Alten sagen, er sey am Zahnwechsel gestorben. $0 \mathrm{ken}$ will in dem dreimaligen Auftreten eines Zahnes den Beweis finden, dass die Zähne, wie die Finger, aus drei Gelenken bestehen.

Die Unbekanntschaft mit den Veränderungen, welche früher oder später in der Zahl und Anordnung der Zähne eintreten, zog manche irrige Folgerung nach sich. So glaubte z. B. Cuvier nach der Beschaffenheit des Zahnsystems an dem von ihm untersuchten Wallross, die natürliche Stellung dieses Thiers sey nicht in der Nähe der Seehunde, sondern nach den Wiederkäuern und unmittelbar vor den Cetaceen anzunehmen; während $\mathbf{R a p p}$ *), der neben einem ausgewachsenen Thier auch noch einen reifen Fötus auf das Zahnsystem untersuchte, fand, dass das Wallross, zu Folge der Zähne, keineswegs von den Seehunden und den übrigen Fleischfressern so sehr entfernt werden dürfe.

Es ist hier noch beizubringen, was Meckel * Alters auf das Zahnsystem und auf die Zähne selbst in wenigen, aber viel bedeutenden Zügen anmerkt. „Die bleibenden Zähne“ sagt er "sind entweder in ansehnlicherer Zahl vorhanden, oder grösser als die Milchzähne, oder beides zugleich. Die ansehnlichere Grösse und Zusammensetzung ist besonders bei manchen Thieren sehr auffallend. So sind bei dem Elephanten die Milchschneidezăhne etwa zwei Zoll lang, die bleibenden erlangen eine Länge von 14 Fuss. Auch sind die bleibenden oft zusammengesetzter. So bestehen die ersten Backenzähne der Elephanten aus 4, die folgenden aus 8-23 Platten. Auch stehen die ersten Zähne, unter übrigens gleichen Umständen, immer während einer weit kürzern Zeit als die folgenden. Beim Menschen ist das Verhältniss ungefăhr wie 1:12. Noch aufallender ist diese Verschiedenheit in andern Beispielen. So z.B. fallen die im fünften bis siebenten Lebensmonate hervorgebrachten Milchstosszähne der Elephanten schon im dreizehnten bis vierzehnten Monat aus, und die folgenden stehen das ganze Leben hindurch."

Andere Veränderungen durch Einfluss des Alters, wie das Keimen, das Auswachsen, die Abnutzung im Dienste und die Abnahme durch Alter betreffen mehr den Zahn als Individuum.

Ueber den sexuellen Einfluss auf die Zahl und Beschaffenheit der Zähne bestehen

*) Würtembergische naturwissenschaftliche Abhandlungen. II. S. 107.

*) M c ckel, vergleichende Anatomie. I, S. 300. 
nur erst so viel Beobachtungen, als nöthig sind, um denselben wenigstens fur gewisse Thiere nicht mehr zu bezweifeln. Bei diesen ist zu gewisser Zeit die Verschiedenheit zwischen dem männlichen und weiblichen Geschöpf in Betreff der Zälnne nicht geringer, als die verschiedener Gattungen. Dieses verdient Berücksichtigung bei bloss auf den Zähnen beruhenden Gattungsbestimmungen. Meckel *) erkennt die durch sexuelle Verschiedenheit bedingten Abweichungen im Zahnsystem und in den Zähnen selbst auch an. Dieser ausgezeichnete Anatom sagt davon: „Die mảnnlichen Zahne sind nicht nur im Ganzen grösser, sondern zum Theil auch in grösserer Zahl vorhanden, als die weiblichen. In Hinsicht auf Grösse bieten vorzuglich die Schneideoder Eckzähne mehrerer Thiere bedeutende Verschiedenheiten dar. So sind die Schneidezahne beim weiblichen Asiatischen Elephanten ausserordentlich viel kleiner, als beim männlichen. Dasselbe gilt, wenn gleich in geringerem Grade, fur die Eckzăhne der Schweine und Raubthiere. Auch die Eckzähne von Moschus sind beim Weibchen kürzer, dünner und gerader. Im Pferdegeschlecht fehlen der Stute so gut als immer die Eckzähne, welche dem Hengst im Oberkiefer beständig, oft auch im Unterkiefer rukommen." Meckel fragt dabei: „Gibt es vielleicht sexuelle Entwickelungsverschiedenheiten der Zähne?" und fährt nach dieser wichtigen Frage mit den Worten fort: ,Nach einer nicht unbeträchtlichen Anzahl von Beobachtungen glaube ich annehmen zu können, dass bei der menschlichen Gattung bleibende Zähne beim Weibe später als beim Manne, und oft gar nicht erscheinen, so dass Milchzahne stehen bleiben, oder, wenn sie späterhin ausfallen, durch keine bleibenden ersetzt werden. Diese Annahme wird theils durch den Mangel und die Kleinheit der Eck-oder Schneidezåhne mehrer Weibchen, theils durch die Angaben bestätigt, dass beim weiblichen Narval die Zähne bedeutend später als beim männlichen hervorbrechen, so dass sie lange sogar dem ersten ganz abgesprochen wurden." Kine weitere Bestätigung dieser Annahme finde ich in einer späteren Angabe Meckel's **;), wonach bei castrirten Pferden die Eckzăhne später hervorbrechen und kleiner seyn sollen; auch die Fangzahne des castrirten Ebers bleiben klein und der Zahnwechsel scheint plötzlich gehemmt zu seyn. Sonach bestände die Verschiedenheit der Zähne des weiblichen Geschöpfes von denen des männlichen hauptsächlich in der Entwickelung einer geringeren Zahl von Zahnen, und in einer geringeren Stärke der wirklich auftretenden.

*) Meckel, a. a. 0. I. S. 253.

**) Ebend. I. S. 472. 
Hierin könnte man auch eine Stutze für die Annahme erhalten, dass das Weib dem Manne gegenüber als eine geringere Entwickelungsstufe zu betrachten sey.

Solche, auf Alters - und sexueller Verschiedenheit beruhende Abweichnngen erschweren nothwendig die Kunst, aus den Zähnen oder gar aus einem einzigen Zahn das Thier, dem er angehörte, selbst dann noch zu errathen, wenn demselben ein unbekannter Typus zum Grund liegt. Sind die individuellen Verschiedenheiten auch von keinem solchen Belang, als die des Alters und des Geschlechtes, so sind sie gleichwohl um so mehr zu berücksichtigen, als sie letztere noch verstärken.

Man unterscheidet dreierlei Arten von Zähnen: Schneidezähne, Eck - oder Hundszähne und Backen - oder Mahlzăhne. Alle sonstige Zahnbenennungen ist es forderlich, diesen unterzuordnen. Weniger die Grösse und Form als der Stand im Kiefer bezeichnet die Art des Zahns. Die Eckzähne und Backenzähne sitzen im eigentlichen Kieferknochen, und erstere immer vor letztern. Beide sind auch gewöhnlich in Form auffallend von einander verschieden. Bisweilen fällt es indessen schwer zu entscheiden, ob man einen Eck - oder vordern Backenzahn vor sich habe. Die Schneidezähne sitzen im vordersten Kieferende, und unterscheiden sich gewöhnlich durch ihre Form von den übrigen Zahnen; aber auch hier ist bisweilen schwer zu entscheiden, ob der Zahn ein Schneide - oder ein Eckzahn sey. Die Schneidezahne des Oberkiefers werden an ihrem Stand im Zwischenkieferknochen erkaunt. Schon aus diesem Grund musste die genaue Darlegung dieses Knochens sehr erwünscht seyn. Dem Galen war dieser Knochen im Menschen nicht unbemerkt geblieben; seine genaue Nachweisung nahm aber eigentlich erst $G$ öth $\mathrm{F}^{*}$ ) vor. Dieser beschaftigte sich auch mit der Darlegung dieses Knochens in verschiedenen Thieren. Mancher Irrthum ist dadurch begangen worden, dass man weniger die Art des Knochens, worin ein Zahn sitzt, als die Aehnlichkeit in der Grösse, Form und Richtung des Zahns beachtete. Die vordern Zahne in den Nagern galten fur Schneidezăhe. Geoffroy Saint-Hilaire **) hält sie jetzt den Hunds - oder Eckzähnen analog, und glaubt, dass ihr Stand im vordersten Kiefertheil nach Art der Schneidezähne nichts dagegen beweise; was in so fern richtig ist, als diese Zähne im Oberkiefer der Nager nicht im Zwischenkiefer, sondern im eigentlichen Kieferknochen stecken. Die beiden grossen Zahne, welche

") Zur Morphologie. I. 2. S. 199. - Göthe's Werke, 120. B. 55. S. 135. - Nova Acta Acad. Leop. Carol. Nat, Cur. XV. 1. S. 1.

bt) Ann. des sc. nat. XXIII. Revue bibliog. S.73. 


\section{- $16-$}

am Vorderende des Dugongschadels *) auffallen und diesem Schädel ein ganz eigenthümliches Profil verleihen, sind, da sie in dem Z Zwischenkieferknochen liegen, Schneidezähne. Aus demselben Grund sind die Stosszähne des Mastodon und Elephanter ***;), welche letztere unter Andern Bris son für Eckzähne gehalten, Schneidezăhne. Aber die langen Zähne, welche aus dem Oberkiefer des Wallrosses herunterhăngen, müssen, da sie im wirklichen Kieferknochen sitzen, als Eckzähne betrachtet werden. Bei dem Rhinoceros sitzen im Vordertheil des Schädels Zähne von verschiedener Gestalt, welche durch ihre Lage im $\mathbf{Z}$ wischenkieferknochen sich als Schneidezahne zu erkennen geben. Die Unterkiefer reiben sie auf Zähnen, deren Länge gewöhnlich nicht unbeträchtlich ist, und die wohl mit Recht Schneidezähne genannt werden, obgleich es bisweilen vorkommt, dass untere Eckzähne mit oberen Schneidezăhnen zusammenreiben. Beim Hyrax (Daman), von dem keine Eckzähne bekannt sind, stecken die nicht unbetrảchtlichen Zähne im Z wischenkieferknochen und sind daher Schneidezähne. Dadurch erhält das Thier ein den Nagern ahnliches Aussehen, wofür dasselbe auch so lange gehalten wurde, bis Cuvier es genauer kennen lernte. Im Hippopotamus ist der Fall gegeben, wo Schneide- und Eckzähne zugleich stark sind; letztere sind die stärkern. Dagegen zeigt der Tapir, dass Schneidezăhne weit grösser seyn können, als Eckzähne; was auch Azzara verleitete, den aussern von den Schneidezähnen für den ersten Eckzahn zu halten.

Schneide - und Eckzähne kommen seltener fossil vor, als Backenzähne. In den Fällen, wo erstere nicht im Zusammenhang mit andern Zähnen in ihrer Năhe oder

*) Eine Abbildung dieses merkwürdigen Schädels nach einer genauen Zeichnung von mir findet sich in Museum Senckenbergianum, I. 2. Taf. VI. Fig. 4. 5.

*) Gö the, der doch den Zwischenkiefer am besten kannte, sagt Anfangs (Werke, B. 55. S. 214): , Man behauptete eine Zeit lang: der Eckzahn des Elephanten stehe im Zwischenknochen; da er doch unabänderlich der obern Kinnlade angehört, und ein genauer Beobachter gar wohl bemerken kann, dass von der obern Kinnlade sich eine Lamelle um den ungeheuern Zahn herumschlingt.6 Dieses widerspricht etwas dem, was Göthe (Werke, B. 50. S. 234) später zu bedenken gibt; , dass bei der ungeheuern Forderung, die hier an die obere Kinnlade geschieht, der benachbarte Zwischenknochen, wo nicht zur Bildung der ungeheuern Alveolen, doch zu deren Verstärkung eine Lamelle hergeben sollte."6 G. Cuvier (Oss. foss. I. S. 15) behauptet geradezu, dass der ganze Stosszahn im Zwischenkieferknochen liege, was auch aus den von ihm mitgetheilten Abbildungen hervorgeht, und ferner von $\mathbf{F}$. Cuvier (Dents des Mammifères, S. 221) angenommen wird. 
mit den ihnen entsprechenden Kiefertheilen bekannt sind, ist schwer zu entscheiden, ob man Schneide - oder Eckzähne vor sich habe.

Gewissen Thieren scheint eine oder die andere Zahnart gänzlich, oder bloss im Ober - oder Unterkiefer zu fehlen; es gibt vielleicht auch Säugethiere, denen Zähre wirklich fremd sind. In andern ist der Unterschied zwischen Schneide-, Eck - und Backenzähnen weder durch Grösse oder Form, noch durch zahnlose Lücken besonders auffallend. Das Gebiss des Menschen ist dadurch ausgezeichnet, dass die Zähne gedrängt auf einander folgen, und in einer kreisförmigen Reihe stehen; die verschiedenen Zahnarten lassen sich nicht gleich auf den ersten Blick von einander unterscheiden. Den meisten Cetaceen und Sauriern steht auch eine monotonere Zahnausbildung zu, die beiden. Schenkel der gekrümmten Reihe, in der sie bei diesen Thieren sitzen, streben aber mehr zum Parallelismus gerader Linien hin, und die Zăhne folgen gewöhnlich nicht so nahe auf einander, als im Menschen. Die Zähne der Cetaceen und Saurier kommen mehr auf die der Fische heraus. Bei manchen Fischen und Reptilien trifft man mehrere Reihen von Zähnen an, und noch dazu Gaumenzähne und Schlundzähne. Den Gaumenzähnen analog könnte man die Beschaffenheit des Gaumens gewisser Säugethiere erachten. Betrachtet man z. B. den Gaumen des Ochsen genauer, so wird man finden, dass er wirklich bewaffnet ist. Seine Rauhigkeit besteht in reihenweisen Erhabenheiten, welche den Gaumenzähnen gewisser Fische und Lacerten sehr ähnlich sehen; es sind zahnartige Bildungen, wie bei den Lacerten mit der Gaumenhaut verwachsen.

Am Zahn ist Krone und Wurzel zu unterscheiden. Fr. Cuvier *) hält sehr sinnreich die Wurzel für die Fortsetzung der Krone. Die auffallende Verschiedenheit 'zwischen beiden rührt gewöhnlich daher, dass die Schmelzbildung aufhört, sobald die noch vom Zahnfleisch umschlossen gehaltene Zahnkrone in der Alveole ausgewachsen ist. Hiedurch entsteht eine Art von Hemmung oder kümmerlicher Fortbildung des Zahns nach unten, wobei die Wurzel entsteht. Die Eintrittszeit dieser Hemmung kann bei verschiedenen Thieren verschieden seyn. Die Backenzăhne der Pferde beweisen, dass, wenn die Schmelzbildung lange fortwährt, die Zahnkrone zu einer hohen Säule sich gestalten kann, die zusammenschrumpft und sich zu Wurzeln verzweigt, sobald die Schmelzbildung aufhört. Man begreift nun auch leichter, warum an Zähnen, welche nur aus einer Substanz bestehen, oder auch aus mehreren, die sich aber ununter-

*) Fr. Cuvier, Dents des Mammif., S. XXXI. 
brochen fortbilden, kein solcher Unterschied zwischen Krone und Wurzel wahrgenommen, und der in der Alveole stehende Zahntheil eher fur die Fortsetzung der Krone gehalten wird. Bę den getheilten Wurzeln entsprechen gewöhnlich die Wurzeläste den Haupttheilen der Zahnkrone.

So lange der Zahn nicht hinlänglich aus dem Zahnfleisch herausragt, und noch keinen Dienst verrichtet, ist er Keimzahn. Verlässt er diesen Zustand, so tritt die Wurzelbildung, gewőhnlich mit Verdickung der Kernsubstanz nach innen, ein. Die gegenseitige Berührung der Zăhne, der Gebrauch derselben zur Gewinnung der Nahrungsmittel, zur Zubereitung letzterer als Speise, und zur Vertheidigung nutzt die Zähne ab. Es entstehen dabei auf der Zahnkrone horizontale oder mehr oder weniger geneigte Abnutzungsflächen, welche die Gestalt der Krone verkndern und deren Höhe abtragen. Die Spitzen, Hügel, Hübel, Kämme etc. werden abgerieben und durchgerieben, und es bilden sich Flächen, von denen sich mehrere verbinden; im Alter sind die verschiedenen Flächen gewöhnlich zu einer einzigen vereinigt, und es ist dann des Zahnes ursprungliche Kronenbeschaffenheit kaum mehr ersichtlich. In solchen Veränderungen liegen Anhaltspuncte zur Beurtheilung des Alters des Individuums, und Erleichterungsmittel zur Bestimmung der Kieferhälfte und der Stelle, auf der ein vereinzelter Zahn gesessen. Die verticalen oder seitlichen Abnutzungsflächen, welche durch die Berührung zweier unmittelbar in der Reihe auf einander folgenden Zahne entstehen, verdienen gleichfalls Berücksichtigung. Sie verändern die Gestalt des Zahnes und verkürzen mit zunehmendem Alter die Länge desselben, was bei der Vergleichung von Zahnlängen in Anschlag zu bringen ist. Die seitlichen Abnutzungsflachen erleichtern auch die Bestimmung vereinzelter Zähne und das Auffinden zusammengehöriger; sie geben in so fern Aufschluss uber die Beschaffenheit der Zahnreihe, als es sich aus ihnen ersehen lässt, ob einem Zahn ein anderer unmittelbar verhergegangen oder gefolgt sey.

Ehe eine andere Eigenthümlichkeit an den Zähnen in Betracht gezogen wird, ist der Substanzen zu gedenken, aus denen die wirklichen Zähne der Säugethiere bestehen. Mit blossem Auge und auf gewöhnliche mechanische Weise lassen sich drei Zahnsubstanzen unterscheiden : Kernsubstanz, Schmelzsubstanz und Rindensubstanz. Jede derselben besitzt ihr eigenes Absonderungsorgan. Es gibt Zähne bloss aus Kernsubstanz; Zähne aus Kernsubstanz und Rindensubstanz (die Zähne des Cachalot sollen so beschaffen seyn); Zăhne aus Kernsubstanz und Schmelzsubstanz; und Zähne aus Kernsubstanz, Schmelzsubstanz und Rindensubstanz. Jeder Zahn 
besitzt also Kernsubstanz, weshalb ich auch diese Substanz so nenne. Bei einem Zahn aus mehreren Substanzen umschliessen sich dieselben in der angeführten Ordnung von innen nach aussen. Die Kernsubstanz wird gewöhnlich Elfenbeinsubstanz oder Elfenbein genannt. Zwar ist letzteres die den erstern analoge Substanz, aber die Kernsubstanz ist nicht immer wirkliches Elfenbein, wie diess am Elephanten selbst zu ersehen ist, wo die Substanz des Stosszahns nicht ganz dieselbe ist, wie die, welche in den Backenzähnen von der Schmelzlamelle umgeben wird. Diese Art von Substanz kann überhaupt in den verschiedenen Zähnen eines Thiers und in den analogen Zähnen verschiedener Thiergattungen von abweichender Natur seyn.

In der Schmelzsubstanz scheint gleichsam das feinere Gepräge der Zähne ausgedrückt zu seyn. Sie verleiht dabei Haltbarkeit und Dauer. Die Rindensubstanz umhüllt gewöhnlich den Zahn aussen, fullt bisweilen auch Höhlungen in der Zahnkrone aus, oder dient den Theilen gewisser Zähne zum festeren Zusammenhalt. Die Seite, mit der der Schmelz der Rindensubstanz anliegt, ist gewöhnlich langsstreifig oder feinrunzelig, um, wie es scheint, beide Substanzen mehr mechanisch zu binden. Wo Schmelz - und Kernsubstanz sich berühren, wird diess gewöhnlich weniger wahrgenommen, da beide schon ohnehin fester zusammenzuhalten scheinen.

Die von Bergmann ${ }^{*}$ ) an frischen und an fossilen Zähnen vorgenommenen Untersuchungen stellen diese drei Zahnsubstanzen keineswegs als einfach dar. Die Schmelzsubstanz, welche selbst bei bewaffnetem Auge homogen aussieht, zersprang beim Glühen in parallele Schichten, in deren Mitte sich ein weisser, scharfbegränzter, durch die ganze Masse gehender Streif zeigte, der selbst in der grössten Hitze keine Veränderung erfuhr, während die ihn von beiden Seiten umgebenden Lagen sich durch Verkohlung schwärzten, und im unbedeckten Tiegel wieder weiss brannten. Die Schmelzsubstanz bestănde demnach aus Lagen von mehr mineralischen und aus Lagen von mehr animalischen Stoffen. Die vom Backenzahn des fossilen Elephanten sorgfältig abgelöste äussere Rindensubstanz verhielt sich beim Glühen, wie die innere Schichte der Schmelzsubstanz. Die Kernsubstanz zeigte beim Glühen ebenfalls drei Lagen, von denen die mittlere vollkommen weiss und durchsichtig, die beiden aussern bläulich-grau und durchscheinend waren; die Gränze von beiden war scharf abgeschnitten und die Härte der äussern Lagen bedeutender, als die in der Mitte.

*) Schweigger's Jahrb. für Chemie etc. 1828. 2. S. 145. 
Die Backenzähne können füglich unter einander betrachtet werden. Bei gehöriger Erwägung und gegenseitiger V'ergleichung ihrer Einzeltheile ergeben sich merkwürdige morphische Verhältnisse, welche an und für sich"interessant, und für die Bestimmung vereinzelter Zähne, insbesondere aber von Zahnfragmenten, von grosser Wichtigkeit sind. Bei diesen Untersuchungen geht man am besten von dem noch mit allen seinen Theilen in ganzer Reinheit versehenen Keimzahn aus. Daran untersucht man die Einzeltheile, und vergleicht sie hierauf bei den Zähnen jedes Alters und an den verschiedenen Backenzähnen der Reihe. Hiebei wird man finden, dass der Reihe der verschiedenen Backenzähne bei vielen Thieren ein gemeinsamer Grundtypus zusteht. Dieser Typus ist gewöhnlich an einem der mittleren Zähne am deutlichsten ersichtlich und am ebenmässigsten ausgedrückt. Nimmt man einen solchen Zahn als Grundform an, und sucht man die abrigen Backenzähne darauf zuruckzuführen, so wird man finden, dass die Verschiedenheiten der diesem vor und nach sitzenden Backenzähne, hauptsächlich auf Abanderung, grösserer oder weniger grossen Ausdehnung oder Verkümmerung gemeinsamer Einzeltheile beruhen, welche der Totalform des Zahns eine ganz andere Gestalt zu geben im Stande sind. Es können indess auch Theilchen auftreten, von denen andere Zähne derselben Reihe gar nichts wahrnehmen lassen.

Solche Mahlzahnreihen erinnern an Reihen von Krystallvarietaten einer Grundgestalt, so wie ferner an ein ähnliches Variiren gleichwerthiger Theile des Knochenskeletts unter sich, namentlich an die Abweichungen der Wirbel an den verschiedenen Stellen der Säule, an die Abweichungen der vordern Bewegungsorgane mit dem Brustapparat von den hinteren Bewegungsorganen mit dem Becken etc.

Die Verschiedenheit der Backenzahne einer Reihe wird bei vielen Thieren durch die Stelle des Zahns bedingt. In der Reihe der Backenzähne liegen gewöhnlich zwei Richtungen ausgedruckt, wonach die von dem Mittelzahn nach vorn hin sitzenden Zähne hauptsächlich in ihrer vordern Häfte, und die nach hinten hin sitzenden Zähne hauptsächlich in ihrer hintern Hälfte Abweichungen zeigen, welche auf dem verschiedenen Ausdehnungsgrad gemeinsamer Theile beruhen, von denen einige ein solches Uebergewicht erlangen können, dass sie andere Theile fast gänzlich verdrängt zu haben scheinen. So sieht man nicht selten zuvor unbedeutende, abhängige, scheinbar ausserwesentliche und in den meisten Abbildungen übersehene Theilchen, Knötchen, Leistchen, Ansätze etc., durch vorherrschende Entwickelung meist auf Unkosten von Theilen, welche in andern Zähnen der Reihe mit entschiedenem Uebergewicht auftreten, Bedeutenheit und Selbstständigkeit erlangen. 
Die Zähne und ihre Einzeltheile sind gewöhnlich so beschaffen, wie es die Stelle, welche sie einnehmen, und der Dienst, den sie zu versehen haben, verlangt; die Natur verfahrt bei diesen Kauwerkzeugen oder Waffen hierin wirklich bewunderungswürdig. Die Theile bevorzugter Abnutzung bestehen gewöhnlich aus härterer Substanz, oder sind verstärkt und noch durch Nebentheile unterstützt; die stärkere Seite der Backenzahnkrone ist auch gewöhnlich die stärkerer Abnutzung. Freistehende Zähne sind schärfer und spitzer ausgebildet, um die Widerstände leichter zu überwinden. Je mehr bei gedrängter Reihe die Zähne nach vorn oder nach hinten sitzen, desto mehr verringert sich der Schutz durch vor oder nach sitzende Zähne. Sehr oft wird diese Verringerung des Schutzes durch die Ausbildung und Richtung dieser Zähne ersetzt, und der erste und letzte Zahn von gedrängt sitzenden Zähnen sind gewöhnlich so beschaffen, dass sie die Backenzahnreihen ohne weitere Stutze vorn oder hinten zu schliessen vermögen. Auch darin ist eine weise Einrichtung zu erkennen, dass die seitliche Abnutzung sich bei gewissen Thieren uber eigene schützende Theile ausdehnt, über die Vorder- und Hinteransätze, die auch oft wesentliche Zahntheile sind.

Die Berücksichtigung eines morphischen Zusammenhangs der Zähne, insbesondere der Backenzähne einer Reihe, gewährt bei der Bestimmung vereinzelter Zähne, welche unter den fossilen Resten so gewöhnlich sind, grosse Vortheile und Erleichterung; das Auffinden zusammengehöriger Zähne, die Festsetzung der Gattung, der Kieferhalfte und der Stelle, in welcher ein Zahn gesessen, wird dadurch ungemein erleichtert, und die Bestimmung kleinerer Zahufragmente ist nur unter Berücksichtigung eines solchen Zusammenhangs mit einiger Gewissheit möglich. Ich zum wenigsten verdanke diesem Verfahren, die Zähne von einander abzuleiten, sehr viel.

Die Zahnwurzeln können, wie bereits erwăhnt, als Fortsetzung der Zahnkrone und ihrer Theile betrachtet werden. Da bei ihrer Entstehung keine Willkühr herrscht, so kann man sich auch ihrer wie der Zähne bedienen; in zweifelhaften Fallen gewähren sie oft gute Dienste. Bei Vermuthungen über das Alter des Thiers sind sie kaum zu umgehen.

Etwas Aehnliches wie bei Zähnen einer Reihe, besteht auch zwischen den Zähnen des' Ober - und Unterkiefers, und zwischen den Zähnen verschiedener Thiergattungen. Ordnet man dieses Alles gehörig, so stellen sich Gruppen verwandtschaftlicher Typen heraus, welche zum Theil schon erkannt sind. Das Ganze führt zu einer wissenschaftlichen Lehre von den Zähnen, deren Durchfuhrung sehr zu wünschen wäre. Ihre Anwendung aber auf die Classification kann nur bedingt geschehen. 
Fur die Odontologie der Säugethiere ist hauptsächlich Folgendes festzuhalten:

Die Zahne finden sich im Kopfe vor. Der Kopf besteht aus dem Schädel und Unterkiefer; in beiden sitzen Zăhne. Im Gegensatz zum Unterkiefer heisst die Stelle, über der im Schädel Zähne verbreitet sind, Oberkiefer, der aus dem eigentlichen Kieferknochen und dem Z Zwischenkiefer besteht. Daher zerfallen die Zähne in solche des Oberkiefers oder obere Zăhne, und in solche des Unterkiefers oder untere Zăhne.

Das Zahnsystem ist die Art und Weise, wie sammtliche Zähne im Kopfe sich vorfinden. Es lässt sich schematisch darstellen, und die numerischen Ausdrücke darin sind für jede Zahnart, oben oder unten, summarisch zu verstehen. Das Schema des Zahnsystems ist das Untersuchungsresultat der Zähne eines Geschöpfes und ein wesentlicher Theil seiner Diagnose. Auf die Veränderlichkeit des Zahnsystems und die Schwierigkeit, die periodischen Verănderungen im Schema zu ermitteln, habe ich bereits hingewiesen.

Oben wie unten zerfallen die Zähne in zwei identische Hälften, in die Hälfte zur rechten, und in die zur linken Seite des Geschöpfes. Daher die Ausdrucke: Zăhne der rechten obern (untern) Hälfte oder der rechten Hälfte des Ober- (Unter-) kiefers; und Zähne der linken obern (untern) Hälfte, oder der linken Hälfte des Ober- (Unter-) kiefers.

Was fur eine Kieferhalfte gilt, gilt auch für die andere; während die Zăhne des Ober - und Unterkiefers in Zahl, Anordnung, Gestalt, Bau und Substanz verschieden seyn können.

Im Kiefer sind die Zăhne reihenweise in horizontalem Sinn angeordnet. Die Zähne der Säugethiere stehen in der Regel einreihig; bisweilen kommt es vor, dass einer oder der andere Zahn doppelt gebildet ist, und Zweireihigkeit ausdruckt. Bei gewissen Fischen und einigen Ordnungen der Reptilien ist die mehrfache Zahnreihe normal. Die Form der Zahnreihe richtet sich nach der des Kiefers, sie ist runder oder spitzer, mehr dem Kreise nahe oder mehr parabolisch, zum Parallelismus zweier Linien hinneigend. Man gebraucht auch den Ausdruck Reihe noch fur die sảmmtlich auf einander folgenden Zähne einer Art; so kann man sagen: die Reihe der Backenzăhne oder die Backenzahureihe, und zwar im rechten oder im linken Ober-oder Unterkiefer; die Reihe der Schneidezähne oder die Schneidezahnreihe, und zwar im Ober-oder im Unterkiefer.

Die Zahnreihe im Allgemeinen wie im Besondern ist entweder geschlossen oder lückenhaft; am vollständigsten geschlossen ist sie im Menschen. Die zahnlosen Lücken sind von mehr oder weniger Belang. Durch sie werden entweder verschiedene Zahn- 
arten einer Reihe getrennt, oder es können auch Zähne einer Art in grösseren oder geringeren Abständen auf einander folgen. Man hat daher auch darauf zu sehen, wo die zahnlosen Lucken liegen, ob sie beträchtlich oder von welchem Belang sie sind, und wie durch sie die Zahne gruppirt werden.

Die Hauptzahnarten sind: Schneidezähne (Incisives, dentes medii, v. incisivi, v. resorii), Eckzähne (Camines, dentes canini), welche Benennung der von Hundszăhnen vorgezogen zu werden verdient, und Backenzähne (Molaires, dentes molares), besser als Mahlzähne, da nicht alle Zähne dieser Art mahlen. Die vordern Backenzähne nennt man wohl auch falsche oder unächte Backenzähne. Den Backenzahnen der Fleischfresser hat man anch eigenthümliche Namen beigelegt; die zwei oder drei vordern nennt man Stock - oder Lückenzahne, den hintersten Backenzahn den Kronzahn, den diesem vorsitzenden den Quer - oder Mahlzahn, und den diesem wieder vorsitzenden den Reisszahn. Es gibt nn̉n noch Gaumenzåhne und Schlundzähne, welche indess hier weniger in Betracht kommen.

Bei den meisten Zahnen ist nicht allein der Zahn, sondern auch die Knochenzelle zu beachten, in der der Zahn im Kiefer steckt, und die Alveole heisst. In Ermangelung des Zahnes selbst gibt diese doch wenigstens Aufschluss über die Existenz eines Zahnes und uber dessen angewiesene Stelle. Man hat also zu unterscheiden: Alveolen der Schneidezăhne, Alveolen der Eckzähne und Alveolen der Backenzähne.

Da Zähne ausfallen und dafür wieder analoge entstehen können, was bei sehr vielen Geschöpfen gesetzlich ist, so unterscheidet man am besten diesen Zahnwechsel, wenn man sagt: ein Zahn der ersten, der zweiten, der dritten etc. Bildung. Nicht die Zăhne jeder Art sind dem Wechsel unterworfen, selbst nicht alle Zahne einer und derselben Art, wie z. B. bei den Backenzahnen gewöhnlich nur die vordern wechseln, die hintern bleiben, d. h. in der Regel nur einmal entstehen. Man nennt jene allgemein Wechselzahne, und könnte daher diese Bestandzăhne nennen. Bei den Wechselzähnen ist fur den Zahn erster Bildung der Name Milchzahn herkommlich; und da in der Regel nur dieser und der Zahn, welcher an seine Stelle tritt, vorkommen, so nennt man letzteren gemeinhin in Bezug auf erstern Wechselzahn oder Ersatzzahn. Das Gesagte gilt von Zähnen des Oberkiefers und Unterkiefers.

Ueber die Substanzen, aus denen die Zahhne bestehen, ist oben Mehreres vorgebracht worden. Hier nur zur Erinnerung, dass sie bestehen in: Kernsubstanz (Ivoire), welche den Zahnkern bildet und wozu auch das Elfenbein gehört; Rindensubstanz (Cortical), Zahnrinde, als Umhullung oder Ausfullung von aussen; und Schmelzsubstanz 
(Email), Zahnschmelz, Schmelzüberzug, der gewöhnlich mehr oder weniger conisch ist, oder Schmelzlamelle, gewöhnlich als Hohlcylinder.

Von seiner Entstehung an bis dahin, wo der Zahn in Function tritt, heisst er Keimzahn (Germe). Man unterscheidet: Keimzahn der Schneidezăhne, Keimzahn der Eckzăhne, Keimzahn der Mahlzähne.

An den Zähnen ist uberhaupt zu beachten:

Die Höhe. Was man unter derselben zu verstehen hat, ist streng festzuhalten; sie ist die gerade Verticallinie, welche sich von dem äussersten Ende der Zahnwurzel oder deren analogen Theile bis zur obersten Spitze der Zahnkrone construiren lässt, die man bisher auch ununterschiedlich Länge genannt hat. Diess also ist die Zahnhöhe. Bei gekrümmten Zähnen kann sie auch nach der Krümmung genommen werden, was alsdann aber ausdrücklich dabei zu bemerken ist. Ausser dieser Höhe des ganzeu Zahnes unterscheidet man auch noch besonders die Höhe der Zahnkrone und die Höhe der Zahnwurzel.

Länge und Breite werden gewöhnlich nur von der Zahnkrone verstanden; und es ist die Länge diejenige gerade Linie, welche sich von hinten nach vorn, und die Breite, welche sich von einer der beiden Seiten zu der andern denken lässt.

Die Axe geht durch die Mitte der ganzen Zahnhöhe, und ist daher bei geraden Zahnen gerade, bei gekrummten krumm.

Die Totalform und Beschaffenheit der Einzeltheile lehren den Zahn genauer kennen. Bei den meisten Zähnen lässt sich Krone (corona v. corpus) und Wurzel (rudix) unterscheiden.

In Rucksicht auf die Totalform der Zahnkrone gibt es prismatische Zähne, solche nămlich, in denen der Parallelismus der Seiten gentigend ausgedrückt ist. Diese Zahnkronen sind gewöhnlich mehr oder weniger rectangulär oder quadratisch, bisweilen auch zum dreiseitigen Prisma hingeneigt. Sie sind ferner cylindrisch mit kreisrundem, elliptischem oder mehr oder weniger regelmässigem, mannichfach gestaltetem Durchschnitt; sie sind conisch, kegelförmig oder pyramidalisch, dabei spitzer oder stumpfer, mit runder, rundlicher, ovaler, quadratischer, rectangulärer, dreieckiger etc. Basis. Die Zähne sind auch entweder gerade oder verschieden gekrummt; dabei ist zu beachten die Richtung, mit der sie im Kiefer stecken, ob sie vorwärts, rückwärts, auswärts, einwärts, aufwärts oder abwärts gerichtet sind. Dann gibt es noch Zähne, deren Totalform sich bekannten Gegenständen vergleichen lassst: bohnenförmige, erbsenförmige, keulförmige, lanzettförmige, messerförmige, pfriemförmige etc.; was zu genauerer 
Versinnlichung und Unterscheidung beiträgt. Die Beachtung der Form des Quer - und des Längendurchschnittes der Zahnkrone kann sehr förderlich seyn. Die Verhältnisse der Hohe, Länge und Breite sind nicht zu vernachlässigen. Ein Zahn ist flach, wénn seine Breite der Länge und Höhe untergeordnet ist etc.

Unten ist bei einem Zahn, aus welchem Kiefer er herruhren mag, immer nach den Wurzelenden hin, und oben an dem entgegengesetzten Ende; die Vorderseite des Zahus liegt nach dem vordern Ende, und die Hinterseite nach dem hintern Ende des Kiefers hin. Die Innenseite ist die, mit der die Zähne, wenn sie im Kiefer sitzen, sich einander gegenüber befinden; die andere Seite am Zahn, welche dieser entspricht, ist die Aussenseite. Man unterseheidet hienach auch den Vorder-, Hinter-, Aussenund Innenrand der Zahnkrone. Gut ist es, bei der Zahnkrone norh die Mitte zu beachten und die Krone selbst sich zerfällt zu denken in eine vordere, hintere, äussere und innere Hălfte, oder in andere, den Zahn gleichmåssig theilende Stücke, die man nicht selten unter einander vergleichen kann.

Es gibt Zähne, an deren Krone eigentlich keine Einzeltheile bemerkbar sind. Gehen diese in eine Spitze aus, so ist zu beachten der Grad und überhaupt die Art der Zuspitzung. Gewöhnlich aber hat man Einzeltheile zu unterscheiden, die bisweilen die Zahnkrone recht complicirt machen. Es ist ferner die Structur oder der Bau der Zahnkrone und die Ausbildung derselben zu berücksichtigen, so wie zu ermitteln, aus wie viel Substanzen der Zahn besteht, wie sie zu einander liegen und wie die Substanzen gestaltet sind. So gibt es z.B. Zähne, in denen die Schmelzsubstanz einem Schmelzblech verglichen werden kann, mit Ein- und Ausbiegungen, Rinnen, Falten, die wieder fein längsgestreift oder runzelig seyn können. Die einfacheren Zähne sind gewöhnlich die Eckzähne und die Schneidezăhne; anch gibt es Backenzăhue, welche nicht weniger einfach sind, jedoch seltener. Die complicirteren Zähne lassen sich oft als reihige Zähne, nămlich als solche betrachten, deren Einzeltheile reihenweise vertheilt sind; sie sind langsreihig, gewöhnlich querreihig, und zwar einreihig, zweireihig, drei- und mehr reihig, in so viel analoge Reihen sich die Zahnkrone zerfallen lăsst. Die Basis der Krone erscheint an gewissen Zähnen entweder ganz oder theilweise mit einem Wulst (Hals, Kragen) umgeben, und die Krone kann einen Vorder - oder einen Hinteransatz oder beide Ansătze (Talons) zugleich haben, und auch an den Seiten mit Ansätzen versehen seyn, was indess seltener vorkommt.

Man unterscheidet Hügel, nur einen, oder ob mehrere paarweise oder zu wie 
viel vorn, hinten, aussen oder innen zusammenstehen; man sagt z. B. vorderer Hügel, hinteres Hügelpaar, äusseres Hügelpaar etc., was bedeuten will, ein Hügel an der Vorderseite der Zahnkrone, ein Hügelpaar an der Hinterseite der Zahnkrone etc. Die Hügel sind entweder einfach oder complicirt, sie können warzenförmig, zitzenförmig, pyramidalisch, sattelförmig etc. seyn. Von Hügeln hat man wieder zu unterseheiden: Haupthügel, Nebenhügel, von keiner solchén Grösse und Bedeutsamkeit als erstgenannter, und gewöhnlich unter dessen Abhängigkeit stehend; sodann noch Ausläufer des Hügels, nămlich Theile, welche mit einem Hügel augenscheinlich zusammenhängen, oder verzweigt sind.

Ein anderer, sehr verschieden sich darstellender Kronentheil ist die Spitze. Es gibt einfache Spitzen, Doppelspitzen, mehrfache Spitzen, und, wie bereits für die Hügel angeführt, in Bezug auf ihren Stand: aussere, innere, vordere, hintere; ferner vordere ausssere, hintere äussere, vordere innere, hintere innere Spitzen. Die Spitzen können auch mit sehr verschiedenen Formen ausgeprägt seyn.

Der Kamm ist auch ein vorwaltender Kronentheil; was so eben in Bezug auf den Stand eines Zahnkronentheils vorgebracht wurde, findet auch hier Anwendung. Die Ausdrücke: Querkamm, Längskamm kommen sehr gewöhnlich vor; und in Rücksicht auf die Form und Ausbildung sagt man: halbmondförmiger, hufeisenförmiger, gerader, geperlter, eingeschnittener etc. Kamm.

Wo Hügel, Spitzen und Kämme zusammen stehen, da gibt es auch Thäler und Einschnitte; doch werden gewöhnlich nur die beträchtlicheren von ihnen beachtet, und man berucksichtigt an ihnen, durch welche Theile sie gebildet werden, ob sie der Quere, der Länge, oder wie sie laufen, und wie tief ungefähr sie in die Zahnkrone eingeschnitten sind.

Man unterscheidet ferner an der Zahnkrone: Hübel, Wülste, Knollen, Knötchen, Perlen, Runzeln, Kanten, Leisten, Schneiden, Säume, Gräthe und andere Unebenheiten und Zwischentheile, Vertiefungen (z. B. napfförmige), Firsten, Wände (z. B. Aussenseite der obern Backenzähne vom Rhinoceros) etc., sämmtlich sehr verschiedener Art, wie, nur um ein Beispiel anzuführen, an der Kante, ob sie eine Höhenkante, ob sie scharf, stumpf, gerundet, gerade, gekrümmt und wie, ob sie vorn, hinten oder wo ist, etc. Wenn man diese verschiedenen Theile gegen einander und gegen die Hügel, Spitzen und Kämme erwägt, so wird man besser den Unterschied der einzelnen Theile begreifen, als durch eine weitläuftige und schleppende Beschreibung.

Aber nicht allein die Structur, Gestalt und Ausbildung, sondern anch die relative 
Grösse und Stärke der Zähne derselben Art, und verschiedener Arten unter einander verglichen, verdienen Beachtung.

Da durch die Abnutzung die Zahntheile verăndert werden, so nimmt man auch auf die Beschaffenheit der Abnutzungsflächen Rücksicht. Da die Verschiedenheit der Theile auf die Gestalt ihrer Abnutzungsflächen Einfluss hat, so kann man umgekehrt auch aus der Verschiedenheit der Abnutzungsflächen auf die der abgenutzten Theile schliessen. Häufiger werden abgenutzte Zähne angetroffen, als Keimzähne, wo dann die Abnutzungsfläche zur Bestimmung eines vereinzelten Zahnes verhelfen, hauptsächlich die horizontalen und geneigten Abputzungsflächen auf der Zahnkrone. Diese Flächen sind kleeblattförmig, bandartig, rautenförmig, halbmondförmig, hufeisenförmig, quadratisch, rectangulär, dreieckig, rund, elliptisch, oval etc. An diesen Formen werden wieder die einzelnen Theile zu unterscheiden versucht, wenn sich deren auszeichnen sollten, und auch die Gegend, in welcher diese auf der Mahlzahnkrone liegen, wird angegeben. Doch passen die Angaben über die Beschaffenheit der Abnutzungsflächen gewöhnlich nur für ein gewisses Alter des Thiers.

Meist gestatten die Abnutzungsflächen auch Einsicht in die Structur des Zahns. Die gleichförmige Abnutzung der verschiedenen Substanzen, aus denen ein Zahn besteht, ruft auf der Fläche Zeichnungen hervor, die entweder der Gestalt der Abnutzungsfläche mehr oder weniger parallel sind, oder davon abweichen, je nach dem Bau des Zahnes. Auch diese Zeichnungen auf den Abnutzungsflächen werden bisweilen genauer beschrieben, wobei zu den bereits angefühten Ausdrücken noch andere hinzutreten, wie Lappen verschiedener Art, Bänder etc.

Von den Schneidezähnen ist der erste der, welcher dem vordersten Ende des Kiefers und dem analogen Zahn der andern Kieferhälfte zunächst sitzt, und von ihm aus werden die auf ihn folgenden weiter gezählt. Der erste Schneidezahn heisst deshalb auch innerer Schneidezahn, im Gegensatz zu dem letzten Schneidezahn jeder Kieferhälfte, welchen man den äussern Schneidezahn nannte. Diese Benennungen passen indess mehr da, wo die Schneidezähne eine geschlossenere Reihe bilden. Es gibt Thiere, bei denen gleichzeitig nur ein oder zwei Schneidezăhne in einer Kieferhälfte vorhanden sind. Sind sie in letzterem Fall an Grösse auffallend verschieden, so unterscheidet man sie wohl auch noch dadurch, dass man sagt: der grössere und der kleinere Schneidezahn.

Der Backenzahn, 'welcher dem Eckzahn zunächst folgt, ist der erste Backenzahn; auf diesen folgt der zweite, dritte etc., bis zum letzten Backenzahn. Gebräuchlich 
lich sind auch die Ausdrucke: der erste Milchzahn, der zweite Milchzahn, der letzte Milchzahn, der erste Ersatzzahn, etc., der letzte Ersatzzahn, oder schlechtweg der letzte Backenzahn, der vorletzte Backenzahn, der vorvorletzte Backenzahn. Man sollte indess für die Falle, wo es angeht, nicht versäumen zu bemerken, der wievielte Zahn in der Backenzahnreihe der Zahn ist, den man naher zu bezeichnen beabsichtigt. Auch kommen die fast noch weniger geeigneten Ausdrucke: kleinere Backenzähne, grössere, vordere, hintere Backenzahne vor.

Schon aus diesen wenigen Andeutungen wird hervorgehen, wie nöthig es sey, in der Lehre von den Zähnen gewisse Begriffe, Ausdrücke und Bezeichnungen festzustellen; ich rathe indess doch nur zu solchen, die eine gründliche Beschaftigung mit dem Gegenstand für unerlässlich erachtet, und die alsdann auch durchgehende Anwendung erlangen werden. 


\section{Die knochenführende Ablagerung von Georgensgmünd.}

Einige Zeit nachdem Cuvier im tertiären Gypagebilde des Montmartre's bei Paris Palueotherium, Anoplotherium und andere erloschene Pachydermengenera, reich an Arten, entdeckt hatte, und bevor dieselben in Deutschland aufgefunden waren, gelang es mir, das Palaeotherium in letzterem Lande nachzuweisen. Die erste Notiz gab ich in Kastner's Archiv für die gesammte Naturlehre, B. VII. H. 2. S. 181, der später eine genauere Nachweisung in meinen Palaeologica S. 422 folgte, und jetzt erscheint das Ausführliche darüber hier.

In der anmuthigen Gegend Bayern's, wo die Schwabische und Fränkische Rezat sich zur Rednitz vereinigen, liegen die drei Ortschaften Georgensgmünd, Petersgmünd und Friedrichsgmünd dicht beisammen, ersteres am linken Ufer der Fränkischen Rezat. Kaum eine Viertelstunde davon gewahrt man am rechten Ufer des Steinbacher Bächleins eine isolirte Anhöhe, Biehl genannt. Diese Gegend liegt nicht weit von Roth, von der Chaussee nach Weissenburg rechts; von Ansbach ist sie sechs Stunden entfernt. Der Biehl erhebt sich ungefähr 150 Fuss über dem Thalgrund, ist kegelförmig, von elliptischem Querschnitt, und endigt, statt in eine Spitze, in ein Plateau. An den Seiten wird eintrüglicher Hopfenban getrieben. Der ganze Hügel besteht aus Tertiärgebilde. Diese Gegend besuchte ich im Sommer 1829. Damals standen auf der Gipfelfläche des Biehls zwei Steinbrüche in Betrieb, deren einer 20 Fuss tief aufgeschlossen war. Das Gestein besteht aus einer unzahligen Menge horizontaler Schichten von ungefahr einem halben Fuss Măchtigkeit. Diese sind fester, mehr oder weniger leicht zerreiblicher und ocheriger Kalkstein, kleinzellig und mit spätigem Kalke durchzogen. Damit wechselt öfter eine dünne Schichte, die fast bloss aus Blättern und Aesten dicotyledonischen Gesträuchs verschiedener Art zu bestehen scheint. In diesen Schichten habe ich keine Säugethierreste angetroffen, wohl aber im Kalkstein. Häufig liegen sie aber auch nicht darin. Einige darunter waren zertrümmert und abgerundet, ehe sie das Gestein umschloss, was auf einen längern Aufenthalt im Wasser oder auf Fortfuhrung deuten würde. Der Kalkstein wird nach der 
Tiefe fester, mächtiger, massiger und unregelmässiger. Von Conchilien findet man nur unvollständige Steinkerne von Helixen, Lymnäen und vielleicht noch einem oder dem andern Lacustermolluske. Das Gebilde wird von Dammerde bedeckt, und ruht auf dem Flötzsandstein der Gegend. Der Hügel ist nicht durch spätere Hebung entstanden, gehört vielmehr zu den Beispielen isolirter Höhen, die aus horizontal geschichteten Gesteinsabsätzen bestehen und vielleicht unter Wasser entstanden in derselben Form, in der sie sich darstellen * ). Seit der Erbauung eines in der Gegend stehenden Klosters vor etwa $\mathbf{3 0 0}$ Jahren wird dieser Kalkstein zu Löschkalk gewonnen. Wie mancher Zahn und Knochen mag unterdessen im Kalkofen verbrannt seyn; als ob die Erde dazu diese Reste eine unberechenbare Zeit, jedenfalls so lang, als der Mensch existirt, aufbewahrt habe! Derselbe Kalkstein soll auch auf dem Hügel in der Nähe, worauf der Weiler Hauslach liegt, in SSW. vom Biehl und von ihm durch das Steinbacher Bächlein getrennt, so wiè auf einer Anhöhe jenseits der Rezat, eine Stunde vom Biehl, brechen. Diese drei Punkte würden mit abnehmender Höhe in eine gerade Linie von SSW. nach NNO. fallen, und sich anderen Stellen bei Schwabach, Abenberg, Hilboldstein, Plainfeld etc. anschliessen, deren Ablagerungen ein Tertiärbecken im hügeligen Lande Mittelbayern's bezeichnen, ein Becken, das nicht ohne Beziehung zu dem in Oesterreich, der Schweiz und des Rheinthals steht ***).

Die früheste Nachricht über die uns hier näher angehende Gegend finde ich in

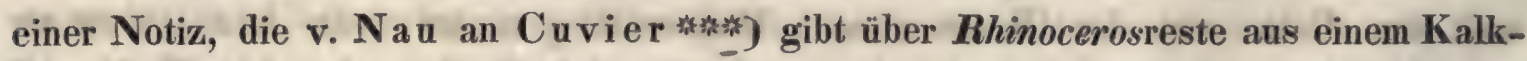
hügel bei Georgensgmund unfern Nürnberg. Diese Reste bestehen in einem fünften oder sechsten Backenzahn aus der linken Kieferhalfte, einem Unterkieferfragment mit den beiden letzten Backenzähnen, und einem untern Schneidezahn, und Cuvier zählt sie zu seinem Rhinoceros incisivus.

Die Reste, welche ich aus dieser Gegend selbst besitze, oder theils von Hern von Gemming, theils von Herrn Grafen zu Munster mitgetheilt erhielt, und in den folgenden Bogen beschrieben und abgebildet sind, fuhrten mich auf folgende Thiere: Mastodon (Tetracaulodon?), und zwar Reste, welche unter Mastodon angustidens und Mastodom Arvernensis begriffen werden; Dinotherium Bavaricum; Hyotherium,

*) Eine Beobachtung an Gesteinsabsätzen des verschiedensten Alters; vgl. meine Palaeologica, S. 339 u. a.

t) Näheres hierüber ist in meinen Palaeologica entwickelt.

Cuvier, Oss. foss. III. S. 391. 
ein schweinsartiges Thier, das sich mit keinem der bekannten vereinigen liess; vielleicht zwei Gattungen rhinocerosartiger Thiere, gewöhnlich unter Rhinoceros incisivus Cuv. begriffen; Palueotherium Aurelianense; Palaeomeryx Bajani, Palaeomeryx Kaupi, vielleicht noch eine dritte Gattung dieses neuen Wiederküuers; Ursus cob Ursus spelaens?); einen Fleischfresser, nach dem vorhandenen Eckzahn Canis ăhnlicher, als Felis; vielleicht zwei andere kleinere Fleischfresser; so wie auf Zahne und Knochen, von denen noch nicht gesagt werden kann, ob sie von den genannten Thieren herrühren, deren Grab sie theilten, oder ob sie andere Gattungen anzeigen; endlich auf Schildkröte. Meine früheren Angaben in Kastne r's Archiv und in meinen Palaeologica sind hienach zu berichtigen; auch die Angaben des Herrn Grafen zu Münster*), in denen die neue Gattung Mustela und eines andern Fleischfressers ungewiss, Rhinoceros pygmaeus gleich Rhinoceros incisivus, Mastodon minutus gleich Mastodon Arvernensis ist, so wie Rhinoceros tichorhinus, Anthracotherium und die beiden Arten Lophiodon wegfallen. Herr Graf zu Münster besitzt auch noch die rechte Unterkieferhălfte eines kleinen, und den letzten Backenzahn aus der linkeu Unterkieferhalfte eines grossen hirschartigen Thiers, welche 25 Fuss tief aus einer offenen Höhlung im Kalkfelsen bei Georgensgmünd herrühren. Diese Reste sind nicht fossil, mögen aber manches Jahr in dieser Höhlung gelegen haben. Schon vor mehreren Jahren machte ich auch Herrn Murchison ***;) auf diese Ablagerung aufmerksam, der sie besuchte und Reste erhielt, in denen Pentland und Clift Palaeotherinm magnum, ein neues Anoplotherium, ein neues Anthrucotherium oder Lophiodon

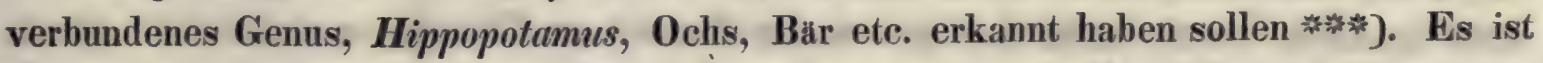
auffallend, hierunter gerade die Thiere zu vermissen, welche in dieser Ablagerung am häufigsten sind. Später führt Murchison †) an, dass in diesem Lacusterkalke vorkommen: Palueotherium, Anoplotherium, deren Species denen des Pariser Beckens identisch sind, mit Mustodon Arvernensis, Rhinoceros incisivus und pygmaeus, Bär, Hirsch, Pferd, Fuchs, einem neuen Fleischfressergenus und anderi unbekannten Thieren. Ich habe eine sehr grosse Anzahl von Resten aus dieser Ablagerung zu

7) In Keferstein's Zeitung für Geognosie, Geologie etc. 1829-1831. X. S. 90.

4in) Hienach verdient das berichtigt zu werden, was derselbe in seiner Address delivered at the anniversary meeting of the Geological Society of London, on the 17. Febr.1832, S. 7, in der Note sagt.

* Proceed. of Geolog. Soc. Mai 1831.

†) Address delivered elc. S. 7. 
untersuchen Gelegenheit gehabt, darunter aber nichts Zuverlassiges von Anoplotherium, Hirsch, Pferd, Anthracotherium, Lopiodon, Hippopotamus, Ochs und dergleichen angetroffen, wohl aber bin ich ofter, ich gestehe es, in Versuchung gerathen, in einem Zahn oder Zahnfragment ein anderes Thier zu vermuthen, als die von mir aufgefuhrten; vollständigere Reste aber haben meine früheren Ansichten berichtigt. Von den nach England gekommenen Resten von Georgensgmünd ist noch keine genaue Beschreibung bekannt; es ist indess vorauszusehen, dass darunter sich manches der angeführten Thiere nicht bestätigen lassen werde. Eben so wenig habe ich etwas von Gattungen gefunden, die denen des Pariser Beckens identisch wären. Unsere Ablagerung zeichnet sich vielmehr gerade dadurch aus, dass sie, so weit die Untersuchungen jetzt gediehen sind, keine Gattung mit dem Pariser Becken gemein hat, und das Palaeotherium, welches am zahlreichsten bei Georgensgmund abgelagert ist, ist gerade das, von dem man Reste nur von Montabusard im Orleanischen, von Montpellier und von Argenton kennt, wo es uberdiess nur sparsam vorkommt. Mit ihm liegen bei Montabusard in einem Lacustermergel Mastodon tapiroides, Lophiodon, eine Rhinocerosgattung von mittlerer Grösse und ein rehartiges Thier, das ich bei der Beschreibung des Palaeomeryx noch näher anführen werde. Das Kieferfragment von Palueotherium Aurelianense, welches $\mathbf{1 7 8 0}$ bei Saint-Geniez, drei Stunden von Montpellier, gefunden wurde, scheint von gelblichem Eisenocher umgeben gewesen zu seyn; was auch für einige Reste von Georgensgmünd gilt, und ruhrt wahrscheinlich aus einem Süsswassergebilde. Diese beiden Ablagerungen lassen sich also mit der, die uns beschäftigt, in Beziehung bringen. Bei Georgensgmünd scheinen die Reste von Rhinoceros nicht viel seltener zu seyn, als die von Pulueotherium, dann kommt Mastodon; weit seltner sind die ubrigen Thiere. 


\section{Beschreibung der fossilen Zähne und Knochen von Georgensgmünd.}

$$
M \text { a s } t \text { o d } \quad 0 \text {. }
$$

Seit der Entdeckung des Tetracaulodon durch Godmann*), das zwar HarIan **) bezweifelt und fur die Jugend von Mastodon hält, erheischt die Untersuchung und Bestimmung der bisher unter Mastodon begriffenen Reste eine Vorsicht eigner Art. In der Ungewissheit, was man eigentlich in solchen Resten vor sich habe, wird man noch mehr durch neuerlich bei Eppelsheim vorgefundene Kieferstücke

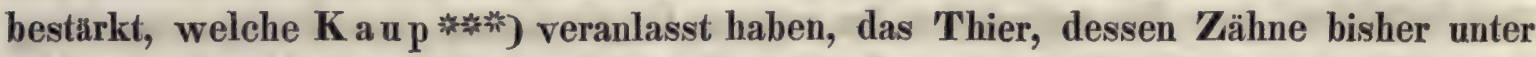
Mastodon angustidens von Eppelsheim begriffen wurden, zu Tetracaulodon hinzuzunehmen. Rührt das Stück, welches derselbe dem vordern Ende des Unterkiefers beilegt, wirklich aus demselben her, so war freilich dieser Kiefertheil, durch seine auffallende Länge und zwei Alveolen für Stosszähne, ganz anders gebildet, als z. B. der bei Wien gefundene Unterkiefer von Mustodon angustidens, worin mehr der Typus des Elephanten ausgedrückt liegt, und beide Thiere können unmöglich vereinigt bleiben, wenn gleich ihre Zähne grosse Aehnlichkeit zeigen. So lange hierüber nichts Gewisses entschieden ist, werden die hieher gehörigen Reste, deren ich zu erwahnen habe, am besten unter Mastodon betrachtet.

Diese Zăhne sind zweireihig und mehrreihig.

$$
\text { Zw ér é hige Backenzähne. }
$$

Die zweireihigen Zähne sind beim Mastodon die ersten Backenzähne.

Der Zahn Taf. I. Fig. 1. a von oben und b von der Seite, besitzt die Grösse des ersten Backenzahns von Mastodon angustidens. Cuvier kannte drei ahnliche Backenzähne, einen in einem Kieferfragmente von Dax COss. foss. I. S. 255. t. 3.

क) Godmann, Trans. of the Americ. Soc.; daraus in Ann. des sciences naturelles, 1830. Juli. S.292.

Harlan, Bulletin des sc. nat. et de géologie, 1830. Aug. S. 320.

K a u, Isis, 1832. VI. S. 326. T. 11. Fig. A. B. C. 


\section{$-34$}

f. 2. a. b), den zweiten von Simorre (S. 256.t. 1. f. 2) und den dritten in Hammer's Cabinet (S.256. t. 3. f. 14) von unbekanntem Fundorte. Auch führt Schinz *) einen solchen Zahn aus der Braunkohle von Käpfnach an.

Die Zweireihigkeit beruht auf zwei Hügelpaaren, den hauptsächlichen Bestandtheilen der Zahnkrone, zwischen denen ein tieferes Thal befindlich ist, als zwischen den beiden Hügeln der Paare. Der Zahn von Dax sitzt noch im Oberkiefer und besitzt keinen Ansatz. Hienach glaubt Cuvier, dass auch der Zahn von Simorre, dem der Ansatz mangelt, aus dem Oberkiefer, der 'Zahn in Hammer's Cabinet aber, da er hinten einen kleinen Ansatz zeigt, aus dem Unterkiefer herrühre. Ausmessungen werden nicht mitgetheilt. Dehnt man die Abbildungen in halber Grösse auf die natürliche Grösse aus, so entspricht diese ganz den Zähnen, welche ich jetzt näher zu beschreiben habe.

Der Zahn Fig. 1 gleicht am meisten dem im Oberkiefer von Simorre, welcher der Ersatzzahn ist. Hienach, und bei Berthcksichtigung dessen, was ich uber die Beschaffenheit der Mastodonzähne in meiner Beschreibung von Resten von Mastodon Arvernensis **;) festsetzte: dass nämlich die complicirteren Hügel mit dem geringeren Einschnitt des Querthals oben an der Innenseite, unten aber an der Aussenseite liegen, wäre auch dieser Zahn der erste Ersatzbackenzahn aus der linken Oberkieferhälfte. Diese Ansicht wird ferner dadurch unterstützt, dass der Hinteransatz * $_{\text {* }}$ ) immer sich von dem complicirteren Hugel des hintern Pares herunter und uber die Hinterseite zieht, wesshalb derselbe in den oberen Zahnen nach aussen und in den untern Zähnen nach innen endigt. Bei diesem Stande des Zahnes würde die etwas auswärts gerichtete Wurzel nach vorn zu stehen kommen, und die andere, eine Doppelwurzel, die Innen - und Hinterseite der Krone unterștützen. Die Krone umgibt an

*) Denkschriften der allgemeinen Schweizerischen Gesellsohaft für die gesammten Naturwissenschaften, I. 2. S. 52. t. 1. f. 7. Es fragt sich, ob der etwas kleinere Zahn von einem Zoll, vier Linien Durchmesser, von dem Schinz in Fig. 8 Abbildung gibt, hieher gehört, und ob er etwa ein Milchzahn sey? Die Abbildung ist nicht geeignet, hierüber zu entscheiden. Schinz sagt von ihm: er sey gerundet, viereckig, höckerig, aber nur mit einem grössern Höcker versehen, doch bemerkt man Hinneigung zum Zwweireihigen; er habe indess auch grosse Aehulichkeit mit den falschen Mahlzähnen der Raubthiere.

*) Nova Acta Acad. Leop. Carol. Nat. Cur. XV. 2. S. 116.

\$s*) Aehnliches gilt auch für den Vorderansatz; doch ist er in manchen Zähnen nicht so deutlich wahrzunehmen, und zeigt sich mehr der Vorderseite parallel. 


\section{$-35$}

der Basis ein dicker Wulst, auf den auch Sehin z bei den Mustodonzähnen aus der Braunkohle bei Käpfuach aufmerksam macht. Er ist bei unserm Zahn innen höher, als aussen, und vorn und hinten abgebrochen. So viel'sieht man indess doch, dass vom innern Hügel des vordern Paars sich ein Ausläufer nach dem Wulste an der Vorderseite verzweigt, der wahrscheinlich am Wulste die Bedeutung eines Vorderansatzes erhălt. Cuvier stellt zwar Ansätze am analogen Zahn von Simorre in Abrede, wobei jedoch bemerkt werden muss, dass er solche Theile, wemn sie nicht sehr auffallend entwickelt waren, gewöhnlich ganz übersah. Dem erwähnten Ausläufer ist ein anderer an der hintern Spitze der Innenseite ahnlich, der sich in die Kronenmitte begibt, und an unberuhrten Zähnen, wie der von Simorre, kleine Nebenhügel trägt. Diess ist der Grund, warum diese beiden Hügel complicirter aussehen, als die Hügel an der Aussenseite, und einander gleichen. Wahrscheinlich besass der hintere Hügel an der Innenseite auch noch nach hinten einen Ausläufer, der mit dem Wulste den Hinteransatz bildete; an diesem Exemplar ist er weggébrochen. Das Querthal läuft nach der Aussenseite (b) am tiefsten aus. Die Abnutzung hatte bereits über allen Hügeln begonnen; doch war der Schmelz erst am vordern Hügelpaar, am meisten am Hügel an der Aussenseite, durchgenutzt.

Der Taf. I. Fig. 2. a von oben und b von der Seite abgebildete Zahn wird der erste Backenzahn aus der rechten Unterkieferhälfte seyn. Ist er das, so besass er hinten einen Ansatz, der als die Fortsetzung eines Ausläufers vom äussern hintern oder complicirteren Hugel angesehen werden kann. Die Abnutzung und das Aufsaugen vor Alter haben den Zahn sehr entstellt. Man gewahrt fast nur Abnutzungsflächen und Gruben von verschiedener Grösse und Tiefe, welche dem Zahn ein zerfressenes Ansehen verleihen, und keine Hügel oder Thäler. Dieser Zahn war entweder schon ausgefallen, oder stak ganz locker und nur vom Zahnfleisch gehalten im Kiefer. Das vordere Huggelpaar ist auf eine grosse vertiefte Fläche reducirt, die auch schon mit der Abnutzungsfläche des hinteren äusseren Hügels in Verbindung steht und durch letztern, mittelst eines breiten Durchgangs, selbst mit der hintern seitlichen Abnutzungsfläche. Diese seitliche Abnutzungsflache breitet sich fast uber die ganze Hinterseite aus, und stellt eine vertiefte und angefressene Fläche in der Knochenmasse dar. Nur die Abnutzungsfläche des hintern Hügels an der Innenseite ist noch durch Schmelz isolirt. Der Schmelz ist an der Basis der Krone nur noch theilweise vorhanden; an der Aussenseite sitzt er über dem hintern Theil, an der Hinterseite ist davon wenig ubrig, dagegen uber der Innenseite grösstentheils vorhanden; der ganzen Vor- 
derseite und der vordern Hälfte der Aussenseite fehlt er, und statt seiner bemerkt man tief zerfressene Knochenmasse. Die Wurzeln sind auch sehr zusammengeschmolzen. Der übrige Schmelz hat ein geglättetes Ansehen, was alteren Zähnen gemein ist. War dieser Backenzahn ein Milchzahn?

Einen weit kleineren zweireihigen Backenzahn, als die vorigen, habe ich Taf. I. Fig. 3. a von oben, b von der Seite und c von unten abgebildet. Sein Aussehen und die Dicke seines Schmelzes verräth Mastodon. Der Zahn ist unregelmåssig oval. Der Schmelz an der Basis ist nur an den längeren Seiten erhalten, wo er keine seitliche Abnutzungsflächen zeigt; an den kurzen Seiten ist er sehr beschädigt und nicht im Stande, die Frage zu entscheiden: ob etwa hier seitliche Abnutzungsflächen lagen. Die Abnutzung der Krone bekundet, dass der Zahn nach der Richtung des Längendurchmessers im Kiefer sass. Die fragmentarische Wurzel ist an der am meisten von Schmelz entblössten Seite merklicher auswärts gerichtet, als an der entgegengesetzten, und es scheint daher, dass an ersterer Seite kein Zahn mehr unmittelbar vorgesessen; vielleicht dass an der entgegengesetzten Seite sich ein Zahn dicht anschloss. Aus diesen Gründen war der Zahn vermuthlich ein erster Backenzahn. Seine an der einen Längenseite gewölbtere Form und die warzen - oder zitzenförmigen Hügel, aus denen die Krone besteht, sind Charaktere des Mastodon, hier insbesondere desjenigen Thiers, das unter Mastodon Arvernensis begriffen wird. Nach der Richtung und Vertheilung der Abnutzung der Krone sass dieser Zahn entweder in der rechten Unter-, oder in der rechten Oberkieferhälfte. Der erste Backenzahn aus dem Oberkiefer von Mastodon Arvernensis ist genügend bekannt *), um einzusehen, dass der in Rede stehende nicht dazu gehört; ersterer ist zweireihig, d.h. er besteht aus zwei deutlichen Spitzenpaaren, und ist überdiess mit einem Vorder - und einem weniger starken Hinteransatz versehen. Zwar ist vorliegender Zahn auch zweireihig, d.h. er lässt sich auch in zwei Spitzenpaaren zerfällen, von denen aber nur das vordere, über der kleineren Kronenhălfte liegende Paar deutlich getrennt ist, während das hintere, über der grössern Zahnhalfte liegende Paar sich nach hinten etwas erhebt und dabei mehr die Bedeutung einer eingekerbten Spitze, als die eines Hügelpaares gewinnt. Befanden sich vorn und hinten Ansătze, so waren sie weit geringer, als in dem ersten Backenzahn des Oberkiefers von Mastodon Arvernensis. Rührt dieser Zahn etwa aus dem Unter-

*) Vgl. meine Beschreibung der Reste von Mastodon Arvernensis in Nova Acta Acad. Leop. Carol. Nat. Cur. XV. 2. 
kiefer her? Croizet und Jobert*j beschreiben den ersten Backenzahn aus dem Unterkiefer des Mastodon Arvernensis als einen Zahn, der nur eine Spitze besitzt, 0,016 lang und nur 0,010 breit ist. Die Abbildung bei Croizet und Jobert ist nicht deutlich genug, um erkennen zu lassen, ob ausser dieser einen Spitze nicht noch Theile vorhanden sind, welche eine Analogie zwischen vierhügeligen oder zweireihigen Backenzähnen begründen. Aber auch schon der ăussern Form nach trifft er nicht ganz zu. Vielleicht ist der Zahn aus der Auvergne der Milchzahn und der von Georgensgmünd der Ersatzzahn des ersten Backenzahns der rechten Unterkieferhälfte. Bestätigt würde dadurch werden, dass der erste Backenzahn des Unterkiefers dieses Mastodon sich von dem des Oberkiefers durch ein einfacheres und seitlich mehr zusammengedrücktes Ansehen auszeichnet. Dieser Zahn ist 0,019 breit und war wenigstens 0,024 lang; die vordere Hälfte ist breiter, als die hintere. Diese Dimensionen entsprechen eher dem ersten Backenzahn des bei Eppelsheim gefundenen Oberkieferfragmentes von Mastodon Arvernensis, den ich für den Ersatzzahn halte, dessen hintere Halfte aber etwas breiter als die vordere ist.

Hier die Dimensionen der ersten Backenzähne von Mastodon angustidens und Mastodon Arvernensis.

\begin{tabular}{|c|c|c|c|c|c|c|c|c|}
\hline \multirow[b]{3}{*}{ Länge ... } & \multicolumn{2}{|c|}{ Georgensgmünd. } & \multirow{2}{*}{\multicolumn{2}{|c|}{ Eppelsheim. }} & \multirow{2}{*}{$\begin{array}{c}\text { Ggmünd. } \\
\text { Fig. } 3 .\end{array}$} & \multirow[t]{2}{*}{ Auvergne. } & \multicolumn{2}{|c|}{ Eppelsheim. } \\
\hline & Fig. 1. & Fig. 2. & & & & & Ersatzz. & Milchzahn. \\
\hline & 0 & 0,0 & 0,0 & & , $00 \times$ & & 0,024 & 0,033 \\
\hline $\begin{array}{l}\text { eite vorn } \\
- \text { hinten }\end{array}$ & 0,04 & $\begin{array}{l}0,031 \\
0,037\end{array}$ & 0,048 & 0,050 & 0,019 & 0,0 ? & $\begin{array}{l}0,0185 \\
0,0285\end{array}$ & 0,026 \\
\hline
\end{tabular}

Zur Länge des Zahns Fig. 1 ist ungefahr 0,01 hinzuzusetzen für den abgebrochenen Schmelz. Durchschnittlich kann man annehmen, dass der erste Backenzahn in Mastodon angustidens fast noch einmal so gross ist, als in Mastodon Arvernensis.

$$
\text { Mehrreihige Backenzähne. }
$$

Mit einem Backenzahn, der sich durch seine Kleinheit eher dem zuletzt erwähnten zweireihigen, als den grösseren zweireihigen Backenzähnen anschliesst, werde

*) Croizet et Jobert, Recherches sur les ossemens fossiles du Puy-de-Dôme. Paris 1828. I. S. 136. 
hier der Anfang gemacht. Meine Beschreibung des Oberkieferstückes von Mastodon Arvernensis von Eppelsheim verfasste ich mit Zuziehung dessen, was über Reste desselben Thiers aus der Auvergne Croizet und Jobert bekannt machten. Ích versuchte darin, die Backenzahnreihe dieses Thiers und die Kenntniss von der Beschaffenheit der Backenzähne selbst zu vervollständigen. Was nun die Grösse und Ausbildung des Taf. I. Fig. 4. a von oben und b von der Seite abgebildeten Zahnes betrifft, so entsprechen sie ganz Mastodon Arvernensis. Ein kaum der Abnutzung ausgesetzt gewesenes Zahnfragment, welches ich nicht abbildete, weil es sonst von keinem Interesse ist, beweist deutlich die Uebereinstimmung in der Ausbildung. Der uns beschäftigende Zahn ist dreireihig. Bei der auffallenden Kleinheit des ersten Zahus der Backenzahnreihe ist er zu gross, um der zweite gewesen zu seyn. Wohl aber kann man in ihm den dritten der Reihe voraussetzen, und dann rührt er nur aus dem Unterkiefer her, und ist der zweite dreireihige, während der dritte der Reihe des Oberkiefers für vierreihig gilt *. Dieser dreireihige Backenzahn ist so sehr abgenutzt, dass nicht bloss die Hügelpaare zu mehr oder weniger lappigen und rautenförmigen Flächen, sondern auch diese Flächen noch unter einander vereinigt sind. Dabei ist die Abnutzungsflache jedes Hugelpaars stark zerfressen und zum Theil ausgehölt. Die Wurzeln sind grösstentheils, wie man es nennt, aufgesogen, und so beschaffen, dass der Zahn nur locker im Kiefer gesessen haben konnte. Dieser Zahn rührt daher entweder von einem alten Thiere her, oder ist ein Milchzahn, vielleicht war er der letzte Milchzahn. Die Verschiedenheit des Grades der Abnutzung uber der Krone ist ein weiterer Anhaltspunkt, um dem Zahn seine Stelle im Kiefer anzuweisen. Hienach konnte er, wenn er aus dem Unterkiefer stammt, nur in der linken Hälfte gesessen haben. Die vordere seitliche Abnutzungsfläche, die fast ganz von Schmelz entblösst ist, lässt erkennen, dass an dieser Seite ein anderer Zahn vorgesessen, der nicht viel schmäler war, als er selbst. Err war wenigstens 0,056 lang und 0,037 breit, mithin etwas länger, als die bekannten dreireihigen, welche zweite Backenzähne sind.

Weit grossser sind die nun zu betrachtenden mehrreihigen Zähne. Der kleinste unter ihnen ist noch der Taf. II. Fig. 7. a von oben und b von der Seite abgebildete. Er ist dreireihig und kommt in seinen Dimensionen dem dritten obern Backenzahn des

-) Vgl. Nova Acta Acad. Leop. Carol. Nat. Cur. a. a. O. t. LVII. S. 120. 


\section{$-\quad 39$}

Mastodon Arvernensis gleich, der jedoch vierreihig ist. Nach Cuvier * *ühren dreireihige Zähue mit einem starken Hinteransatz aus dem Oberkiefer her. Ein sehr starker Hinteransatz kann an diesem Zahn nicht in Abrede gestellt werden. Er würde daher aus dem Oberkiefer herrühren; dann verweisen ihn die Abnutzungsflächen der Krone in die linke Kieferhälfte. Der dritte Backenzahn ist im Oberkiefer des Mustodon maximus und des Mastodon Arvernensis, vielleicht auch in noch andern Mastodonten, vierreihig. Sonach könnte er kein dritter seyn, für den er auch nicht gross genug wäre. Als zweiter Backenzahn scheint er ganz zu passen. Ihm kounte ein erster Backenzahn, wie Fig. 1, vielleicht derselbe, vorgesessen haben; es sclfeint wirklich, dass diese beiden Zähne von einem und demselben Individuum herruhren. Die Berührungsstellen, welche hierüber allein Gewissheit geben, sind abgebrochen. Die Farbe und das anhängende Gebilde beider Zähne sind ganz übereinstimmend. Der dreireihige Zahn ist 0,076 lang und 0,052 vorn und 0,05 hinten breit, und der Schmelz der Hügelspitzen, mit Ausnahme des hintern Hügels an der Aussenseite, bereits durchgenutzt. Die complicirteren Hügel, an der Innenseite liegend, und unter diesen die vordern, sind am stärksten abgenutzt. Der Hinteransatz ist stark und warzig. Die vordere seitliche Abnutzungsfläche ist deutlich, die hintere nur schwach vorhanden, und hat erst ganz unten an der Basis begonnen. Der auf diesen gefolgte Zahn sass daher noch tief und mochte kaum das Zahnfleisch durchbrochen haben. Der Zahn besass drei Wurzeln; eine sitzt unter dem letzten Hügelpaar und dem zweiten Hügel an der Aussenseite, die zweite unter dem ersten und zweiten Hügel an der Innenseite und die dritte unter dem ersten Hügel an der Aussenseite, und half zugleich den ersten Hügel an der Inuenseite mit unterstützen.

Die bisher vorgebrachten Gründe dienen auch bei der Bestimmung des Taf. I. Fig. 5. a von oben und b von der Seite abgebildeten Backenzahns. Dieser Zahn zeigt vorn und hinten eine seitliche Abnutzungsfläche, wo ihm Zähne gefolgt und vorgesessen. Seiner Grösse nach konnte er nicht wohl der zweite, aber wahrscheinlicher der dritte der Reihe seyn. Bei der Voraussetzung, dass der dritte im Oberkiefer vierreihig, im Unterkiefer aber, wie der zweite, zweireihig ist, ist dieser der dritte aus dem Unterkiefer und nach der Art der Abnutzung über der Krone, aus der rechten Halfte. Die stärkere Abnutzung verbreitet sich über die Hügel der Aussenseite, welche die complicirteren sind, namentlich über den vordern. Das vordere Hügelpaar ist auf eine

\#) Cuvier, Oss. foss. (3e éd.) I. S. 257. 
gemeinschaftliche, etwas vertiefte Abnutzungsfăche reducirt. Der Zahn ist 0,11 lang, 0,057 vorn und 0,063 hinten breit; die vordere Breite ist etwas zu gering wegen Mangel des Schmelzes in dieser Gegend; die grösste Breite liegt in der ungefähren Mitte und beträgt 0,068. Der Zahn besitzt drei Hauptwurzeln; eine sass unter dem hintern Hügelpaar und dem zweiten innern Hügel, die zweite unter dem ersten und zweiten Hügel an der Aussenseite und die dritte unter dem ersten Hügel an der Innenseite und unterstutzte zum Theil noch den ersten Hügel an der Aussenseite.

Von Zahnfragmenten will ich vornehmlich des Taf. II. Fig. 8. a von oben und b von der Seite abgebildeten gedenken. Es besteht nur im hintern Theil des Zahns, aus einem Hügelpaar mit einem Ansatz, der den letzten Backenzahn charakterisirt. Damit hat das Fragment grosse Aehnlichkeit, welches v. Humboldt vom Riesenfeld in Amerika mitgebracht und durch Cuvier * ${ }^{*}$ ) publicirt wurde, der es für den Hintertheil eines letzten untern Backenzahns von Mastodon angustidens hält. Bedenkt man ferner, dass der breitere Wulst den geringen Einschnitt des Querthals bei den untern Backenzähnen an der Aussenseite veranlasst, so ist zu vermuthen, dass dieses Fragment aus der linken Kieferhälfte herrïhrt. An den Hügeln des Fragmentes bemerkt man noch keine Abnutzung; vielleicht lagen sie noch im Zahnffeisch. Ein tiefes Querthal trennt den starken Hinteransatz vom Hügelpaar, das mit demselben in keinem besonderen Zusammenhange steht. Dieser Ansatz ist eine selbstståndige Querreihe, und besteht nicht sowohl in einem Hügelpaar, als aus einem hügeligen Kamm. Hinter diesem liegt noch als letzter Theil ein kleiner warziger Ansatz, der fur einen Ausläufer vom Ende des hügeligen Kammes an der Innenseite gedeutet werden kann. Der Schmelz ist über dem ganzen Fragmente noch etwas warzig oder faltig, was vom Zahnfleisch bedeckt gewesene Zähne auszeichnet. Zu diesem Fragmente gehören wahrscheinlich noçh zwei andere Stücke, die aber nicht unmittelbar davor sassen. Daran sieht man eine geringe vordere seitliche Abnutzungsfläche, ihre Spitzen sind erst schwach abgenutzt. Diese Stücke sind Theile der vordersten Querreihe.

An allen Backenzăhnen von Mastodon aus dieser Ablagerung ist der Schmelz gut erhalten, stark glänzend, graulich gelbbraun und hie und da mit schwärzern oder braunern Flecken besetzt.

Die Bestimmung dieser Zăhne geschah auf den Grund dessen, was vor mir darüber bekannt war. Nur daran konnte ich mich halten, da die Reste von Greorgens-

") Cuvier, Oss. foss. I. t. 2. f. 4. 6. S. 259. 
gmünd nicht so beträchtlich sind, um bisher bestandene Vermuthungen zu bestätigen, zu berichtigen, oder Verhaltnisse daran ausgedehnter darzulegen. Nach vorstehenden Untersuchungen findet sich bei Georgensgmünd Mustodon angustidens und Mastodon Arvernensis. Ka u p ${ }^{*}$ ) bezweifelt die Existenz letzterer Species, indem er sie für die Jugend von ersterer oder seines Tetracaulodon longirostris hält. Seine Gründe fơr eine solche Verschmelzung sind mir nicht bekannt. Es ist schwer zu begreifen, wie es geschieht, dass Zähne, deren Grösse uud Ausbildung so constant, wie diese, von einander abweichen, uud die sich in zwei gut geschlossene Abtheilungen bringen lassen, einer und derselben Thierart angehören.

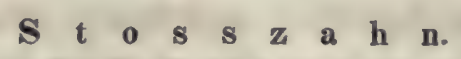

Das Tafel I. Fig. 6 abgebildete Fragment scheint ein Stückclien Stosszahn zu seyn. Die Elfenbeinmasse, auch von Elfenbeinstructur, wird von einem etwas über 0,001 starken Schmelz uberkleidet. Dieser Schmelz ist cannelirt; weniger deutlich bemerkt man diess an dem darunter liegenden Elfenbein. Ich fand vor mehreren Jahren bei Eppelsheim ein Stosszahnfragment von Mastodon angustidens, das zwar cannelirt, aber ohne Schmelzbedecküng ist. Auch. an den Stosszahnfragmenten aus letzterer Ablagerung in der Sammlung in Darmstadt konnte ich die Schmelzdecke nicht ermitteln; doch befindet sich in dieser Sammlung ein kleineres Stosszähnchen mit Schmelzüberzug. Schinz***) gibt Beschreibung und Abbildung von einem aus der Braunkohle bei Käpfnach herruhrenden Stosszahnfragmente von über zwei Fuss Länge. Es ist die Spitze und das bald auf dieselbe folgende Stück, und soll zu einem an derselben Stelle gefundenen Kopf gehören, von dem aber nicht weiter die Rede ist. Der Stosszahn ist massiv und von Elfenbeinstructnr. Es wird angeführt, dass nur die nach dem Kopf gekehrte Seite (die obere) der Länge nach gefurcht und platt sey; von Schmelz wird nichts erwähnt, was freilich dessen Mangel noch nicht beweist. Das Fragment von Georgensgmünd verräth einen Stosszahn von der Stärke der Stosszähne von Mastodon angustidens von Eppelsheim, der eher noch stärker als der von Käpfnach war.

\$) J. J. Ka up, Catalogue des plâtres des ossements fossiles etc. Darmstadt 1832. S. 13.

(⿻) A. a. 0. S. 53. t. 1. f. 9. 10. 


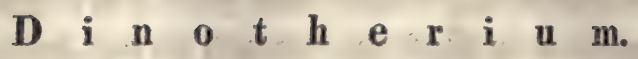

Unter den in der Gegend von Georgensgmund gefundenen Zähnen befindet sich auch ein Backenzahn meines Dinotherium Bavaricum. Von dieser Species machte ich anderwärts ein sehr beträchtliches Stück einer, gleichfalls in Bayern gefundenen, linken Unterkieferhalfte durch Abbildung und Beschreibung bekannt, wobei ich auch schon dieses Zahnes ausführlich gedachte. Unnöthige Wiederholung wäre es daher, wollte ich hier das wieder vorbringen, was ich schon dort daruber gesagt und durch Abbildung erläutert habe. Ich verweise auf meine frühere Beschreibung ${ }^{\text {** }}$ ) und erwähne

*) Nova Acta Acad. Leop. Carol. Nat. Cur. XVI. 2. S. 507. t. 36. f. 16 u. 17. - Ka u p nannte diese Species Dinotherium Cuvieri. Er und Andere (Jahrb. für Min. 1833. S.510. - Bayer'sche Annalen, 12. April 1834) wollen diese Benennung statt meiner angenommen wissen, weil sie älter und passender sey. Ich würde sie gerne aufgeben, wenn dem so wäre. Die Priorität ist auch in der Wissenschaft ein heiliges Recht, das zunächst auf Autorität und Geschichte Einfluss hat, aber leider so oft durch Eitelkeit verletzt wird. Wie sehr ich bemüht bin, dieses Recht zu schützen, kann aus meinen „Palaeologica" vielfältig ersehen werden. - Die ausführliche Darlegung meiner Species Dinotherium Bavaricum an besagtem Kieferfragment sowohl, als an allen zu derselben gehörigen, aber als solche vorher unerkannt gebliebenen Resten, ging bereits am 26. Januar 1832 bei der Kaiserlichen LeopoldinischCarolinischen Akademie ein. Früher schon hatte ich die Existenz dieser neuen Species im Jahrbuch für Mineralogie angezeigt. Meine Benennung ist daher unstreitig älter. Sie ist aber auch nicht weniger passend, als die von $K$ a up. Denn $\mathrm{Cu}$ vier, von dessen unendlichen Verdiensten ich gewiss tief durchdrungen bin, verdient am wenigsten in den Dinotherien Verehrung, da er dieselbe ganz verkannt und für Tapire gehalten hat. Wollte man einen Gelehrten damit ehren, so hätte man Kennedy oder Sömmerring nennen müssen, welche zuerst Zähne dieser Species bekannt machten, doch ohne das Thier richtig erkannt zu haben. Dass Dinotherium Bavaricum nicht auf Bayern allein beschränkt ist, kónnte mir nicht entgangen seyn, indem ich alle Nachrichten über ähnliche Reste prüfte, und diese zu bestimmen versuchte. Diese Species findet sich namentlich an den von mir näher angegebenen Orten in Frankreich vor. Die Benennung einer Species nach dem Lande, in der sie vorkommt, ist gebräuchlich; doch sucht man Gattungen, welche mehreren Ländern gemein sind, vorzugsweise nach dem Land zu benennen, das für sie noch besonders merkwürdig ist. Hiezu war nun Bayern ganz geeignet. Es findet sich gerade diese Species dort an mehreren Orten; es bot mir beträchtliche Reste dar, und darunter solche, welche mir über die Existenz dieser kleinern Species keinen Zweifel liessen; endlich aber glaubte ich diesem Lande auch dadurch noch den Vorzug geben zu müssen, weil in ihm am ersten Reste dieser Species gefunden, und schon von Kennedy und Sömmerring, zwei ausgezeichneten Bayer'schen Gelehrten, darauf aufmerksam gemacht wurde. Diess die Gründe, welche mich 
nur, dass dieser Zahn dreireihig, und in ihm sich Alles dahin vereinigt, dass er der letzte Milchzahn aus der linken Unterkieferhälfte ist. Von Dinotherium ist mir aus dieser Ablagerung sonst nichts bekannt.

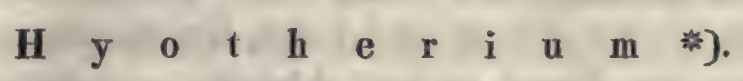

Die Reste schweinsartiger Thiere aus Ablagerungen, älter als das Diluvium, verdienen besondere Aufmerksamkeit. Wenn man ihr Zahnsystem nicht kennt, so ist die Bestimmung ihrer Zähne sehr erschwert. Der sicherste Weg ist aber auch hier, erst die Structur der Backenzähne zu ergründen, sodann die Entwickelung der Backenzahn reihe zu versuchen, und endlich über die Eck- und Schneidezähne Begriffe zu fassen.

$$
\text { B a c } k \text { e } n \text { z ä } h \quad n \text { e. }
$$

Eśs gelang mir, die Taf. II. Fig. 9, a von oben abgebildeten drei hintern Backenzähne mit der grössern Hälfte des diesen vorsitzenden, aus der rechten und den beiden letzten Backenzähnen aus der linken Unterkieferhälfte wieder zusammen zu finden. Alle diese $\mathbf{Z}$ ähne rühren ohne $\mathbf{Z}$ weifel nur von einem Individuum her. Die vier zusammengehörigen Zähne sind Fig.9.b noch von der Aussen- und c von der Innenseite abgebildet.

Die drei hintersten Backenzähne können für sich abgeschlossen betrachtet werden. Von den lebenden schweinsartigen Thieren lassen sich nur die analogen des Babirussa damit vergleichen, welche ihnen sehr ähnlich sind. Ich benutzte dabei mehrere Babirussaköpfe von Thieren verschiedenen Alters, die in ihren Zahndimensionen unter einander übereinstimmten, darunter einen, worin die Zähne auf demselben Grade der Abnutzung sich befanden, wie die fossilen.

Aus der Krone jedes der drei hintersten Backenzähne ragt ein vorderes und ein hinteres Paar Haupthügel, von niedrigern Nebenhügeln umgeben, hervor, und die Krone selbst ist mit einem Vorder - und einem Hinteransatz versehen. Der Vorderansatz ist kleiner, aber von der Krone deutlicher getrennt, als der Hinteransatz, der grösser und mit der Krone mehr verwachsen oder verschmolzen ist. Im letzten Backen-

zur Benennung Dinotherium Bavaricum bewogen, und zugleich der Beweis, dass andere weder älter noch passender sind, am wenigsten aber die Benennung Dinotherium Cuvieri hier sich eignet.

*) Von vंs, viós, Schwein, und Ingiov, wildes Thier; Schweinthier. 
zahn übersteigt der hintere Ansatz das Drittel der ganzen Zahnlänge noch etwas, und ist von dem analogen Ansatz in den vorsitzenden Zähnen in so fern verschieden, als sein hinterstes Ende zu einer starken Hügelspitze sich erhebt, vor der eine Gruppe von Nebenhügeln liegt.

Zwischen den beiden Haupthügeln an der Aussenseite liegt in diesen drei hintersten Backenzähnen ein kleiner Nebenhügel. Bei Babirussa ist dieser weniger stark und wahrscheinlich aus dem Grund in zwei kleinere getheilt, weil der vor ihm liegende kleinere Nebenhügel selbstständiger ausgebildet ist, und sich des Raumes bemeistert, während in den fossilen Zähnen dieser den vordern Haupthügel mit zusammensetzen hilft und dem andern den Raum nicht beengt. An der Innenseite sind diese Nebenhügel nicht vorhanden; die beiden Haupthügel bilden dort zwischen sich ein offenes Thal. Bei Babirussa ist dadurch, dass die Basis der Krone an dieser Stelle wulstiger aufgetrieben ist, dieses Thal weniger frei. Im letzten Backenzahn liegen zwischen dem hintern Paar Haupthügel und der hintersten Hügelspitze, am Aussenwie am Inmenrande, drei bis vier kleine Hügel, durch deren Abnutzung besagte Ränder ein gekerbtes Ansehen erhalten. Zwischen diesen Hügelchen der beiden Ränder, dem hintern Haupthügelpaar und der hintersten Hügelspitze, finden sich zwei sechsseitige sattelförmig gebogene Flächen vor, von denen die vordere gröśser, als die hintere ist. Babirussa besitzt mehrere solcher Flächen, und überhaupt keine so regelmässige Zusammensetzung dieses innern Theils des hintern Ansatzes am letzten Backenzahn; in Sus Scrofa ist sie noch weniger regelmässig. Dieser letzte Backenzahn ist gleichschenkelig dreieckig, in Babirussa regelmässig, im fossilen Zahn so, dass seine Aussenseite in der Richtung der Aussenseite der ganzen Zahnreihe fällt, die Innenseite aber sich nach hinten mehr zur Aussenseite auswärts zieht.

In jedem dieser drei Zähne liegen, von den vier Haupthügeln umgeben, noch zwei Nebenhügel, ein kleinerer am vordern Haupthügel an der Innenseite, der diesen zusammensetzen hilft, und ein grösserer, der sich bis in die Mitte zwischen den vier Haupthügeln erstreckt, am äussern Hügel des hintern Paares. Der Hauptabfall dieser Hügel geschieht nach der Aussenseite hin. Aehnliche Nebenhügel haben auch die Zähne von Babirussa, wo sie sich aber noch in das Thal zwischen den beiden Haupthügeln an der Innenseite nach der Kronenbasis verzweigen, was ich an den fossilen Zähnen nie bemerken konnte. In den beiden, dem letzien vorsitzenden Backenzähnen ist auf dem hintern Ansatz auch ein sich dem hintern Haupthügelpaar etwas anlehnender Nebenhügel vorhanden, und dieser ganze Ansatz repräsentirt den grossen 
Ansatz am letzten Backenzahn um so füglicher, als der eigentliche Wulst ersteren Ansatzes schon die Kerbung besitzt, welche für die beiden Seiten des grossen Ansatzes am letzten Backenzahn bereits erwähnt wurde. Wie unrecht ist es daher, die einzelnen kleinen Theile an Backenzahnkronen, als unwesentlich und willkührlich entstanden, unbeachtet zu lassen, wo doch bisweilen sie allein es sind, welche zur sichern Bestimmung eines vereinzelten Zalınfragmentes führen.

Die Abnutzungsflächen über der Krone dieser Zähne sind unregelmässig rund. Ihre Hinneigung zum Kleeblattförmigen räumt ihnen Aehnlichkeit mit denen gewisser Gattungen von Mastodon und tief abgenutzter Zähne von Hippopotamus ein. Am vorletzten Backenzahn ist der Schmelz des mittlern Nebenhügels eben erst durchsunken und die Knochensubstanz als ein kreisrunder Punkt entblösst. Der diesem vorsitzende Zahn ist am meisten abgenutzt. Die Haupthügelspitzen sind paarweise zu einer Fläche verschmolzen, und in der Mitte beginnt auch schon die Vereinigung dieser beiden Flächen. Im vorletzten Backenzahn sind nur die Hügel ihrer Spitzen beraubt Der Schmelz des letzten Backenzahns ist erst zu Facetten abgenutzt, wodurch die Haupthügel nach der Kronenmitte hin pyramidalisch und die Nebenhügel sattelförmig aussehen; der Schmelz ist noch nirgends durchsunken.:

In diesen Zähnen hat gleichsam jeder Haupthügel seine Wurzel unter sich, der letzte Backenzahn besitzt fünf und jeder der beiden andern Zahne vier Wurzeln. Je näher dem Ende der Backenzahnreihe die Wurzeln sitzen, um so mehr stehen sie hinterwärts heraus. An der hintersten Wurzel des letzten Backenzahns ist diess besonders auffallend. Diese stark hinausstehende Wurzel ersetzt den Mangel des Schutzes, den ein dahinter sitzender Zahn gewähren würde. In der Zahl und Richtung der Zahnwurzeln besteht also keine Willkühr. Ein mehrwurzeliger Backenzahn gleicht bisweilen einer Zusammensetzung aus mehreren einfachen Individuen.

Ich gebe hier die Ausmessungen der drei letzten Backenzähne des fossilen Thiers mit denen in Babirussa.

\section{Fossil. Babirussa.}

\begin{tabular}{|c|c|c|c|}
\hline $\begin{array}{r}\text { Vorvorletzter lang } \\
-\quad \therefore \quad \text { breit }\end{array}$ & $\because \quad$ & $\begin{array}{r}0,016 \\
. \quad 0,012\end{array}$ & $\begin{array}{l}0,012 \\
0,009\end{array}$ \\
\hline Vorletzter lang & 0 & . 0,018 & 0,015 \\
\hline breit & & . 0,014 & 0,011 \\
\hline Letzter lang & 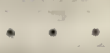 & . 0,028 & 0,025 \\
\hline - breit vorn & - & . 0,015 & 0,013 \\
\hline$-\quad-$ hinten & & . 0,009 & 0,008 \\
\hline
\end{tabular}


Die fossilen Zähne sind also nicht allein in der Structur der Krone, sondern auch in den Dimensionen von denen des Babirussa verschieden. Der letzte Backenzahn des fossilen ist ein 12tel länger, als der in Babirussa. Mit diesem 12tel sind die Längendimensionen beider, der fossilen, wie der Zähne in Bubirussı, genau messbar, wobei man folgende Verhältnisse erhält:

Vorvorletzter Backenzahn $=8 / 12: 5 / 12$
Vorletzter Backenzahn * $=8 / 12: 7 / 12$
Letzter Backenzahn * $=13 / 12: 12 / 12$

Die Breitendimensionen eignen sich nicht zu solchen Versuchen.

Herr Graf zu Münster besitzt zwei zu einer andern Zeit in derselben Ablagerung gefundene Zahnfragmente, welche ich Tafel II. Fig. 11 und $\mathbf{1 2}$ abzubilden vesuchte, und die unbezweifelt einem Thier derselben Gattung angehören, wie die der eben betrachteten fossilen Zähne. Beide Fragmente rühren aus der linken Unterkieferhälfte eines und desselben Individuums her, das jünger war. Das a von oben und b von der Hinterseite dargestellte Fragment Fig. 12 ist etwas mehr als die hintere Hälfte des vorletzten, und das Fig. 11. a von oben und b von der Aussenseite zu sehende Fragment nicht viel mehr von dem vorvorletzten Backenzahn. Ihre Structur bestätigt vollkommen, was ich bereits über die fossilen Zähne der Art vorgebracht. Da ihre Krone noch nicht so tief abgenutzt ist, so sieht man in diesen zierlichen Zähnen deutlicher, wie spitz dieselbe aufwärts ausgeht, auch dass der Schmelz an einigen Stellen runzelig, und die Ansätze gefurcht sind.

Aus mehreren Bruchstucken gelang es mir, das den drei hintern Backenzähnen in Taf. II. Fig. 9 vorsitzende Zahnfragment zusammen zu setzen. Seine hintere seitliche Abnutzungsfläche liess sich genau in die vordere des vorvorletzten Backenzahns der rechten Unterkieferhälfte einfügen. Dieses Fragment fand sich mit den Zähnen des ältern Thiers zusammen, und gehört gewiss demselben Individuum an. Erst einige Jahre später fand ich unter von Herrn Gräfen zu Münster mir mitgetheilten Zähnen derselben Ablagerung die beiden Taf. II. f. 13. a von oben und b von der Aussenseite abgebildeten Zähne zusammen. Von diesen halte ich den Zahn zur Rechten für den analogen des zuvorgenannten aus der linken Unterkieferhälfte. Es unterliegt daher keinem Z Zweifel, dass beide Zähne einer Thiergattung und zwar derselben angehören, von der auch die drei hinteren Backenzähne herrühren. Der Zahn $\alpha$ erinnert an Zăhne in Fleischfressern, unterscheidet sich aber von denen, die mit ihm noch am ersten ver- 
glichen werden könnten, hauptsăchlich durch die complicirtere Krone und den deutlichen Vorder - und Hinteransatz, Charaktere, welche ihn unverkennbar den Pachydermenzähnen zuführen, und in Beziehung bringen mit analogen Theilen in den oben beschriebenen drei hinteren Backenzähnen. Die hintere seitliche Abnutzungsfläche verrăth auch, dass hier dieser Zahn mit einem Zahn in Berührung stand, der weit breiter war, als sie gewöhnlich in Fleischfressern sind. Die Mitte der Krone besteht in einer Hauptspitze, zu einer kleeblattförmigen Abnutzungsfläche abgestumpft, von der nach dem Vorderansatz ein unebener Kamm herunterführt. Dieser Kamm oder Schårfe besitzt eine breite, schräg an der Aussenseite nach vorn und innen gerichtete Abnutzungsflache, deren Schmelz noch nicht durchgearbeitet ist, und die sicherlich durch das Eingreifen eines ăhnlichen schneidenden Backenzahns im Oberkiefer veranlasst wurde. Der Zahn war zweiwurzelig und ist 0,015 lang und 0,008 breit. In Babirussa steht ein ähnlicher Zahn unmittelbar vor den rectangulären, der aber verhältmissmăssig kleiner ist.

Dass vor dem rechten der beiden Zăhne Taf. II. Fig. 13 noch ein anderer Zahn sass, geht unläugbar aus dem genauen Ineinandergreifen der beiden Zähne hervor, welche von einem Individuum, vielleicht von demselben, das die beiden Backenzahnfragmente Fig. 11. 12 besass, herruhren. Der Zahn zur Linken ist noch schneidender und spitzer, als der auf ihn folgende. Seine Spitze ist sogar dreitheilig, d. h. unmittelbar vor und hinter der höchsten Spitze sitzt eine kleinere Spitze, von der aus der Kamm oder die Schneide nach vorn und hinten herunterführt. Dieser Zahn erinnert also noch mehr, als der vorige, an Fleischfresser. Doch ist immer noch der Vorderund Hinteransatz pachydermenartig vorhanden, auch lässt sich der dreitheilige Haupthügel oder die Spitze ganz auf die Theile des ihm nachsitzenden Zahns zurückfuhren, die unmittelbar vor dem Hinteransatz liegende Nebenspitze ist noch, wenn auch nur in einem Hübelchen, angedeutet, und der vordere Kamm ist eben so mit einer schrägen Abnutzungsfläche versehen, wie sie stärker der darauf folgende Zahn zeigt. Der Zahn ist überhaupt nur wenig abgenutzt. Er war zweiwurzelig und misst 0,016 Länge, 0,007 Breite und 0,012 Kronenhöhe. Die Aehnlichkeit, welche man immer noch mit Babirussa finden könnte, hat mit diesem Zahn ihr Ende erreicht, und es muss überraschen, zu sehen, dass der zuletzt betrachtete fossile Zahn eine kleine runde vordere seitliche Abnutzungsfläche an sich trägt, welche andeutet, dass ihm noch ein Zahn unmittelbar vorgesessen, von dem man in Babirussa nichts weiss. Hier ist also ein treffendes Beispiel zu dem oben S. 8 von mir ausgesprochenen Erfahrungssatze. 
Was fur ein Zahn hat aber dem zuletzt beschriebenen unmittelbar vorgesessen? Aus Bruchstücken, welche sich mit den hinteren unteren Backenzähnen aus beiden Kieferhälften des ältern Thiers vorfanden, gelang es mir, das Taf. II. Fig. 14. a. b. c abgebildete Zahıfragment zusammenzusetzen. Dasselbe gleicht noch auffallender Zähnen von Fleischfressern, als die bisher betrachteten vordern Backenzähne. ,Dennoch ist es nicht unwahrscheinlich, dass es dem fossilen schweinsartigen Thier angehört habe. Dieses Zahnfragment besitzt nur an einer Seite eine kleine seitliche Abnutzungsfläche, welche fur die hintere zu halten ist. Es scheint gerade von dem Zahn zu seyn, den wir suchen und der dem Zahn $\beta$ vorgesessen. Das Fragment rührt wahrscheinlich auch von einem Zahn aus der linken Unterkieferhälfte her, doch von einem eher noch altern Individuum. Die Grösse ist einem solchen Zahn ganz angemessen. Die Länge beträgt $\mathbf{0 , 0 1 4}$, bei $\mathbf{0 , 0 0 5}$ grösster Breite und $\mathbf{0 , 0 0 8}$ Kronenhöhe. Der Vorder - und Hinteransatz ist noch angedeutet, ersterer weniger deutlich. Die Hügelspitze scheint nur einfach gewesen zu seyn. Dafür fällt ungefähr in der Mitte des von diesem Hügel hinterwärts ziehenden Kammes eine kleine spitzenförmige Erhebung auf, welche die Aehnlichkeit mit einem Fleischfresserzahn noch deutlicher macht. Die hintere Wurzel ist noch vorhanden, wahrscheinlich war auch eine vordere vorhanden, und der Zahn zweiwurzelig. Der Schmelz des Zahns ist durch Abnutzung noch nicht durchbrochen. Am vordern Kamm sieht man auch hier die schräg an der Aussenseite liegende Abnutzungsfläche angedeutet.

Sonst habe ich von Backenzähnen aus dem Unterkiefer nichts untersucht. Aber ein anderer Zahn hat sich noch vorgefunden, der hier betrachtet zu werden verdient. Er ist Taf. II. Fig. 15, a von oben und b von Aussen gesehen, abgebildet. Auch er ist spitz und Fleischfresserzähnen ăhnlich. Doch zeigt er die nächște Verwandtschaft mit den eben beschriebenen vordern Backenzähnen, und es ist leicht mogglich, dass er von dem Individuum der Zähne Fig. 13 herruhrt. Der Vorder - und Hinteransatz ist denen in diesen Zähnen ähnlich; der Vorderansatz besitzt keine seitliche $\mathbf{A b -}$ nutzungsfläche, der Hinteransatz aber ist an der Stelle, welche über eine Abnutzungsflăche entscheiden könnte, fragmentarisch. So viel ist indess gewiss, dass diesem Backenzahn kein anderer unmittelbar vorgesessen. Die Zahnkrone ist noch reiner einspitzig, als die bisher betrachteten, und die Hügelspitze dabei etwas deutlicher hinterwärts gekrummt. Von ihr zieht nach vorn und nach hinten ein Kamm herunter. Denkt man sich eine Ebene durch diese Kämme und die Spitze gelegt, so steht dieselbe nicht genau in der geraden Längsrichtung, sondern diagonal von dem aussern hintern 
Ende nach dem innern vordern. An ersterem Ende verbindet sich der Kamm mit dem Ansatz und verleiht dadurch dem hintern Theil der Backenzahnkrone nach innen eine napförmige Gestalt. Weniger deutlich verbindet sich der vordere Kamm mit dem Vorderansatz. Beide Ansätze ziehen sich über die Innenseite an der Basis als ein schwacher Wulst. Aus dieser Beschreibung ist zu entnehmen, dass der Zahn ein Backenzahn aus der linken Oberkieferhälfte ist. Im Unterkiefer könnte er nur in der rechten Hälfte gesessen haben. Dann würde aber die Abnutzungsfläche an der Innenseite liegen, was directer Beobachtung in den untern Backenzähnen widerstreitet. So aber liegt, wenn der Zahn aus der linken Oberkieferhälfte herrührt, die Abnutzungsfläche an dem hintern Kamm der Innenseite. Die eigene Beschaffenheit der Krone wird die Verweisung des Zahns in deu Oberkiefer unterstutzen. Der Zahn ist 0,0135 lang, 0,007 breit, und von 0,009 Kronenhöhe. Ein anderes Fragment, zu unvollständig, um einer Abbildung werth zu seyn, besitzt 0,0085; daran fehlt das hintere Kronenende; es ist im Uebrigen auf ganz ähnliche Weise gebildet und zeigt vorn eine seitliche $\mathbf{A b -}$ nutzungsfläche. Ich glaube, dass dieses Fragment von dem Zahne herrührt, der dem vorigen hinten ansitzt und vielleicht von demselben Individuum. Sonst kenne ich nichts von oberen vordern oder hintern hieher gehörigen Backenzähnen.

Aus diesen Untersuchungen ergibt sich, dass das Thier wenigstens sechs Backenzähne in einer Reihe hinter einander besessen habe. In Structur gleichen sie keinen in den lebenden Schweinsgattungen vollkommen. Die grösste Aehulichkeit besteht mit den drei hintersten Backenzähnen in Babirussa, von dem sich aber das fossile Thier schon allein hinsichtlich der Backenzähne auffallend unterscheidet, nicht bloss durch die Structur der vordern Backenzähne, sondern hauptsächlich dadurch, dass das fossile Thier einen solchen Zahn mehr besass.

$$
\text { E c } k \text { z }
$$

Mit den Backenzähnen des ältern schweinsartigen Thieres fanden sich zwei Fragmente von Eckzähnen vor. Ich bezweifele nicht, dass dieselben dem nämlichen Individuum angehört haben, von dem ich vorhin Backenzähne aus beiden Unterkieferhälften beschrieb. Diese beiden Fragmente, welche ich Taf. II. Fig. 16 und 17 in Abbildung gebe, ahneln zunächst dem Eckzahn in Sus Scrofa und sind also von Babirussa, dem die Backenzähne, man kann sagen, zum Verwechseln ähnlich sehen, sehr verschieden. Am Durchschnitt des Eckzahns (d) fallen besonders drei Winkel auf, wie in Sus Scrofa und Hippopotamus. Das eine Fragment, Fig. 16, ist der grösste 
Theil der Eckzahnspitze, an der das ausserste Ende oder die eigentliche Spitze fehlt. Eine bedeutende Abnutzungsfläche (c), ahnlich der in Sus Scrofa, gestaltete die Spitze dreiseitig. Dieser fossile Zahn war daher wohl auch auf ahnliche Weise, wie in Sus Scrofu, etwas herausgerichtet. Durch Vergleichung erfährt man ferner, dass dieses Fragment von einem Zahn in der rechten Unterkieferhälfte herrührt. Die Lage und Form der Abnutzungsfläche macht es wahrscheinlich, dass der obere Eckzahn, der sie hervorbrachte, wie im Wildschwein, horizontal herausstand. Das zweite Eckzahnfragment, Fig. 17, ist ein mittleres Stück von einem Eckzahn aus der linken Unterkieferhälfte. Aus beiden Fragmenten ergibt sich noch Folgendes über den untern Eckzahn. Die Krummung dieses Zahns war kein wirkliches Kreissegment, sondern mit der obern Spitze etwas mehr gebogen. Die Zahnsäule wird nach unten oder der Wurzelseite hin etwas breiter. Ausser dieser Krummung besitzt der Zahn noch eine schwache seitliche Biegung. Die hintere Seite ist in der Längsmitte etwas convex, und nicht mit Schmelz bekleidet, wie die beiden andern Seiten, wovon die etwas nach vorn gerichtete innere die breitere, dabei längs convex gerichtet ist und mit der schmelzlosen Seite, gegen die sie sich unter einem spitzen Winkel neigt, an der Kante eine feine Leiste und die schärfste Kante des Zahnes bildet. Die andere Seite ist die äussere. Sie ist schmäler und hängt mit der innern Seite durch Umbiegung zu einem rundkantigen spitzen Winkel zusammen; sie ist weniger stark convex, als die innere Seite, und bildet mit der schmelzlosen, unter stumpfwinkeliger Neigung und nach vorhergegangener geringer Convexität, eine feine Leiste. Der Schmelz dieses Fragmentes zeigt bisweilen kleine oder flache Querreife. Diese Querreife und letztere Leiste vermehrt die Aehnlichkeit mit Sus Scrofa. Die Verschiedenheit zwischen beiden besteht hauptsachlich darin, dass der fossile verhältnissmässig kleiner und stärker, und in ihm die vorderste Kante nicht so scharf ausgeht. Abgesehen von der Schmelzdecke bestehen die fossilen Zähne aus fester Masse, durch deren Längsmitte eine feine Nervenröhre führt.

Von der Länge des Eckzahns lässt sich nur sagen, dass er nach der äussern Krümmung über 0,068 betrug, so viel nämlich messen beide Fragmente.

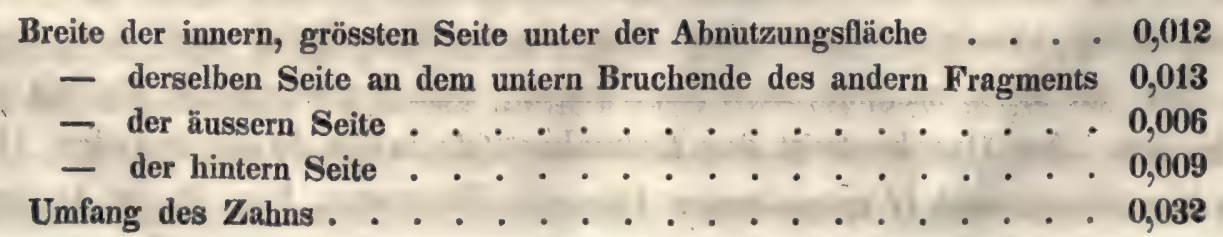


Nachdem ich die fossilen Zahne genau beschrieben und mit dem verglichen habe, was unter den lebenden Thieren ihnen am nächsten steht, wende ich mich nun zu den fossilen schweinsartigen Thieren, welche bisher bekannt wurden, um zu sehen, ob sie keinem derselben angehören. Dazu wird indess eine genaue Untersuchung der uber die fossilen schweinsartigen Thiere bestehenden Nachrichten erfordert.

Ich begegne da zuerst einem im Jahr 1805 in der Molasse der Rappenfluhe, eines unmittelbar an die Aar stossenden Felsens, bei ungefähr 20 Fuss verticaler Tiefe und 16 Fuss vom Aarufer entfernt, in einem Steinbruch gefundenen Unterkieferfragments, welches Me is s n er *) beschreibt. Derselbe sagt, dass die drei noch darin sitzenden Zähne mit dem zweiten, dritten und vierten Zahne seines Unterkiefers von Babirussa vollkommen übereinstimmen, auch in Grösse, Form und Zeichnung der Abnutzungsflächen. Nach letztern zu urtheilen, rühren sie von einem alten Thiere her. Was Meissner anführt, bestätigt die seiner Beschreibung beigegebene, nicht besonders deutliche Abbildung, die auch die grosse Aehnlichkeit mit den von mir beschriebenen analogen Zähnen erkennen lăsst. In Betreff der Grösse würden sich die Zähne bei Meissner zu den unsrigen ungefähr so verhalten, wie letztere zu den Zăhnen von Babirussa; die Zähne aus der Rappenfluhe wăren also kleiner und von denen von Georgensgmünd mindestens specifisch verschieden. Mit dem Unterkieferfragment aus der Molasse fand sich die Krone eines obern Backenzahns vor, von der Meissner glaubte, dass sie von einem Anoplotherium herrühre. Studer's **) Untersuchungen haben aber belehrt, dass sie den Zähnen des Oberkiefers verglichen werden müsse, welche Cuvier seinem Chaeropotamus beilegt. Dieses und die Aehnlichkeit, welche zwischen den untern Backenzähnen von Cuvier's Chaeropotamus und denen bei Meissner besteht, haben mich veranlasst, das Kieferfragment und die Krone eines obern Backenzahus aus der Molasse unter einer, sowohl von unserm schweinsartigen Thier, als auch von Cuvi er's Chaeropotamus $\boldsymbol{P}$ arisiensis verschiedenen Thiergattung zu begreifen, die ich Chueroptamus Meissneri nannte. Mit diesen Resten kamen auch Theile von einer Landoder Süsswasserschildkröte vor.

*) Museum der Naturgeschichte Helvetiens, No.9 u. 10. S. 71. F.2. Aus Cuvier's Oss. foss. V. S. 499 geht hervor, dass er Meis n ner's Arbeit über fossile Knochen aus der Molasse der Schweiz kannte; er nimmt indess von diesem Kieferfragment keine Notiz.

*) Studer, Monographie der Molasse. S. 294 . 
Aus welchen Resten aber hat Cu vi er *) sein Genus Chaeropotamus gebildet, dessen Typus sich noch mehr den schweinsartigen Thieren nahern soll, als Anoplotherium oder Palaeotherium, und von dem er glaubt, dass es den Uebergang von den Schweinen zu den Anoplotherien, namentlich durch Dichobune, vermittele? Vom Unterkiefer kannte Cuvier nur zwei Backenzahne (t. 51. f. 3. A. B. ***) und ein Stück aus dem Vordertheil (C), aus dem über die Schneidezähne nichts erhellt. Beide wurden in den Gypsbrüchen von Villejuif gefunden. Ich will zuerst geben, was über diese Reste Cuvier anführt und sich nach den Abbildungen noch hinzufügen lässt. Der Eckzahn (a) ist spitz und von mittlerer Grösse; zwischen ihm und dem ersten Backenzahn (b) ist ein leerer Raum. Der erste Backenzahn ist conisch, spitz, etwas flach, aber nirgends schneidend und sitzt auf zwei starken divergenten Wurzeln. Der zweite Backenzahn (c) ist noch etwas flacher, besitzt auch zwei Wurzeln, und hinter seiner stumpfen Spitze sind weit niedrigere und kaum herausragende Spitzen vorhanden, die für einen zweiten Lappen gehalten werden könnten. Diese beiden Zähne sind durch einen zahnlosen Raum von einander getrennt. Auf letzteren folgten (Cuvier gemäss) die beiden andern Zähne (B. C), deren Krone ungefähr rechtwinkelig ist, länger als breit, mit vier Haupthügeln, welche zwei kleinere Hübel zwischen sich fassen. Um die Basis liegen einige Unebenheiten. Cuvier sagt dabei ferner: Diese rechtwinkeligen Zähne gleichen dem dritten und vierten Backenzahn in Babirussa, aber kein Schwein besitzt Zähne wie der conisch geformte erste Backenzahn, und der Eckzahn ist so klein wie in Pecari. In dem Zeitraum von mehr als 20 Jahren, innerhalb welchem Cuvier fast täglich Knochen aus dem Montmartre erhielt, brachte man ihm nur ein zweites Stück, das er mit den eben erwähnten Resten zu einer Gattung zählt. Es ist eine unvollständige Schädelbasis (t.68. f. 1), woran die Gegend der Schneide- und Hundszähne fehlt. Der erste obere Backenzahn (n) gleicht in Form und in den auswärts stehenden Wurzeln dem untern, und weicht von ihm nur durch einen leichten Hübel an seinem Hinterrand ab. Hinter diesem vermuthet Cuvier einen dem zweiten untern analogen Backenzahn (m), der aber nicht wirklich vorhanden ist. Hierauf kommt ein mehr wie ein stumpfer Kegel geformter Zahn (i), hinter dessen Spitze etwas niedriger noch ein kleiner Hübel, wie ein zweiter Lappen, sitzt. Der vierte Zahn (k) gleicht einem starken stumpfen einfachen Kegel, an dessen Basis nach innen ein sehr

*) Oss. foss. III. 260.

*) Cuvier's Bezeichnung. 
deutlicher Wulst liegt. Der darauf folgende (1) ist der letzte Wechselzahn, er ist breiter, als lang, und über dem Wulst an der Innenseite mit einem zweiten Wulst umgeben; der mittlere ragt wie ein Hübel heraus, und die Spitze des Kegels ist etwas gekerbt. Die drei hintern Mahlzähne (f. g. h.) sind beinahe quadratisch, sămmtlich etwas breiter als lang. Sie zeigen vier Haupthügel in Form stumpfer Kegel. Zwischen den beiden vordern dieser Hügel liegt ein kleinerer, und zwischen den beiden hintern ein noch kleinerer. In der Mitte der vier Haupthügel ist eine kleine unregelmässige und schwach zweizackige Hervorragung. Die Krone ist mit einem Wulste ganz umgeben, der sich an der vordern äussern Ecke und in der Mitte des äussern Randes in Hübeln erhebt. Diese drei hintern Backenzähne gleichen einander, nur ist der zweite breiter, als der erste, und am dritten ist die hintere äussere Ecke stumpfer, wodurch die Krone im Umriss etwas schief erscheint. Wie Cuvier ferner erwähnt, gleichen diese Zähne etwas den analogen in Babirussa, besonders in Pecari; sie sind aber grösser, verhältnissmåssig breiter und haben einen starken Wulst, der den beiden genannten Genera abgeht. Ueberdiess sind die vordern Backenzähne sehr verschieden. Das Zygoma scheint mit dem in Pecari in einige Beziehung gebracht werden zu können. Aber der hintere Gaumeneinschnitt geht, indem er bis zum Hinterrande des vorletzten Backenzahns ragt, tiefer als in den beiden lebenden Genera.

Diess ist die Beschreibung von Cu vier's Chaeropotamus Parisiensis (Ch.gypsorum Desmar.). Es wirft sich dabei gleich die Frage auf: Gehört das Oberkieferfragment derselben Thiergattung an, von dem die Zähne und Theile des Unterkiefers herrüren? Nach Cuvier wären nicht weniger als 8 Backenzähne in einer Oberkieferhälfte enthalten. Aus der Unterkieferhälfte kannte Cuvier vier Backenzahne wirklich. Den beiden rectangulären Zähnen derselben konnte nicht wohl mehr als noch ein einziger und zwar der letzte der ganzen Reihe, gefolgt seyn. Dieser hat sich nicht vorgefunden. Der erste und zweite Backenzahn ist vorhanden und auf letztern sind, nach Cuvier's ausdrücklicher Angabe, die rectangulären Zähne gefolgt. Die Backenzahnreihe bestand also im Unterkiefer aus fünf Zähnen. Nehme ich den letzten Backenzahn auch von der doppelten Länge eines Rectangulärzahnes, was eher zu viel, als zu wenig Wäre, so erhalte ich für die Länge der ganzen Backenzahnreihe im Unterkiefer noch immer nicht die Länge der ganzen Backenzahnreihe im Oberkiefer. Dieser kommt nan näher, wenn man, freilich gegen Cuvier's ausdrückliche Bemerkung, vor dem ersten rectangulären Backenzahn noch einen Zahn voraussetzt, der auch einen natürlicheren Uebergang der breiten Zahne zu den schmalen in Betreff der Structur bilden 
würde, als er ohne die Annahme eines solchen Zahns besteht. Fs erwuchsen hieraus der Backenzahnreihe des Unterkiefers 6 Zăhne, mit einer zahnlosen Lücke zwischen dem ersten und zweiten Backeuzahn. Doch selbst bei dieser gesteigerten Zahl der Backenzähne im Unterkiefer waltet noch einiges Missverhältniss ob zwischen ihr und der Zahl der Backenzähne im Oberkiefer. Wie Cuvier dieses entgehen konnte, ist mir unbegreiflich. Vielleicht ist ferner noch der von $\mathrm{Cu}$ vier vermuthungsweise angenommene Zahn m im Oberkiefer zu verwerfen. Hiedurch würde auch zwischen dem ersten und zweiten Zahn im Oberkiefer eine zahnlose Lücke herbeigefuhrt; ein freistehender Backenzahn und sechs sich berührende Backenzähne, drei vordere und drei hintere, würden die Reihe bilden. Dieses würde auch besser mit dem Typus in Sus Scrofa übereinstimmen, welches, unten wie oben, in der Backenzahnreihe einen freistehenden und sechs sich berührende Zähne besitzt, die aber von ganz anderer Structur sind. In Dicotyles fehlt der freistehende Backenzahn und in Babirussa sind oben wie unten nur fünf einander anschliessende. Diess ist es, was ich gegen Cuvier's Beschreibung derjenigen Reste vorzubringen habe, aus denen er seinen Chaeropotamus errichtete. In diesen Resten liegt unverkennbar ein eigenthümlicher Typus ausgedrückt. Die Verhaltnisse der Reste unter einander sind aber noch keineswegs genügend ermittelt und erwogen, was ich denen überlassen muss, die sich der Benutzung dieser seltenen Reste erfreuen.

Vergleiche ich nun die Zähne unsers fossilen Thiers mit diesen unter Chaeropotamus begriffenen, so stosse ich auf bemerkenswerthe Analogien. Die Structur der rectangulären Backenzähne scheint ganz dieselbe zu seyn, und zwischen dem Backenzahn Fig. 14 von Georgensgmünd und dem gleichgrossen Fig. 3. A. c. des Chaeropotamus besteht, selbst bis auf die Spitze oder den Lappen in der Mitte des hinterwärts laufenden Kammes und den Mangel einer vordern seitlichen Abnutzungsfäche, Aehnlichkeit. So wenig auch uber den Eckzahn von Chaeropotamus erhellt, so ist doch nicht zu lăugnen, dass die Abbildung, welche Cuvier's Werk davon gibt, Aehnlichkeit mit dem Eckzahnfragment Fig. 16 besitzt. Ehe ich den vordern Theil der Backenzahnreihe des Thiers von Georgensgmund näher kannte, verführte mich die Aehnlichkeit der hintern Backenzahne und des Eckzahns, in diesen Resten einen Chaeropotamus zu erblicken und zwar eine von der Pariser verschiedene Species, da der dem vorletzten von Georgensgmünd analoge Backenzahn, Fig. 3. B bei Cuvier, genau ein Funftel, und der andere Backenzahn bei Cuvier, Fig. 3. C, dem ersten von unsern drei hiutern Zähnen in Fig. 9 entsprechend, genau ein Sechstel grösser ist. Diese Spe- 
cies nannte ich Chaeropotamus Sömmerringii. Nachdem nun aber Chaeropotamus, nach Cuvier's freilich nicht unbestrittener Angabe, einen Backenzahn im Unterkiefer weniger enthält, zwischen dem ersten und zweiten Backenzahn dieses Thiers eine zahnlose Lücke besteht, und, der erste obere Backenzahn, nach der Abbildung, nicht übereinzustimmen scheint, so wird mit demselben das fossile schweinsartige Thier vou Georgensgmünd nicht mehr zu vereinigen seyn.

In der Knochenbreccie von Villefranche-Lauraguais (haute Garonne) ward mit Helix, Bulimus, Pupa und Nerifina ein Zahn gefunden, den Marcel de Serres ${ }^{*}$ ), seiner Aehnlichkeit wegen mit den Zähnen Fig. 3. B. C bei Cu vier, dem Chaeropotamus zuerkannte. Er besitzt dieselbe Grösse, wie der Zahn B bei Cuvier, und ist daher auch genau ein Fünftel grösser, als der vorletzte der von uns betrachteten. Die Gegenwart von Chaeropotamus kann indess aus diesem einen Backenzahn noch nicht mit Gewissheit hergeleitet werden, wie unsere Betrachtungen bisher belehrt haben.

Mit dem vorletzten untern Backenzahn von Georgensgmünd hat auch ein Türkiszahn Aehnlichkeit, den Fis cher ${ }^{*}$ ) unter No. 3, „Dents molaires ì quatre tubercules", aufführt; es lässt sich aber aus der Beschreibung und Abbildung desselben nichts Genaueres ermitteln; vom Fundorte wird nichts erwăhnt.

Clift und Buckland *** machen ein Stuck Unterkiefer bekannt, worin ein Zahn sitzt, der selbst in Grösse mit dem vorletzten Backenzahn des schweinsartigen Thiers von Georgensgmünd übereinkommt. Dieses Fragment von einem Schwein, wie sie es nennen, gehört zu den Resten aus der knochenführenden Ablagerung des Irawadithals in Birmanien, wo es mit Mastodon elephandoides, Mastodon latidens, Rhinoceros, Ochs, Hirsch oder Antilope, Gavial, Schildkröte etc. zusammen lag. Da selbst aus der vollkommensten Uebereinstimmung einzelner Zähne sich die Identität der Gattung nur vermuthen lässt, so muss es vollständigeren Fragmenten überlassen bleiben, zu entscheiden, ob Südasien und Bayern dieses Thier mit einander gemein haben.

Die Ablagerung von Eppelsheim macht durch ihren Gehalt an Mastodon, Rhinoceros, Dinotherium etc. besondere Ansprthche auf Berkcksichtigung der dort

*) Ann. des sciences naturelles, IX. S. 191. t. 46. f. 6. Die dunklere und braunere Farbe des Emails dieses Zahnes im Vergleich zu dem anderer Zähne aus dieser farblosen Knochenbreccie erlaubt wohl die Frage, ob ersterer Zahn hier auf anfänglicher Lagerstätte sich befand?

*) Fischer, Essai sur la Turquoise et sur la Calaite. 2. ed. 1818. S.41. t. 3. f. 3.

क* Geolog. Trans. 2. II. t. 40. f.5. 
sich vorgefundenen schweinsartigen Thiere. K a up * beschreibt Reste dreier Arten: Sus antiquus, Sus paldeochoerus und Sus antediluvianus. Aus diesen Resten ergibt sich, dass in Sus antiquus sieben Backenzähne in einer Unterkieferhälfte sitzen, zwischen dem ersten und zweiten eine zahnlose Lücke besteht, der erste Backenzahn nur wenig dem Eckzahn näher, als dem zweiten Backenzahn liegt, und sechs Schneidezähne vorhanden waren. Hienach wäre das Zahnsystem von Sus antiqun dem in Sus Scrofa analog. In Grösse und Structur des Kiefers und der Zähne weicht letzteres von ersterem sehr ab. Der Kiefer ist vier Zoll länger und fast um die Hălfte höher, als in Sus Scrofa und Sus Arvernensis, der Processus coronoideus erhebt sich vertikal, in Sus Scrofa schief, und die Symphyse hat die Gestalt wie in Rhinoceros tichorhinus. Ueber die Structur der Zähne kann ich Einiges nachholen. In den drei hintern Backenzähnen haben die Kronentheile ein weniger complicirtes Ansehen und kommen unter den lebenden mehr auf Dictyles, Babirussa, und auf die bisher angefuhrten fossilen heraus, worin die Haupthügelpaare, Nebenhügel und Thäler sich deutlicher unterscheiden. Der letzte Backenzahu zeichnet sich unter allen aus durch seine ansehnliche Lănge und gleichförmigere Breite selbst nach seinem hintern Ende hin, wo er das Ansehen hat, als endige er hier auch mit einem Spitzenpaare. Hierin gleicht er mehr dem grössern Anthracotherium. Dafür aber scheinen die zwei, dem letzten vorsitzenden Zähne eine mehr quadratische Form zu haben. Vom ersten freistehenden Backenzahn sind nur die Wurzeln vorhanden. Der Eckzahn ist auch über seiner Wurzel abgebrochen. Er ist im Vergleich zu den Backenzahnen auffallend klein, wesshalb Kaup vermuthet, dass dieser Kiefer von einem weiblichen Thiere herruhre. Die äussere Seite gleicht etwas dem von Georgensgmünd, letzterer scheint aber mehr gekrummt, und der Winkel, den die Aussenfläche mit der hintern innern Fläche macht, ist in diesem spitzer, als in dem von Eppelsheim. Von dem Thiere von Georgensgmund ist nicht entschieden, ob es, ausser den sich berührenden Backenzähnen, noch einen freistehenden Backenzahn besessen. Niemand wird aber wohl beide Thiere unter eine Gattung bringen. Ein Astragalus, den $\mathbf{K}$ a up dem Sus antiquus beilegt, gleicht, die Grösse ausgenommen, ganz dem im Schwein.

Die Reste von Sus palaeochoerus bestehen hauptsaichlich in einem Fragment aus der linken Unterkieferhälfte. Es sitzen darin die fün hintern Backenzähne und der

*) K a u p, Description dossements fossiles de Mammifères qui se trowvent au Muséun de Darmstadt. 2. Cahier, Darmstadt 1833. S. 8. 
hintere Alveolentheil des vorsitzenden Zahnes. Hatte dieses Thier dasselbe Zahnsystem, als Sus antiquus? Das Thier wird ein wenig grösser, als Sus Scrofa und Sus Arvernensis gewesen seyn.: Der Kiefer war aber höher. In Betreff der Structur der Backenzähne gilt hier dasselbe, was ich zuvor erwähnte. Der letzte Backenzahn des Unterkiefers zeigt aber andere Grössenverhältnisse, indem er viel kürzer und breiter, als in Sus Scrofa ist, während die vordern Backenzähne eher länger und stärker sind. Namentlich ist der hintere Theil des letzten Backenzahns kürzer und kreisformig gerundet, und die Wurzel unter diesem Theil einfach, während sie in Sus Scrofa drei- und in Babirussa viertheilig ist. Ein oberer letzter Backenzahn ist weit kurzer als in Sus Scrofa, aber vorn eben so breit; seine Form scheint im Allgemeinen mehr Aehnlichkeit mit dem letzten obern Backenzahn in Babirussa zu besitzen, gleicht aber nicht entfernt dem letzten Backenzahn des Oberkieferfragmentes, das Cuvier dem Chaeropotamus beizăhlt. Das schweinsartige Thier von Georgensgmünd war etwas kleiner. Die hinteren, hauptsächlich aber der letzte Backenzahn ist in Sus palaeochoerus verhältnissmässig etwas länger und letzterer nach hinten spitzer, die Hugel sind nicht so rein und nicht so bestimmt begrenzt, als in den Zähnen von Georgensgmünd, welche auch glatter sind. Die Seiten der Hugel und die Wülste an der Basis sind in Sus palaeochoerus stärker gefureht, und auch von den Hügeln führen zur Mitte der Zahnkrone Furchen herunter, woher es ruhrt, dass die Abnutzungsflächen der Zähne von Eppelsheim mit aus - und einspringenden Biegungen versehen sind, während sie in denen von Georgensgmünd mehr dem Kreis nahe kommen und rundere Formen darstellen.

Sus antediluvianus ist von $\mathbf{K}$ aup nach einem letzten obern Backenzahn und nach einem untern Backenzahn, der der vorvorletzte seyn wird, aufgestellt. Der obere Backenzahn scheint dem in der vorigen Species analog gebildet, nur ist er etwas kleiner. Beides gilt auch von dem untern Backenzahn, der uberdiess verhältnissmăssig länger und schmäler ist, als in den vorigen Arten, und sich also hierin vom analogen von Georgensgmünd, ungeachtet beide Thiere in Grösse nicht viel konnten verschieden seyn, nur um so mehr entfernt. Der Zahn von Eppelsheim besitzt noch die Eigenthümlichkeit, dass zwischen den beiden aussern Wurzeln sich noch eine kleine vorfindet. K a u p glaubt, dass die Grösse dieses fossilen Schweins die von Babirussa *) kaum ubertroffen habe.

*) Die Längen - und Breitendimensionen des analogen untern Zahns habe ich in allen Schädeln 
Demnach besitzen die verschiedenen Arten schweinsartiger Thiere aus der Ablagerung von Eppelsheim in der Structur ihrer Zähne grössere Aehnlichkeit unter einander, als mit dem schweinsartigen Thier von Georgensgmünd, das in Ansehung der Grösse von Sus antediluvianus nicht viel abgewichen haben wird.

Ich habe Mastodonzähne solchen verglichen, welche in der Auvergne gefunden wurden; daher ist auch hier der Reste aus derselben Ablagerung in der Auvergne zu gedenken, die Croizet und Jobert J als Aper Arvernensis beschreiben. Es sind zwei entsprechende Fragmente aus dem Ober - und Unterkiefer. Die Abbildungen geben keinen Aufschluss uber die Structur der Backenzahnkrone, woruber auch die Beschreibung nur flüchtig hingeht. Darin wird der Aehnlichkeit mit dem lebenden Wildschwein gedacht. Der letzte Backenzahn ist nicht gekannt. Es scheinen indess sechs Backenzähne hinter einander gesessen zu haben. Ueber die Existenz eines siebenten Backenzahns lässt sich nichts bestimmen. Die Schneidezăhne und der Eckzahn sassen näher beisammen; die Schnauze des fossilen Thiers wird daher kürzer gewesen seyn, als die des lebenden. Die Backenzahnreihe ist etwas kurzer, der Unterkiefer aber etwas höher, als im lebenden Wildschwein, und der Kopf überhaupt etwas gedrängter, mehr dem Siamschwein (cochon de Siam) vergleichbar. Ich glaube, dass diese Reste eher den schweinsartigen Thieren von Eppelsheim verglichen werden können, als denen von Georgensgmünd.

Die fossilen Reste schweinsartiger Thiere aus jungern Gebilden, aus dem Diluvium und den Torfmooren, zeigen, so weit sie bis jetzt untersucht sind, Thiere an, welche dem lebenden Wildschwein näher standen, als die Thiere, deren Reste wir betrachteten. Die Schweinsreste aus der Ablagerung des Valdarno, einem späten Tertiär - oder einem frühen Diluvialgebilde, verdienten genaue Untersuchung. Cuvier halt diese, so wie jene aus der Muschelnagelfluh der Molasse des Berges la Molière, vom Wildschwein gar nicht verschieden. Die Reste aus dem eigentlichen Diluvium und analogen Gebilden scheinen indessen auch denkwürdige Eigenthümlichkeiten an sich zu tragen. So ist z. B. die Schnauze an Sus priscus ***; aus der Sundwicher Höhle betrăchtlich länger und breiter, als an den jetzt lebenden Schweinen, ein Verhalten,

von Babirussa, deren ich mich bei meinen Vergleichungen bediente, jede um 0,0025 kleiner erhalten, als $\mathbf{K}$ a up.

*) Croizet et Jobert, a. a. 0. I. S. 157. t.13. f. 3.4.5.'

tholdfuss, Nova Acta Acad. Leop. Carol. Nat. Cur. XI. 2. S. 482. t. 56. f.4. 5. 
das dem gerade entgegengesetzt wăre, welches wir vorhin von einigen schweinsartigen Thieren aus früheren Ablagerungen angefuhrt haben.

Ich kann unmöglich meine Untersuchungen über das schweinsartige Thier von Georgensgmünd für beendet halten, ohne zuvor auch auf die Anthracotherien einen Blick geworfen zu haben, da es sich nicht läugnen lässt, dass zwischen den Zähnen beider Aehnlichkeiten bestehen.

Unter die vollständigeren Stücke von Anthracotherium gehört ein Unterkieferfragment, das im Becken der Limagne gefunden wurde. An ihm lässt sich die Reihe der Backenzähne, der Eckzahn und die Schneidezähne erkennen. Ihm zufolge sitzen in einer Unterkieferhälfte sechs Backenzăhne unmittelbar hinter einander. Diese Zăhne besitzen mit denen fossiler schweinsartigen Thiere überhaupt Aehnlichkeit. Allein die von Croizet und Jobert*) gegebene Abbildung ist undeutlich, und das, was sie über die Structur der Backenzahnkrone anführen, ungenügend. Eine Alveole zwischen diesen Backenzăhnen und dem Eckzahn zeigt wahrscheinlich noch einen freistehenden Zahn an. Der Eckzahn ist konisch und gleicht hierin nicht dem des Sehweins. Das Thier besass sechs Schneidezähne von eigener, längerer Form und Richtung. Auch der Kieferknochen ist eigen gebildet. Der aufsteigende $\mathbf{Z}$ weig ist sehr breit, der Unterrand fuhrt hinten herunter, die Apophysis coronoidea bildet hinten einen Schnabel, wie in Anoplotherium, liegt aber weiter vorn. Unter dem zweiten und dritten Backenzahn bildet der Kiefer an der Aussenseite eine merkwürdige seitliche Herausragung. Aehnliches ist von einem lebenden Thier nicht bekannt. Unter den hinteren Backenzähnen ist der Kiefer auch wieder seitlich etwas aufgeworfen: Die Innenseite des Kiefers ist eben. Der Grösse der Backenzähne nach gehören diese Reste zu Anthracotherium magnum.

Die Structur der Backenzăhne von Anthracotherium magnum lässt sich besser aus einer Mittheilung Cuvier's * j entnehmen. Der letzte und vorletzte Backenzahn war ihm genauer bekannt. Diese Backenzăhne bestehen aus zwei Paar stumpf-konischen Haupthügeln; an der Aussenseite sind sie gewölbt, während von jedem nach der Mitte oder dem Innern der Zahnkrone eine unregelmässige, bisweilen zweitheilige Kante herunter zieht. Hierin und, wie es scheint, in dem Mangel an Nebenhügeln, unterscheiden sie sich von den Zähnen der schweinsartigen Thiere. Der letzte Backenzahn

*) Croizet et Jobert, Ann. des sc. nat. XVII. t. 10. S. 139.

*) Cuvier, Oss. foss. III. S. 396. t. 80. f. 1. 2. 3. 6. 7; IV. S. 500. 


\section{$-60$}

besitzt hinten noch einen besondern, etwas eingeschnittenen Haupthügel. Von den oberen Backenzähnen sind die hinteren bekannt, die nach Cuvier's eigenem Gestăndniss, sehr denen in Chaeropotamus gleichen und von ihnen nur durch geringe Verschiedenheiten in den Krümmungen auf der Oberflache abweichen. Vergleiche ich die Abbildungen der obern hintern Backenzähne beider Thiere und das, was daruber angeführt wird, so sehe ich die Zähne, welche Cuvier für Chueropotumus anspricht, mit einem nicht unbeträchtlichen Wulste an der Kronenbasis umgeben, während die Zähne von Anthracotherium denselben nicht haben. Der Mangel oder die Gegenwart eines Wulstes an der Basis ist an vordern Backenzähnen von weniger Bedeutung, als an hintern. Chaeropotamus und Anthracotherium weichen übrigens von den Thieren, welche schweinsartiger sind, durch grössere Einfachheit des letzten obern Backenzahns ab, der von dem nicht sehr verschieden ist, welcher demselben unmittelbar vorsitzt. Was sich mit diesen Stücken bei Cadibona von Schneide- und Eckzähnen vorgefunden, ist nicht geeignet, zu einer Vorstellung über den Vordertheil des Kopfes in beiden Kiefern zu führen. Theilweise lässt es sich sogar mit dem nicht in Einklang bringen, was die Ueberreste aus der Limagne unbestreitbar darthun. Darin aber scheinen die Vermuthungen sich zu vereinigen, dass der vordere Kiefertheil und namentlich der Eckzahn nach einem andern Plan gebildet war, als in den schweinsartigen Thieren.

Anthrucotherium minus *) ist eigentlich nur durch einen letzten Backenzahn bekannt, der mit dem analogen in der grossen Species in Bildung ubereinstimmt, aber nur kaum halb so lang und dabei verhältnissmässig schmăler ist; auch ist der hinterste Haupthügel tiefer eingeschnitten.

Anthracotherium minimum ist von Cuvier ***) errichtet nach einem Kieferfragmente mit den drei hinteren Backenzähnen aus der linken Unterkieferhälfte, das sich mit Knochen von Trionyx und Crocodil bei Hautevigne (Lot-et-Garonne) gefunden hat. Auch diese Zähne bestehen aus zwei Paar Haupthügeln, deren Form, nach Cuvier, denen im grossen Unterkiefer von Cadibona ähnlich sieht; der letzte Backenzahn hat hinten noch einen unpaarigen Haupthügel. Es lassst sich nicht läugnen, dass diese Zähne sehr an die analogen des schweinsartigen Thiers von Georgensgmünd erinnern, an denen aber die von den Haupthügeln nach der Mitte der Zahnkrone fuhrenden scharfen Kanten nicht vorhanden, und die auch ungefăhr ein Drittel grösser und

*) Cuvier, Oss. foss. III. S. 403.

sa) Cuvier, Oss. foss. III. S. 404. t. 80. f. 5. 
verhăltnissmässig breiter sind, als die von Cuvier für Anthracotherium angesprochenen Zahne.

Das Anthracotherium Alsaticum *) besteht in einem Fragment aus der rechten Unterkieferhalfte eines jungen Thiers, bei Lobsan gefunden, ans dessen Abbildung ich Folgendes entnehme. Von Schneidezähnen liegt nur der hinterste oder äussere als Keimzahn in der Alveole; er ist nach der Abbildung flach und scharf der Quere nach. Die Beschaffenheit des vordern Kiefertheils erlaubt nicht, zu entscheiden, ob wirklich sechs oder nur vier Schneidezähne vorhanden waren. Der Unterkiefer aus dem Becken der Limagne bestimmt dafü, wie wir gesehen, die Zahl 6. Dem Schneidezahn folgt noch schneller, als in letzterm Kiefer, eine Alveole, wahrscheinlich die des Eckzahns, der alsdann nicht besonders gross war, und gleichfalls in geringem Abstand davon ein schneidender, flacherer, einspitziger, wie es scheint, vorn mit einem Ansatz versehener Backenzahn, von den folgenden durch eine geringe zahnlose Lucke getrennt, mithin ein freistehender Zahn. Diesem folgt ein etwas grösserer, ihm ähnlicher Zahn mit drei Spitzen in einer Langslinie, von denen wohI nur die mittlere die Bedeutung eines Haupthügels, die vordere aber die eines Ansatzes hat. Diesem sitzt unmittelbar ein Zahn mit drei Hügelpaaren an, den auch ich für den letzten Milchzahn halten möchte. Darauf folgt noch ein Backenzahn mit zwei Spitzenpaaren. Cuvier gibt diesen gewiss richtig fur den vorvorletzten der ganzen Reihe aus, und sagt von ihm, er sey sehr ähnlich dem vorletzten in der grossen Art von Cadibona, aber genau $\frac{3}{5}$ weniger lang. Dieser 'Zahn im vorliegenden Stück wird zu keiner. Verwechselung mit einem schweinsartigen Thier, oder mit Chaeropotamus führen. Diesem Fragmente zu Folge würde die Backenzahnreihe aus sechs Zähnen bestehen, von denen der erste sich nicht unmittelbar den folgenden anschloss, und zwischen diesem und dem Eckzahn würde kein Raum mehr übrig séyn für einen vermutheten siebenten freistehenden Backenzahn. Alles dieses widerstreitet dem, was sich ans dem in der Limagne gefundenen Kiefer theils durch den Augenschein unbestreitbar ergibt, theils mit Wahrscheinlichkeit vermuthen lässt. Daher können nicht beide Kieferfrägmente Anthracotherium angehören.

Die Reste der beiden Anthracotherien von Puy-en-Velay geben über das Zahnsystem keinen sichern Aufschluss. Threr Beschreibung nach scheinen sie sich mehr den Anoplotherien zu nähern. Sie lassen übrigens eben so wenig eine Verwechselung

*) Cuvier, Oss. foss. IV. S. 500. t. 39. f. 5. 


\section{$-62$}

mit schweinsartigen Thieren zu, als die Zashne aus Bengalen, aus denen Pentland *k sein Anthracotherium Silistrense errichtete.

Aus dem, was ich hier über Anthracotherium vorbrachte, ist ersichtlich, dass dasselbe sich den schweinsartigen Thieren früherer Ablagerungen nähert, hauptsächlich in den hintern Backenzähnen; es ist daraus ferner ersichtlich, dass die Zähne von Georgensgmünd, so wie die Ueberreste von schweinsartigen Thieren der anderen Orte nicht zu Anthracotherium gehören; aber auch, dass es zweifelhaft ist, ob alles wirklich Anthracotherium sey, was man bisher darin vereinigt hat. Bei Wien soll sich ein trefflich erhaltener Unterkiefer von Anthracotherium gefunden haben ***). Vielleicht dass dieser sich eignet, über das Zahnsystem dieses Genus zu entscheiden. Dieser Kiefer soll, nach Parts ch, einer neuen Species angehören. Fitzin g er bemerkt dabei, dass das Thier die năchste Verwandtschaft mit Dicotyles habe. Cuvier glaubt, das Anthracotherium stehe in Betreff der Backenzähne den Chaeropotamen und Dichobunen nahe, aber der starke Eckzahn, den es besitze, lege ihm einen eigenen generischen Charakter bei.

Endlich aber ergibt sich aus diesen Betrachtungen, dass das fossile schweinsartige Thier bei seiner grossen Aehnlichkeit in einzelnen Zähnen mit andern schweinsartigen Thieren und selbst mit Anthracotherium sich mit diesen doch nicht vereinigen lässt. Ich begreife es daher unter dem Namen Hyotherium Sömmerringii.

\section{Rhina e ro sartige Thiere.}

Die beträchtlichen Reste, welche sich bei Eppelsheim fanden, machten es

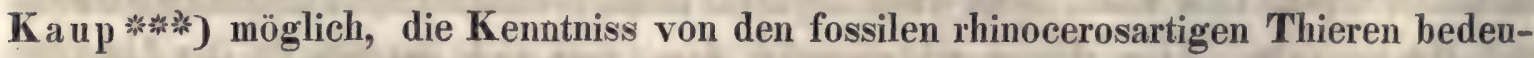
tend zu fördern. Seinen Untersuchungen liegen fast vollständige Köpfe zum Grunde. Er unterscheidet zwei Gattungen: Rhinoceros incisivus, von dem er gefunden, dass

*) Geolog. Trans. 2. II. t. 45. f. $2-5$.

**t) Fitzing er, Nachrichten über fossile Zähne und Knochen etc. S. 16. Note.

* K a u p, Isis, 1832. VIII. tab. 18; - Description d'ossements fossiles de Mammifères qui se trouvent au Muséum de Darmstadt. 3. Cahier. Darmst. Von diesem noch nicht erschienenen Hefte kenne ich, durch die Güte des Herrn Verfassers, einige Tafeln über die Rhinocerosgattungen. 
die Nasenknochen nicht geeignet waren, ein Horn zu tragen *), weshalb er es von Rhinoceros unter dem Namen Aceratherium trennt; und Rhinoceros Schleiermacheri; beide im Kopfbau auffallend von einander verschieden, auch in den Zähnen angedeutet, doch lange nicht so scharf, und an isolirten Zähnen nicht immer mit Gewissheit zu erkennen. Wir begegnen also hier abermals einer Bestätigung meines frühern Ausspruches (S.8); und selbst bei der Kenntniss vollständiger Schädel mit allen ihren Zăhnen ist unsere Arbeit, die wir an einzelnen Zähnen vorzunehmen haben, nicht so sehr erleichtert, als man denken sollte.

$$
\text { Unteres ch neidezäh ne. }
$$

Von Georgensgmünd untersuchte ich weit mehr Zähne der Art, als auf Tafel III. und V. dargestellt sind. Das Zahnfragment Fig. 21 aus der rechten Unterkieferhălfte ist a von oben, wo die Abnutzungsfläche liegt, b von unten, e von der Innenseite und d im Durchschnitt zu sehen; das Fragment Fig. 22, auch aus der rechten Unterkieferhälfte, a von unten, b von der Innenșeite, c im Durchschnitt; das Fragment Taf. V. Fig. 38, aus derselben Unterkieferhälfte, a von der Seite und b im Durchschnitt; und der vollständige Zahn, Taf. III. Fig. 23. a von oben, wo die Abnutzungsfläche liegt, b von der Seite, c von unten und d im Durchschnitt abgebildet.

Von Ausmessungen habe ich folgende mitzutheilen:

\section{Rhinoceros}

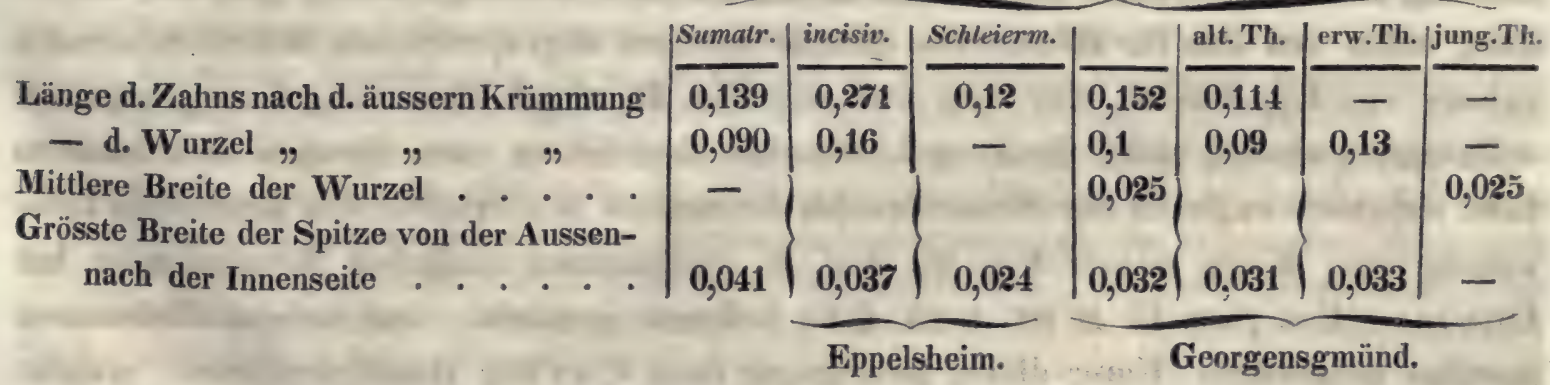

*) Im Temps, No. 1448. 5. Octob. 1833, las ich, Lamarre Picot habe an der Mündung des Ganges einen weiblichen Rhinoceros getödtet. Dieser, so wie der junge Rhinoceros, der zu gleicher Zeit getödtet wurde, besitzen nicht die geringsten Anzeigen von einem Horne. Die Häute beider sollen nach Frankreich gekommen seyn. Es wird dabei gefragt, und noch unentschieden gelassen, ob diese Thiere eine neue Gattung, oder bloss eine Varietät des einhörnigen Rhinoceros bilden? 
Der Rhinoceroszahn des alten Thiers von Georgensgmünd ist Taf. III. Fig. 23 abgebildet. Der Zahn des jungen Thiers ist ganz so gestaltet, wie die andern. Die Jugend verrăth die grössere Deutlichkeit der Kante, welche an der Hinterseite von der Basis bis zu einer gewissen Höhe sich erstreckt. Mit dem Alter wird sie stärker, und der Durchmesser der Wurzel erreicht die Stärke der Krone an der Basis.

Zu den Abbildungen wurden vorsătzlich solche Stücke gewählt, welche die Verschiedenheit erkennen lassen, die zwischen den grossen untern Schneidezähnen besteht, doch ohne dass sie dadurch mehr als einer Gattung könnten beigelegt werden. So weit der der Zahnkrone analoge Theil reicht, bestehen diese Zähne aus Knochensubstanz, mit einer dünnen Schmelzlage bedeckt. Die Abnutzungsfläche liegt, den Zahn im Kiefer gedacht, an der obern Seite etwas nach innen. Unausgesetzte Abnutzung erhielt den Zähuen ihre Schärfe, welche nach innen gerichtet ist. Vorn sind die Zähue zugerundet oder mehr oder weniger spitz.

Die Länge der Schneidezähne im Rhinoceros incisivus (Aceratherivom) gibt Kaup zu 0,27 bis 0,3 an. Nach dem vorhin mitgetheilten Dimensionenverhältniss würden also die Zähne von Georgensgmünd durchschnittlich nur die halbe Länge der Zahne von Rhinoceros incisivus von Eppelsheim, und die Grösse der Zähne in Rhinoceros Schleiermacheri besitzen, und dabei noch etwas kürzer, als die eines alten Thiers von dem lebenden Rhinoceros Sumatrensis seyn; der Zahn letzterer Gattung ist an der Spitze breiter, als in der fossilen Gattung. Kaup gibt die Abbildung eines von ihm fur Rhinoceros Schleiermacheri angesprochenen untern Schneidezahnes von Eppelsheim, der dem von mir Fig. 23 abgebildeten von Georgensgmünd vollkommen ähnlich zieht. Beide gehören ohne Zweifel zu einer Species. Mit letzterm fand sich auch zugleich der Schneidezahn der andern Kieferhälfte von demselben Individuum vor. Einen meiner Fig. 38. Taf. V. vollkommen ăhnlichen Schneidezahn hat Cuvier (Oss. foss. II. S. 91. t. 15. f. 6) bekannt gemacht, und seinem Rhinoceros minutus beigezahlt. Unter dieser Benennung fasst Cuvier Reste zusammen, welche wohl mehr als einem rhinocerosartigen Thier angehören werden. Der Zahn Taf, V. Fig. 38 ist sehr stark abgenutzt, und deutet auf einen Zahn, der eher etwas grösser war, als die andern derselben Ablagerung. Seine Schmelzbedeckung an der Aussenund Unterseite ist braun und stark glänzend. Es ist noch ein anderer Kronentheil bemerkenswerth, da er einen fast noch grössern Schneidezahn vermuthen lässt. Und dennoch war es nicht möglich, in den wirklich vorhandenen Abweichungen Gründe zu 
finden, welche die Annahme von mehr als einer Gattung erlaubten, der diese Schneidezähne von Georgensgmünd angehörten.

O b e re Schneidezä h ne.

Die obern Schneidezähne gehören zu den Seltenheiten. Ein grosser Schneidezahn aus dem Oberkiefer, bei Georgensgmünd gefunden, ist Taf. III. Fig. 24. a von aussen, b von innen und e von hinten abgebildet. Seine Form ist weder die des Schneidezahns von Rhinoceros Schleiermucheri, noch die des Aceratheriums; sie steht zwischen beiden in der Mitte. Die Schlankheit würde eher letzterem entsprechen, aber auch die Form überhaupt stimmt damit nicht überein. Der gütigen Mittheilung des Herrn Grafen zu Munster verdanke ich auch den Taf. III. Fig. 25. a von aussen, b von innen und $\mathrm{c}$ von hinten abgebildeten Schneidezahn von Westeregeln *). Auch dieser gleicht keinem von den bisher bekannten, und weicht namentlich von dem von Georgensgmünd durch grössere Breite (Länge) ab. An dem Schneidezahn von Georgens-

*) Bei Westeregeln scheinen, zu Folge der mir von Herrn Grafen zu Münster mitgetheilten Reste, zwei knochenführende Gebilde verschiedenen Alters zu liegen, von denen das eine sich durch Rhinoceros tichorhinus, das andere durch ein Rhinoceros incisivus bezeichnen liesse. Das Gebilde, welches Rhinoceros tichorhinus umschliesst, ist, nach dem, was davon den fossilen Resten noch anhängt, eine graue lehmige Erde mit etwas grobem Sand gemengt. Die Beschaffenheit der Substanz der Knochen und Zähne ist ganz wie die der fossilen Reste aus Höhlen. Das Gebilde dagegen, welches Rhinoceros mcisivus umschliesst, ist nach dem Wenigen, was sich davon noch an den Zähnen erhalten hat, eine gelbliche, nicht sehr feste Mergelmasse mit kleinen Körnern von Bohnenerz. Sonach begreift man nun auch, warum die auf die Annahme von nur einem Gebilde zu Westeregeln gegründete gleichzeitige Ablagerung gewisser Thiergattungen sich nicht ganz vereinigen lasse mit dem, was sich über dieselben an so vielen andern Ablagerungen bestätigt hatte. Es ist nun übrig, die vorgefundenen Reste in die beiden Gebilde gehörig zu vertheilen. Das Gebilde, welches Rhinoceros tichorhinus lieferte, ist wohl das jüngere, und nicht älter, als das Diluvium; das andere aber den eigentlichen Tertiärgebilden näher verwandt. Aus letzterem untersuchte ich den oben genannten grossen Schneidezahn aus der rechten Oberkieferhälfte, den dritten Backenzahn aus der linken Unterkieferhälfte von Rhinoceros und noch ein Zahnfragment, wie es scheint, von einem Wiederkäuer. Der Rhinocerosbackenzahn ist Taf. IV. Fig. 34, a von oben und b von der Aussenseite abgebildet; er entspricht ganz gut dem Fig. 31 abgebildeten Zahn von Georgensgmünd, nur dass dieser aus der rechten Unterkieferhälfte herrührt. Der Zahn von Westeregeln misst 0,031 Länge und 0,02 grösste Breite, und hat vorn und hinten sichtbarlich einen Ansatz, der sich aber an der überhaupt mit keiner Rauhigkeit versehenen Basis an der Aussenseite nicht bemerkbar macht. Dieser Backenzahn wird von demselben Thier herü̈hren, dem der Schneidezahn angehört; die Zahnsubstanz beider ist von ganz gleicher Beschaffenheit. Das Zahnfragment eines Wiederkäuers scheint von einem hintern untern 
gmünd fällt auf, dass die Wurzel an der Vorderseite eher concav, als convex, und an der Aussenseite flach, selbst etwas concav ist, wăhrend die Wurzel des Schneidezahns von Westeregeln zu beiden Seiten sich verdickt; man ersieht diess aus der Abbildung beider Zähne von hinten. Auch erhebt sich der Schmelzrand in der

Backenzahn eines hirschartigen Thiers von ziemlicher Grösse herzurühren. Es ist daran keins von den Kennzeichen der neuen fossilen Wiederkäuergenera wahrzunehmen.

Von Rhinoceros tichorhinus hat sich in dem sicherlich jüngern Gebilde von Westeregeln der grösste Theil von der linken Unterkieferhälfte eines jungen Thiers vorgefunden, worin noch drei Backenzähne sitzen; ferner der letzte Backenzahn aus der linken Unterkieferhälfte eines ausgewachsenen Thiers, einer von den vordern Backenzähnen, wahrscheinlich der dritte aus der rechten Unterkieferhälfte, wohl von demselben Individuum, 0,033 lang und 0,019 breit; und einer von den vordern Backenzähnen aus der rechten Oberkieferhälfte, 0,041 lang und 0,037 breit. Alle diese Backenzähne zeichnen sich von denen der Rhinocerosgattungen älterer Ablagerungen dadurch aus, dass Krone und Wurzel noch mit der Rindensubstanz umgeben sind, wie diess auch an den Backenzähnen der Elephanten und Pferden paralleler Ablagerungen wahrgenommen wird. Diese Zähne sind weniger versteinert, als calcinirt, und die Rindensubstanz lässt sich leicht ablösen. Die drei hintern Backenzähne in der Unterkieferhälfte des jungen Thiers sohen besonders lappig aus. Die Firste der Halbmonde ist mit einem breiten Wulste besäumt. Der vordere Halbmond biegt sich nicht gleich vorn von der Innenseite nach der Aussenseite um, sondern bildet zuvor in Form eines deutlichen Längswulstes die vordere äussere Kante; auch ist der Winkel des vordern Halbmondes an der Aussenseite zu einem Längswulst deutlich verdickt, und die hintere Hälfte der Firste des vordern Halbmondes durch einen Einschnitt zweilappig. Am hintern Halbmonde sind diese Eigenthümlichkeiten, welche der Abnutzungsfläche weniger eine halbmondförmige als eine rechtwinkelige Gestalt geben, kaum wahrzunehmen. Der vordere Halbmond der vordern Backenzähne besitzt sie zum Theil, aber nur in geringerem Grad. Die Backenzähne zeigen überdiess noch einen schwachen Vorder - und einen noch schwächern Hinteransatz. Durch. die seitliche Abnutzung verschwinden die Ansätze baìd; an Keimzähnen sind sie nicht zu verkennen. Von stärkeren Ansätzen, oder von besondern Wülsten an der Basis an der Aussenseite oder vor der Mündung der Thäler an der Innenseite habe ich nichts wahrgenommen. Diese Zähne sitzen im Unterkiefer weniger schräg; als in den Rhinocerosgattungen älterer Ablagerungen. Die hintere Wurzel des letzten Backenzahns ist eigenthümlich hinterwärts gekrümmt. Der Zahn scheint dadurch bei seiner sonst geraden Stellung die nöthige Festigkeit zu erhalten und im Stande zu seyn, der Backenzahnreihe von dieser Seite her Zusammenhalt zu geben. Dieser letzte Backenzahn ist 0,05 lang und 0,023 breit. Die oberen Backenzähne von diesem Rhinoceros zeichnet die deutliche lochförmige Vertiefung aus, welche auf der Krone nach der Aussenseite hin in dem hintern Querhügel liegt. Die Vertiefung hinter dem hintern Querhügel ist ebenfalls mehr lochartig. Der Vorder- und Hinteransatz ist auch nur undeutlich, und ein besonderer Wulst an der Basis nicht zu bemerken. Die Querhügel sind auf ihrem Zug nach der Innenseite auffallend nach hinten gebogen. Der Kiefer ist unten stark gebogen, und unter der ungefähren Mitte der Backenzahnreihe auffallend dick und schwer; nach hinten hin wird er dünner. Die Innenseite des Kiefers ist gerade oder etwas concav, die Aussen- 


\section{$-.67$}

Gegend der Mitte der Innen - und Aussenseite im Zahn von Georgensgmünd nicht so hoch nach der Wurzel hin, sondern ist, namentlich an der Aussenseite, selbst eher ausgeschnitten als gerade, und an der Innenseite hinten deutlich aufgeworfen. Die starke Abnutzungsfläche, die der Schneidezahn von Westeregeln besitzt, lässt einen grossen oder vielmehr starken Schneidezahn in dem Unterkiefer voraussetzen. Dieser obere Schneidezahn ist sehr breit, selbst in der Wurzel fast gleichförmig, nur am Anfang derselben eingezogen und am Ende zugerundet und mit einer kleinen Vertiefung versehen. An der Innenseite ist hinten der Schmelz durch Abnutzung polirt. Es fragt sich: ist diese Abnutzung natürlich, und wodurch ist sie veranlasst? Man weiss nåmlich bis jetzt nicht, dass einem solchen Schneidezahn nach hinten und innen ein anderer Zahn dicht angesessen habe. Dieser Zahn gleicht sehr dem fossilen, welcher, in Deutschland gefunden, von Camper beschrieben wurde, und den auch Cuvier erwähnt (II. 1.S. 89. t. VI. f. 9.10); nur ist die Wurzel des ersteren ein wenig kürzer, dafür aber stärker; beide rühren umbezweifelt von Thieren derselben Gattung her. Gegen diese ist der Schneidezahn von Georgensgmünd ungefahr $\frac{1}{4}$ kleiner, aber doch noch zu gross für einen Schneidezahn von Rhinoceros minutus (Cuvier, II. 1. S. 91. t. 15. f. 4. 5), der statt ein Drittel, wie mehrere andere fossile Schneidezăhne, zwei Drittel kleiner ist, als der Schneidezahn der lebenden Rhinocerosgattungen; indem seine Krone nur 0,02 lang und 0,009 breit ist. Diese Ausmessungen betragen bei dem Zahn von Georgensgmünd 0,038 und $\mathbf{0 , 0 1 3}$, und bei dem von Westeregeln 0,04 und 0,019 .

seite dagegen bauchig. Setzt man auch 7 Backenzähne in diesem Kiefer voraus, so kommt doch der erste Backenzahn in die Gegend, wo die Symphyse beginnt. In Rhinoceros leptorhinus scheint der erste Backenzahn weiter vorn zu sitzen, und die untere Linie des Kiefers nicht so stark geschwungen zu seyn.

Unter den fossilen Resten von Westeregeln befand sich noch die hintere Hälfte eines Craniums von Rhinoceros in fragmentarischem Zustande. Die Beschaffenheit der Knochen spricht nicht für die ältere Ablagerung, vielmehr ist das anhängende Gebilde ganz dasselbe, wie an dem Unterkiefer von Rhinoceros tichorhinus. Fragmente aus der vordern Hälfte des Craniums deuten ein starkes Nasenbein an, das ein Horn getragen. Dieses Cranium rührt daher von keinem Aceratherium. Es lassen sich daran keine specifische Kennzeichen prüfen, wie etwa: der Winkel, den das Hinterhaupt macht, wie weit die Augenhöhlen gingen, ob Schneidezähne oben sassen, ob eine knöcherne Nasenscheide vorhanden war, ob das Thier zwei Hörner getragen etc.; so dass eine Bestimmung nicht wohl möglich ist. Der Schädel scheint einem jungen Thier angehört zu haben, vielleicht demselben, von dem der Unterkiefer herrührt. 
Taf. III. Fig. 26 bildete ich ein kleines Zahnchen ab, welches sich zugleich mit den beiden untern grossen Schneidezahnen bei Georgensgmünd fand, von denen ich einen in Fig. 23 darstellte. Die Krone ist elliptisch, erbsenförmig, sie sitzt auf einer starken Wurzel und ist an der Basis etwas eingezogen. Die Abnutzungsfläche an der Spitze liegt gerade, rechtwinkelig zur Zahnaxe. Genannte Fläche ist schwach halbmondförmig. An einer Seite ist der Schmelz der Krone weggebrochen. Nirgends bemerkte ich eine seitliche Abnutzungsfläche. Der Zahn stak daher frei im Kiefer. Mit diesem Zähnchen liesse sich nur der kleine Schneidezahn im Oberkiefer vergleichen, der frei hinter dem grössern sitzt. Auch die Form der Abnutzungsfläche unterstüzt den Gedanken an Rhinoceros. In Rhinoceros Schleiermacheri sitzt ein solches Schneidezăhnchen hinter dem grössern; es ist aber flacher oder mehr bohnenförmig. Von Rhinoceros incisivus ist der Theil des $\mathbf{Z}$ wischenkiefers, in welchem ein $\mathbf{Z a ̈ h n c h e n ~ d e r ~}$ Art sitzen würde, eben so wenig als das Zähnchen selbst bekannt. Unter diesen Umständen ist daher nur so viel wahrscheinlich, dass dieser Zahn dem Rhinoceros Schleiermacheri nicht angehört haben wird.

Am Castlemansriver, 13 Meilen von Turkey-Foot (Grafs. Sommerset in Pensylvanien) fand man ein Kieferfragment, auf das Harlan *) seinen Rhinoceroüdes Alleghaniensis gründete. Er soll sich dadurch unterscheiden, dass der erste Backenzahn von der Zwischenkiefernaht noch einmal so weit entfernt ist, als in Rhinoceros Indicus, und über diesem Raume zwei Schneidezähne stehen. Diess erinnert allerdings an die fossilen Rhinocerosgattungen mit Schneidezähnen, namentlich an das Aceratherium oder Rhinoceros incisivus. Es sollten damit genauere Vergleichungen angestellt werden. Featherstonhaugh bemerkt, dass sich dieses Thier zu Rhinoceros verhalte, wie Mastodon zu Elephant.

Untere Backe nzähne.

Von allen bis jetzt bekannten fossilen oder lebenden Rhinocerosgattungen zeichnet sich Rhinoceros incisivus (Acerutherium) durch die namhafte Grösse seiner untern Schneidezähne aus. Daher ist auch in dieser Gattung das vordere Unterkieferende stärker, und vielleicht rührt es von derselben Ursache her, dass die untern Backenzăhne gewöhnlich etwas kleiner sind. Dem Thier mangelte das Horn, und die horntragenden Theile sind anders ausgebildet; der Schädel ist ähnlicher dem des Schweins

*) Harlan, in Featherstonhaugh, Monthly Amer. Journ., 1. July 1831. 
und die Kürze seiner Nasenknochen erinnert an $\boldsymbol{P}$ alaeotherium; auch können die gezähnelten oder warzigen Schmelzfaltchen auf der äussern Kronenfläche der untern Backsonzähne von Rhinoceros incisivus dem Wulste an der Basis der untern Backenzähne vón Palaeotherium analog erachtet werden, so dass in den angeführten Theilen mehr. Aehnlichkeit zwischen Rhinoceros incisivus oder Aceratherium und Pelaeotherium besteht, als zwischen ersterem und Rhinoceros Schleiermacheri, der sich mehr den übrigen Rhinocerosgattungen, namentlich dem Rhinoceros Stumatrensis, anschliesst. Bei diesen unverkennbaren Analogien steht jedoch in Betreff der Schneide - und Eckzähne das Palaeotherium in demselben Masse dem Tapir näher, als das Aceratherium dem Rhinoceros. Das Aceratherium ist daher geeignet, Rhinoceros und Palaeotherium zu. vermitteln.

Berücksichtige ich nun alles dasjenige, was für die Backenzähne des Rhinoceros incisivus oder Aceratherium bezeichnend seyn soll, so finde ich, dass sämmtliche Backenzähne, die ich von Georgensgmünd kenne, dieser Species angehören würden, und nicht Rhinoceros Schleiermacheri; denn ihre Aussenflache besitzt die eigenthümlichen gezähnelten oder warzigen Wulstchen, die bisweilen einen wirklichen Wulst an der Kronenbasis darstellen.

Die Richtung und Neigung der halbmondformigen Kronentheile, die Länge - und Breitedimension der Backenzahnkrone, die Beschaffenheit der Einzeltheile der Krone, so wie die seitlichen Abnutzungsflachen, waren mir Anhaltspunkte bei der Bestimmung von Fragmenten und der Stellung des Zahnes, sowohl in Betreff der Kieferhäfte, als der Zahnreihe. Unter Beachtung dieser scheinbaren Nebenumstände ward ich mit allen sieben Backenzähnen der Reihe bekannt, freilich von Thieren sehr verschiedenen Alters. Davon habe ich abgebildet: einen ersten Backenzahn aus der linken, Taf. IV. Fig. 27, und einen ersten Backenzahn aus der rechten Kieferhälfte, Fig. 28, beide von jungen, vielleicht von einem Individuum; einen ersten Backenzahn aus der linken Kieferhälfte von einem etwas altern Thier, Fig. 29 *); wahrscheinlich den dritten aus der rechten Unterkieferhalfte, Fig. 30; Fig. 31 ist wahrscheinlich der dritte und vierte von einem Individuum; Fig. 32 wahrscheinlich der vierte und fünfte von einem Individuum; und Fig. 33 wahrscheinlich der sechste Backenzahn, sämmtlich aus der rechten Unterkieferhälfte. Der siebente oder letzte Backenzahn, dessen Halbmonde noch schräger

*) Ein zweiter Backenzahn fand sich auch vor, wurde aber nicht abgebildet, weil er unvollständig war. 
stehen, und der hinten keine seitlichen Abnutzungsflachen besitzt, wurde seines fragmentarischen Zustandes wegen nicht abgebildet.

\begin{tabular}{|c|c|c|c|c|c|c|}
\hline \multirow{2}{*}{$\begin{array}{c}\text { Untere } \\
\text { Backenzähne. }\end{array}$} & \multicolumn{2}{|c|}{ Rhin. Schleierm. } & \multicolumn{2}{|c|}{ Rhin. incisivus. } & \multicolumn{2}{|c|}{ gmünd. } \\
\hline & Länge. & Breite. & Länge. & Breite. & Länge. & Breite. \\
\hline $1^{\mathrm{r}}$ & - & - & - & - & 0,018 & 0,01 \\
\hline $2 r . .$. & 0,029 & 0,019 & 0,026 & 0,019 & 0,028 & 0,019 \\
\hline $3^{\text {r. }} \cdot \cdot \cdot$ & 0,037 & 0,026 & 0,03 & 0,026 & 0,033 & 0,022 \\
\hline $4^{r} \cdot \ldots \cdot$ & 0,038 & 0,029 & 0,033 & 0,028 & 0,037 & 0,023 \\
\hline 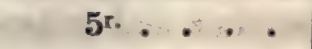 & 0,046 & 0,033 & 0,034 & 0,025 & 0,039 & 0,024 \\
\hline $6^{\mathrm{r}} \cdot \ldots \cdot \cdot$ & 0,047 & 0,033 & 0,039 & 0,026 & 0,038 & 0,025 \\
\hline $\mathrm{7r}^{\mathrm{r} .} \cdot$. & 0.044 & 0,031 & 0,039 & 0,025 & 0,04 & 0,026 \\
\hline
\end{tabular}

Auch nach diesen Dimensionen würden die rhinocerosartigen Zahne von Georgensgmünd sich eher dem Rhinoceros incisivus von Eppelsheim, als dem Rhinoceros Schleiermacheri anschliessen. Die Verschiedenheiten mögen zum Theil darauf beruhen, dass die Ausmessungen des Ersteren von Zähnen mehrerer Individuen, die des Letzteren hingegen von einem Individuum entnommen sind. Ein letzter Backenzahn von Georgensgmünd besitzt die Lănge des analogen Zahns in Rhinoceros Schleiermacheri, die Breite aber und die Wulstchen an der Aussenseite gleichen ganz Rhinoceros incisivus.

Einige Zähne (Fig. 30 u. 32) besitzen an der Aussenseite an ihrer Basis einen niedrigen, flachen, aber deutlich entwickelten Wulst, während andere (Fig.27.31 u.33) statt dessen nur wulstartige, gekerbte oder warzige Stellen höher über ihrer Basis wahrnehmen lassen, die bisweilen noch mehr oder weniger verwischt sind. Hierin liegt keine specifische Verschiedenheit, sondern eher verschiedenes Alter ausgedrückt; wenigstens ist bei den meisten jungern Zähnen an der Basis mehr ein wirklicher Wulst, und bei alteren Zahnen die andere Beschaffenheit wahrzunehmen.

Der Zahn Fig. 30 ist sehr geeignet, die Form der einzelnen Zahnkronentheile erkennen zu lassen. Allerwärts ist er unberbhrt oder frei von Abnutzung; er war wahrscheinlich noch vom Zahnfleisch bedeckt, ein sogenannter Keimzahn. Die ganze Oberfläche ist innen mit feinen, aussen mit weniger feinen kurzen Längsrunzeln übersăet. Die Haupttheile der Zahnkrone sind zwei Querkämme, deren jeder etwas schräg von hinten innen nach vorn aussen gerichtet, und hierauf nach der Mitte und vorn 
umgebogen ist. Man nennt diese beiden Theile gewöhnlich die halbmondförmigen oder Halbmonde. An ihnen ist kein Hügel oder Spitze vorherrschend. Der hintere Querkamm oder Halbmond ist ungefähr ein Viertheil niedriger, als der vordere. Zwischen beiden Querkämmen ist nur oben ein kleines Thălchen oder Einschnitt, sonst besteht keine Communication zwischen der Aussen - und Innenseite. Durch die Krummung der Querhügel nach vorn entstanden zwei nur nach innen abfallende und mündende Thaler, von denen das hintere etwas grösser und tiefer ist, als das vordere. Die Firste der Querkamme ist wie gesäumt, etwas nach innen eingebogen und hie und da körnig oder warzig. Die Unebenheiten an der Aussenseite der Kronenbasis könnte man ansehen für Runzeln derselben Art, wie die des Schmelzes dieser Zähne überhaupt, nur deutlicher hervorstehend; sie sind aber doch an ihrer obern Grenze stärker und grösser, wie spitze Längswarzen, und verlieren sich nach unten. Beide Ansătze, der vordere und der hintere, sind vorhanden. Sie sind flach, erheben sich bis zur halben Höhe der Seite, woran sie liegen, treten an ilirer Firste am starksten und leistenartig heraus, sind an dieser Stelle wie gesăumt und mit Knötchen oder Perlen besetzt, und verlieren sich an der Aussenseite in die Unebenheiten der Basis. Der vordere Ansatz biegt fast bis zur Mitte der Innenseite um, wo er endigt; der hintere Ansatz endigt schon auf der Hinterseite.

Sämmtliche untere Backenzähne besitzen gemeinsame Einzeltheile, nach dem Stand in der Reihe und dem Alter des Individunms eigenthümlich ausgebildet und abgenutzt. Hierauf beruht die Kunst, vereinzelte Zähne und selbst Zahnfragmente mit derselben Gewissheit zu bestimmen, als wenn sie noch im Zusammenhang mit der ganzen Zahnreihe im Kiefer ständen.

Sogar der erste Backenzahn lässt sich, ungeachtet seiner Kleinheit und Einfachheit, mit den übrigen Backenzähnen seiner Reihe in Beziehung bringen. In diesem Zahn scheint der Basaltheil vorzuwalten und der Kronentheil über der Basis mehr zurückgedrängt, als in den andern Zähnen. Vorhanden ist: der hintere halbmondförmige Querhügel (Fig. 27, d. 28), nur gerade und mehr längs gestellt, auch das ihm angehörige, nach innen mündende Thal; ferner vom vordern Halbmond nur der Hintertheil, und zwar etwas schräg gerichtet, während der Vordertheil zur Langskante wurde, welche über die vordere Hälfte des Zahns herunterführt. Das Thal des vordern Halbmondes ist nur durch eine schwache, vorn an der Innenseite liegende Concavitat angedeutet. Die Stelle, in der die beiden Querkămme an einander sitzen, bezeichnet eine, von der Spitze über die vordere Hälfte der Aussenseite herunter- 
laufende Furche. Deutlicher sind die warzigen Unebenheiten an der Aussenseite an der Basis vorhanden, zwar nicht so dick, als in andern Zahnen, aber fast bis zur Spitze der Zahnkrone hinauf. Der vordere und hintere Ansatz ist nicht zu verkennen, sogar auch die Eigenthümlichkeit des vordern Ansatzes, sich zur Innenseite umzubiegen. Nur die Hinterseite besitzt eine seitliche Abnutzungsfläche, der Zahn lag also nur hier einem andern unmittelbar an. Die hintere Hälfte dieses Zahns war hauptsăchlich der Abnutzung unterworfen und es scheint, dass dieser Zahn etwas weiter nach vorn gestanden, als der obere, mit dem er zugleich den Dienst des Kauens versah. Der Fig. 29 abgebildete Backenzahn aus der linken Unterkieferhälfte bestätigt, was ich über den ersten Backenzahn vorbrachte. Dieser ist durch längeren Dienst auf der Krone starker abgenutzt, und auch die. Seiten seiner. Krone sind durch Alter glätter. Von den vorigen unterscheidet er sich durch einen deutlicheren vordern Ansatz und durch eine lange starke Wurzel, welche an der Innenseite durch eine Längsfurche zweitheilig aussieht. Die hintere seitliche Abnutzungsfläche ist deutlich, liegt aber grösstentheils unter der Kronenbasis auf der Wurzelsubstanz. Die Zahnkrone ist 0,02 lang und 0,011 breit.

Am zweiten Backenzahn treten die einzelnen Theile schon deutlicher und mehr so heraus, wie ich sie bereits für den Keimzahn anfuhrte; doch erlangt der vordere halbmondförmige Querkamm und sein Thal noch keine solche Bedeutenheit. Die Unebenheiten an der Basis erheben sich bis zu $\frac{1}{3}$ ganzer Zahnhöhe; die Warzen sind daran sehr deutlich.

Den dritten Backenzahn habe ich schon als Keimzahn ausfuhrlich beschrieben. Die Unebenheiten an seiner Basis erheben sich kaum halb so hoch, als am vorhergehenden. Fin anderer Backenzahn (einer von den beiden in Fig. 31) besitzt eine weniger wulstförmige, als warzige oder gekerbte Basis, die sich so hoch als im zweiten Backenzahn erhebt. Verschiedenheit des Alters der Zähne scheint der Grund hievon zu seyn. Taf. IV. Fig. 34 habe ich auch einen dritten Backenzahn, entweder von derselben oder von einer verwandten Gattung abgebildet, der bei Westeregeln gefunden wurde; ich gedachte seiner schon S. 65 in der Note. Der andere Backenzahn von Fig. 31 wird der vierte der Reihe seyn. Unebenheiten an der Basis sind daran so gut wie nicht vorhanden. Der vordere Ansatz biegt sich noch über die Aussenseite merklich herum, während der hintere Ansatz nicht einmal die ganze Hinterseite einnimmt. An diesem Zahn bemerkt man in der Längsfurche, welche da, wo die beiden halbmondförmigen Querkămme sich berühren, an der Aussenseite herunterlăuft, unten uber der 


\section{$-73-$}

Basis ein von der vờdern Hălfte ausgehendes Hübelehen. Vor der Mündung der beiden Thaler an der Innenseite sieht man ähuliche Hübelchen, stårker vor dem hintern Thal dieses und des vor ihm liegenden Zahnes. An einem andern Zahn, der mir der sechste Backenzahn aus der linken Unterkieferhalfte zu seyn scheint, ist dieser Hübel zwischen den beiden halbmondförmigen Querkämmen an der Aussenseite und vor der Mündung jedes der beiden Thaler an der Innenseite besonders stark. Ich vermuthe, dass diese Zähne, zumal letzterer, derselben Thiergattung angehören, von der die obern Backenzähne mit der Spitze an der Innenseite herrühren. Dieser untere Zahn ist 0,037 lang und hat 0,027 grösste Breite; er war schon stark gebraucht, und gehörte vielleicht mit den Taf. VI. Fig. 48 abgebildeten obern Backenzăhnen einem Individuum an.

Die Eigenthümlichkeiten an den Zähnen Fig. 32 sind nicht unerheblich, sollten sie auch bloss in der Jugend des Thiers, dem sie angehörten, ihren Grund haben. Ich vermuthe in ihnen den vierten und funften Backenzahn. Die Unebenheiten an der Aussenseite an der Basis sind hier wieder deutlich wulstförmig, und am hinteren Zahn, zumaI an der hintern Halfte desselben, am wenigsten hoch. Der hintere Ansatz biegt sich deutlich nach der Aussenseite um, der vordere führt, als eine körnige Kante, bis vor die Mündung des hintern Thals uber der Innenseite. Die Abnutzung dieser Zähne hatte erst begonnen.

Der Zahn Fig. 33 stand länger im Dienste. Man sieht daran starke Wurzeln. Ich halte ihn für den sechsten der Reihe. Von Unebenheiten an der Aussenseite an der Basis ist daran weiter nichts vorhanden, als der in schräger Lage umgebogene Theil des vordern und hintern Ansatzes.

Am letzten Backenzahn ist der hintere Ansatz niedrig und überhaupt nicht so bedeutend; er zeigt begreiflich keine Abnutzungsflăche. Der vordere Ansatz aber ist nicht weniger beträchtlich, als in den zuvor betrachteten Zähnen. Eir zieht sich mit ziemlicher Breite über die Basis der vordern Halfte der Aussenseite; der hintere Theil der Basis an der Aussenseite ist von Unebenheiten frei. An diesen Zabhnen ist die vordere Hälfte kleiner, als die hintere. Vor der Mündung der beiden Thäler an der Innenseite liegen auch hubelige Unebenheiten.

Die durch Abnutzung auf der Krone entstandenen Flächen sind horizontal oder schräg nach aussen und hinten gerichtet. Die horizontalen offnen am ersten den Schmelz und entblossen die Kerusubstanz des Zahns. Die Ungleichheiten in der Höhe der Zahnkrone wird durch sie bald geebnet. Zwei halbmondförmige oder vielmehr sichelförmige Flächen von Kernsubstanz werden sichtbar. Fortgesetzte Abnutzung 
entfernt die Schmelztrennung und macht beide Flächen zusanmenhängend, wie ein Zahn von Fig. 31 wahrnehmen lässt. Die schrägen Abnutzungsflächen nach aussen und hinten ruhren von den ubergreifenden aussern Theilen der obern Zahnkrone her. Diese Flächen sind bisweilen ausgedehnt und bilden mit der mehr oder weniger horizontalen Abnutzungsfläche eine bei fortwăhrendem Kauen sich immer wieder erneuernde Kante, welche den Zahn zu einem scharfen Instrumente macht.

\section{O b e re B a c ke n z ä h u e.}

Die oberen Backenzahne sollen in Rhinoceros incisivus (Aceratherium) quadratischer seyn, als in Rhinoceros Schleiermacheri und Rhinoceros Indicus; es soll ferner in erstgenannter Gattung am letzten Backenzahn der hintere Ansatz über der Hinterseite wirklich vorhanden seyn, während er in Rhinoceros Schleiermacheri nur in einer oder zwei kräftigen Spitzen besteht, und der zweite, dritte und vierte Backenzahn soll an der Innenseite an der Basis einen Wulst haben. Berucksichtigt man dieses gehörig bei den zu Georgensgmünd vorgefundenen oberen Backenzuhnen, so wird man finden, dass sie unbezweifelt eher zu Rhinoceros incisivus, als zu Rhinoceros Schleiermacheri gehören. Damit sind auch folgende Dimensionen einverstanden :

\begin{tabular}{|c|c|c|c|c|c|c|c|}
\hline \multirow{2}{*}{$\begin{array}{c}\text { Obere } \\
\text { Backenzähne. }\end{array}$} & \multicolumn{4}{|c|}{$\frac{\text { Eppelsheim. }}{\text { Rhin. Schleierm. } / \text { Rhin. incisivus. }}$} & \multicolumn{2}{|c|}{$\begin{array}{l}\text { Georgens- } \\
\text { gmünd. }\end{array}$} & 347 \\
\hline & Länge. & Breite. & Lăn & Bre: & Läng & Breite. & \\
\hline $\mathbf{1}^{\mathrm{r}} \cdot \cdot$ & - & - & 0,023 & 0,021 & 0,027 & 0,023 & \\
\hline $2^{r .} \cdot . \quad$. & 0,084 & 0,043 & 0,036 & 0,044 & - & - & \\
\hline $3^{\text {r. }} \cdot \ldots$ & 0,041 & 0,056 & 0,039 & 0,053 & - & - & \\
\hline $4^{\mathrm{r} .} . .$. & 0,043 & 0,06 & 0,042 & 0,057 & 0,046 & 0,046 & oder $3^{\text {r. Bac }}$ \\
\hline 5r. . . & 0,052 & 0,062 & 0,05 & 0,058 & 0,05 & 0,053 & oder $\mathbf{6}^{\mathrm{r}} \cdot$ Backenzah \\
\hline $6^{r .} \cdot$. & 0,054 & 0,065 & 0,05 & 0,059 & & - & \\
\hline yr. . . . . & 0,056 & 0,056 & 0,0575 & 0,054 & 0,044 & 0,045 & \\
\hline
\end{tabular}

In diesem Dimensionenverzeichniss fällt nur auf, dass der letzte Backenzahn von Georgensgmünd fast mehr als 0,01 kleiner ist, als der in den beiden verschiedenen Gattungen von Eppelsheim.

Was nun die Beschaffenheit der Zähne selbst betrifft, so kann man sie unterscheiden in solche, deren Basis an der Innenseite mit einem starken und hohen Wulste versehen ist, und in solche, woran derselbe fehlt. Dieser hohe starke Wulst ist so 


\section{$-75-$}

auffallend, dass, wenn man diese Zähne mit denen ohne denselben vergleicht, man kaum glauben sollte, dass sie einer und derselben Gattung angehören könnten. Mehrere dieser Zähne, namentlich die drei Zahnfragmente, Taf. V. Fig. 39. 40, Taf. VI. Fig. 52, erinnern durch diesen hohen Wulst und durch den Zusammenhang der beiden Hügelspitzen an der Innenseite eher an obere Backenzähne von Palaeotherium magnum *), als von Rhinoceros, für die sie leicht zu verkennen wären, besonders wenn andere Reste von diesem Palaeotherium in der Ablagerung sieh vorgefunden hătten, was indess meines Wissens bis jetzt nicht der Fall war. Cuvier ist diese Aehnlichkeit wohl aufgefallen, indem er es für leicht hielt, eine Verwechselung mit den Zähnen beider Thiere zu begehen. Der starke Wulst erinnert auch an den Daman (Hyrax) ***), wie denn auch sonst wohl der Kiefer des Palaeotheriums. Manches enthält, was Daman analog ist. Es lasst sich auch einige Aehnlichkeit mit Lophiodon nicht absprechen, von dem sie sich aber eben so sehr entfernen, als sie sich Rhinoceros entschiedener năhern. Die obern Backenzähne von Palueotherium latum * * * scheiden sich von den fossilen von Georgensgmünd nur dadureh, dass sie kleiner sind. Diese Zähne von Georgensgmünd sind selbst denen im Palaeotherium magnum weit uhnlicher, als letztere den Zähnen im Pulaeotherium Aurelianense, das mit ihm doch generisch verwandt ist. Der Rhinoceros incisivus oder das Aceratherium gleicht also gerade in den Theilen, worin es sich von den gewöhnlichen Rhinocerosgattungen entfernt, wie in der Kleinheit der Nasenknochen, in den wulstähnliehen Unebenheiten an der Aussenseite an der Basis der unteren Backenzähne, und in dem Wulste an der Innenseite an der Basis der obern Backenzähne, den gewöhnlichen Palaeotherien, und was die obern Backenzähne betrifft, allermeist dem Palaeotherium mugnum.

Zu diesen Zähnen mit auffallendem Wulste gehören die bereits erwähnten drei Fragmente; Taf. V. Fig. 39 stammt aus der rechten, Taf. V. Fig. 40 und Taf. VI. Fig. 52 aus der linken Oberkieferhälfte. Es waren, nach den seitlichen Abnatzungsflächen zu schliessen, mittlere Zähne der Reihe. Dasselbe gilt von den beiden andern vollständigeren Zähnen der Art Taf. V. Fig. 41 u. 42, welche aus der rechten Oberkieferhälfte herrūhren; sie haben starke seitliche Abnutzungsflächen. Der Zahn Fig. 42

\#) Cuvier, Oss. foss. III. t. 43. f. 1. S. 50.

(t) Cuvier, Oss. foss. II. S. 142. t. 2. f. 6. - F. Cuvier, Dents des Mammifères. No. 89.

) Cuvier, Oss. foss. III. t. 44. f. 4.

†) Cuvier, Oss. foss. III. t. 48. f. 2. 
ist auf seiner Krone so sehr abgenutzt, dass die Querhugel, bei dem Mangel eines tiefen sie trennenden Thales, zu einer Fläche vereinigt sind, in der nur noch eine kleine runde, und eine grössere Schmelzgrube vorhanden sind. Dieser Zahn misst 0,026 Länge und 0,036 Breite. Im andern Zahn mit ausgezeichnet hohem Wulste ist das Thal, welches die beiden Querhügel trennt, etwas tiefer. Dieser Zahn ist 0,032 lang; wegen Mangel seines äussern Kronentheils lässt sich die Breite nicht messen. An letzterem Zahn haben die Wurzeln ein besonders krankhaft zerfressenes oder aufgesogenes Aussehen, und ihre Form ist schmächtiger. Ein Zahnfragment, welches ich in der Ablagerung von Eppelsheim selbst fand, gleicht letztgenanntem Zahne ganz uberaus, so dass ich mich gedrungen fühle, dasselbe hier zur Vergleichung mit abzubilden (Taf. V. Fig. 43). Aus dieser Ablagerung ist von Palaeotherium noch keine Spur bekannt, wohl aber finden sich Rhinoceroszähne von ahnlichem Aussehen. Daher werden auch die Zăhne solcher Art von Georgensgmünd keinem Palaeotherium angehören. Der Zahn von Eppelsheim rührt aus der linken Oberkieferhälfte her, besitzt ebenfalls schmächtige, krankhaft aussehende Wurzeln und ist 0,038 lang.

Ich habe nun noch einiger oberen Backenzähne mit starkem Wulste an der Innenseite an der Basis zu gedenken. Ein fragmentarischer Zahn der Art aus der rechten Oberkieferhälfte von wenigstens 0,05 Breite ist Taf. V. Fig. 44 abgebildet. Er befremdet durch eine aufallende dicke Spitze in seinem Wulste vor dem Eingang ins Thal an der Innenseite. Sonst ist der Zahn gebildet wie die Zăhne von Rhinoceros incisivus mit Wulst. Der Zahn hat eine grosse hintere seitliche Abnutzungsfläche. Diese Spitze, von der an der Gaumenseite der Schmelz weggebrochen, erinnert an die Spitze, in welche der vordere Querhügel an der Innenseite der oberen Backenzahne von Anoplotherium endigt, wodurch sich die hinteren oberen Backenzähne dieses Thiers von denen des Palaeotheriums unterscheiden lassen, weshalb schon dieses Zahnfragment nicht von Palaeotherium herrühren könnte. Man bemerkt bisweilen an dem Wulste an der Innenseite in dem 2., 3. und 4. oberen Backenzahn des Rhinoceros incisivus von Eppelsheim eine dornartige Verstarkung. Diese mag etwas Analoges seyn, wie die Spitze an den Zähnen von Georgensgmünd, sie ist aber mit derselben nicht ganz übereinstimmend, indem sie keineswegs sich so betrăchtlich und eigentlich sich nicht aus dem Wulste und in Form einer conischen Spitze erhebt, sondern mehr als eine kleine Verzweigung des Wulstes an der Basis in das Querthal hinein und nach dem hintern Hügel hin anzusehen ist. Später theilte mir Herr Graf zu Munster einen mit einer Spitze versehenen Zahn von Georgensgmund mit, der noch mit dem in der Reihe auf 
ihn folgenden zusammen liegt; dieses schöne Stük habe ich Taf. VI. Fig. 48 abgebildet. An dem einen dieser Zähne ist die Spitze im Wulste an der Innenseite überaus stark und hoch, und offenbar ein wesentlicher Kronentheil; der andere besitzt diese Spitze nicht. Beide umzieht an der Basis ein starker Wulst, der in ersterem höher ist, als in letzterem. Eine kleine Erhöhung im Wulste des letztern kann um so sicherer für den der Spitze analogen Theil angesehen werden, als er uber dem entsprechenden Wurzeltheil, welcher hier nur schwächer ist, sitzt. Hier belehrt also der Augenschein, dass Backenzähne mit der starken Spitze an der Innenseite mit Zähnen in der Backenzahnreihe zusammen sitzen können, woran dieselbe nicht vorhanden ist. Anf den Grund, dass eine spitze oder dornartige Verstarkung an der Innenseite des 2., 3. und 4. Backenzahns der Reihe vorkomme, würden diese beiden Zähne für den vierten und fünften aus der linken Oberkieferhälfte zu nehmen seyn. Wenn nun auch die Spitze in den Zähnen nach dem vierten verschwindet, so ist doch diess mit dem deutlichen Wulste keineswegs der Fall. Der Zahn Taf. VI. Fig. 49 zeigt vielmehr, dass sogar der letzte Backenzahn noch mit diesem Wulste umgeben ist, weshalb ich ihn derselben Thiergattung beizulegen Ursache habe, von der die beiden Zähne Taf. VI. Fig. 48 herrühren. Alles dieses weicht sehr von dem in den lebenden und den bekannten fossilen Rhinocerosgattungen ab, und selbst die Annäherung zu Aceratherium ist nicht vollständig. Dieses vereinigt sich mit den Eigenthümlichkeiten des kleinern und grössern obern Schneidezahns und mit dem einiger untern Schneidezähne zur Vermuthung, dass hier eine neue Thiergattung ausgedrückt liege, was indess vollstandigere Stucke zn bestätigen haben. Solcher Zahhne mit einer Spitze im Wulste sollen mehrere gefunden worden seyn, die mir aber noch nicht naher bekannt wurden. lch bezweifele nicht, dass auch diese rhinocerosartigen Thieren angehören werden. Man ersieht übrigens hieraus, wie Zähne Manches besitzen können, was isolirt betrachtet leicht zu falschen Bestimmungen verführt, auf die Folgerungen gestützt werden, die den Irrthum unabsehbar vergrössern.

An Keimzähnen vom Rhinoceros erkennt man für einen allgemeineren Theil an der längeren Aussenseite einen starken Langskamm oder eine Wand, mit der zwei etwas hinterwarts gerichtete Querkämme in Zusammenhang stehen, die an der Innenseite hügelartig endigen; der vordere dieser Querkämme ist merklich länger, als der hintere. An der Aussenseite ist vorn ein hugeliger, etwas mehr nach innen und eigentlich schon vor dem vordern Querkamme liegender Vorstoss, der der Abnutzungsfläche hier ein zweilappiges Aussehen ertheilt. Ein analoger Theil liegt auch vor dem hintern 
Querkamm nach der Mitte der Zahnkrone hin. Der tiefen Grube in der Mitte der Zahnkrone, oder hinter dem ersten Querkamm, entspricht eine Grube hinter dem zweiten oder hintern Querkamm, die nicht so gross und tief ist, als erstere. Die vordere und hintere Hälfte dieser Zähne besitzen also unter einander grosse Aehnlichkeit, bei deren Berüksichtigung sich die Abweichungen fasslicher darlegen lassen, welche hintere Zähne hauptsächlich in der hintern und vordere Zähne hauptsảchliçh in der vordern Hälfte der Backenzahnkrone, im Vergleich zu mittlern Zähnen, darbieten. Die Zähne haben einen vordern und hintern Ansatz in Form deutlich abstehender Leisten, die auf ihrer Firste mehr oder weniger warzig sind. Der vordere Ansatz biegt sich gewöhnlich etwas zur Innenseite um, was beim hintern Ansatz nicht bemerkt wird. Es entsteht dadurch eine wulstige Unebenheit vorn an der Basis des vordern Hügels an der Innenseite; ein ähnlicher Theil wird auch vorn an der Basis des hintern dieser Hügel oder an der Mündung des durch beide Hügel gebildeten Thals an der Innenseite bemerkt. Ist letztere Unebenheit der analoge Theil, welcher in gewissen Zähnen mit starkem Wulste als Spitze oder als eine Verzweigung mehr hinein nach der Backenzahnkrone sich darstellt? Noch ist zu bemerken, dass der vordere Querkamm, ehe er an der Innenseite endigt, sich verengt, hierauf aber sich zur Hügelendigung ausbreitet; hiedurch erhält die Abnutzungsfläche in einer gewissen Tiefe an dieser Stelle das eingezogene Aussehen. An der Hügelendigung des hintern Querkammes an der Innenseite ist Aehnliches, aber lange nicht so deutlich bemerkbar. Das Gesagte wird deutlich beim Hinblick auf die Backenzähne Taf.V. Fig. 45 und Fig. 46; ersterer ist wahrscheinlich der vierte aus der linken Oberkieferhälfte, letzterer der funfte oder sechste aus der rechten, a von der Krone, b yon innen, $\mathbf{e}$ von vorn, d von hinten und e von aussen dargestellt.

Diese Beschaffenheit mittlerer Zähne stimmt ganz mit der in Rhinoceros incisivus überein. Der erste Backenzahn aber gleicht dadurch, dass seine aussere Seite geralder steht und er etwas grösser ist, eher dem in Rhinoceros Schleiermacheri als in Rhinoceros incisivus oder Aceratherium. Der Taf. V. Fig. 47. a von innen, b von aussen, $c$ von vorn und $\mathbf{d}$ von der Krone abgebildete Zahn aus der rechten Oberkieferhälfte ist an der Imenseite hinten beschädigt. Vorn hat er begreiflich keine Abnutzungsfląche, wohl aber hinten. Der Vorstoss an der Aussenseite vorn liegt mehr in gerader Linie mit der Aussenseite; in Rhinoceros incisivus steht diese ganze Aussenseite schräger. Der vordere Querkamm ist. sehr verkümmert, vor ihm liegt eine starke Grube. Ein hinten vollständigerer erster Backenzahn zeigt den hintern Querhügel noch deutlich; so sind 
also am ersten Backenzahn noch alle Theile vorhanden, welche die mittlern deutlicher enthalten. Die an den Enden der Aussenseite herunter laufenden Wülste haben weniger die Bedeutung des Vorder - und Hinteransatzes, als der, auch an mittleren wulstigen Backenzähnen vorhanden, Vorder - und Hinterkante, in die freilich die Ansätze auch verlaufen. Die Abnutzungsfläche fällt schräg nach der Innenseite ab. Dieser Zahn von Georgensgmünd würde grösser seyn, als der des Rhinoceros incisivus von Eppelsheim. Ein anderer Zahn aus ersterer Fundgrube aus der linken Kieferhălfte, dem beschriebenen ganz ähnlich, besitzt die Wurzel vollständig; sie misst, von der Kronenbasis an gerechnet, 0,036 Länge. Die Krone eines anderen Zahns mit Wurzeln, auch aus der linken Kieferhălfte, misst 0,025 Lănge und 0,02 Breite, die Wurzel ist so lang, als am vorigen. Diese Dimensionen kommen denen des Aceratheriums von Eppelsheim näher. Der Zahn gehört zu denen mit gerader gerichteter Aussenseite.

Es ist nun noch der letzte Backenzahn aus dem Oberkiefer zu betrachten übrig. Taf. VI. Fig.49 stellt denselben aus der linken Kieferhälfte, a von der Krone, b von innen and c von aussen, dar. Die Verschiedenheiten zwischen diesem und den andern Zähnen der Reihe beruhen nur auf Abweichungen analoger Einzeltheile. Der Zahn hat statt der quadratischen eine mehr dreieckige Form, zu dessen Scheitel die Aussenseite reducirt ist. Der hintere Querkamm ist hinten statt ein-, nunmehr ausgebogen. Der vordere Ansatz zieht sich als deutlicher Wulst an der Basis uber die vordere Halfte der Innenseite. Dieser Ansatz hat vorn eine seitliche Abnutzungsfläche. Die Unebenheit an der Mündung des Thals zwischen den beiden Hügeln an der Innenseite stellt einen Wulst dar, der in das Thal sich hineinzieht. Der hintere Ansatz ist nicht so breit, aber dicker, an seinem Ende an der Aussenseite bildet er eine Art stumpfe Spitze, und ist auch etwas umgebogen, wodurch ein kleines Grïbchen entsteht, welclies der Grube zwischen dem hintern Querkamm und dem hintern Ansatz mittlerer Zähne verglichen werden kann. Der Zahn ist dreiwurzelig; die grösste Wurzel sitzt unter der ganzen Innenseite und noch unter der halben Vorderseite; die Wurzel unter der Aussenseite und unter der andern Hälfte der Vorderseite ist die zunăchst stärkere; die dritte Wurzel sitzt unter dem hintern Ansatz. Vergleiche ich diesen Zahn mit dem letzten obern Backenzahn in Rhinoceros incisivus und Rhinoceros Schleiermacheri, die noch am ersten dazu geeignet sind, so finde ich, dass er dadurch, dass der hintere Ansatz über einer Strecke der Hinterseite wirklich vorhanden ist, weit mehr Aehnlichkeit mit ersterm besitzt, als mit letzterm, wo der hintere Ansatz in nichts Anderm, als in einer oder in zwei deutlichen Spitzen besteht. Ich unterstitze meine Aussage 
mit der Abbildung, welche ich von dem letzten obern Backenzahn aus derselben Kieferhalfte des Rhinoceros Schleiermacheri von Eppelsheim, Taf. VI. Fig. 51. a von der Krone, b von innen und c von aussen gebe. Später theilte mir Herr Graf zu Munster noch den Taf. VI. Fig. 50. a von der K'rone, b von innen und $\mathrm{c}$ von aussen abgebildeten Zahn, zu Georgensgmünd gefunden, mit. Dieser weicht hauptsächlich in dem so charakteristischen Hinteransatze von dem zuvor aus derselben Fundgrube erwăhnten auffallend ab, indem der Ansatz mehr einem einspitzigen Wülstchen gleicht, das hinten an dem hintern Hügel an der Innenseite aus dem Basalrande sich erhebt. Bei genauerer Beachtung ist dieselbe Stelle des Basalrandes selbst auf eine kleine Strecke etwas körnig. Man wird hiedurch zweifelhaft, welcher Gattung man diesen Zahn zuschreiben soll. Nach der Beschaffenheit seines hintern Ansatzes würde er eher dem Rhinoceros Schleiermacheri als dem Aceratherium angehören. Ueber die Innenseite an der Basis zieht sich kein Wulst, wodurch der Zahn auch noch auffallend von dem andern aus derselben Gegend abweicht. Nur zwischen den beiden Hügeln, mehr am hintern, ist in der Basis etwas Rauhigkeit zu bemerken. Dieser Zahn gehört also wahrscheinlich einer andern Art an; er ist nur 0,037 lang und 0,047 breit, und rührt von einem etwas jüngern Thier her. Die auffallende Verschiedenheit, die er gegen den früher erwähnten zeigt, können nicht wohl allein auf Altersverschiedenheit beruhen. Selbst diese vielen Reste von Georgensgmünd sind noch nicht geeignet, einen bestimmten Ausspruch darüber zu thun, wie viel Gattungen, und ob bereits bekannten, oder neuen sie angehören. Hierauf kommt es auch vorerst weniger an, als auf eine genügende Darlegung der Reste selbst, wodurch allein ihre Bestimmung sicher vorbereitet wird.

\section{P a l a e o $\quad$ t h}

Die Entdeckungsgeschichte dieses untergegangenen Pachydermengenus darf ich hier als bekannt voraussetzen. Sie ist in Cuvier's Beschreibung der Knochen aus der Umgegend von Paris * enthalten und spielt hauptsächlich im Montmartre bei Paris, aus dem wenigstens acht Gattungen dieses uberaus merkwürdigen Geschlechtes herruhren,

Die meisten Reste bei Georgensgmünd ruhren von Palaeotherium her. Darunter

*) Cuvier, Oss. foss. III. 


\section{$-81-$}

habe ich aber noch keine von den im Montmartre gefundenen Gattungen angetroffen. Sămmtlich gehören sie bis jetzt nur einer Gattung an, und zwar der, welche in geringen Bruchstücken in der Gregend von Orléans, Montpellier und Argenton sich vorfand. Es ist das seltenste der bisher bekannten Palaeotherien. Schon Guettard *)

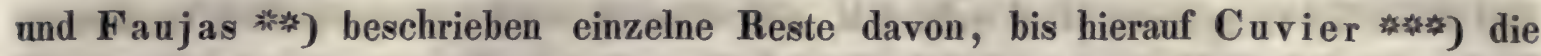
eigentliche Deutung derselben gab, und das Thier, von dem sie herrühren, Palaeotherium Aurelianense nannte.

Dieses Palaeotherium zeichnet sich besonders durch die doppelte Spitze seines mittleren Hügels an der Innenseite der untern Backenzähne aus, während diese Spitze bei den ubrigen Gattungen einfach ist. Nur einige bei Issel gefundene Zähne besitzen dieses Merkmal mit andern Abweichungen, in denen Cuvier †) Andentungen einer eigenen Species erblickt. Meine Untersuchungen über die Zähne von Palneotherium Aurelianense werden auch zur Beurtheilung dieser geeignet seyn.

Unterkiefer mitseinen $B$ akenzăhnen.

Zuvor von der Zahl der Backenzahne in einer Reihe oder Halfte des Unterkiefers. Hierüber geben die Kieferstücke Taf. VII. Fig. 53 u. 54 erwünschten Aufschluss. Das grössere Kieferfragment Fig. 53 ergibt sechs grosse Backenzăhne in einer Reihe; dabei fand sich noch ein kleines Backenzähnchen vor, so dass die Reihe aus sieben einander anliegenden Backenzähnen besteht, aus sechs grossen und einem síebenten kleinen, der diesen vorsitzt. Der erste grosse Backenzahn und der letzte sind etwas grösser, als die zwischen ihnen liegenden, welche fur gleich gross gelten kðnnen. Der vierte ist am gleichformigsten gebildet; die vor ihm sitzenden werden nach vorn und die hinter ihm nach hinten schmäler.

Zur Darlegung der Beschaffenheit der Zahnkrone eignen sich am besten Keimzahne. Von diesen fand ich den zweiten, dritten und vierten Backenzahn aus der rechten Unterkieferhälfte (Taf. VIII. Fig. 61) vor. Sie ruhren unbezweifelt von einem und demselben Individuum her. Nirgends noch fand Abnutzung oder Berührung statt, selbst an den Seiten nicht; sie sind ganz unversehrt und mit ihren zartesten Theilen

क) Guettard, Mém. V. t. 7. f. 1.

क) F a u a s, Ann. du Mus. XIV. S. 382. t. 24. f. 5. 6.

the) Cuvier, Oss. foss. III. S. 254. 256. t. 67. f. 2. 12.13.14.17.

†) A. a. 0. S. 257. t. 67. f. 18. 
erhalten, so dass sie entweder noch unter dem Zahnfleisch verdeckt lagen, oder dieses kaum anfingen zu durchbrechen. Das Ebenmass des vierten Backenzahns răumt demselben den Vorzug ein, als Entwickelungsnorm für die Kronenbeschaffenheit zu dienen. Die allgemeine Form des Zahnes kann rechtwinkelig angenommen werden. Bei sămmtlichen grossen Backenzăhnen, mit Ausnahme des letzten, ist die Hinterseite am geradesten, und die grossen Backenzähne sind ohne Ausnahme nach aussen und vorn mehr gerundet.

Nach Cuvier bestehen die untern Backenzähne der Pulaeotherien aus zwei Halbmonden. Vergleicht man die Backenzähne verschiedener Thiere unter einander genaner, so wird man einsehen, was eigentlich diese sogenannten Halbmonde sind. Sie haben nämlich die Bedeutung von Querhügeln oder Kämmen. Einfache Fälle sind solche, wo diese Kronentheile gerade quer gerichtet sind (Elephas, Mastodon, Dinotherium etc.). Hierauf kommen solche, wo eine Umbiegung dieser Querhugel stat hat, wie z. B. in den untern Zähnen des Rhinoceros an der Aussenseite nach vorn und innen. Diese hier nur theilweise bestehende Umbiegung geht im Palneotherium so weit, dass der Querkamm schon mit einer schiefen Richtung beginnt, und eine halbmond-, sichel- oder richtiger hufeisenförmige Krümmung beschreibt. Aus zwei solchen Theilen, die vordere und hintere Häfte des Zahns bildend, besteht die Backenzahnkrone. Sie sind einander analog; denn jeder derselben hat drei Hugelspitzen als eine Art von Stutzpunkten, von denen zwei an den beiden Enden an der Innenseite, und der dritte am Knie an der Aussenseite auftritt. Der vordere Scheitel des hufeisenförmig gekrümmten Kammes bildet, indem er niedriger wird, die ganze Vorderseite der Zahnkrone und biegt sich in der sehr schwachen vordersten Hügelspitze an der Innenseite zu dieser Seite etwas um; diese Beschaffenheit erinnert zunächst an die Hügel der untern Backenzahne des Rhinoceros. In der mittlern Hugelspitze an der Innenseite treten der hintere Schenkel des vordern und der vordere Schenkel des hintern hufeisenförmig gekrümmten Kammes zusammen. Diese Spitze ist die stärkste von allen. In den bisher im Montmartre gefundenen Arten von Palcueotherium ist sie nur einfach, während sie in den aus der Gegend von Orléans, Montpellier, Argenton, Issel und Georgensgmund zweitheilig ist, und den Begriff eines Doppelhugels unterstützt, wie es denn auch zwei Schenkel sind, welche in ihr zusammentreffen, und von deren niedrigeren Kämmen sich der vordere deutlicher bis zur Höhe der Spitze hinaufzieht. Der hintere dieser beiden Spitzentheile endigt in zwei und der vordere in drei, am zweiten Backenzahn in vier Hübeln. Die hintere Hügelspitze an der Innenseite ist etwas 
niedriger, als die mittlere. Aber beide sind etwas schräg von hinten imnen nach vorn aussen in die beiden an der Imnenseite mündenden Thäler hineingerichtet. Die vordere und hintere Kronenhalfte bildet zwischen sich ein von der Doppelspitze nach der Aussenseite abfallendes und mündendes Thal. Ein analoges Thal liesse sich auch an den Rhinoceroszähnen nachweisen. Die hufeisenförmigen Krümmungen enthalten ein vorderes und ein hinteres, nach der Innenseite abfallendes und mündendes Thal; ihre Firste ist warzig. In der Kniebiegung dieser Krümmungen verstarkt und erhebt sie sich zu einer runden, in das Thal an der Innenseite sich verloren herunterziehenden Hügelspitze. Es lassst sich nicht läugnen, dass in den Rhinoceroszähnen etwas Aehnliches zu bemerken ist. Cuvier gibt die Annahme von Hügeln oder Spitzen an der Aussen- und Innenseite bei Palaeotherium nicht zu; er räumt sie nur Anoplotherium ein, bei dem er sich davon durch Keimzäne überzeugte. Wenn sie sich darin auch deutlicher darstellen mögen, so sind sie doch, nach dem, was ich so eben uber die Keimzahne von Palaeotherium Aurelianense vorbrachte, demselben keineswegs abzuisprechen. Diese Palaeotherienzahne besitzen einen Vorder - und einen Hinteransatz. Beide biegen sich nicht nach der Innenseite um, und stehen mit dem deutlichen Wulste an der Aussenseite, für dessen Fortsetzung sie gehalten werden können, in vollkommenem Zusammenhang. An der Innenseite liegen warzige Unebenheiten über der Basis, am deutlichsten vor der Mundung der beiden Thäler. Analog den letzteren Unebenheiten erhebt sich auch vor dem Thal an der Aussenseite der Wulst an der Basis etwas mehr. Der Hinteransatz ist der stärkere und complicirtere. Um ihn besser zu begreifen, habe ich den Zahn Fig. 61. c von der Seite abgebildet, über die der Wulst sieh hinzieht. Auf dieser Hinterseite der Backenzahnkrone tritt über der innern Hälfte ein kleiner Hügel heraus, und an seinem Fuss die Kante der Ansatzleiste, welche ununterbrochen in den Basalwulst an der Aussenseite fortsetzt. Diese Kante ist von ihrem Ursprung an uber letzterem Wulste bis zum Ende des Vorderansatzes fein gesäumt und körnig. Der Vorderansatz zeigt statt des kleinen Hügels nur eine etwas stärker körnige Beschaffenheit nach der Innenseite hin. Die Schmelzoberfläche ist an diesen umberührten Zähnen rauher, als an denen, die im Dienste der Abnutzung standen.

Nachdem nun die wesentlichen Theile der Zahnkrone an dem am besten dazu geeigneten mittlern Backenzahne hervorgehoben sind, lassen sich die Abweichungen leichter begreifen, welche hauptsächlich zwischen diesem und dem ersten und letzten grossen Backenzahn bestehen, ja selbst die Aehnlichkeit einsehen, die damit der kleine Backenzahn besitzt. Im ersten grossen Backenzahn ist die hintere Halfte ganz 
so beschaffen, wie in den auf ihn folgenden Zähnen; die Abweichung seiner vordern Hälfte beruht bloss auf verschiedener Ausdehnung von allen Zähnen gemeinsamen Theilen, was man freilich beim ersten Anblick nicht so gleich gewahr wird. Der vordere Schenkel der vordern hufeisenförmigen Krummung besitzt deutlichere Längsrichtung, und die eigentlich nur an Keimzähnen genauer wahrnehmbare vordere Hügelspitze an der Innenseite bildet hier einen wesentlichen Zahnkronentheil, indem sie als eine wirkliche Hügelspitze, die vordere Zahnkronenhalfte unterstützend, auftritt, was in darauf folgenden Zähnen weniger nöthig war, da diese durch vorsitzende Zähne geschuttzt werden. In diesem ersten grossen Backenzahn ist der Hinteransatz einfacher, als in mittleren Zähnen; es ist nämlich der kleine Huggel desselben von der Ansatzleiste nicht getrennt; letztere steht nicht so weit nach hinten ab, und ihre Kante führt bis zum Gipfel des kleinen Hügels hinauf. Dafür aber besteht in diesem Zahn der Vorderansatz aus zwei Theilen: aus einer Kante, welche sich vom vordern Hügel an der Innenseite nach vorn und hierauf nach der Innenseite herunterwendet, wobei sie in der halben Höhe der Zahnkrone endigt, und aus dem vom Basalwulste unzertrennlichen Theil, der sich vorn an der Aussenseite schräg herunterzieht. Unter der vordern Hügelspitze an der Aussenseite ist eine wulstfreie, und daher des nöthigen Schutzes ermangelnde Stelle an der Basis, wofür in zwei Drittel Höhe des Hügels selbst noch eine kleine Spitze sich vorfindet. Dieses sind die Abweichungen des ersten grossen Backenzahns von dem darauf folgenden. Sie beruhen nicht auf neu hinzugetretenen Kronentheilen, sondern nur auf einer deutlicheren Ausbildung gemeinsamer Theile der vordern Kronenhălfte der Backenzăhne, welche selbst auf Unkosten von Theilen der hintern Kronenhalfte geschah. Selbst aus nicht mehr Masse scheinen diese Zahne zu bestehen, als an mittlern ist, da die grössere Länge sich im schmälern, mehr gleichschenkeligen Dreieck ausgleicht. Wie ein der Abnutzung unterworfener Backenzahn der Art aussieht, ergibt sich aus Taf. VII. Fig. 56.

Der kleine Backenzahn ist auffallend kleiner, als die ubrigen, denen er sich auch in keinem Stück vergleichen zu lassen scheint. Oefter gleichen vordere Backenzähne eher denen von Fleischfressern, als von Pachydermen; eine solche Aehnlichkeit kann daher hier auch nicht weiter stören. Vergleicht man indess diesen kleinen Backenzahn mit dem ersten grossen genauer, so wird man finden, dass die Unähnlichkeit zwischen beiden bloss auf der Verschmelzung analoger Kronentheile beruht. Am kleinen Zahn sind drei Theile vorherrschend, welche sich dem Vorderansatz, dem mittlern Hügel an der Innenseite und dem Hinteransatz der grossen Backenzähne vergleichen lassen. 
Der mittlere Hügel steht mehr in der wirklichen Mitte der Zahnkrone und die hufeisenförmigen Krümmungen erscheinen mehr als Längskämme, von denen der eine von der Hügelspitze zum Hinteransatz, und der andere von derselben Spitze zum Vorderansatz herunterführt. Der hintere Kamm ist etwas länger, als der vordere, daher wird auch der Hügel hauptsächlich als eine Verschmelzung des mittlern und vordern Hügels an der Innenseite und vorderen Hügels an der Aussenseite anzusehen seyn. Vielleicht wird einst ein Keimzahn diese Vermuthung uber den kleinen Backenzahn bestätigen.

Ich habe nun den letzten Backenzahn darzulegen. Zwar besitze ich hievon keinen Keimzahn, aber doch einen Zahn (Taf. VII. Fig. 55), dessen Einzeltheile kaum berührt sind, und der sich daher gauz eignet. Die vordere Halfte dieses Zahns ist von der mittlerer Backenzăhne nicht verschieden; die hintere Hălfte aber besitzt ein complicirteres Ansehen, jedoch nur insofern scheinbar, als der Hinteransatz, hauptsächlich aber dessen kleiner Hügel, nur eine selbstständigere Entwickelung nach hinten besitzt, wo kein Backenzahn mehr folgt. Eine Vergleichung zwischen diesem hier freier entwickelten Hügel und dem kleinen beim Hinteransatz befindlichen Hügel der vorsitzenden Zăhne lässt über die Analogie beider keinen Zweifel kommen; diese Deutung wird auch noch dadurch unterstüzt, dass hinter diesem Huggel des letzten Backenzahns keine hintere Ansatzleiste folgt. In dem Thal zwischen diesem hintersten Hügel und der eigentlichen Zahnkrone bemerkt man noch eine kleine hügelige Verstårkung. Die freiere Entwickelung des letzten Backenzahns nach hinten hatte auf die Ausbildung des Zahns sonst keinen Einfluss. Für ihn scheint selbst nicht mehr Masse, als zu den grössern Zähnen überhaupt aufgewandt worden zu seyn, indem dafür der Zahn im Uebrigen etwas schwacher ist.

Aus dieser Entwickelung ist ersichtlich, dass das Palaeotherium zu den Thieren gehört, bei denen einer von den mittleren Zähnen für eine Art Grundform genommen werden kann, auf die sich die übrigen Backenzähne der Reihe, so verschieden sie auch aussehen mögen, zurückführen, oder nach dem sich dieselben beurtheilen lassen. Von dieser Grundform sind die übrigen Backenzahne, je nach der Stellung im Kiefer und dem Dienst, den sie zu verrichten haben, verschieden, doch nur entweder durch vorherrschende Entwickelung oder Unterdrückung gewisser Zahntheile.

Ich lasse nun die Beschreibung der von mir abgebildeten Zăhne dieser Palaeotheriumgattung folgen. Ich habe deren ausserdem so viele untersucht, dass ich sie unmöglich alle aufzählen kann.

Das Taf. VIII. Fig. 63. a von oben, b von aussen, c von hinten und d von vorn 
abgebildete Zähnchen besitzt unverkennbare Aehnlichkeit mit den untern Backenzahnen des Palceotherium Aurelianense. Es scheint aber dasselbe nur eine von beiden halbmond- oder hufeisenförmigen Krümmungen besessen zu haben. Die vordere seitliche Abnutzungsfläche fehlt, die hintere dagegen ist ausgebreitet vorhanden. Hienach ist der Zahn der erste grosse Backenzahn aus der rechten Unterkieferhăfte. Seine eigenthümliche Form aber und das krankhafte, stark abgenutzte Aussehen lassen in ihm den Milchzahn vermuthen. Die Wurzeln scheinen stark divergent gerichtet gewesen zu seyn.

Die drei Keimzahne Taf. VIII. Fig. 61. a von oben, b von der Innenseite und c der letzte derselben von der Hinterseite, sind der erste grosse und die zwei zunächst darauf folgenden Backenzahne aus der rechten Unterkieferhalfte. Sie sehen graulichbraun, an den Spitzen und Kanten etwas schwärzer aus.

Taf. VII. Fig. 56 ist, a von oben, b von vorn und innen und $c$ von hinten und aussen, wahrscheinlich der Ersatzzahn des ersten grossen Backenzahns aus der rechten Unterkieferhälfte.

Taf. VII. Fig. 55 ist der letzte Backenzahn aus der rechten Unterkieferhälfte, woran alle erwahnte Theile sich vorfinden werden, so gut ist er erhalten. Er ist a von oben, $b$ von vorn und innen und $\mathrm{c}$ von hinten und aussen gegeben.

Taf. VII. Fig. 59 scheint der vierte Backenzahn der Reihe, vielleicht der hinterste Ersatzzahn, aus der rechten Unterkieferhalfte, a von oben, b von vorn und c von hinten, noch im entsprechenden Kieferstïcke sitzend, zu seyn.

Von Taf. VII. Fig. 57 ist a ein Fragment von der linken Unterkieferhälfte mit dem letzten, vorletzten und der Wurzel des diesem vorgesessenen Backenzahns, so wie ein Fragment von der rechten Unterkieferhălfte mit den drei hintersten Backenzähnen von oben, ersteres in b von aussen, gesehen. Es rühren beide Fragmente unverkennbar - von einem Individuum her. Die starke Abnutzung, welche sich selbst uber die letzten Backenzähne verbreitet und das krankhafte. Aussehen der Zahne und des Kiefers, namentlich in der Gegend der Alveolen, verrath ein sehr altes Thier.

Taf. VII. Fig. 58 ist ein Fragment aus der rechten Unterkieferhälfte, mit dem letzten, vorletzten und dem diesem vorsitzenden, nur fragmentarisehen Backenzahn von der Seite gesehen. $\mathbf{Z}$ wischen dem letzten und vorletzten ist das Kieferfragment durch einen Bruch getrennt, der nicht später als die Erhärtung der Gesteiusmasse sich ereignet haben konnte. Das Fragment war von der Kalkmasse ganz bedeckt. Das Thier, von dem es herrührt, stand in dem besten Alter. 
Taf. VIII. Fig. 62 sind die drei ersten grossen Backenzähne ans der linken Kieferhălfte, a von oben und $b$ von aussen, und $\mathrm{e}$ dieselben aus der rechten Kieferhälfte von innen. Sie scheinen Ersatzzähne von einem und demselben Individuum zu seyn. Der Schmelz ist an den Erhabenheiten noch nicht durchgenutzt.

Taf. VII. Fig. 53 ist die linke Unterkieferhalfte mit den sechs grossen Backenzăhnen und dem kleinen Backenzähnchen, letzteres ergänzt, a von aussen und b von innen dargestellt. Bei letzterer Abbildung bemerkt man das kleine Backenzähnchen aus der rechten Unterkieferhalfte mit seiner Ansicht von aussen $(\alpha)$, von innen ( $\beta$ ), von hinten $(\gamma)$ und von oben $(\delta)$. Fig. 54 ist ein Fragment des rechten Unterkiefers mit den grossen Backenzähnen, den ersten ausgenommen, von der Aussenseite; beide Kieferhalften rühren unbezweifelt von einem Individuum her und sind auch zusammen gefunden. Sie sind stark seitlich gepresst, durch Druck, der nicht viel spatter, als die Zeit ihrer Ablagerung, konnte auf sie eingewirkt haben. Daher ist auch der Knochen des Kiefers sehr zersprungen. Der kleine Backenzahn hat nur eine Wurzel, die stark und oval ist. Die übrigen Backenzähne haben zwei der Quere nach breite Wurzeln. Mit der hintern Wurzel des letzten Backenzahns ist noch ein Wurzeltheil vereinigt, der den hintersten Hugel stutzt. Die Länge des Raumes, welche die sieben Backenzähne der Reihe einnehmen, beträgt 0,114. Meine Abbildungen sind genau in natürlicher Grösse ausgefuhrt, und überheben mich daher der Auffuhrung von Dimensionen der einzelnen Zähne.

Das Stückchen Taf. VII. Fig. 60 ruhrt aus der rechten Unterkieferhalfte her, kann also zur Ergänzung ebengenannter Fragmente dienen. Es sitzt darin der kleine Backenzahn mit dem ersten grossen Backenzahn. Dem kleinen Backenzahn geht ein zahnloser Baum vorher. Dabei senkt sich der Kieferknochen stumpfkantig vom kleinen Backenzahn ein wenig herunter, läuft aber hierauf gerade oder unmerklich aufwärts nach vorn. Die wahre Länge dieses zahnlosen Raumes kann aus diesem Fragment nicht ermittelt werden.

In dem Kiefer Fig. 53 liegt das Gefassloch unter dem zweiten grossen Backenzahn, dagegen in einem andern Kieferstuck, das ich nicht weiter abzubilden für nöthig fand, unter dem ersten grossen Backenzahn mehr nach der hintern Wurzel desselben, also weiter vorn. Letzteres Fragment ist nicht gedruekt und daher geeignet, uber die Form des Kiefers Aufsehluss zu geben. Derselbe ist an der Aussenseite, besonders unterwärts, starker gewölbt, als an der Innenseite, wo er flacher ist. Seine untere Grenze ist nach innen gerundet und biegt sich unter dem Anfang des ersten 


\section{$-88-$}

grossen Backenzahns an der Innenseite merklich einwärts. Etwas Aehnliches sieht man an dem Kieferstük Fig. 59. Ersteres Fragment reicht nicht bis zur Symphyse, ich kann daher nichts über die Vereinigung beider Halften anfuhren. Folgende Ausmessungen liessen diese Fragmente zu:

Höhe unter dem ersten grossen Backenzahn an der Aussenseite 0,025

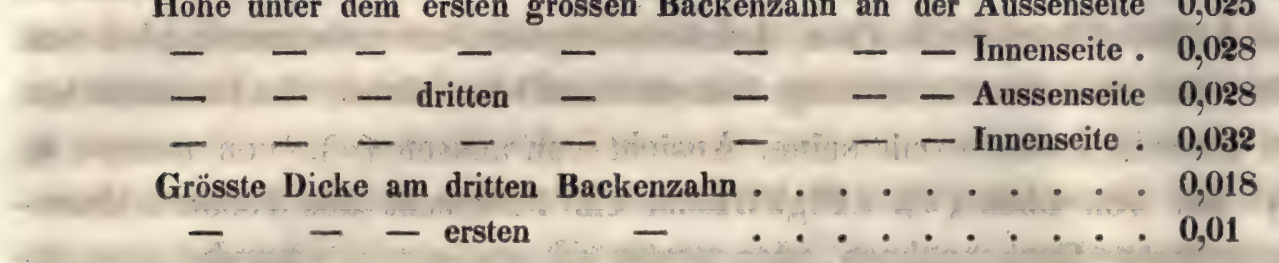

Backenzähne aus dem Unterkiefer sind von mir noch viele untersucht worden, die unmöglich alle hier aufgeführt werden köunen. Ich will nur anführen, dass darunter sich einige befinden, die eine verhältnissmässig niedrigere Krone besitzen und sich überhaupt durch ein weit schmächtigeres Aussehen von den übrigen auszeichnen; sind diess Milchzähne? Dabei besitzen sie Hinneigung zum Palaeotherium Isselumum *), dem sie sich jedoch weniger anschliessen lassen, als dem Palaeotherium Aureliunense, von dem ich sie daher auch ohne weiteren Grund nicht trennen mochte.

Sämmtliche Zähne und Kieferfragmente rubren von Thieren sehr verschiedenen Alters her, und aus verschiedenen Schichten, welche theils aus festem, zelligem, weissem Lacusterkalk, theils aus einer weichern Kalk - oder Mergelmasse von Ocherfarbe bestehen.

$$
\text { S c h } n \text { e i d e z ä h } n \text { e. }
$$

Unter einer Menge vereinzelter Backenzahne des Palaeotheriums fand ich den Taf. VIII. Fig. 70. a von oben, b von aussen, e von hinten, d von der linken Seite und e von der rechten Seite abgebildeten Schneidezahn vor. Ich lege ihn dem Palaeotherium Aurelianense bei. Es ist daran ein Theil vorhanden, der dem an der Basis der untern Backenzahne besagten $\boldsymbol{P}$ alaeotheriums befindlichen Wulste analog ist. Die Abnutzung auf der Schneide war noch nicht weit vorgerückt. Der napfförmig vertiefte Theil seiner Krone ist noch unberuhrt. Es sind am Zahn zwei seitliche Abnutzungsflächen vorhanden und in der Abbildung (d, e) auszudrücken versucht worden. Der Zahn war daher ein mittlerer Schneidezahn und, wie ich vermuthe, ein vorderer. Bei einer spatern Sendung des Herrn Grafen zu Münster fand ich noch die beiden

*) Cuvier, Oss. foss. III. S. 25\%. t. 67. f. 18. 
Taf. VIII. Fig. 69. 71 abgebildeten Schneidezähne. Am grössern derselben ist der napfförmige Theil nicht ganz so tief, als am vorigen. Die Schneide ist nicht viel mehr abgenutzt; auch er besitzt zu beiden Seiten eine Abnutzungsflache, doch nicht so stark, als der vorige. Ich halte daher diesen Zahn für einen mittlern Schneidezahn von den dreien einer Kieferhalfte oder fur den zweiten. Der kleinere Zahn besitzt wieder ganz dieselben Theile. Er ist kleiner, etwas schiefer, weniger abgenutzt und nur auf seiner höhern Seite mit einer seitlichen Abnutzungsflăche versehen, wesshalb er unbezweifelt der hintere Schneidezahn ist. Dieses Palaeotherium hätte demnach in einer Kieferhälfte drei Schneidezähne gehabt, die im Vergleich zu den Backenzähnen nicht besonders gross waren.

Man könnte zwischen dem hintern Schneidezahn und dem Zahn Taf. VIII. Fig. 74 einige Analogie auffinden; ich wüsste freilich nicht, wo letzterer beim Palaeotherium gesessen haben sollte.

\section{B a ckenzähne a s dem oberkiefer.}

Die Backenzähne aus dem Oberkiefer fanden sich seltener, als die aus dem Unterkiefer. Von Keimzähnen kenne ich nur das Taf. VIII. Fig. 64. a von innen und b von der Seite abgebildete Fragment. Es ist die Aussenseite eines Zahns aus der linken Oberkieferhälfte. Zu deutlicher Darlegung der Form und Structur der oberen Backenzähne glaubte ich einen unberuhrten, wahrscheinlich der zweite Zahn aus der linken Kieferhälfte (Taf. VIII. Fig.65), und zwei theilweise abgenutzte, wahrscheinlich der zweite und dritte aus der linken Kieferhälfte, a von oben, $b$ von innen, $c$ von aussen, $d$ von hinten und e von vorn, abbilden zu sollen.

Die oberen Backenzăhne sind quadratisch, etwas breiter als lang, an der Vorderseite etwas länger, als an der Hinterseite, was hauptsächlich von einem hügelartigen Theil an der von der Vorder - und Aussenseite gebildeten Ecke herrührt, der an der entsprechenden hintern Ecke fehlt. In den oberen Backenzähnen rhinocerosartiger Thiere ist etwas Aehnliches wahrzunehmen; überhaupt besitzen letztere mit den vorliegenden noch manche andere Analogie. Die Backenzahnkrone kann aus vier Haupthügeln bestehend betrachtet werden; zwei derselben liegen an der Aussen- und die zwei andern an der Innenseite. Die Hugel an der Aussenseite sind höher, als die an der Innenseite, und etwas nach innen gekrümmt. Thre eigenthümliche Form işt besonders aus Fig. 64 ersichtlich. Die Kante, welche die Spitzen beider Hügel zickzack- 


\section{$-90-$}

förmig verbindet, ist am Keimzahn (Fig. 64) fein gesäumt und körnig. Zwischen diesen beiden Hügeln tritt an der Aussenseite ein hügelförmiger Theil hervor, welcher dēm an der von der Vorder - und Aussenseite gebildeten Ecke analog ist. Die Zahnkrone lasst sich in Hälften zerfälen, die einander ahnlich sind. Hienach lässt sich ausser der bereits erwähnten, auch noch die Aehnlichkeit der beiden Hügel an der Innenseite und zweier Kämme annehmen. Von diesen Kämmen zieht der eine von dem vordern hügelförmigen Theil an der Aussenseite, der andere von dem in der Mitte dieser Seite befindlichen hügelförmigen Theil, etwas schrag und unter sanfter Biegung, jeder zu dem entsprechenden Hügel an der Innenseite, in dessen Spitze er endigt. Es lässt sich nicht läugnen, dass auch in diesen Querkämmen Aehnlichkeit mit den oberen Backenzăhnen rhinocerosartiger Thiere besteht, doch ohne sonstige Uebereinstimmung in der Anordnung der Theile. Ich habe ferner einer Unebenheit zwischen dem hintern Querkamm und der Hinterseite des Zahns zu gedenken, die auch in oberen Rhinoceroszähnen vorkommt; sie besteht in einem kleinen winkelförmig gebogenen, an der Winkelspitze eingeschnittenen Kamm. Die Querkämme neigen in ihrer ungefähren Mitte zum Hügeligen. Die Basis der Krone ist bei einigen Zähnen mit einem vollstăndigen Wulst umgeben. An der Aussenseite zieht er sich an den hügelförmigen Theilen hinauf und verläuft sich in ihren Spitzen. Der Wulst an der Vorder- und Hinterseite wird die Bedeutung des Ansatzes haben. Andere Zahne scheinen von einem solchen Wulste frei; und an ihrer Vorder - und Hinterseite nur durch eine Wulstleiste geschlossen zu seyn. Dagegen gibt es wieder andere, die nicht allein einen Wulst an der Innenseite, sondern noch vor dem Thal zwischen den an dieser Seite liegenden Hügeln eine besondere wulstige Unebenheit liegen haben. Sonst bestimmt nichts, in diesen Zähnen verschiedene Gattungen vorauszusetzen; sie scheinen vielmehr sämmtlich nur einer Gattung anzugehören, in der die wulstigeren Zähne mehr nach vorn, die wulstarmern mehr nach hinten in der Reihe sassen. Die Uebereinstimmung, welche sich in diesen Verschiedenheiten an den oberen Backenzähnen mit Rhinoceros incisivus darbietet, ist wirklich auffallend, und bringt beide Thiere hierin einander näher.

Eine spăter untersuchte innere Hälfte von einem Keimzahn rechter Kieferhalfte weist aus, dass darin die Kämme, Hügel, Spitzen und Kanten scharf, gesäumt und feinhöckerig, und hierin den untern Keimbackenzăhnen ganz ähnlich sind. Der Abfall der Kämme und Hügel ist hinterwärts etwas steiler, und der winkelförmige Theil an der hintern Zahnseite hat in sich noch einen kleinern, diesem ähnlichen Theil liegen, der durch die Abnutzung bald verschwindet. Ein anderes Keimzahnfragment zeigt 


\section{$-91-$}

von diesem kleineren Theile nichts, und scheint daher einem in der Reihe weiter vorn gesessenen Zahn, angehört zu haben.

Die Zähne Taf. VIII. Fig. 65 u. 66 unterscheiden sich von den übrigen durch eine längere Aussenseite. Der Grund hievon ist, dass der am äussern vordern Eck liegende hügelförmige Theil mehr nach vor, als nach aussen gervickt, und auch ein deutlicherer Hügel ist. Dieses Auftreten eines dritten Hügels an der Aussenseite ist vergleichbar einer ähnlichen Erscheinung an der Innenseite des ersten grossen Backenzahns im Unterkiefer, und beruht wohl auf derselben Ursache, auf dem Mangel eines vorsitzenden grossen Backenzahns. Dass aber diesen $\mathbf{Z a ̈ h n e n ~ g l e i c h w o h l ~ n o c h ~ e i n ~ Z a h n ~ v o r g e s s e n , ~}$ beweist die Gegenwart der seitlichen Abnutzungsflache an der Vorderseite.

Die hinter solchen Zähnen folgenden Backenzăhne sind ungefâhr unter sich gleich gestaltet. Der kleinste Zahn unter ihnen ist Taf. VIII. Fig 67. a von oben, b von innen, $c$ von hinten, $d$ von vorn und e von aussen abgebildet, 0,015 lang, 0,02 vorn und 0,013 hinten breit, und zeigt von den übrigen nur darin Abweichung, dass die Stelle, wo der hintere Querkamm zur Hügelbildung neigt, năher an dem hintern Hügel der Innenseite liegt, und dass von dieser Stelle sich wirklich ein Huggelchen zu den Unebenheiten zwischen dem hintern Querkamm und der Hinterseite erhebt. Es ist diess vielleicht ein Kennzeichen des letzten Backenzahns. Der Zahn rührt übrigens aus der rechten Oberkieferhälfte her.

Durch Abnutzung verändert sich die Form der einzelnen Theile dieser Backenzähne sehr; die Hügel werden abgetragen, die Kämme offnen sich, und beide treten mit einander in Zusammenhang.

Diese Zăhne besitzen drei Wurzeln, zwei einfachere, an jedem Eck der Aussenseite eine, und eine complicirtere, stärkere, an der Innenseite.

In der Beschaffenheit des Schmelzes sind sie den untern Backenzähnen ähnlich. So gleicht auch die Farbe der Keimzahnfragmente genau der der Keimzahne aus dem Unterkiefer.

In Betreff der Grösse vermuthet Cuvier, dass das Palceotherium Aurelianense etwas kleiner sey, als das Palueotherium medium.

Wären die Abbildungen bei Cuvier mit der erforderlichen Genauigkeit und Schärfe ausgeführt, so würde ich vielleicht im Stande seyn, über den Taf. VIII. Fig. 68 abgebildeten Zahn mich gewisser auszusprechen. Die grōsste A ehnlichkeit besitzt 
damit der Eckzahn, den Cuvier ${ }^{*}$ in einem Schadelfragmente von Pulueotherium medium mittheilt. Der Zahn von Georgensgmund ist nicht starker, als dieser. Ich glaube auch in dem bei Cuvier abgebildeten Zahn den scharfen Grath an der Unterseite und die Eingezogenheit der Wurzelform zu erkennen. An der Abbildung des Schadels von Palaeotherium grassum ***; scheint dieses sich bestatigen zu lassen, und auch die Art der Lage eines solchen Eckzahns im Kiefer ersichtlich zu seyn, die schweinsartig nach aussen gerichtet war, so dass die Abnutzungsfläche mehr nach vorn zu liegen kam. Die Grössenverwandtschaft, welche zwischen Palaeotherium medium, Palaeotherium grassum und Palueotherium Aurelianense besteht, bestärkt die Vermuthung, dass dieser Zahn von letzterem Thiere herruhre und sein Eckzahn sey, der alsdann in der linken Oberkieferhälfte gesessen hat. Er wäre für diesen Fall a von innen, b von aussen, c von der Abnutzungsfläche und d im Querdurchschnitt dargestellt. Er besitzt zwei deutliche diametrale Langskanten. Cuvier dagegen behauptet, der Eckzahn des Oberkiefers habe in den Palueotherien nur eine Längskante. Vielleicht macht hievon Pulaeotherium Aurelianense eine Ausnahme, dessen Backenzahne ohnehin von den im Pariser Gypse vorkommenden Gattungen fast mehr als specifisch verschieden sind. Zwar besitzen die unteren Eckzahne der Palaeotherien nach Cuvier zwei Langskanten, dabei aber die innere Flăche etwas ebener, die aussere mehr halbconisch und um die Basis einen Wulst; von diesem Allen ist an vorliegendem Zahn nichts wahrzunehmen. Der Zahn ist gut erhalten und hellbraun.

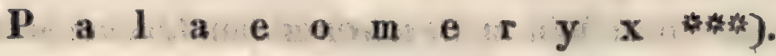

Warum, so fragte man noch kürzlich, warum findet man keine fossile Fleischfresser und Wiederkäuer, welche von den lebenden generisch verschieden sind, während doch andere Wirbelthierordnungen, die mit ihnen in demselben Gebilde oder gleichzeitig abgelagert sind, so reich erfunden werden an untergegangenen Genera? Bei dem Reichthum an erloschenen Typen, die namentlich für die Ordnung der Pachydermen schon so weit aufgedeckt sind, musste es wirklich auffallen, Reste von Thieren anderer Ordnungen mit ihnen vorkommen zu sehen, die nicht auf ahnliche Weise von

*) Cuvier, Oss. foss. III. t. 3. f. 1. S. 28.

the) Cuvier, Oss. foss. III. t. 53 f. 1. t. 54 f. 1.

*\$*) Mñ pvว , Name eines vermeintlich wiederkäuenden Fisches der Alten. 
ihren Analogen späterer Zeit und den lebenden verschieden waren. Freunde der Hypothesen fanden hierin schönen Stoff zur Bebauung ihres ephemeren Feldes.

Fragen wir aber nach dem Grund dieses Missverhältnisses, so finden wir, dass es bloss scheinbar ist, und auf mangelhafter Beobachtung beruht. Früher schon lagen Reste von Fleischfressern vor, ohne dass man, was merkwürdig, im Stande gewesen wäre, zu erkeunen, dass sie, wie es sich jetzt erst zeigt, wirklich eigenthumlichen, lebend nicht gekannten Genera angehören. Reste von erloschenen Fleischfressergenera sind eigentlich nicht viel später aufgefunden, als die der Pachydermen; man war nur erst später im Stande, ihren wahren Werth zu erkennen, und jetzt, wo die grösste Schwierigkeit uberwåltigt, die Bahn zu ihrer Erkennung gebrochen ist, jetzt sehen wir die Fleischfresser nicht länger mehr mit ihrem Reichthum vorweltlicher Typen zurückstehen. Von Wiederkäuern aber glaubte vor einiger Zeit Bojanus oin

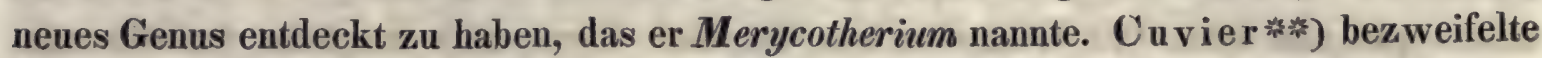
indess, dass die Zähne, wonach das Merycotherium Sibiricum errichtet ward, einem andern Thier, als einem Camel angehörten, wie es denn auch nicht hinlänglich erwiesen werden konnte, ob die Zähne wirklich fossil seyen. Es bestünde sonach kein Wiederkảuergenus, das unbezweifelt nur vorweltlich wăre.

Taf. IX. u. X. Fig. 75. 77-80 stellen aus der Gegend von Georgensgmünd fossile Zähne und Kieferfragmente dar, welche von Thieren aus der Ordnung der Wiederkäuer herruhren, die aber offenbar von den bekannten generisch verschieden sind. Das Unterkieferfragment Taf. X. Fig. 77 lässt fünf wirklich vorhandene Zähne erkennen, und die Grösse und Beschaffenheit des ersten derselben lässt noch auf einen sechsten schliessen, der mit den andern auch in Berührung stand, so dass die Zahl der in einer Reihe sich berührenden Backenzähne nicht unter sechs war. Sechs Backenzähne sitzen in der Unterkieferhälfte der Giraffe, der Hirsche, der Antilopen, der Schafe, der Ochsen und des Moschus zusammen, während ihrer im Camel nur fünf sind, von denen einer in der Nahe des Eckzahnes sich befindet. Bei den Lama's fehlt selbst dieser fünfte Backenzahn. Ich bedaure um so mehr, über Zähne aus dem Vordertheil des Kiefers von dem fossilen Thier nichts mittheilen zu können, als gewöhnlich auch in diesem Theil des Zahnsystems sich die Wiederkäuer mit weniger Backenzähnen von denen mit sechs in einer Reihe unterscheiden, und namentlich der Moschus von den

*) Bojanus, Nova Acta Acad. Leop. Carol. Nat. Cur. XII. 1. S. 263. 333. t. 21. f. 1-8.

*) Cuvier, Oss. foss. V. 2. S. 507. 
übrigen mit sechs Backenzahnen verschieden ist. Diess hindert indess nicht, schon allein aus der Beschaffenheit der fossilen Backenzähne unzweifelhaft darzuthun, dass die Thiere derselben nicht allein den sechszähnigen, sondern allen bekannten Wiederkäuern unähnlich sind.

Vom Moschus unterscheiden sie sich schon durch den letzten Backenzahn im Unterkiefer, der eher dem der andern Wiederkäuer vergleichbar, d.h. complicirter ist, als die ihm vorsitzenden Zähne, während der letzte Backenzahn im Moschus die Form mittlerer Backenzahne besitzt**); was um so mehr auffallt, da die mittlern fossilen Zahhe der Reihe sich in Betreff der allgemeinen Form noch am ersten denen im Moschus vergleichen lassen. Die fossilen Zähne zeichnet hauptsächlich auch eine gedrängtere Kronenhöhe aus. Die drei hintern untern Backenzähne besitzen im Allgemeinen die Structur wie in den Hirschen und Antilopen, unterscheiden sich aber von diesen und von allen Wiederkäuern hauptsächlich durch eine deutliche wulstförmige Erhabenheit, welche an der Hinterseite des vordern halbmondförmigen Theils an der Aussenseite nach der Mitte der Zahnkrone herunterlauft. Diesen charakteristischen Theil habe ich selbst an Moschus pygmaens nicht vorgefunden. Z War könnte man am vordern Halbmond des dritten untern Backenzahns einen wulstförmigen Theil der Art vermuthen. Die genauere Vergleichung indess hebt diesen Anschein wieder auf, den ich in den andern Backenzahnen auch nicht weiter angetroffen habe. Die vordern fossilen Backenzähne sind weit ahnlicher denen in den Hirschen und Antilopen, als im Moschus; die des letztern sind schmäler und, wie es scheint, länger und schneidender.

Ueber die fossilen Backenzähne von Wiederkäuern, welche aus der Gegend von Georgensgmünd herruhren, habe ich nun noch folgende nähere Angabe zu machen. Der Theil, welcher vor dem von den beiden Halbmonden an der Aussenseite gebildeten Thale liegt, ist von namhafter Breite und besteht nicht so wohl in einer runden, als in einer dreiseitigen Hügelspitze, die bis zur ungefăhren halben Höhe der Halbmonde sich erhebt. In den Wiederkäuern ist dieser Theil gewöhnlich eine fast bis zur Zahnhöhe ragende Rohre oder ein cylindrischer Theil. Die fossilen Zähne scheinen überhaupt verhaltnissmässig breiter oder weniger lang, von etwas geringerer Höhe und von zierlicherer Ausbildung zu seyn. Die Halbmonde an der Aussenseite sind spitzwinkeliger, und die beiden Hauptspitzen an der Innenseite scheinen sich höher zu erheben. Die Nebenspitzen an der Inuenseite, namentlich die, welche zur vordern Haupispitze gehört

*) Vergl. F. Cuvier, Des dents des Mammifères etc., tab. 93. 
oder zwischen den beiden Hauptspitzen liegt, sind deutlich als conische Spitzen entwickelt. Die Abbildungen werden, wie ich glaube, dieses Alles gut versinnlichen. An dem Tafel X. Fig. 78 dargestellten Zahn, dem vorletzten aus der linken Unterkieferhälfte, hat die Abnutzung kaum begonnen; er ist daher auch zur Darlegung der Einzeltheile ganz geeignet. Der letzte Backenzahn lag noch nicht fest an ihm an. Vorn und hinten besitzt der Zahn einen deutlichen Ansatz. Die auf der Basis vor dem Thale zwischen den beiden Halbmonden an der Aussenseite aufsteigende Spitze ist noch unberuhrt; sie zeigt in diesem Zustande noch ein kleines. Anhägsel nach aussen und dem hintern Halbmonde hin, das aber durch den Dienst der Zähne bald verschwindet.

Im letzten Backenzahn tritt noch als hinterster Theil ein Halbmond auf, der etwas kleiner als die beiden an der Aussenseite, und hinten etwas mehr nach innen gerichtet ist. Ich habe diesen Theil im Kieferfragmente Taf. X. Fig. 77 deutlich auszudrücken versucht. Durch Abnutzung entsteht eine Fläche, denen der Halbmonde an der Aussenseite sehr ăhnlich, wie diess der Zahn Taf. X. Fig. 79 versinnlicht. Hinter diesem hintersten Theil des letzten Backenzahns sind noch Andeutungen vom hintern Ansatz zu bemerken, und zwischen dem hintern Halbmonde und dem hintersten Theil vor dem Thal an der Aussenseite eine Spitze, welche der Spitze vor dem vordern Thal dieses Zahnes analog ist. Die complicirtere Gestalt des letzten Backenzahns beruht also hier auf wirklichem Hinzutreten von Zahnkronentheilen, was Moschus nicht zeigt. Der letzte Backenzahn hat zwei Wurzeln, eine zweifache unter dem vordern Theil und eine dreifache unter dem hintern und hintersten Theil. Die Zähne vor dem letzten Backenzahn besitzen zwei Wurzeln, welche zweifach sind, eine unter der vordern und eine unter der hintern Halfte.

Der Zahn vor den drei hintern sieht einfacher aus, er gleicht in den beiden Kieferfragmenten, welche meine Untersuchungen leiten, dem analogen Ersatzzahn in den Antilopen und in einigen Hirschen, weniger den vorderen Backenzähnen im Moschus, da diese schmăler und, wie es scheint, länger und schneidender sind. Der fossile Zahn ist im Vergleich zu den hinteren einfacher. Seine höchste Stelle, welche in der Mitte der Innenseite liegt, scheint durch die vorherrschendere Ausbildung der conischen Nebenspitze an dieser Seite und Verringerung der beiden Hauptspitzen, zwischen denen jene Spitze liegt, entstanden zu seyn oder gedeutet werden zu können. Das Thal an der Aussenseite führt nur als eine schwache Furche an der Zahnkrone hinauf. Diese Seite hat ein geräderes Aussehen, der vordere und hintere Ansatz ist verringert, der 
Zahn wird nach vom schmaler, und die Krone sieht uberhaupt im Vergleich zu den hinteren Zähnen schärfer aus.

Die übrigen Backenzähne der Reihe sind mir nicht bekannt. Die Dimensionen der bereits erwahnten fossilen Zähne sind, wie folgt:

\begin{tabular}{|c|c|c|c|c|}
\hline & Fig. $7 \pi$. & Fig. 38 & Fig. 89 & Fig. 75. \\
\hline Länge des letzten Backenzahns & $\overline{0,023}$ & - & 0,029 & \\
\hline Breite desselben & 0,013 & - & 0,0135 & \\
\hline Länge des vorletzten Backenzahns & 0,017 & 0,019 & 0,019 & 0,0 \\
\hline Breite desselben $\ldots \ldots$ & 0,013 & 0,013 & 0,014 & 0,014 \\
\hline Länge des Backenzahns vor den drei hintern & 0,017 & - & - & 0,02 \\
\hline Breite desselben & 0,009 & - & - & 0,011 \\
\hline & I. & II & III. & IV. \\
\hline
\end{tabular}

Diesen Dimensionen wird ihr wahrer Werth erst beigelegt, und sie weichen mehr von einander ab, wenn man bedenkt, dass der letzte Backenzahn von I. kaum durch Abnutzung beruhrt ist, während der von III. schon lange im Dienste stand, wobei er, was die starke Abnutzung an der Vorderseite ersehen lässt, etwas kürzer ward, so dass man fur seine, dem letzten Zahn von I. vergleichbare Lange 0,03 annehmen kann. Um eine richtige Dimension für den zweiten Zahn von Numiner III. zu erhalten, kann der angemerkten Zahl wenigstens eben so viel zugezählt werden. Die Gleichheit der Lange des zweiten Zahns von II. und III. beruht darauf, dass der Zahn von II. so gut wie gar nicht durch seitliche Abnutzung verkürzt ist. Wird dieses berücksichtigt, so erhält der Zahn von II. dieselben Dimensionen, wie der vorletzte von I. Der vorletzte $Z$ ahn von IV. ist nur deshalb länger, weil er weniger seitlich abgenutzt ist.

Sonach liessen sich die Zähne in zwei Abtheilungen bringen. In die eine würden die Zähne von Nummer I. und II. kommen, und in die andere die Zähne III. und IV. Eirstere Abtheilung würde ein verhältnissmässig etwas kleineres Thier, als letztere, amzeigen. Die Zähne sind übrigens ganz ähnlich geformt, nur finde ich an dem vor den drei hinteren sitzenden Zahn von IV. in der Furche, welche das Thal der hinteren Zähne vertritt, einen feinen Wulst sich herunterziehen, den man an dem analogen Zahn von I. nicht bemerkt.

In der Voraussetzung, dass diese constante, und keineswegs unmerkliche Grössenverschiedenheit zwei Species anzeigt, nenne ich die grössere, zu der Taf. IX. Fig. 75 und Taf. X. Fig. 79 gehört, 


\section{- $98-$ \\ Palaeomeryx Bojani,}

und die kleinere, zu der Taf. X. Fig. 77 u. 78 gehört,

$$
\text { Pa lae omeryx Ka upii. }
$$

Die Grösse dieser Thiere wird zwischen dem Renn und Cervus Elaphus liegen.

Herr Graf zu Münster schrieb mir später, dass er noch ein linkes Unterkieferfragment von diesem neuen Wiederkäuergeschlecht erhalten habe, mit dem ersten Backenzahn und dem darauf folgenden; die Zähne seyen aber nur den vierten Theil so gross, als die kleineren mir bekannten, und rührten daher wohl von einer neuen kleinern Gattung her. Ich kenne diese Reste noch nicht näher. Hienach wären vielleicht drei Gattungen Palaeomeryx zu unterscheiden.

Aus dem Oberkiefer kenne ich von diesem Wiederkauergenus bis jetzt nur einen Zahn, den ich glaube Taf. X. Fig. 80 von verschiedenen Seiten hinlänglich deutlich abgebildet zu haben. Dieser Zahn sass in der rechten Oberkieferhälfte, und war entweder der erste von den drei hinteren oder der letzte von den drei vorderen Backenzähnen. Dieser obere Backenzahn unterscheidet sich in denselben Theilen vom analogen der lebenden Wiederkäuer, worin die untern fossilen Backenzähne von den analogen der lebenden verschieden sind. In dem fossilen obern Zahn sind die Halbmonde an der Innenseite spitzer gekrümmt, und die Nebenspitzen an der Aussenseite auffallend stark und conisch, was namentlich von der mittlern gilt. Diese Spitzen sind in den lebenden Wiederkäuern mehr feine Lăngscylinder, und gleichen eher denen in den Pferdezähnen. Die mittleren Zähne des Moschus haben hierin noch die grösste Aehnlichkeit mit dem fossilen. Wie in den untern Backenzähnen von dem vordern Halbmonde an der Aussenseite, so führt bei diesem obern Backenzahn von dem vordern Halbmonde an der Innenseite ein Wülstchen nach der Mitte der Zahnkrone herunter. Dieses Wülstchen ist im obern Backenzahn noch deutlicher, als im untern, und dabei schärfer ausgedrückt. An keinem andern Wiederkäner, selbst an Moschus nicht, war dieser Theil zu bemerken. An der Innenseite der Backenzahnkrone liegen Andeutungen zu einem schwachen Wulste an der Basis.

Nachdem ich meine Untersuchungen uber diese Zăhne von Wiederkäuern beendigt hatte, war ich begierig, jene Zähne genauer kennen za lernen, welche das Naturalienkabinet in Darmstadt aus der Ablagerung von Eppelsheim besitzt. Bei meiner Anwesenheit in Darmstadt theilte mir Herr Dr. Ka up mit, dass er ein neues Wiederkäuergenus, Dorcatherium, entdeckt habe. Das Dorcatherium besitzt Backenzähne 
in der Reihe einer Unterkieferhälfte. Die zwei ersten Backenzähne sind nur durch ihre Alveolen nachgewiesen, und noch nicht selbst gefunden. Was diese fossilen Reste von den analogen Theilen in den lebenden Wiederkäuern unterscheidet, und Kaup bewog, sie einem neuen Genus beizuzahlen, ist, dass die Backenzähne nicht nur um einen vermehrt sind, sondern sich auch bis über die Kinnsymphyse erstrecken, wăhrend sie in den lebenden Wiederkäuern dieselbe nicht erreichen. Er nimmt zwei Gattungen an : Dorcatherium Naui, wovon eine, mir noch nicht näher bekannte Beschreibung mit Abbildung, über den grössten Theil des Unterkiefers handelnd, in den Annales des Sciences naturelles erscheinen soll, und Dorcatherium Meyeri (fruher D. crassirostris). Bei letzterer Gattung finde ich, dass die Zähne ungefähr ein Serhstel grösser, und der Kiefer weniger hoch und breiter oder stärker, als in ersterer ist. Es ist davon der vorletzte und der ihm unmittelbar vorsitzende Zahn in der linken Unterkieferhälfte bekannt. Meine Vermuthung, dass die eigenthümliche Stellung der Backenzahnreihe zur Kinnsymphyse mit Eigenthümlichkeiten in der Structur der Zahnkrone verbunden seyn werde, fand ich wirklich bestätigt. Die Structur dieser Backenzăhne ist von der in den bekannten lebenden Wiederkäuern und selbst von der in meinem Palaeomeryx verschieden. Suche ich die Zahntheile, welche ich an letzterem hervorgehoben, auch hier auf, und stelle ich damit die gehörige Vergleichung an, so finde ich denkwürdige Abweichungen, welche schon fur sich allein berechtigt haben würden, das anfänglich bloss aus der Erstreckung der Backenzähne bis über die Kinnsymphyse erkannte Wiederkäuergenus anzunehmen. Ueber die Structur habe ich Folgendes beobachtet. Den untern Backenzähnen des Dorcatheriums mangelt die an der vordern Hügelspitze oder zwischen beiden Hauptspitzen an der Innenseite liegende conische Spitze, welche in meinem Palaeomery $x$ so deullich entwickelt ist, ganzlich. Die wulstförmige Erhabenheit an der Hinterseite des vordern halbmondförmigen Theils in den untern Backenzähnen des Palueomeryx ist im Dorcatherium zur Bedeutung des hinteren Schenkels des vordern Halbmondes gesteigert, und steht in unmittelbarer Verbindung mit dem vordern Schenkel des hintern Halbmondes. Dabei ist die Verbindung des Theils, welcher eigentlich die Bedeutung des hintern Schenkels des vordern Halbmondes besitzt, mit der hinteren Hauptspitze an der Innenseite mehr unterstützt, und in der Vereinigungsstelle tritt auch noch der hintere Kamm der vordern Hauptspitze an der Innenseite hinzu. Zwischen diesem Kamm und der eigentlichen Spitze läuft eine tiefe Furche. Hiedurch besitzt das Ende der vordern Halfte der Backenzahnkrone im Unterkiefer des Dorcatheriums, von oben gesehen, die von Palueomeryx ganz abwei- 
chende Gestalt eines $\Sigma$ ). An der hintern Halfte des hintern halbmondformigen Theils liegt, wenigstens an den letzteren Backenzähnen des Dorcatheriums, auch ein wulstförmiger Theil, der dem am vordern Halbmond in Palaeomeryx verglichen werden kann. Ueberdiess sind die Zähne ersterer Art noch um ein Drittel kleiner, als die meines kleinern Palaeomeryx. Sonach wäre die Existenz beider Genera erwiesen. Besass Palaeomeryx auch sieben Backenzähne in einer Reihe, und gingen dieselben ebenfalls über die Kinnsymphyse? Hierüber, oder wie der vordere Theil des Kiefers überhaupt beschaffen war, vermag ich, in Ermangelung passender Stücke, noch nichts mitzutheilen.

Mit dem Dorcatherium liegen bei Eppelsheim auch Zähne zusammen, deren Structur ganz mit der in lebenden Wiederkäuern übereinstimmt; was Beachtung verdient. Dabei kommt auch ein rehartiges Thier vor, das Kaup Cervus nanus naunte. Von diesem ist bis jetzt aus dem Oberkiefer nichts bekannt. An den Zahhnen des Unterkiefers sieht man, dass ihnen der wulstförmige Theil an der hinteren Hälfte nicht ganz mangelt; er ist nur schwach angedeutet. Vielleicht, dass diese geringe Abweichung in der Structur der Backenzähne mit anderweitigen typischen Eigenthümlichkeiten im Zusammenhang steht, die erst spăter aufgefunden werden.

Ich gedenke nun noch eines Unterkieferfragmentes, welches sich in dem festen, wie es scheint, an Knochen reichen tertiaren Kalk von Vintheim bei Oberingelheim mit Resten eines schweinsartigen Thiers und eines Rhinoceros gefunden. Es zeigt sieben Backenzähne, etwas mehr als halb so gross wie die des Dorcatheriums, aber eine freie Symphysis. Am vierten Backenzahn bemerke ich den Wulst an der hintern Hälfte des vordern Halbmondes.

Diese Backenzähne von.abweichender Structur aus Tertiarablagerungen erinnern an die Reste, welche Cuvier ${ }^{*}$; von einem zu Montabusard gefundenen Wiederkăuer beschreibt. Dort finden sie sich bekanntlich auch mit Palueotherium Aurelianense. Cuvier vergleicht sie dem Reh, sagt aber, die fossilen hinteren Backenzähne aus dem Oberkiefer beşitzen weit stärkere Spitzen an der Aussenseite, worin sie selbst die meisten Hirsche ubertreffen, und einen Wulst an der Innenseite, der zwar in einigen Hirschen, namentlich in Cervus peronii existirt, aber darin mehr als Spitze hervortritt. Die Hauptverschiedenheit fand Cuvier in den zwei vordern obern Backenzähnen,

क) Taf. IX. f. 76 habe ich einen Zahn von Dorcatherium von Eppelsheim abgebildet.

(t) Cuvier, Oss. foss. IV. S. 103. t. 8. f. 3-6. 
welche einfach, schneidend und in drei Lappen getheilt sind; nur der zweite Zahn ist mit einem Wulst an der Basis begabt. Im Moschus sind die zwei ersten Backenzähne eben so gestaltet, aber der zweite Backenzahn hat darin an seiner Basis an der Innenseite eher einen Hubel, als einen Wulst. Ich finde weder in der Beschreibung von Cuvier, noch in den dazu gehörigen Abbildungen etwas von dem wulstförmigen Theil angemerkt, der sich an den hinteren Backenzähnen von Georgensgmünd von dem vordern Halbmonde nach der Mitte der Backenzahnkrone zieht. Da Cuvier gewöhnlich solchen kleineren Theilen an Zähnen keine Aufmerksamkeit schenkte, so wăre zu wünschen, dass die Zähne von Montabusard einer neuen Untersuchung unterworfen wurden. Demselben Thier zahlt Cuvier auch ein Unterkieferfragment mit den drei letzten Backenzähnen aus derselben Fundgrube bei, von dem er sagt, dass es sich von dem analogen Theil im Reh gar nicht unterscheiden lasse. Ich kann mir nicht denken, dass hier bei einer solchen, fast generischen Verschiedenheit der obern Backenzăhne die untern gar keine Eigenthümlichkeiten besitzen sollten. Die Abbildung gibt keinen weiteren Aufschluss. Aus dieser Abbildung sind nur die Längenmasse zu entuehmen: der letzte Backenzahn 0,016, der vorletzte 0,011 und der vorvorletzte 0,01. Diese Masse sind um vieles kleiner, als die der analogen Zähne von Georgensgmünd, während doch der obere Backenzahn letztern Ortes auch in den Ausmessungen sehr gut denen entspricht, welche Cuvier von oberen Backenzảhnen von Montabusard bekannt macht. Ich kenne bis jetzt von Georgensgmüud keine untere Backenzähne, welche denen von Montabusard zu vergleichen wăren. Vielleicht liegen an letzterem Orte fossile Wiederkäuergenera mit Gattungen zusammen, die in Zahnstructur von den lebenden Wiederkäuergenera nicht verschieden sind, wie diess bei Eppelsheim der Fall ist. Cuvier erwăhnt noch von Montabusard zwei Geweihfragmente, welche, wie er sagt, eben so wohl dem Reh, als -dem Cervus peronii verglichen werden können, denen aber die zur genaueren Bestimmung erforderlichen Theile fehlen. Von Georgensgmünd kenne ich nichts von Geweihen. War Palaeomeryx mit Geweihen, mit Hörnern oder mit keinem von beiden versehen?

Bei dieser Gelegenheit habe ich auch die fossilen Zähne eines kleinen Wiederkăuers anzuführen, deren Pentland ${ }^{*}$ ) aus Bengalen gedenkt, und die dem Moschus ähnlich seyn sollen. Die nur von der Seite gegebenen Abbildungen erinnern an unsere Wiederkauuer von Georgensgmund mehr, als an lebende Gattungen. Es scheint aber nicht,

") Geolog. Trans. 2. II. t. 45. f. 1.13 etc. 
dass sie ihnen angehört haben. Die Reste von Bengalen rühren jedenfalls von einem Thier her, das nur halb so gross war, als das von Georgensgmünd. Möchten nun auch diese Zähnchen einer genaueren Untersuchung unterworfen werden! So viel scheint jetzt schon ersichtlich, dass daran der Nebenhügel an der Innenseite der untern Backenzähne vorhanden war.

Auch erwähnt Schinz ${ }^{*}$ ) aus dem mergeligen Sandstein, worin die Braunkohle bei Käpfnach liegt, Kieferstücke (f. 6. 7), deren Zähne von denen des Edelhirsches nicht zu unterscheiden seyn sollen; sodann noch eines Stückes (f.8), das einen Wiederküuer anzeige, dessen Zähne die des Moschusthiers nicht übertroffen haben mögen und einer Antilope konnten angehört haben, welche der Antilope dorcas nahe verwandt war. Alle diese Stucke sind nur von einer Seite abgebildet, und erlauben unmöglich, Einsicht in die Structur der Backenzahnkrone zu nehmen. Aber schon die conișche Form ihrer Haupt- und Nebenspitzen lasst vermuthen, dass sie vielleicht eigene Wiederkäuer andeuten.

Nun hat noch Ge of froy Sain t-Hil aire * fossile Reste von Wiederkäuern ans dem Indusienkalke bei Saint-Gérand-le-Puy in der Auvergne untersucht, in denen er ein neues, von ihm Dremotherium genanntes Genus erblickt, das zu der Familie Moschus gehören und die Lücke zwischen Moschus (porte-musc) und Chevrotain (Tragulus, Brisson u. Geoff.) ausfullen soll. Geoffroy sah nicht, dass sein neues Genus lange obere Eckzahne, wie dessen lebende Verwandte, besessen, und glaubt daher, dass es nicht in Felsen, sondern in Ebenen und Wiesen in der Gegend von Seen und Flüssen gelebt habe. Es besass keine Hörner, und, wie es scheint, aller Vertheidigungsmittel beraubt, konnte es sich nur durch Schnelligkeit seines Laufes retten. Er unterscheidet zwei Gattungen, von deuen er die grössere Dremotherium Feignoui nennt. Weiter ist hierüber bis jetzt nichts bekannt; es lässt sich daher auch noch keine Vergleichung mit den bereits' aufgezahlten Resten fossiler Wiederkăuer anderer Localitäten vornehmen.

In früheren Zeiten der Erde existirten also wirklich Wiederkåuergenera, welche von denen späterer Zeiten und den jetzigen verschieden waren. In der Eutdeckung derselben erging es dieser Ordnung nur wie z. B. den Fleischfressern. Man vermuthete

-) Denkschriften der allgemeinen Schweizerischen Gesellschaft für die gesammten Naturwissenschaften, I. 2. S. 55. t. 2.

*) Revue Encyclopédique, LIX. (1833.) S.82. 95. . 
keine neue Genera, weil man sie nicht zu entdecken wusste; ihre Kennzeichen waren, ehe man sie kannte, nicht so leicht zu finden. Jetzt, wo die Bahn gebrochen ist, bezweifele ich nicht, dass die Entdeckungen von fossilen Wiederkäuergenera sich mehren werden. Vornehmlich empfehle ich die genaue Beachtung der Zähne, und die Beschäftigung mit den Resten, in denen man an verschiedenen Orten Moschus oder ihm verwandte Wiederkäuer wahrzunehmen glaubte.

\section{F l e i s c h $\mathrm{res}$ s e r.}

Der Taf. X. Fig. 81 abgebildete Zahn ist unverkemubar der Fek- oder Hundszaln eines Fleischfressers, und scheint aus der linken Oberkieferhalfte herzurühren. Es ist bekanntlich kaum möglich, einem vereinzelten Eckzahn eines Fleischfressers ohne Beistand der Backenzähne das Genus anzusehen, von dem er herrührt. Deswegen hielt es auch Fr. Cưvier für überflüssig, in seinem Werk über die Zähne der Säugethiere des Eckzahns von mehr als einem Genus zu gedenken, was indess nicht zu billigen ist, da doch immer einige Verschiedenheit in den Eckzähnen der verschiedenen Genera, vergleicht man sie nur hinläuglich genau, sich werden auffinden lassen. Die schlankere Form des fossilen 'Zahnes der Gegend von Georgensgmünd schliesst Ursus und Hyaena aus, und führt ihu selbst Canis näher, als Felis; denn es fehlt ihm die eine oder beide Furchen auf der äussern sowohl, als auf der innern Fläche, welche Fr. Cuvier*) für einen Charakter von Felis anfuhrt. Durch die beiden scharfen Längskanten ist der Zahn ähnlicher dem Eckzahn des gewöhnlichen Hundes, als dem des Canis vulpes. Zur Erleichterung einer vielleicht später möglichen genaueren Bestimmung habe ich diesen Zahn a von aussen, $b$ von innen, $e$ von hinten, $d$ von vorn, e im Wurzeldurchschnitt und $f$ im Zahnkronendurchschnitt abgebildet.

Der, wie es scheint, hintere, grössere Theil eines, Taf. II. Fig. 18. a von oben und b von der Seite dargestellten kleinen Zähnchens erinnert auch zunächst an Fleischfresser. Ich habe daran keine seitliche Abnutzungsfläche wahrgenommen, und die einwärts

*) G. Cuvier, Oss. foss. IV. S. 234. Ich ziehe die hier gegebene Beschreibung und Abbildungen dem vor, was in Fr. Cuvier's Werk: Dents des Mammifères, S. 77 darüber enthalten ist. Man stösst an letzterem Ort öfter auf nicht vorgemerkte Druckfehler, welche zu Irrthümern Anlass geben. 
gebogene Form der Wurzel spricht auch dafür, dass der Zahn im Kiefer stak, ohne andern unmittelbar angelegen zu haben. Der Zahn ist für das, was die lebende Viverrugattungen ergeben, nicht spitz, nicht schlank und nicht dünn genug; eher würde er Mustela zu vergleichen seyn, namentlich der Mustela foina, selbst auch in Grösse. Die Form im Allgemeinen und die Richtung der Wurzel des Zahns scheinen aber diesem Genus zu widerstreiten. Unter den damit verglichenen Fleischfressern ist dieser Zahn dem ersten Backenzahn aus der linken Unterkieferhälfte von Felis catus, dessen hinterer Theil er seyn könnte, am ähnlichsten, er ist nur etwas grösser, als der genannte in Felis catus domesticus. Der fossile Zahn besitzt hinten eine Art von Ansatz, der sich zu beiden Seiten gleich in die Zahnkrone verläuft. Z Zwischen diesem Ansatz und der eigentlichen Kronenspitze liegt in ein Drittel Höhe der Zahnkrone auf der Schärfe oder dem Kamm eine kleine Spitze.

Für den zuvor beschriebenen Eckzahn scheint dieser Backenzahn etwas zu klein zu seyn. Seine Form und selbst Einzeltheile erinnern auch an den ersten Backenzahn des schweinsartigen Thiers derselben Ablagerung, namentlich der Wulst hinten und die kleine, aus dem hintern Kamm herausragende Spitze. Allein dieser Zahn scheint für dieses Thier viel zu klein, und die Höhe und die Beschaffenheit der Hauptspitze eher einem wirklichen Fleischfresser angemessen, als einem Pachyderm, dessen vordere Backenzähne sich Fleischfresserzähnen nähern.

Herr Graf zu Münster theilte mir noch später mit, dass der Unterkiefer eines kleinen Fleischfressers gefunden worden sey, den er aber noch nicht habe erhalten können.

\section{Zähe, deren Classification noch ungewiss ist.}

Eigenthumlich ist das Taf. II. Fig. 20 abgebildete Fragment, welches wahrseheinlich von einem Eck - oder Schneidezahn aus dem Unterkiefer herrührt. Ein solcher Zahn würde sich am ersten noch mit Schneidezähnen aus dem Unterkiefer des Rhinoceros incisivus vergleichen lassen, die jedoch weit grösser sind. Auch war der Zahn. verhaltnissmăssig breiter und ovaler (c). Von den Schneidezăhnen des Rhinoceros incisivus zeigt er noch folgende Abweichungen. Ersterer wird in der Gegend, wo die Schmelzbedeckung aufhört, nach dem Wurzelende hin nicht dünner, die Wurzel nimmt sogar, so weit sie an diesem Fragmente vorhanden ist, an Breite und Stărke zu; die nach der Wurzel gekehrte Spitze, in welche die Schmelzbedeckung ausgeht, liegt nicht am Rande der flacheren Seite, sondern uber der breiteren Seite (b), welche, 
versucht man die natürliche Lage des Zahns nach der Abnutzungsfläche (a) und nach Analogie der Schneidezähne im Unterkiefer von Rhinoceros incisivus zu bestimmen, die Unterseite wäre. Die meiste Aehnlichkeit besitzt damit der Eckzahn aus dem Unterkiefer von Palaeotherium magnum *). Dieses, so wie dass Aehnliches sich auch in der Sammlung der Reste von Eppelsheim in Darmstadt, von wo kein Palaeotherium bekannt ist, vorfindet, lassst fast vermuthen, dass dieser Zahn von einem rhinocerosartigen Thier herruhre. Seine Farbe ist hell gelbbraun.

Taf. X. Fig. 82 wird ein Schneide- oder Stosszahnfragment seyn. Es fand sich mit kleineren Stucken von demselben Zahn aus der andern Kieferhäfte vor; beide rühren unbezweifelt von einem Individuum her.

Die Stosszahne von Mastodon sind rund oder mehr oder weniger oval und deutlich cannelirt; die untern Stosszähne von Dinotherium passen, da sie oval sind, eben so wenig auf den in Betracht stehenden Zahu von Georgensgmund, und sind überdiess frei von Abnutzungsfächen, die ein anderer Zahn verursacht hätte, was von diesem nicht behauptet werden kann. Die von Ka up ***) anfänglich für obere Stosszähne des Dinotheriums angesprochenen Zähne, welche nach der neuerlich erst aufgefundenen, ganz eigenthümlichen Form des Vordertheils des Unterkiefers nun nicht mehr dafür zu halten sind, besitzen auch einen ovalen Querdurchschnitt, und es könnte mit diesen höchstens in der schiefen nach der Spitze hingehenden Abnutzungsfläche Aehnlichkeit bestehen.

Das Zahnfragment, mit dem wir uns hier zu beschäftigen haben, ist schwach cannelirt, was an Hippopotamus erinnert, aber doch auch an den untersuchten fossilen Schneidezähnen rhinocerosartiger Thiere dieser Ablagerung nicht zu verkennen ist. Zwischen ihm und letztern Schneidezähnen besteht uberhaupt noch die grösste Aehnlichkeit. Von einer Schmelzbedeckung aber, welche diese Schneidezähne über derselben Gegend liegen hatten, konnte ich bei diesem nichts wahrnehmen. Der Zahı besteht nur aus einer Art von Substanz von der Structur des Elfenbeins. Auf der grössern Bruchfläche (d) scheint diese Zahnsubstanz an der Peripherie eine andere Textur besessen zu haben, und sich leichter von der abrigen Masse zu trennen. Diese concen-

\#) Cuvier, Oss. foss. III. t. 39. f. 3. c.

*) Ka u p, Description d'ossements fossiles du Muséum de Darmstadt, S. 3. t. 3. f. 1. 2. 


\section{- $105-$}

trische Hülle besteht aber nur scheinbar und ist am andern Fragmente nicht vorhanden. Die schwache Cannelirung führt hauptsächlich an der grossen, convexen Seite (b) herunter, nach der Spitze hin scheint sie sich durch Abnutzung verloren zu haben, doch ohne dass deutliche Abnutzungsflächen an ihre Stelle getreten wären, wie diess auf der Wölbung der coneaven Seite (a) der Fall ist.

Die Grösse und Stärke dieser Fragmente übertrifft Alles, was bisher über Rhinocerosschneidezähne bekannt war. Ob dieselben wirklich Thieren dieses, oder welch' anderem Genus sie angehört haben? Diess kann nur aus vollstanndigeren Resten entnommen werden.

Eben so wenig war es mir möglich, das Taf. II. Fig. 19. a von oben und b von der Seite abgebildete Backenzahufragment mit den Backenzähnen eines der Thiere in eine verwandtschaftliche Beziehung zu bringen, welche mit ihm in der Ablagerung der Gegend von Georgensgmünd sich vorfanden. Dieser Backenzahn war nicht klein; er besass wenigstens vier Haupthügel, oder war zweireihig. Nur von einem Hügel ist die Abnutzungsflache vorhanden, welche sich kleeblattförmig verzweigt zu haben scheint. Man sieht daran ferner noch eine seitliche Abnutzungsfläche, die uber einem schwachen Ansatz liegt. Die Beschaffenheit dieses Ansatzes und seine Stellung zu dem noch vorhandenen Kronentheil stimmt nicht mit dem überein, was man in derselben Gegend an den Backenzähnen von Mastodon, Dinotherium und Hippopotamus wahrnimmt, welche sich noch am besten damit vergleichen lassen; auch mit Rhinoceros lässt sich keine Vereinigung herbeifuhren, dem uberdiess das steile Anfsteigen des Haupthügels und die so deutlich ausgesprochene Kleeblattform nicht zusagt. Die beiden letzteren Eigenthümlichkeiten, und selbst die Beschaffenheit an der Basis, erinnern eher an Hippopotamus, für den aber die Kleeblattform zu einfach, die Biegungswinkel dieser Abnutzungsfläche zu scharf oder spitz sind, und die Beschaffenheit des Ansatzes sich nicht zu eignen scheint. Vielleicht rührt dieser Zahn von demselben Thier her, dessen Stoss - oder Schn̨eidezähne ich vorhin betrachtet und Taf. X. Fig. 82 abgebildet habe. Die Entscheidung darüber muss vollständigern Stucken uberlassen bleiben.

Die beiden Zähne Taf. VIII. Fig. 72 u. 73 scheinen einer Gattung, ja einem Individuum angehört zu haben. Sie besitzen Abnuizungsflachen auf der Kroue, die schräg liegen, aber keine seitlichen, weshalb sie mit keinem andern Zahn der Reihe in unmit- 
telbarer Beruhrung standen. Diese beiden Zähne sassen in versehiedenen Kieferhalften. Für Sehneidezähne fehlen ihnen die an denselben gewöhnlich vorhandenen seitlichen Abnutzungsffaschen, auch scheint Zahnkrone und Wurzel sich mit dieser Ansicht nicht ganz zu vertragen. Eher nähren diese Zähne den Gedanken ah vordere Backenzähnè, die etwas schräg gerichtet waren. Deutet die Verschiedenheit beider Zăhne darauf hin, dass mehrere solcher isolirten Zahne in einer Kieferhälfte auf einander folgten? oder rührt der eine Zahn aus dem Unterkiefer, der andere aus dem Oberkiefer her? Von ihnen ist der Zahn Fig. 72, 0,01 lang, 0,005 breit bei 0,007 Kronenhöhe, und der Zahn Fig. 73, 0,009 lang, 0,005 breit, bei 0,007 Kronenhöhe. Die Structur der Krone lasst sich von den ubrigen aus dieser Ablagerung bekannten Zähnen noch am ersten mit den vordern Backenzähnen des schweinsartigen Thiers in Betracht ziehen. Besonders ist der Zahn Taf. II. Fig. 15 hiezu geeignet, den wir für den ersten Backenzahn aus der linken Oberkieferhälfte erkannten. Von Ansätzen ist nichts vorhanden. An der Innenseite aber liegt an der Kronenbasis bei beiden Zähnen, am kleineren am stärksten, ein dünner Wulst, welcher dem an der Innenseite des damit verglichenen Zahnes entspricht; auch ist, ähnlich diesem Zahn, der Theil der Zahnkrone, welcher für den hintern angesprochen werden kann, in beiden Zähnen mehr napförmig, und alsdann der Vordertheil etwas massiver ausgebildet, auch der vordere Kamm mehr. diagonal gerichtet oder gekrümmt, als der hintere Kamm. Diese beiden Zähne waren einwurzelig. Ruhren sie wirklich vom schweinsartigen Thiere her, so waren sie entweder der vorderste freistehende Backenzahn, wie in Sus Scrofa und den wirklichen Schweinen, oder obere Schneidezahne und sind dann zunächst denen in Dicotyles oder Pecari zu vergleichen.

Eigenthümlich ist auch der Taf. VIII. Fig. 74 abgebildete Zahn gestaltet. Fir sieht aus, wie eine an der etwas schneidenden Spitze mit Schmelz bedeckte, gekrümmte Zahnwurzel. An der einen Seite führt eine flache Furche herunter, welche die Zahnkrone an dieser Seite in zwei ähnliche, aber ungleiche Theile unterscheiden lässt, die sich wahrscheinlich durch Haupthügel von Backenzähnen desselben Thiers werden erklären lassen. Diese Seite ist eher convex, die ihr entsprechende andere eher concav oder vertieft; letztere wird von dem Schmelzsaume der Schärfe und der Vorderund Hinterseite eingefasst, der sich an der Basis in einem. kleinen Schmelzknötchen etwas erhebt. In der für concav ausgegebenen Seite zieht sich von der Spitze zu diesem Knötchen eine schwache Convexităt herunter, vielleicht von der Bedeutung 
eines Hügelabfalls in einem complicirteren Zahn der Reihe. Seitliche Abnutzungsflächen habe ich daran nicht wahrgenommen. Er war frei von unmittelbarer Berührung mit andern Zähnen der Reihe; und wohl entweder ein letzter Schneidezahn, oder ein erster isolirt stehender Backenzahn. Seine Länge beträgt 0,005, Breite 0,004 und Kronenhöhe 0,008. Er erinnert an den kleinen freistehenden oberen ersten Backenzahn in gewissen Wiederkåuern (Camel). War Palateomeryx mit einem Zahn der Art begabt?

K n o c he n von $S$ äuget hi e r e n.

Aus der Ablagerung der Gegend von Georgensgmünd sind mir Knochen bekannt von einer Grösse, wie sie die grössten Thiere besitzen. Sie werden wohl von Mastodon herrühren, waren aber zur Bestimmung zu fragmentarisch.

Ein Knochenstück aus der Gegend des letzten Backenzahns der linken Unterkieferhälfte war auch zu unbedeutend, um abgebildet zu werden; es liess sich daran nur erkennen, dass es von einem rhinocerosartigen Thiere herrührt, ohne über dasselbe weiteren Aufschluss zu gewähren.

Wirbelfragmente, auch von dem rhinocerosartigen Thier, werden aus demselben Grund hier nicht näher betrachtet.

Ein Stück von einigen Decimetern Länge gehört der oberen Halfte einer Rippe aus der rechten Körperseite an. Die Form des Querschnittes und die sonstige Beschaffenheit dieser Rippe lässt sich nur dem vergleichen, was man in Rhinoceros wahrnimmt. Indess ist die Rippe bei eben so gerundetem Querschnitt etwas dünner, und die Schärfe, in welche sich dieselbe nach dem oberen Ende hinterwärts verdünnt, besonders dentlich und breit. Die fossile Rippe verräth demnach ein kleineres und leichteres Thier, als die lebenden Rhinocerosgattungen.

Ein anderes Knochenstuck rührt, so fragmentarisch es auch ist, augenscheinlich vom Becken her; es ist daran die Pfanne der Einlenkung des Oberschenkels (Femur) vorhanden. Die Aehnlichkeit mit dem analogen Theil in Rhinoceros ist unverkennbar; der fossile Knochen ist kleiner.

Eine Kniescheibe (Patella) des rechten Hinterfusses ist unbezweifelt die eines rhinocerosartigen Thiers; was an ihr auffallt, ist hauptsăchlich ihre Kleinheit.

Bedeutender ist der Fund des untern Kopfes eines Schienbeins (Tibia) mit seiner Einlenkung in das Sprungbein (Astragalus), des Sprungbeines selbst, des schiffformigen Beins (Os naviculare, Scaphoïde) und des keilförmigen Beins (Os cuneiforme). Tibia(A), 
Astragahus (B), und Os naviculare (C) sind aus einem Fuss derselben Seite, und wie sie in einander greifen, Taf. XII. Fig. 86 abgebildet. Der Astragahts und das 0 s naviculare rühren unverkennbar von einem und demselben Individuum her. Diese Knochen haben nur mit Rhinoceros zunächst Aehnlichkeit, weshalb sie auch von den Thieren herrühren werden, deren Zähne sich denen im Rhinoceros vergleichen lassen.

Der Kopf der Tibia ist an der Innenseite fragmentarisch, was verhindert, seine Breite zu nehmen. Dieser Kopf misst von vorn nach hinten 0,055 im lebenden Rhinoceros Javanus 0,06. Damit kommt nur die Tibia eines jungen Thiers von Rhinoceros Schleiermacheri von Eppelsheim überein; die von einem altern Thier letzterer Gattung ist fast noch einmal so gross, und hangt auch über dem Astragalus länger herunter.

Der Astragalus ist seiner Lage zum Fusse nach in Taf. XII. Fig. 87. a von oben und b von unten abgebildet. Von Eppelsheim ist noch kein Astragalus bekannt, der mit Gewissheit dem dort vorkommenden Rhinoceros incisivus zugeschrieben werden könnte, wohl aber der Astragalus von einem ältern und von einem jüngern Thier, welche K a u dem Rhinoceros Schleiermacheri beilegt. Ich verglich beide und fand, dass der des jüngern Thiers von dem des altern hauptsăchlich darin abweicht, das der Bogen der Rolle auf der innern Beinseite oder auf der Schienbeinseite auffallend der Fusswurzelseite näher liegt und auf der andern Seite seitlich weiter über die vordere oder Fusswurzelseite heraussteht. Hiezu treten noch andere, weniger erhebliche Abweichungen. Es ist möglich, dass beide Astragali zwei verschiedenen Gattungen angehören, und dass, wenn der mit dem der Fusswurzelseite näher liegenden Bogen der Rolle sich fur Rhinoceros Schleiermacheri bestatigen sollte, der andere von Rhinoceros incisivus herrühre. Es scheint sogar, dass letzterer Astragalus ungefahr so viel von ersterem abweicht, als er sich dem Astragalus des Palueotheriums *) năhern würde, ohne gerade dadurch Rhinoceros entfremdet zu werden. Rhinoceros incisivus besitzt nun aber schon in manchen Stucken Beziehungen zum Pulaeotherium. Der Astragalus vou Georgensgmünd gleicht weit weniger dem Astragalus von Eppelsheim, den auch wir eher dem Rhinoceros Schleiermacheri beilegen würden, als dem andern. Er ist aber auch wieder von letzterem hinlänglich und hauptsăchlich darin verschieden, dass er verhältnissmåssig kleiner ist, und der erwähnte Bogen der Rolle nicht so weit von der Fusswurzelseite absteht, auch nicht so weit auf der andern Seite seitlich über dieselbe hinaus-

क) Cuvier, Oss. foss. III. S. 99. t. 54. f. 2-4. Ich bediente mich bei der Vergleichung noch einos gelungenen Abgusses des Astragalus vom Palaeotherium magnum. 
ragt. Bei Oppenheim ist ein Astragalus mit dem Unterkiefer eines Rhinoceros incisivus gefunden worden, der dem von Georgensgmünd auch nicht vollkommen gleicht. In seiner Lage zum Fuss von oben betrachtet, ist der an der innern Beinseite oder nach der Schienbeinseite liegende Bogen der Rolle mit der Fusswurzelseite verwachsen (ein Charakter, der auch den Astragalus von Palaeotherium Aurelianense von dem der anderu Palaeotheriumgattungen auszuzeichnen scheint), und anf der untern Seite fallt eine kurze Rinne auf, die nach vorn oder in die Fusswurzelseite mündet. Ein auch für Rhinoceros incisivus angesprochener Astragalus von Mombach besitzt wieder nicht vollkommene Uebereinstimmung mit allen bisher betrachteten. Dasselbe lässt sich von einem Astragalus von Frankfurt sagen von der ungefăhren Grösse des von Georgensgmünd, wobei doch immer Aehnlichkeit mit Rhinoceros besteht. Wie schwer mag es demnach seyn, die Astragali einzelner Gattungen rhinocerosartigev Thiere von einander zu unterscheiden; für die fossilen kommt nun noch hinzu, dass es den Anschein hat, als unterschieden sich die Astragali verschiedener Individuen einer Gattung nach der Localität.

Die grösste Aehnlichkeit mit dem Astragalus von Georgensgmünd besitzt indessen unstreitig jener, dessen Cuvier (Oss. foss. II. S. 215. t. XI. f. 1. 2.) gedenkt. Diesen aber legt er seinem Lophiodon giganteum bei. Der Fundort ist die Gegend von Orléans, und das Gestein dasselbe, in welchem das Palaeotherium Aurelianense lag. Wir haben gesehen (S. 31), dass Georgensgmünd auch Lophiodon liefern soll, woran indess nach den Zähnen zu zweifeln ist. Mithin ist noch kein weiterer Grund vorhanden, den Astragalus aus dieser Gegend, die in manchem Betracht der bei Orléans sich vergleichen lăsst, einem Lophiodon zuzuschreiben. Es wird sogar wahrscheinlich, dass der von Cuvier beschriebene Astragalus nicht so wohl von einem Lophiodon, als von einem Rhinoceros herrührt. Sicherer würde hierüber zu entscheiden seyn, wenn man wüsste, ob die Reste von Rhinoceros incisivus und minutus, welche für die Gegend von Orléans angeführt werden *), aus demselben Gebilde herrühren, in welchem man Lophiodon und Palaeotherium fand.

Von den lebenden Rhinocerosgattungen habe ich mit dem Astragalus von Georgensgmünd den des Rhinoceros Javamus verglichen. In Allgemeinen stimmen sie in der Form uberein, nur ist ersterer merklich kleiner. Aber an dem der lebenden Gattung fällt noch hauptsächlich auf, dass die vordere Bogenendspitze an der innern Beinseite oder an der Schienbeinseite einen concaven Einschnitt besitzt, der auch in der unge-

*) Vgl. meine Palueologica, S. 385. 


\section{$-110$}

fähren Mitte des Vorderrandes der Rolle deutlicher vorhanden ist. Am Astragalus des Tapirs bemerkt man etwas, das ersterem Einschnitt ähnlich ist, doch nicht so concav, sondern mehr geradlinig. An keinem der fossilen Astragali habe ich diese Einschnitte bemerkt.

Hier die Ausmessungen.

Länge der Schienbeinseite . . . . .

Breite der Rolle hinten . . . . . .

Sehne d. Bogens dies. Rolle an d. Schienbeinseite

Dieselbe an der Wadenbeinseite . . . ...

Breite unten mit dem Hübel .......

Breite der Fusswurzelseite . . . . . .

Durchmesser dieser Fläche von vorn nach hinten

\begin{tabular}{|c|c|c|c|c|c|}
\hline & \multicolumn{2}{|c|}{ Eppelsheim. } & Frankft. & Orléans. & Gmünd. \\
\hline $\begin{array}{l}\text { Rhin. } \\
\text { lebend. }\end{array}$ & $\begin{array}{c}\text { Rhin. } \\
\text { Schleierm. }\end{array}$ & $\begin{array}{c}\text { Rhin. } \\
\text { incisiv.? }\end{array}$ & $\begin{array}{c}\text { Rhin. } \\
?\end{array}$ & $\begin{array}{l}\text { Lophiod. } \\
\text { gigant.? }\end{array}$ & Rhin. \\
\hline - & 0,07 & 0,078 & - & - & 一 \\
\hline 0,083 & 0,078 & 0,078 & 0,072 & 0,07 & 0,068 \\
\hline 0,073 & 0,062 & 0,067 & 0,056 & - & 0,057 \\
\hline 0,082 & 0,065 & 0,063 & 0,058 & - & 0,059 \\
\hline - & 0,087 & 0,079 & 0,066 & - & 0,063 \\
\hline 0,088 & 0,076 & $0,07 t$ & - & 0,06 & 0,068 \\
\hline 0,049 & 0,038 & 0,041 & 0,036 & - & 0,037 \\
\hline
\end{tabular}

Das Os naviculare (Scaphoïde), Taf. XII. Fig. 88. a. b, gleicht dem in der lebenden Gattung Rhinoceros Javanus, womit es verglichen wurde. Es besitzt dieselbe grösste

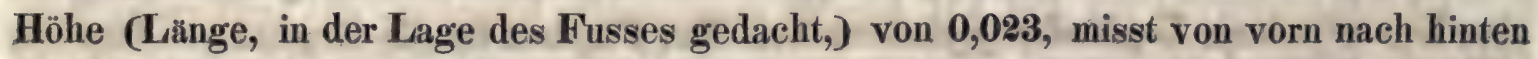
(von oben nach unten) $\mathbf{0 , 0 5}$, in der lebenden Rhinocerosgattung $\mathbf{0 , 0 6}$, und ist breit (von aussen nach innen) an der Astragalfläche gemessen 0,05, in der lebenden Gattung 0,07.

Das Os cuneiforme ist zu wenig vollstăndig, um naher betrachtet zu werden; seine Aehnlichkeit mit dem in Rhinoceros ist unverkennbar.

Vom äussern Mittelfussknochen des rechten Fusses habe ich drei Exemplare untersucht, welche also eben so viel Individuen voraussetzen. Es waren immer nur Röhrenfragmente mit dem oberen Kopf. Taf. XIII. Fig. 94 habe ich einen dieser Knochen abzubilden versucht, woran alle Gelenkflächen deutlich erhalten sind. Der nämliche Knochen fand sich auch bei Mombach mit Resten des Rhinoceros incisivus. Dieser gleicht den vorigen weniger, als letztere unter einander; auch ist die obere Fläche, die in das würfelförmige Bein (Os cubiforme, Cuboïde) einlenkt, in dem von Mombach etwas mehr triangular. Die beiden Flächen am innern Kopfrande, mit denen er in Berührung mit dem mittlern Mittelfussknochen steht, sind sehr deutlich. Dieser fossile Knochen zeigt, gegeu den in Rhinoceros Javamus, ein kleineres und schlankeres Thier an. Schon das Fragment des fossilen Knochens war länger und die Röhre vor dem untern Kopf mehr eingezogen. Aehnlichheit mit Rhinoceros ist indess nicht zu verkennen. Es misst 
Die Breite am obern Kopf .

- - der Röhre in der Mitte

\begin{tabular}{|c|c}
$\begin{array}{c}\text { Rhin. } \\
\text { Javanus. }\end{array}$ & $\begin{array}{c}\text { Knochen } \\
\text { v. Ggmünd. }\end{array}$ \\
\hline $\begin{array}{c}0,049 \\
0,04\end{array}$ & $\begin{array}{c}0,04 \\
0,031\end{array}$
\end{tabular}

Den in Taf. XIV. Fig. 101 abgebildeten Knochen halte ich für den zweiten Phalanx der innern Zehe des rechten Hinterfusses, auf den, dem Rhinoceros zu Folge, der Nagelphalaux folgen würde. Dieser Knochen ist sehr gut erhalten, und a von oben (nach der Lage im Fuss, von hinten), b von vorn (oben), c von unten (vorn), d von aussen und e von innen zu sehen. Er besitzt unverkennbar die Form des analogen Knochens im Rhinoceros, ist aber rücksichtlich seiner Breite verhältnissmässig länger (höher), als in der damit verglichenen lebenden Gattung, wie folgende Ausmessungen darthun.

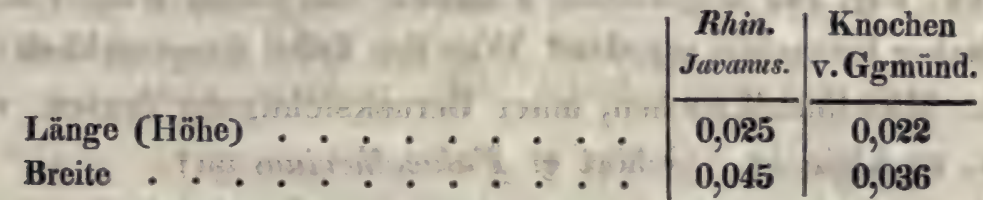

Unverkennbar ist der Taf. XII. Fig. 89 dargestellte Knochen, das keilförmige Bein (Os cuneiforme, Cuneïforme), das aussen in der Handwurzel linker Seite liegt. Nicht allein die Form im Allgemeinen, sondern auch die obere und untere Gelenkflache, so wie die beiden Gelenkflachen, womit dieser Knochen an der Innenseite mit dem mondformigen Bein (Os lunare, Semi-lunaire) in Berührung tritt, sprechen dafür. Ich habe dasselbe a von aussen, b von oben und c von innen dargestellt. Es ist dem in Rhinoceros sehr ahnlich, von gleicher Höhe mit dem damit verglichenen aus der lebenden Gattung, aber nicht so dick und breit; daher ganz im Einklang mit dem, was die Knochen aus den hintern Gliedmassen ergeben, die schon auf ein schlankeres Thier, als das lebende Rhinoceros, hinwiesen.

Ausserdem besitze ich noch fast sämmtliche Handwurzelknochen, aber von verschiedenen Individuen, und theils aus dem rechten, theils aus dem linken Fuss. Um nicht zu sehr mit Abbildungen zu uberhäufen, beschrănke ich mich auf die Bemerkung, dass auch sie den analogen Knochen im Rhinoceros ähnlich sind, aber ein kleineres Thier, namentlich ein Thier mit schlankerer Hand, als in den lebenden Rhinocerosgattungen, anzeigen.

Der Knochen Taf. XU. Fig. 90 scheint ein Mittelhandknochen (Metacarpus, Metucarpien) zu seyn. Er lässt sich dem äussern Knochen der linken Mittelhand der 


\section{$-112-$}

lebenden Rhinocerosgattung vergleichen, ist aber wieder weit schmächtiger als dieser, und würde sich sogar Palaeotherium nähern; für Palaeotherium Aurelianense ist er aber viel zu gross. Ich habe ihn a von vorn, b von hinten, c von innen, d von unten und e den Durchschnitt seiner Röhre gegeben. Er ist etwas platt gedrückt. Mit dem Mittelhandknochen des Rhinoceros Schleiermacheri von Eppelsheim besitzt er nicht viel Aehnlichkeit; er ist auch kleiner, als dieser. Die obere Halfte des Mittelhandknochens an der Innenseite des linken Vorderfusses ist Taf. XII. Fig. 95 abgebildet. Dieselbe entspricht in allgemeiner Form dem, was hieruber Rhinoceros darbietet.|Ich habe aber auch hier wieder anzufuhren, dass der fossile Knochen im Ganzen kleiner, verhältnissmässig etwas schmäler und weniger flach zu seyn scheint, also ebenfalls auf ein Thier schlankeren Baues hindeutet, als die eigentlichen Rhinocerosgattungen.

Ruhrt der Taf. XIV. Fig. 102 abgebildete Phalanx von einem Finger des Thiers her, dessen Knochen bisher betrachtet wurden? Was ihm dabei hauptsächlich im Wege steht, ist, dass er zum Mittelhandknochen, unter Berticksichtigung dessen, was Rhinoceros erkennen lässt, zu klein ist. Gehört er Palaeotherium an?

Die Rolle des Humerus im Palaeotherium besteht *) an der Aussenseite aus einer einfachen und deutlich gewölbten Convexităt, worauf eine Concavităt folgt, die am Innenrande endigt, indem sie sich erweitert und ihre Gestalt eine conische Oberfläche ohne neue deutlichere Erhabenheit annimmt. In Tapir beginnt die Aussenseite der Rolle mit einer Concavität, der eine schmälere Convexitä folgt, worauf die gewöhnliche Concavität und der nach dem Innenrande zu liegende Conus kommt. Betrachtet man unter Berücksichtigung des Gesagten den von mir Taf. XI. Fig. 84. a von vorn, b von unten, c von hinten, d von aussen, e von innen und $f$ im Durchschnitt seiner Röhre abgebitdeten Humerus oder Oberarm, so wird man sich nicht geneigt fühlen, denselben dem Palaeotherium beizulegen, da er an der Aussenseite mit einer Concavitat beginnt, der die Convexität und hierauf die andere Concavität folgt, welche nach dem Innenrande hin conisch sich erweitert. Er gleicht hierin dem Humerus des Tapirs, und unverkennbar auch jenen beiden Humerusfragmenten von Montabusard, die Cuvier **) anfänglich für Palaeotherium Aurelianense hielt, aber nach Feststellung der Charak-

*) Cuvier, Oss. foss. II. 1. S. 216.

*) Cuvier a. a. 0. t. XI. f. 3-6. 


\section{$-113-$}

tere der Rolle, und wegen ihrer Aehnlichkeit mit Tapir, einer noch nicht weiter durch Zähne bestätigten, sondern allein aus diesem Knochen errichteten Lophiodongattung (Lophiodon Aurelianense), von geringerer Gestalt als Lophiodon giganteum, beilegt. Der bisherige Mangel an unzweifelhaften Resten von Lophiodon bei Georgensgmünd erlaubt nicht, auf diesen Humerus allein die Gegenwart dieses erloschenen Pachydermengenus zu gründen; jedenfalls wird es zuvor nöthig seyn, zu untersuchen, ob dieser Knochen nicht einem von den Thieren konnte angehört haben, über deren Existenz in der Ablagerung von Georgensgmünd kein $\mathbf{Z}$ weifel waltet.

Grossen Pachydermen und Fleischfressern konnte dieser Humerus unmöglich angehören, da derselbe in diesen Thieren ganz anders gestaltet ist; auch nicht Palaeotherium aus schon vorgebrachten Gründen: so bliebe nun noch von den bis jetzt in der Ablagerung erkannten Thieren das schweinsartige Thier und der Wiederkäuer zu näherer Berücksichtigung übrig. Die Gliedmassen des Schweines aber und die von Wiederkäuern, namentlich von Schaf und Hirsch, besitzen gerade im Humerus grosse Aehnlichkeit, was die Entscheidung über einen einzelnen Knochen nothwendig erschweren muss. Den Humerus des Schweins zeichnet ein Loch über der Rolle aus. Im fossilen Humerus liegt zwar über der Rolle auch ein Loch, jedoch nur in Folge von Beschädigung. Was aber die Rolle selbst betrift, so beginnt sie im Schwein und in den genannten Wiederkäuern, wie im fossilen, an der Aussenseite mit einer Convexităt, auf die eine Concavität, dann die zweite Convexität und hierauf die an der Innenseite in einen Conus endigende Concavität folgt. Ich finde nun, dass beim Schwein die zweite Convexitat mehr nach der Mitte zu liegt und der Conus an der Innenseite nicht so stark und auch die erste Convexität an der Aussenseite nicht so deutlich gewōlbt erscheint, als in den Wiederkäuern und in dem fossilen Humerus; hiedurch werden die beiden letztern augenscheinlich einander năher gefülırt. Die Wahrscheinlichkeit, dass der fossile Knochen von einem Wiederkäuer herrühre, wird erhöht, wenn man damit die in Croizet und Jobert's Werk ) t, 2. f. 4, t. 3. f. 1, t. 6. f. 2, t. 7. f. 4, t. 9. f. 1 etc. abgebildeten Humerusknochen von fossilen Hirschen vergleicht. Aus einigen dieser Abbildungen lässt sich sogar eine åhnliche Richtung des obern Endes der zweiten Convexität nach der Convexitat an der Aussenseite hin vermuthen, wie sie im fossilen Humerus besteht.

*) Croizet et Jobert, Recherches sur les ossemens fossiles du Puy-de-Dôme. 1824. 


\section{$-114$}

Gehört dieser Humerus wirklich einem Wiederkaner an, so wird er wohl dem Palaeomeryx beizulegen seyn.

Ueber die beiden von Cuvier beschriebenen Humerusfragmente aber kann nur eine wiederholte Untersuchung derselben entscheiden, da seine Abbildungen nicht die erforderliche Deutlichkeit besitzen, um Vermuthungen sicher weiter zu geleiten. Cuvier fand diese Knochen von denen des Tapirs and Palaeotheriums hauptsächlich dadurch verschieden, dass der Conus an der Innenseite der Rolle stärker gewölbt ist, ein Merkmal, das er mit dem Humerus von Georgensgmünd gemein hat. Die Breite der Rolle der Humerusknochen, die C u vi er beschreibt, ist am einen 0,048, am andern 0,053, im jungen Amerikanischen Tapir 0,048, genau so viel, als bei einem $\boldsymbol{P}_{\text {alaeotherium aus }}$ dem Montmartre; die grösste Breite der Rolle am Humerus von Georgensgmünd beträgt 0,053. Bei dieser Uebereinstimmung ist nicht zu vergessen, dass bei Montabusard Reste eines Wiederkäuers *) vorkommen, dessen Zähne in manchen Stücken mehr Aehnlichkeit mit meinem Palaeomeryx verrathen, als mit den lebenden hirschartigen Thieren.

Ausser dem abgebildeten Humerus besitze ich noch ein Fragment eines Humerus aus derselben Seite, an dem die Rolle fehlt, wodurch also zwei Individuen bezeichnet werden. Die grösste Aehnlichkeit fand ich zwischen diesen Humerusfragmenten und den entsprechenden Theilen in der Antilope Addax.

Unter allen Săugethieren findet sich bekanntlich nur in der Ordnung der Wiederkäuer die Mittelhand zum Canon vereinigt. Das Taf. XI. Fig. 85 abgebildete Knochenfragment ist der obere Theil eines solehen Canons (Mittelhand) aus dem linken Vorderfuss. In Grösse und Gestalt ist dieser Knochen dem analogen Theil in der Antilope Dama ähnlich, im Cervus Elaphus und zumal in Renn ist er davon auffallend verschieden. Da mir bis jetzt aus der Ablagerung der Gegend von Georgensgmünd von Wiederkäuern nur Palaeomeryx bekannt ist, und dieser Knochen in Grösse dazu passt, so lege ich ihn diesem Thiere bei. Stand dasselbe den Antilopen năher, als den Hirschen? Ich kenne ganz denselben Knochen noch einmal, woran aber auch noch der obere Kopf abgebrochen ist.

*) Cuvier, Oss. foss. IV. S. 103. t. 8. f. 3-6. 
Ausser Wirbelfragmenten, welche wahrscheinlich dem rhinocerosartigen Thier angehören, die aber nicht genauer bestimmt werden konnten, fanden sich noch die Taf. XIII. Fig. 91 und Taf. XIV. Fig. 96 abgebildeten beiden, unverkennbar aus dem Schwanze herrührenden Wirbel vor.

Der grössere dieser Wirbel (Fig. 91) ist sehr breit und; daher einer der ersten des Schwanzes. Seine Fortsätze sind am Wirbelkörper abgebrochen. Unter den von Cuvier (Oss. foss. III.) abgebildeten kommt hier zunächst der S. 239. t. 38. f. 1 in Betracht, den er fưr einen der ersten Schwanzwirbel von Anoplotherium ausgibt, der aber ein Drittel grösser zu seyn scheint. Der Wirbelkörper des Knochens von Georgensgmünd misst

$$
\begin{aligned}
& \text { Länge } .0,048 \\
& \text { Breite } \\
& \text { Höhe } \\
& 0
\end{aligned}
$$

Dieser Wirbel ist von Natur so schief, wie ich ihn abgebildet habe.

Der kleinere Wirbel (Fig. 96) ist mehr rund und sass eher in der hintern, als in der vordern Hälfte des Schwanzes. Er misst

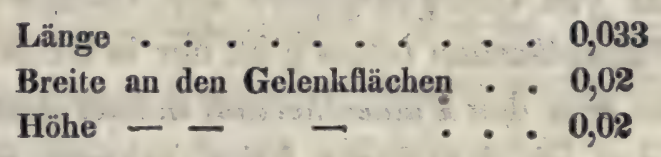

Die ersten der Wirbel von einem Palaeotherium mittlerer Gestalt, welche Cuvier von einem Schwanzende (Oss. foss. III. S. 230. 234) t. 38. f. 9 in nicht sehr deutlicher Abbildung gibt, sind von ăhnlicher Grösse, indem für jeden derselben 0,03 Länge und 0,02 Breite angeführt wird; und in f. 4 (S. 240) theilt derselbe einen ungefähr ein Drittel grössern Wirbel mit, der durch die Reduction seiner Fortsătze dem von Georgensgmünd ähnlich ist, von $\mathbf{C u v i e r}$ aber Anoplotherium beigelegt wird.

Vielleicht gehört dieser und der zuvor betrachtete Wirbel von Georgensgmund dem Palaeotherium Aurelianense an. Beide Wirbel sind verhältnissmăssig länger und stärker, als die, welche im Pferde damit verglichen werden könnten, und zeigen daher ein gut geschwänztes Thier. Ihre Beschaffenheit gleicht noch am ersten denen in Pachydermen. 
Einen kleineren Astragalus (Sprungbein), als den oben (S. 108) beschriebenen, habe ich Taf. XIII. Fig. 92. a von oben, b von unten, c von vorn mit der Fusswurzelseite, d von der innern Beinseite oder von der Schienbeinseite und e von der Wadenbeinseite abgebildet. Er ist ganz vollstandig, und dem, was die Palueotherien über diesen Knochen ergeben, ähnlich; weicht aber von den bekannten in Grösse und Beschaffenheit einzelner Theile ab. Ich konnte damit naher vergleichen den Astragalus von Pulaeotherium indeterminatum, latum und medium, und von Dimensionen folgende geben.

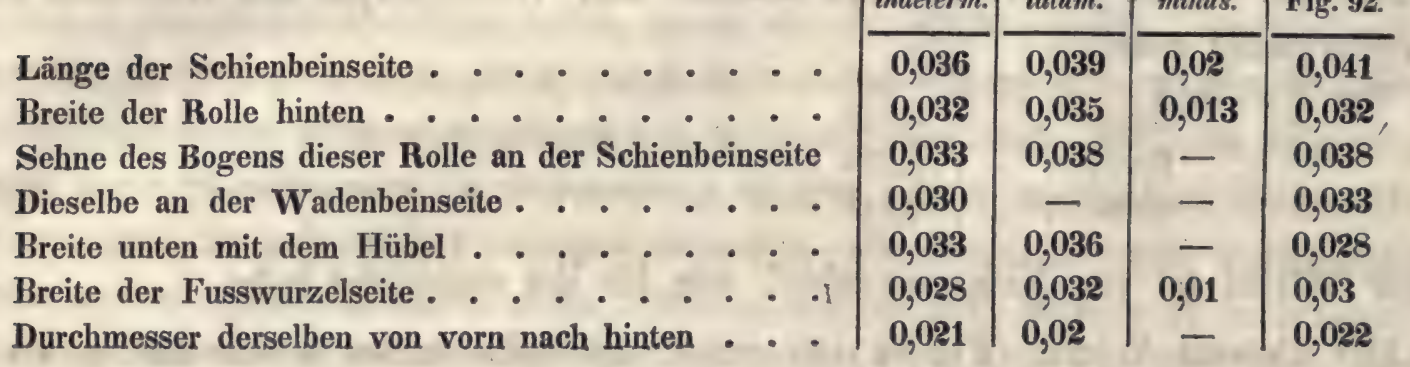

Am meisten gleicht der Astragalus von Georgensgmund der Abbildung, welche Cuvier ${ }^{*}$ ) von diesem Knochen des Palaeotherium latum gibt, der in Grösse mehr mit dem des Palaeotherium medium, als mit dem des Palaeotherium indeterminatum ubereinstimmt. Doch ist der Astragalus, den ich darzulegen habe, grösser, als der des $\boldsymbol{P}$ alaeotherium latum und medium, ubertrifft selbst noch etwas den des Palaeotherium indeterminatum und ist ungefahr noch einmal so gross, als der in Palcueotherium minus. Bei gleicher Rollenbreite mit Palaeotherium indeterminatum hat er ein schmäleres Aussehen, und selbst ein längeres, als Palaeotherium latum, dessen Bogensehne mit ihm doch gleiches Mass besitzt. Es rührt diess hauptsächlich daher, dass im Astragalus von Georgensgmünd die Bogen der Rolle sich etwas nåher liegen, ohne dadurch die grösste Breite der Rolle zu beeinträchtigen. Der Bogen der Rolle an der Wadenbeinseite begibt sich mit seinem an der Fusswurzel liegenden Ende nicht so weit nach dem Wadenbein hin, als in.Palaeotherium medium und indeterminatum. Die auffallendste Abweichung aber von allen bekaunten Knochen der Art in Palueotherien besteht unverkennbar darin, dass das eine Ende seines Bogens an der Schienbeinseite mit der

") Cuvier, Oss. foss. III. S. 93. t. 40. f. 4-8. 
Fusswurzelseite in Berührung sich befindet, wobei dieser Knochen nicht nur nicht verkürzt, sondern eher noch länger ist, wăhrend in den andern Palaeotherien an dieser Stelle ein mehr oder weniger grosser Trennungsraum liegt. Dieser Astragalus bezeichnet ein etwas stärkeres Thier, als Palaeotherium latum. Die Menge Zähne von Palaeotherium Aureliunense in dieser Ablagerung steht ganz im Einklang mit der Häufigkeit, womit sich auch der Astragalus findet.

Ich kenne auch untere Köpfe von der Tibia, welche in die Rolle des Astragalus ganz genau einlenken; sie sind aber für eine Darstellung zu fragmentarisch.

Der Taf. XIV. Fig. 97 abgebildete Calcaneus (Calcaneum, Fersenbein) rührt aus dem rechten Hinterfuss her. Der Theil, in welchen der Astragalus eingreift, fehlt. In den Hirschen und Antilopen ist der analoge Knochentheil verhăltnissmässig etwas länger und unmittelbar unter seinem Kopfe stärker eingezogen. Hierin wird er passender mit Palaeotherium verglichen. Dieser Knochentheil ist in Palaeotherium crassum etwas grösser und breiter, sein Kopf kleiner, und dabei die hintere Umrisslinie schwach bogenförmig gekrümmt und nicht eingebogen. Im Palaeotherium indeterminatum kommt diese Linie der geraden năher, und ist daher der in vorliegendem Stück ăhnlicher. Ungeachtet dieses Calcaneusfragment sich mit Zähnen des schweinsartigen Thiers zusammen vorgefunden, so zweifele ich doch nicht, dass es dem bei Georgensgmünd so reichlich vorkommenden Palaeotherium Aurelianense angehören wird. Das Fragment misst:

$$
\begin{aligned}
& \text { Långe . . . . . 0,056 } \\
& \text { Breite am Kopf . . } 0,021 \\
& \text { - in der Mitte . } \mathbf{0 , 0 1 3} \\
& \text { Von vorn nach hinten . } 0,032
\end{aligned}
$$

Was ich von Phalangen oder Finger- und Zehenglieder hier zu betrachten habe, ist in Taf. XIV. Fig. 98-103 abgebildet. Sie lassen sich unterscheiden in solche, deren Unterseite hohl (Fig. 98. 99), und in solche, welche diese Seite nicht so tief ausgehöhlt besitzen (Fig. 100-103). Es ist nicht denkbar, dass Phalangen beider Arten sich an einem und demselben Thier vorgefunden, obgleich man nicht unversucht bleibt, sie zusammen zu passen. 
Der Mangel an genauen Beschreibungen und dentlichen Abbildungen der bisher von ahnlichen fossilen Thieren aufgefundenen Phalangen erschwert ihre Bestimmung sehr. Cuvier's Werk befragt man darüber vergebens. Die Knochen der Gliedmassen, namentlich die Hand - und Fusswurzelknochen, so wie die Mittelhandand Mittelfussknochen, werden von ihm wohl sorgfältig beschrieben; uber die Phalangen aber wird mehr hinweggegangen und nicht einmal angeführt, ob sie unten hohl sind oder nicht.

\section{Phalangen mit tief ausgehöhter Unterseite.}

Hieher gehören die beiden in Fig. 98. 99 abgebildeten Phalangen. Durch die tiefe Aushöhlung der Unterseite gleichen sie sich einander mehr, als den übrigen. Rühren sie von einer Gattung her? Das stärkere Herunterhängen der rechten Seite an beiden Phalangen lässt vermuthen, dass sie der rechten Seite des Thiers angehören. Dieses Herunterhängen besitzt der kleine Phalanx (Fig. 98) verhältnissmässig stärker, als der grössere (Fig. 99), was auf einen seitlicheren Finger oder Zehe schliessen lässt, und zwar von der äussern rechten Seite, wie diess auch die schiefe Richtung seiner vordern und hintern Gelenkfläche andeutet. Die Kürze dieses Phalangen lässt vermuthen, dass er ein zweiter sey, und seine eigenthümliche, aus der Abbildung von verschiedenen Seiten deutlich ersichtliche Beschaffenheit und Höhlung, dass er zu Palaeotherium gehöre, wovon nur Palueotherium Aurelianense aus der Ablagerung bekannt ist, zu dem seine Grösse passen würde. Dieser Phalanx besitzt

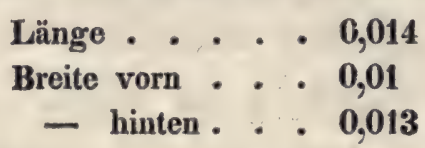

Letztere Breite würde mit der des zweiten Phalangen des Mittelfingers in $\boldsymbol{P a -}$ lueotherium crassum (Cuvier, Oss. foss. III. S. 129) vollkommen übereinstimmen, dessen Länge beträgt aber nur $\mathbf{0 , 0 0 7}$. Gehört der Phalanx von Georgensgmünd einer Zehe an?

Der grössere unten ausgehöhlte. Phalanx (Fig. 99) hăngt mit der etwas verstårkten rechten Seite nicht so stark herunter, dass er nicht für einen mittlern Phalanx gelten könnte, der er wirklich zu seyn scheint; ich möchte ihn fur den ersten Phalanx der Mittelzehe des rechten Fusses halten. Seine Beschaffenheit wird aus der Abbildung von verschiedenen Seiten klar werden. Er misst 


\section{$-119-$}

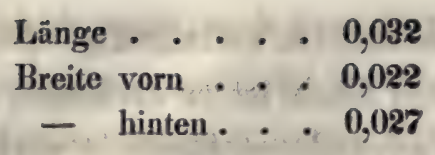

Die Aehnlichkeit, welche zwischen diesem Knochen und den bei Cuvier (Oss. foss. III.) t. 22. f. 1 und t. 42. f. 3 abgebildeten Phalangen von Anoplotherium, selbst in Ansehung der Grösse gefunden werden könnte, hindert nicht, eine generische Verschiedenheit beider Thiere, denen sie angehört, vorauszusetzen. Die Ausmessungen dieses Phalangen weichen von denen des ersten Phalangen des Mittelfingers in Palaeotherium crussum, fur den Cuvier nứ 0,012 Lange und 0,013 Breite angibt, ab.

\section{Phalangen mit nicht so tief ausgehöhler Unterseite.}

Zuerst werde der Taf. XIV. Fig. 102 abgebildete Phalanx betrachtet. Seine Form erinnert sogar mehr an den zweiten Phalanx aus der Hand des Hippopotamus, als aus der des Rhinoceros. Er besitzt

$$
\begin{array}{r}
\text { Länge * . } \quad 0,02 \\
\text { Breite vorn } \cdot 0,026 \\
\text { - hinten } . \quad 0,03
\end{array}
$$

und entspricht daher in Grösse am besten dem in dem Palaeotherium magnum. Unter diesen Umständen glaube ich den Phalanx von Georgensgmünd, ungeachtet seiner Kleinheit, doch dem rhinocerosartigen Thiere beilegen zu sollen. Vielleicht rührt er von einem jungen Thiere her.

Man sieht dem Taf. XIV. Fig. 103 von verschiedenen Seiten abgebildeten Phalangen an, dass er der erste aus dem aussern Finger oder Zehe der rechten Seite eines hirschartigen Thiers ist. Es fallt jedoch im Vergleich zu diesen an ihm hauptsăchlich auf, dass er verhältnissmässig ungefähr nur halb so lang, und seine hintere Hälfte stärker ist, als in den hirschartigen Thieren. Dieses würde indessen nicht hindern, ihn demselben Wiederkäuer beizulegen, von dem der vorhin erwähnte Canon herrührt, nämlich meinem Palaeomeryx. Dieser Phalanx misst

$$
\begin{aligned}
& \text { Länge . . . . 0,025 } \\
& \text { Breite vorn . 0,011 } \\
& \text { - hinten . . 0,012 } \\
& \text { Höhe }-\ldots 0,018
\end{aligned}
$$


Der Taf. XIV. Fíg. 100 abgebildete Knochen ist vollständig. Nirgends ist daran eine Bruchfläche wahrzunehmen. An dem einen Ende ist er dreieckig, von wo er sich nach dem andern Ende hin zu einer stumpfen gerundeten Schärfe verflacht, doch nach der einen Seite schneller, als nach der andern. Die Basis ist, besonders unter der flachern Halfte, etwas concav. Nicht genau in der Mitte, ein wenig mehr in der flacheren Hälfte, führt durch diesen Knochen ein unregelmässiges Loch, zu dem auf der untern Seite von der Gegend der schärferen Seite her eine trichterförmige Vertiefung führt. Die Knochenmasse ist sehr fest, durchaus dicht, und von gleichförmiger Textur. Behandelt man die Bruchflache mit Säure, so erkennt man, dass das Wachsthum dieses dichten Knochens mit concentrischen Lagen geschah. Nur Amphibienknochen und Nagelphalangen bestehen aus einer solchen dichten, festen Masse. Ich wüsste nicht, in welcher Gegend dieser Knochen bei einem Reptil seine Stelle eingenommen haben könnte; auch ist in der Gegend von Georgensgmünd nur Emys gefunden, an dessen Skelett ich keinen Theil kenne, der diesem Knochen zu vergleichen wäre. Es ist daher nicht unwahrscheinlich, dass dieser Knochen ein Nagelphalanx ist; aber von welchem Thier? Unter den mir bis jetzt aus dieser Ablagerung durch die Zähne bekannten Thiergattungen ist nur Palueotherium dasjenige Thier, auf welches man verfallen könnte. Von dieser Thiergattung kennt man aber noch keine lange Nagelphalangen. Diess hinderte indess nicht, in Pálaeotherium Aurelianense Nagelphalangen vorauszusetzen, welche von denen der andern Palaeotheriumgattungen grössere Verschiedenheit besitzen, als diese unter einander. Gibt es doch auch unter den Anoplotherien Gattungen, deren Nagelphalangen an den Hinterfüssen schmal und lang sind (Anoplotherium secundarium; Cuvier, III. S. 103. t. 24. f. 9), während andere kurze und breite Phalangen dieser Art haben (Anoplotherium commune; Cuvier, III. S. 87. t. 24. f. 7). Durch die langen Nagelphalangen dieser Thiere gehen auch Löcher, nach der Abbildung zu schliessen, sogar zwei, die noch etwas weiter vorwärts liegen *). Dabei gehen diese Phalangen nath vorn spitzer zu, sind etwas einwärts (beide gegen einander) gekrümmt und nicht so gleichförmig breit; sie messen 0,032 Länge und 0,015 Breite, Masse, welche bei unserm fossilen 0,034 und 0,016 betragen; letzterer ist 0,011 hoch. An diesem Knochen ist keine deutliche Fläche vorhanden, mit der er in einen andern Phalanx eingelenkt hätte; die bestehende Verbindungsfläche ist durch Zellen rauh, und eher etwas vertieft, als eben. Ist die

*) An den Seiten der Nagelphalangen in Rhinoceros liegt ein ähnliches Loch. 
trichterformige Aushöhlung, welche auf der Unterseite nach dem Loche hinführt, der Aushōhlung der Unterseite analog, welche man an einigen von den Phalangen bemerkt; die ich dem Palaeotherium beilegte? Die Breite dieses Knochens erinnert auch an die Nagelphalangen in Echidna und in Tatou, von Reptilien an die der Hände von Testudo.

Von Fleischfressern habe ich den Tafel IV. Fig. 35. a. b und Taf. XIII. Fig. 93 abgebildeten Knochen zu erwähnen, der die grōsste Aehnlichkeit mit dem fünften Knochen aus dem linken Mittelfuss (Metatarsus) von Ursus besitzt. Der analoge Knochen im Höhlenbären steht ihm am nächsten, stimmt aber mit ihm nicht vollkommen uberein. Ersterer Knochen wird eine andere Gattung anzeigen.

Der Taf. IV. Fig. 36 dargestellte zweite Knochen aus der rechten Mittelhand (Metacarpus) lag mit dem dazu gehörigen Phalangen, Fig. 37, nach des Herrn Grafen zu Münster Bemerkung, ungetrennt im festen Kalkstein zusammen. Beide Knochen habe ich von verschiedenen Seiten dargestellt. Sie besitzen die grösste Aehnlichkeit mit den analogen im Ursus spelaeus. Der Mittelhandknochen besitzt dieselbe Läuge, wie in Ursus arctos, in letzterem ist er aber nur ungefahr zwei Drittel so breit.

Die beiden letzteren Knochen werden derselben Thiergattung angehören; wie erstgenannter Mittelfussknochen, vielleicht demselben Individuum. Die Zăhne, welche ich für Fleischfresser erkannte, sind zu klein und zu wenig bärenartig, um auch dieser Thiergattung anzugehören. Dagegen schreibt mir Herr Graf zu Münster, dass in dieser Ablagerung ,auch ein grosser Fangzahn vom Bären gefunden worden", den ich noch nicht näher kenne.

\section{$\begin{array}{lllllllllllllllll}S & c & h & i & l & d & k & r & 0 & t & e .\end{array}$}

Von Schildkröte kenne ich nur die Taf. X. Fig. 83. a von oben, b von unten (innen) und c von der Seite abgebildete Rippe oder Rippenschild des Rückenpanzers. Viel ist es freilich nicht. Es genügt indess zum Beweis, dass diese Ablagerung auch Reste von Thieren dieser Ordnung umschliesst. Die Tertiärablagerungen von Hohenhöven sind ihrer Schildkröten wegen berühmt. Die Thiere, mit denen sie dort zusammenliegen, sind wahrscheinlich Wiederkäuer und Fleischfresser; das Gebilde 


\section{$-122-$}

ist Helix fuhrender Süsswassergyps. Die Gattung der hieraus bekannten sieben Schildkrötenindividuen nannte Bronn*) Testudo antiqua. Vorliegende Rippe gleicht am ersten Emys, weicht aber davon dadurch ab, dass sie nach einer Seite hin, hier nach der, wo sie den unparigen Schildern ansass, welche von vorn nach hinten über den Rücken gehen, breiter wird, wodurch sie Testudo sich nähern würde. Diese Abweichung ist indess selbst noch an einer Emys aus ganz jungen Torfmooren wahrzunehmen, wie ich demnächst näher darlegen werde. Die Querstreifen auf der fossilen Rippe sind für die Schildkröte von Georgensgmünd bezeichnend, weshalb ich sie Emys striata nenne.

*) Nova Acta Acad. Leop. Carol. Nat. Cur. XV. 2. S. 201. 


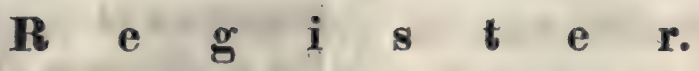

Ablagerung von Georgensgmünd, 29.

Abnutzungsfläche, 18, 27.

Aceratherium, 62, s. Rhinoceros incisivus.

Alveole, 23.

Analogie, 3, 9; Trüglichkeit derselben, כ̌. Anthracotherium, 8.

$$
\text { - }
$$

$\begin{array}{ll}" & \text { Alsaticum, 61. } \\ " & \text { magnum, 59. } \\ " & \text { minimum, 60. } \\ " & \text { minus, 60. } \\ " & \text { von Puy, 61. } \\ " & \text { Silistrense, 62. }\end{array}$

Antilope, 101.

Aper Arvernensis, 58.

Babirussa, 44, 51.

Backenzähne, 15, 23, 27; unter einander verglichen, 20.

Cachalot, 18.

Canis, 18.

Cervus nanus, 99.

" von Westeregeln, 65 Note.

- Chaeropotamus, 8.

$" \quad$ Meissneri, 51.
$" \quad$ Parisiensis, 52.
$\Rightarrow \quad$ Soemmerringii, 55.

Chinchilla, 7.

Classificationsmethode, 11.

Daman, s. Hyrax.

Dinotherium, 7.

2 Bavaricum, 49.

Dorcatherium, 97.

Dremotherium, 101.

Dugong, 8, 16.
Eckzähne, 15, 23.

Elephas, 13, 14, 16, 19.

Elfenbein, 19, 23.

Emys striata, 121.

Ersatzzahn, 23.

Felis, 103.

Fleischfresser von Georgensgmŭnd, 102, 121.

Gaumenbewaffnung, 17.

Hippopotamus, Vorderzähne, 16.

$$
\text { " medius, } 8 .
$$

Hirsch, s. Cervus.

Hundszähne, s. Eckzähne.

Hyotherium, 8, 43, 106.

Hyrax, 16, 75.

Keimzahn, 18, 24.

Kernsubstanz, 18, 23.

Kronzahn, 23.

Lagostomus, 7.

Lophiodon, 75.

" Aurelianense, 113.

" giganteum, 109.

Lückenzahn, 28.

Machairodus, 8.

Mahlzähne, s. Backenzăhne.

Mastodon, 16.

\# angustidens, 8, 33, 38-41, 107.

\# Arvernensis, 36, 38, 41.

Merycotherium, 93.

Milchzahn, 23.

Moschus, 14, 94, 100.

Mustela, 103. 
Nager, Vorderzãhne, 15.

Narval, 14.

Odontologie, 1, 22.

Palaeomeryx, 92, 107, 112, 114, 119.

Palaeotherium, 69, 75, 80, 112.

, Aurelianense, 81, 109, 115, 116, $118,120$.

\% Isselanum, 88.

\%. magnum, 75, 108.

Plan geschaffener Formen, 3.

Querzahn, 23.

Reisszahn, 23.

Rhinoceroïdes Alleghaniensis, 68.

Rhinoceros, Schneidezähne, 16.

" incisivus von Eppelsheim, 62, 76; von Georgensgmünd, 30, 62; von Mombach, 109, 110; von Oppenheim, 109; von Westeregeln, 65.

y leptorhinus, 68 Note.

" minutus, 64, 67.

\% Schleicrmacheri, 62, 80.

" tichorhinus, 66 Note.

" von Vintheim, 99.

9. ohne Horn, lebend, 63 Note.

Rhinocerosartige Thiere von Frankfurt, 109; von

Georgensgmünd, 30, 62, 104, 107, 119.

Rindensubstanz, 18, 23.

Schmelzsubstanz, 18, 23.

Schneidezähne, 15, 23, 27.

Schweinsartiges Thier von Georgensgmünd, s.

Hyotherium; vom Irawadi, 55; jüngerer

Gebilde, 58; von Vintheim, 99.

Steneodon, 7.
Stockzähne, 23.

Sus antediluvianus, 57 .

, antiquus, 56.

" (Aper) Arvernensis, 58.

"palaeochoerus, 56.

2priscus, 58.

"Scrofa, 44.

Tapir, Vorderzähne, 16.

Tetracaulodon, 8, 33, 41.

Ursus, 121.

$\Rightarrow$ cultridens, 7 .

Vintheim, 99.

Viverra, 103.

Wallross, 13, 16.

Wechselzahn, 23.

Westeregeln, 65 Note.

Wiederkăuer, von Bengalen, 100; von Georgensgmünd, s. Palaeomeryx; von Montabusard, 99; der Schweiz, 101; von Vintheim, 99.

Zahnaxe, 24.

Zahnbreite, 24.

Zahnliöhe, 24.

Zahnkrone, 21.

Zahnlänge, 24.

Zahnreihe, 22.

Zahnsubstanzen, 18, 23.

Zahnsystem, 22.

Zahnwechsel 12, 23.

Zahnwurzel, 17.

Zähne u. ihre Verschiedenheit, 1, 6, 7, 9, 11, 13, 22 .

Zähne von Georgensgmünd, 33; deren Classification ungewiss ist, 103.

Zwischenkiefer, 15. 


\section{Hinweisung der Abbildungen anf die Beschreibung.}

Tafel 1. Fig. 1. Seite 33.

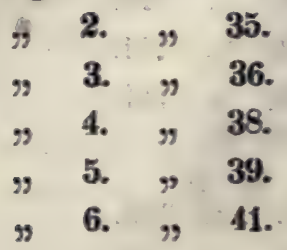

Tafel II. Fig. 7. Seite 38.

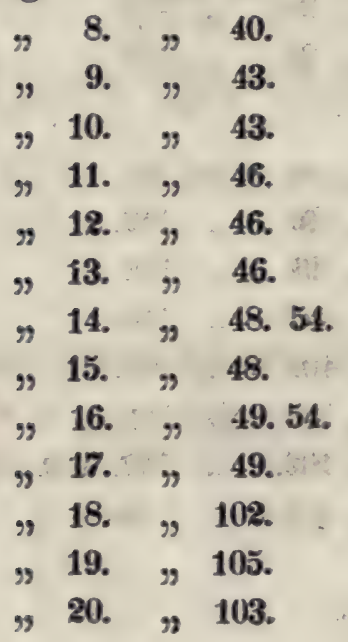

Tafel III. Fig. 21. Seite 63.

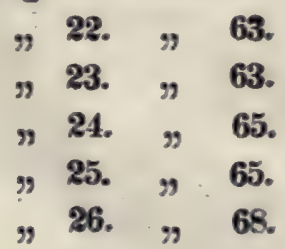

Tafel IV. Fig. 27. Seite 69. 71.

$$
\begin{array}{llll}
\eta & 28 . & & 69.71 . \\
\eta & 29 . & \eta & 69.72 . \\
\eta & 30 . & \eta & 69.70 .
\end{array}
$$

Tafel IV. Fig. 31. Seite 69. 72. 74.

$$
\begin{aligned}
& \text { " 32. }, 69.73 . \\
& \text { 33. } \% 69.73 . \\
& \text { 34. }, 65 \text { Note. } 72 . \\
& \text { 35. }, 121 . \\
& \text { 36. y } 121 . \\
& \text {, 37. }, 121 .
\end{aligned}
$$

Tafel V. Fig. 38. Seite 64.

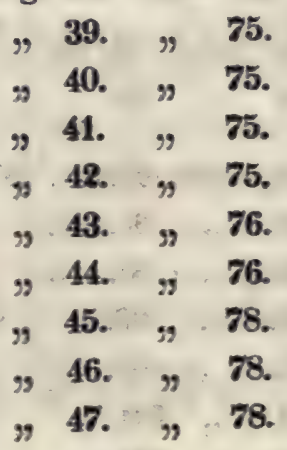

Tafel VI. Fig. 48. Seite 7.

$$
\begin{array}{llll}
\text { " } & 49 . & & 77.79 . \\
& 50 . & & 80 . \\
& 51 . & & 80 . \\
& 52 . & 7 & 75 .
\end{array}
$$

Tafel VII. Fig. 53. Seite 81. 87.

$$
\begin{aligned}
& \text { \%54. } 81.87 . \\
& \text { ת 55. } \Rightarrow 85.86 \text {. } \\
& \text { \%56. } \% \text { 84. } 86 \text {. } \\
& \text { 957. } 39 . \\
& \text { و58. }, 86 . \\
& \text { \% } 59 \text {. } 786.88 . \\
& \text { भ } 60.98 .
\end{aligned}
$$


Tafel VIII. Fig.61. Seite 81. 86.

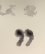

$$
\text { 62. }, 87 .
$$

و 63. $" 85$.

, 64., 89.

"65., 89.91.

\%66. $\Rightarrow 91$.

967. 99.

"68., 91.

" 69. ", 89.

"70. $\Rightarrow 88$.

,71., 89.

72., 105.

,73. 105.

\%74. $\%$ 89. 106.

Tafel IX. Fig. 75. Seite 93. 96.

$$
\text { " 76. } \Rightarrow 99 \text {. }
$$

Tafel X. Fig. 77. Seite 93. 95. 97.

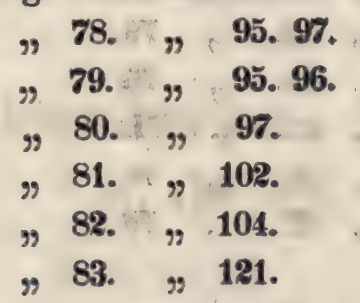

Tafel XI. Fig. 84. Seite 112. \% 85., 114.

Tafel XII. Fig. 86. Seite 108.

$$
\begin{array}{llll}
\Rightarrow & 87 . & & 108 . \\
" & 88 . & \Rightarrow & 110 . \\
" & 89 . & \Rightarrow & 111 . \\
\Rightarrow & 90 . & \Rightarrow & 111 .
\end{array}
$$

Tafel XIII. Fig. 91. Seite 115.

$$
\begin{aligned}
& \text { "92. }, 116 . \\
& \text { "93. \# } 121 . \\
& \text { "94. }, 110 . \\
& \text { "95. } 1112 .
\end{aligned}
$$

Tafel XIV. Fig. 96. Seite 115.

,97., 117.

"98. " 118.

,99. $\because 118$.

"100., 120.

"101. " 111.

"102. $" 112.119$.

, 103. 


\section{䡛 U \\ SENGK ENBER GIANUM. \\ A b h a nd lung en \\ a $\mathbf{s}$ d e m \\ Gebiete der beschreibenden Naturgeschichte.

$$
\text { Von }
$$

Mitgliedern der Senckenbergischen naturforschenden Gesellschaft in Frankfurt am Main.

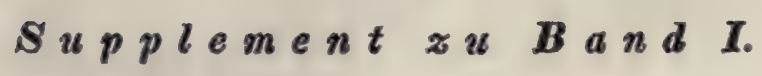

\section{Frankfurt am Main.}

Druck und Verlag von Johann David Sauerländer. 


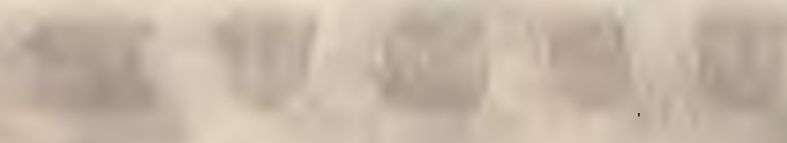

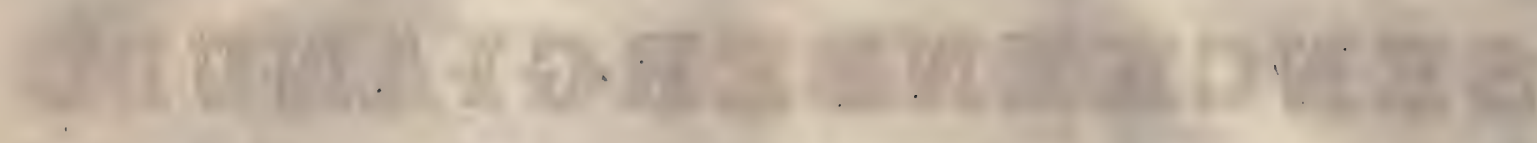 \\ toge a whoteds 4

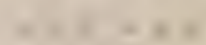

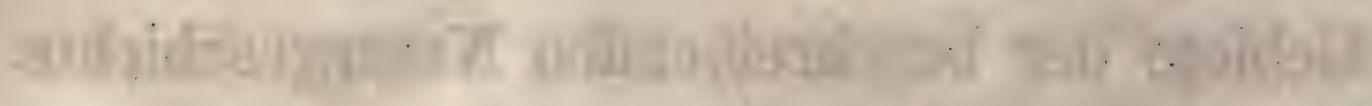

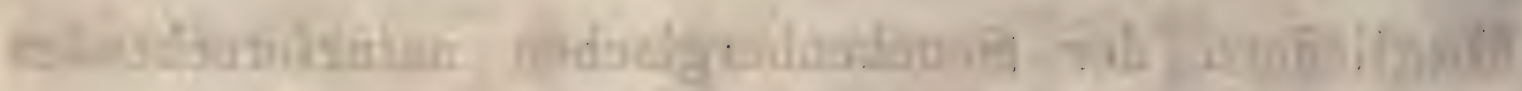

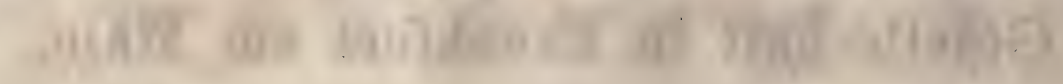

$$
\begin{aligned}
& \text {-1. - . - n- } \\
& \therefore=
\end{aligned}
$$

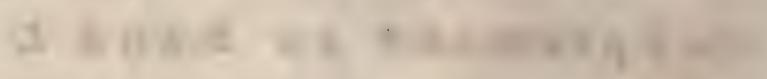

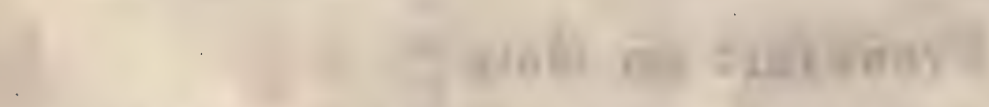

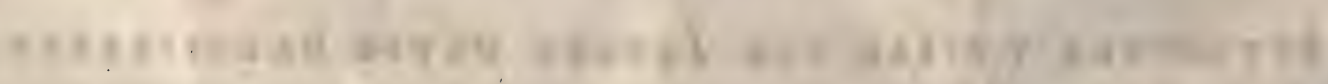

$$
\text { whe }
$$



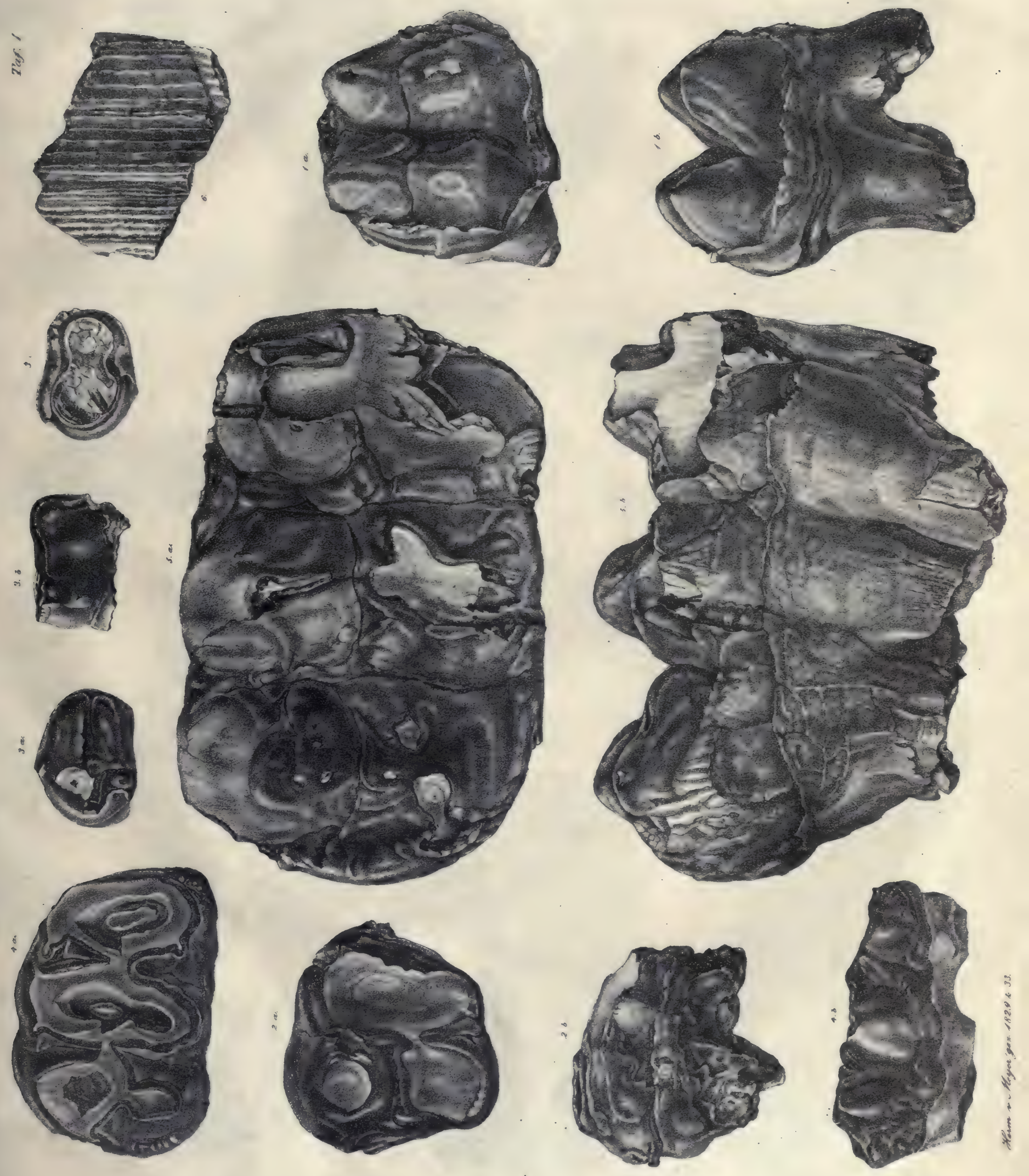



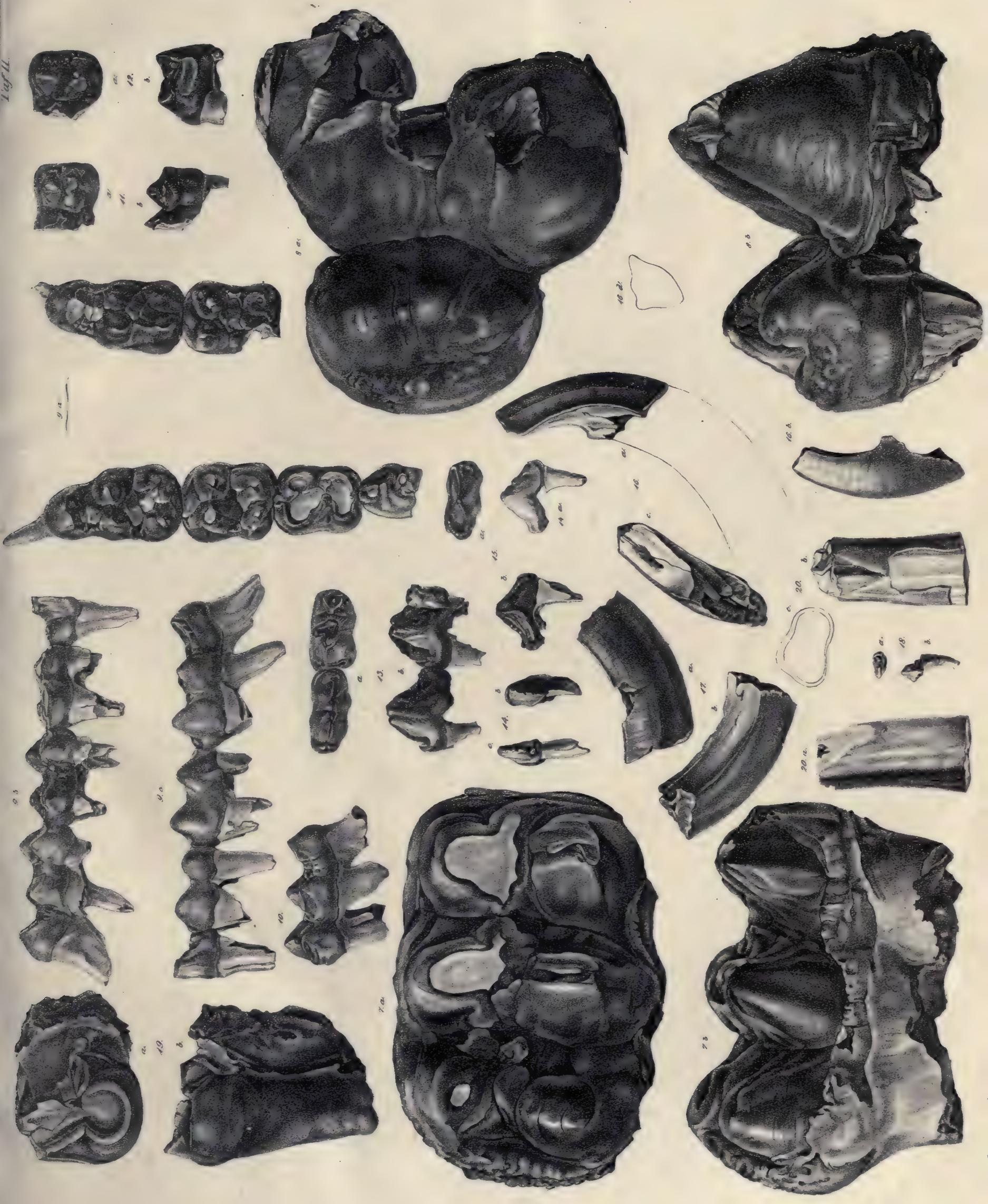






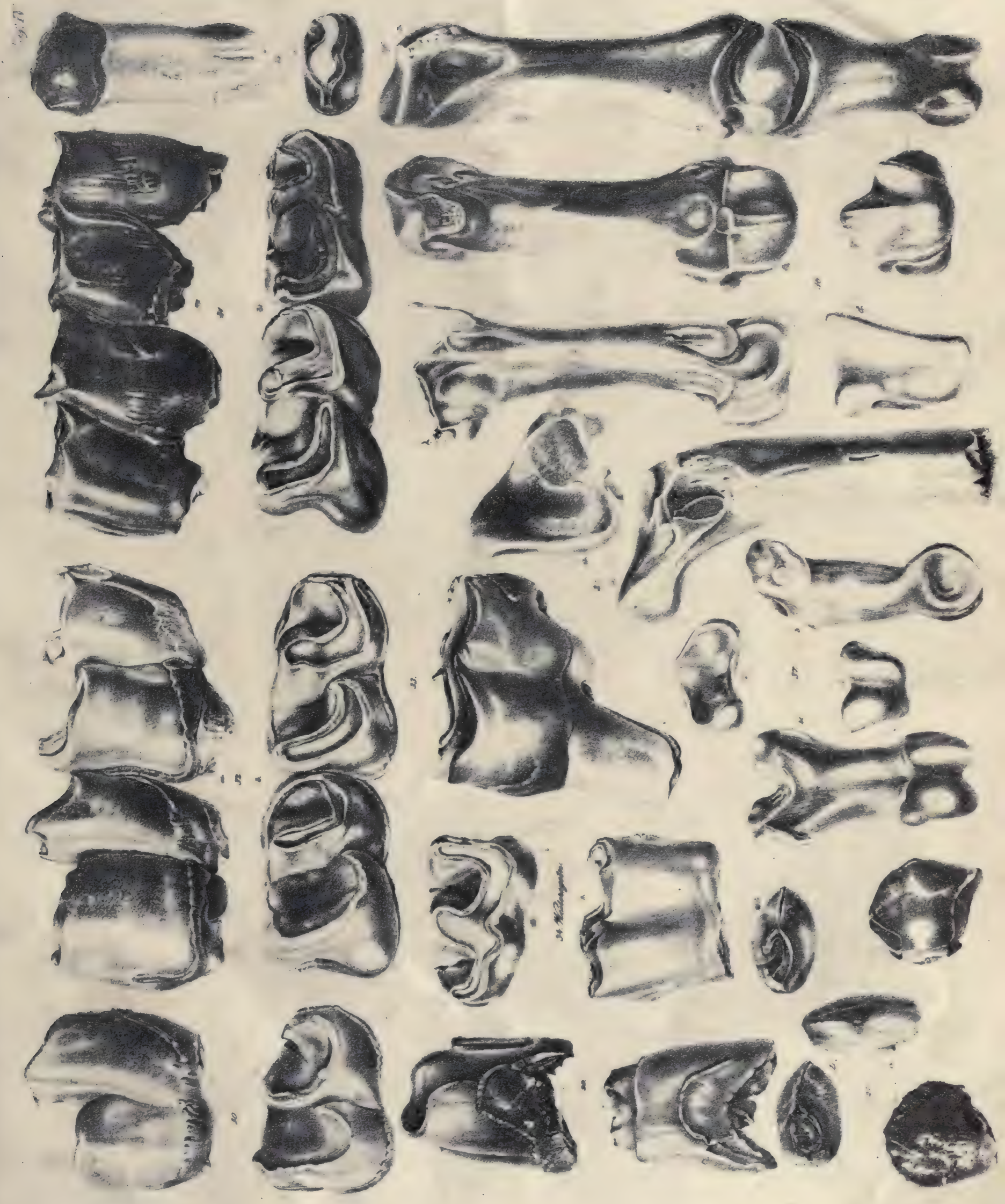





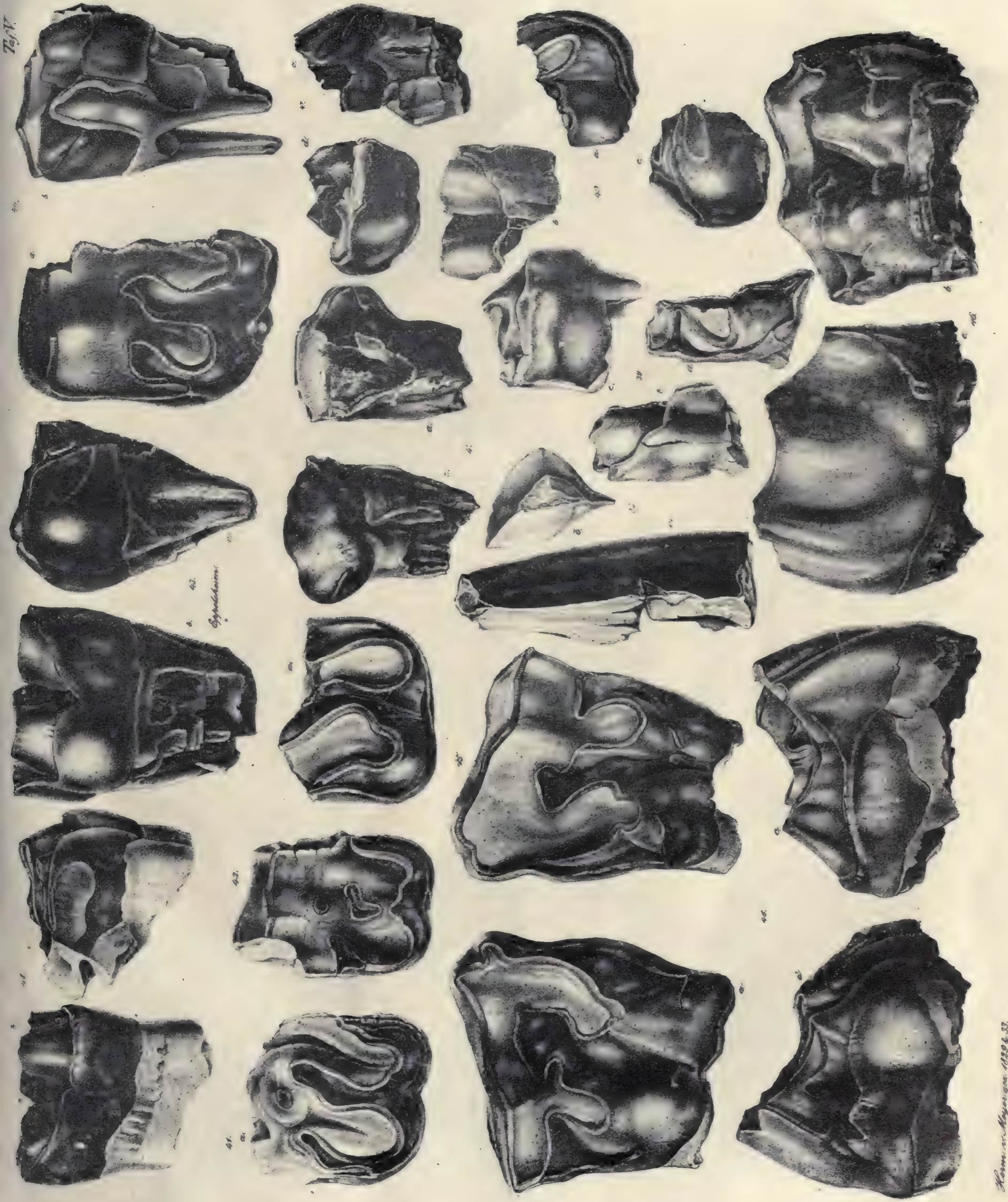




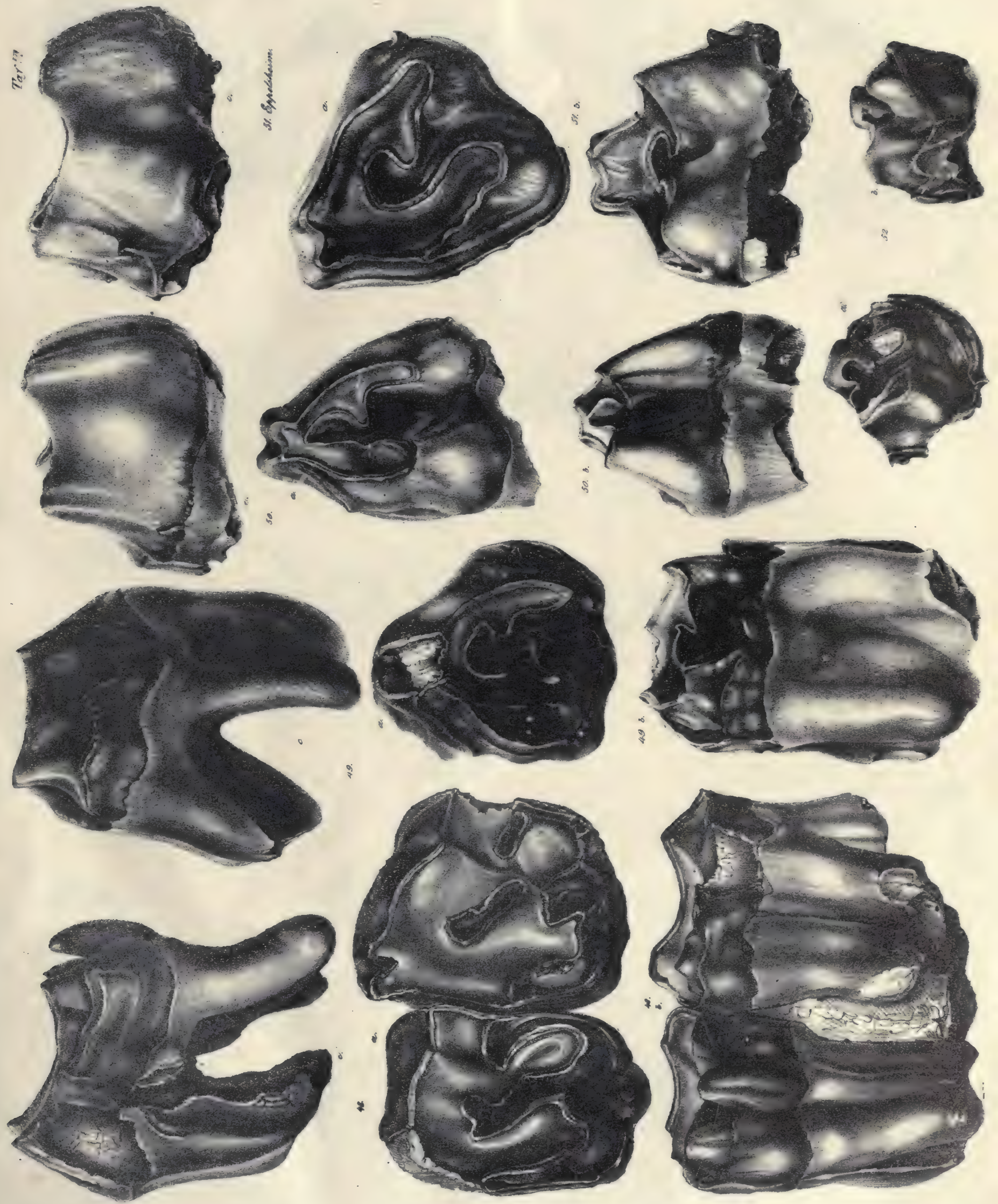



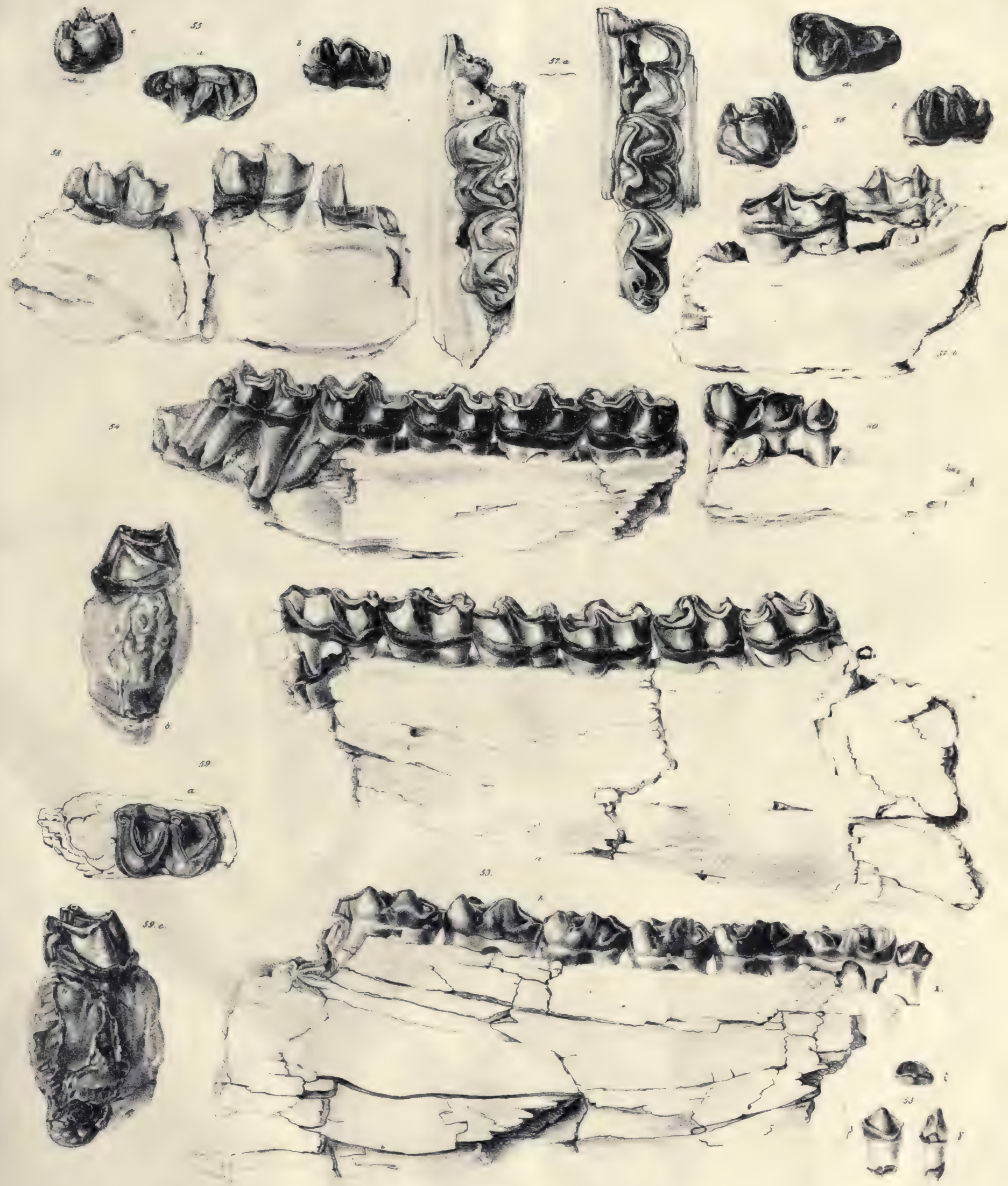




(14) D. (2) 1

(2)

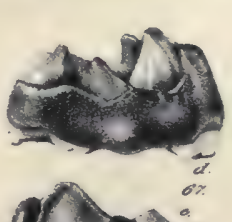
Qu

1

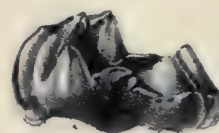

1.

6

通
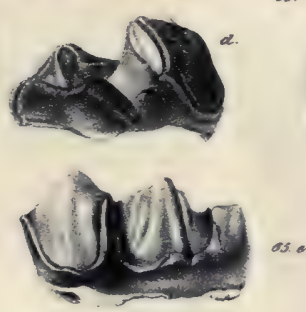

(1) 3
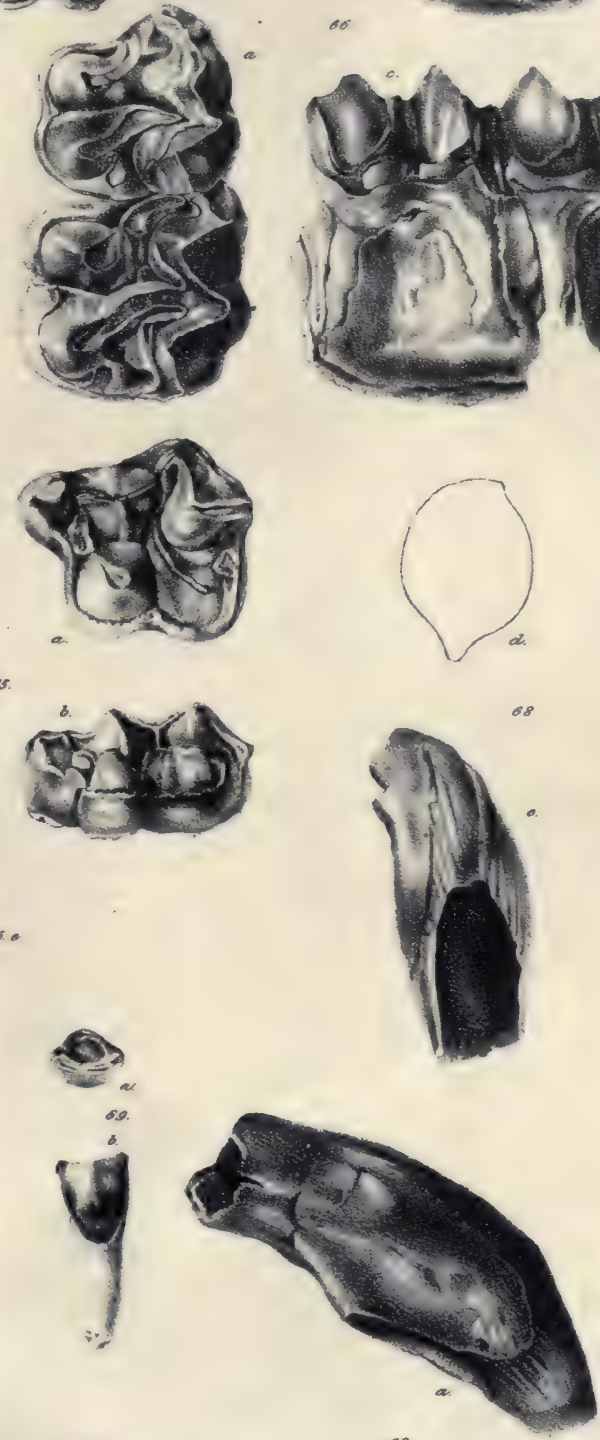

3
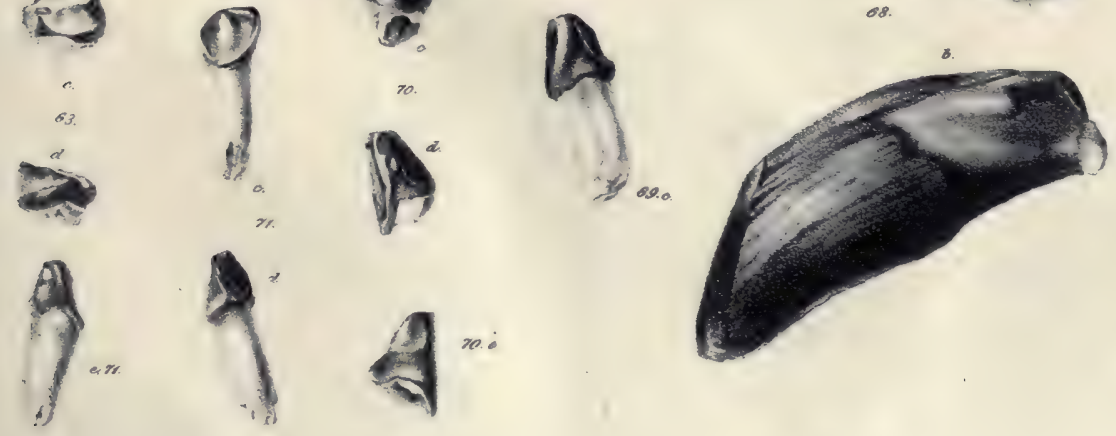
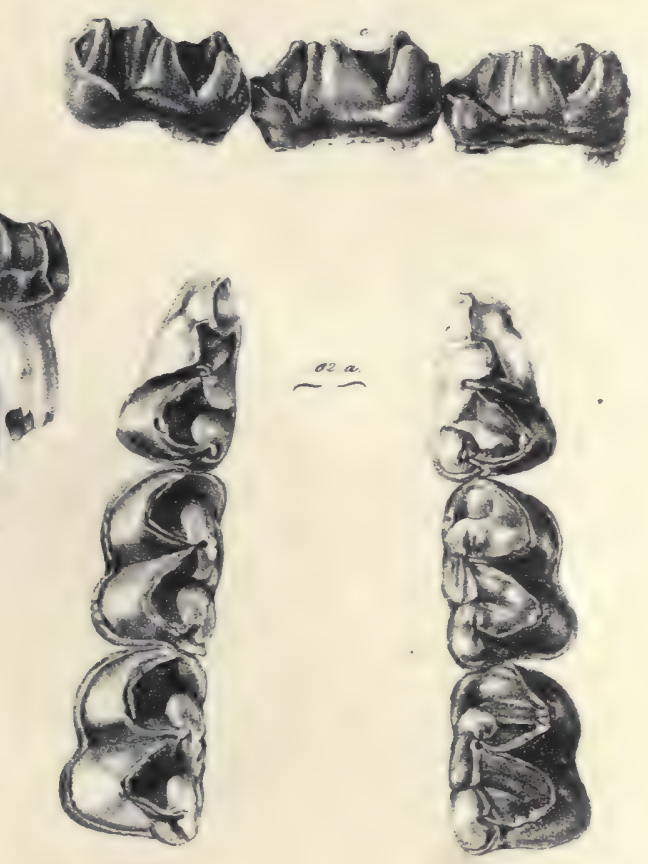

nouty
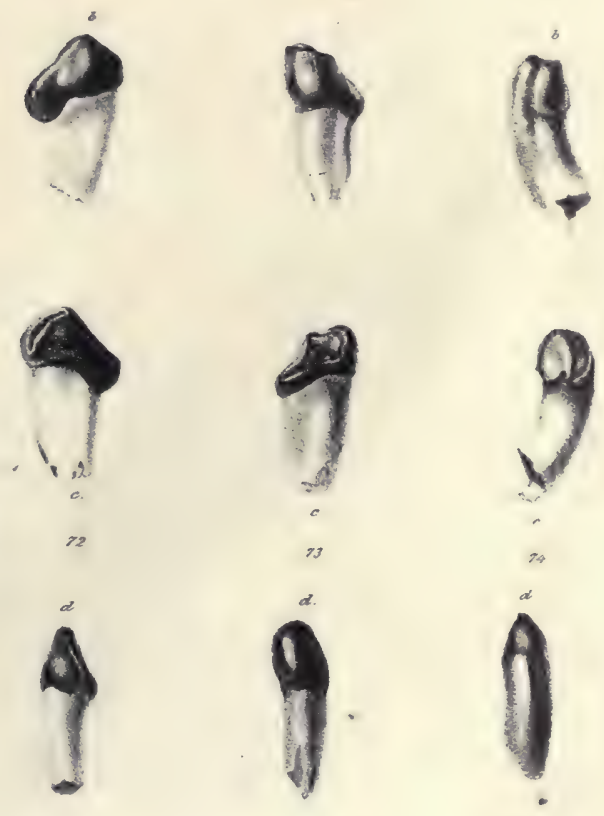



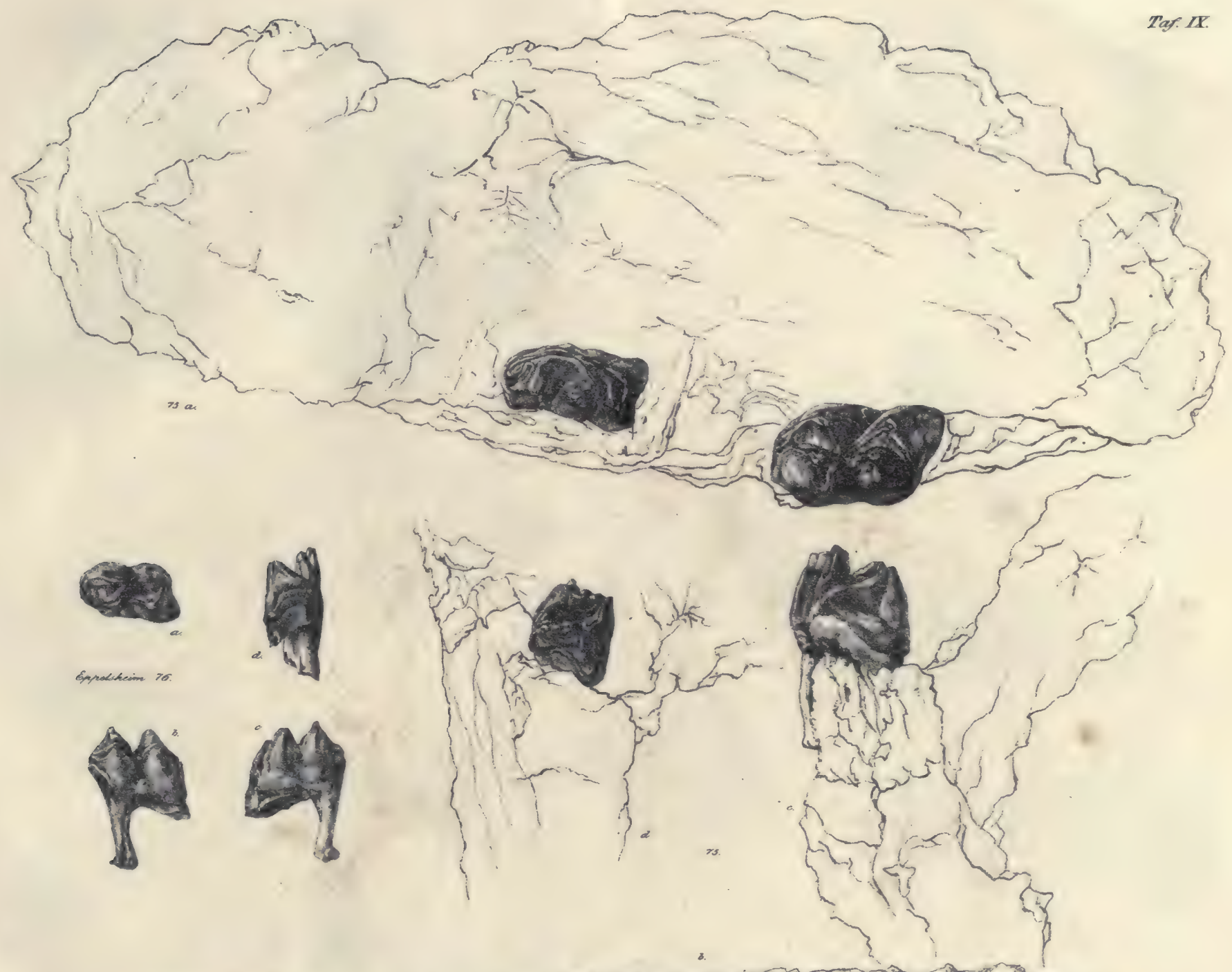

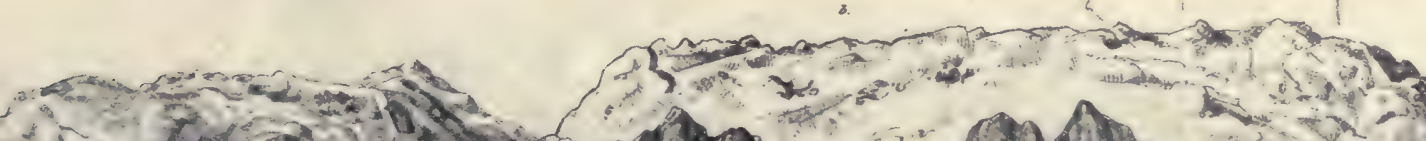

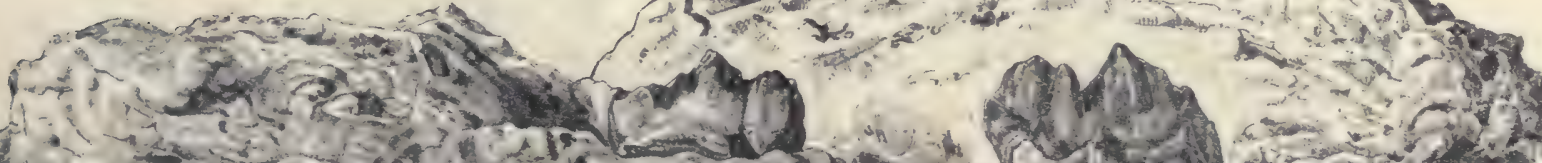

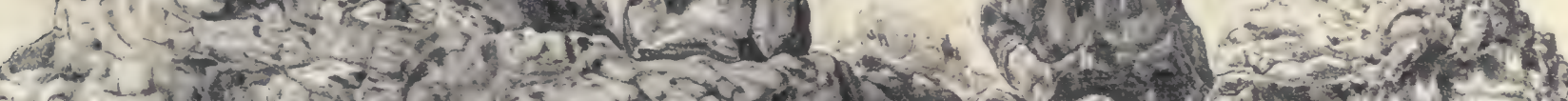

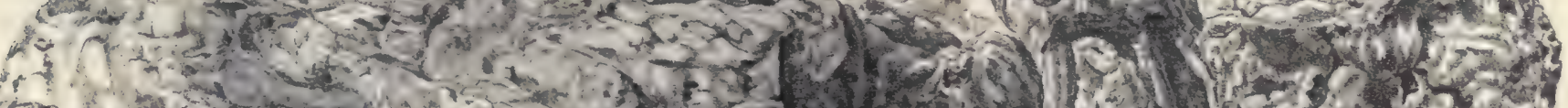

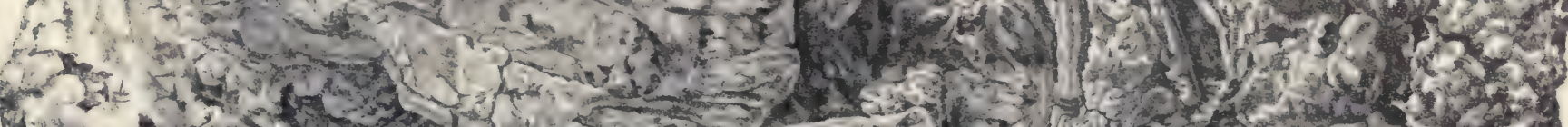

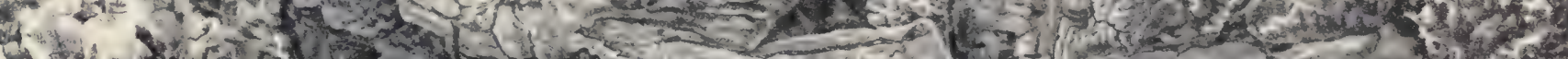

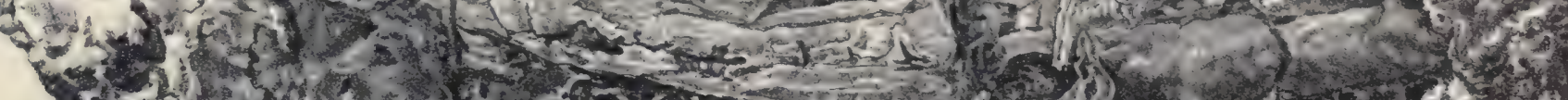

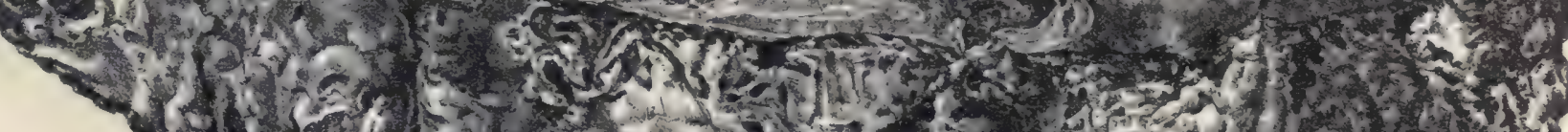

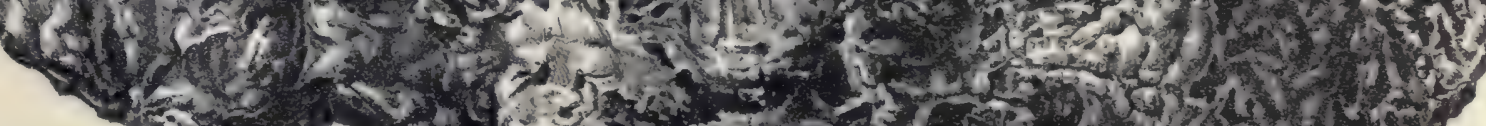

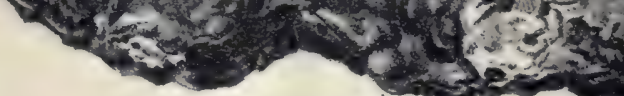




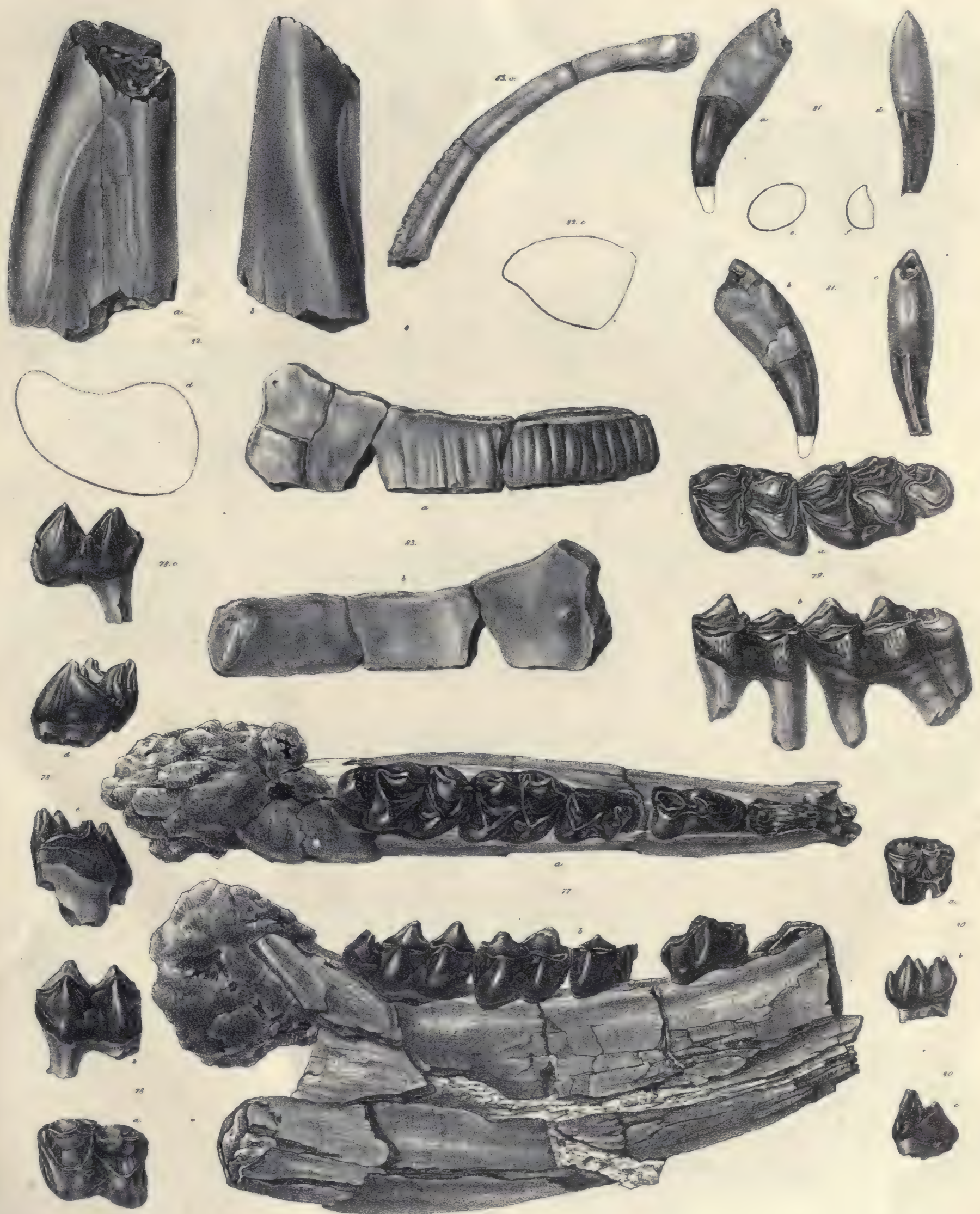


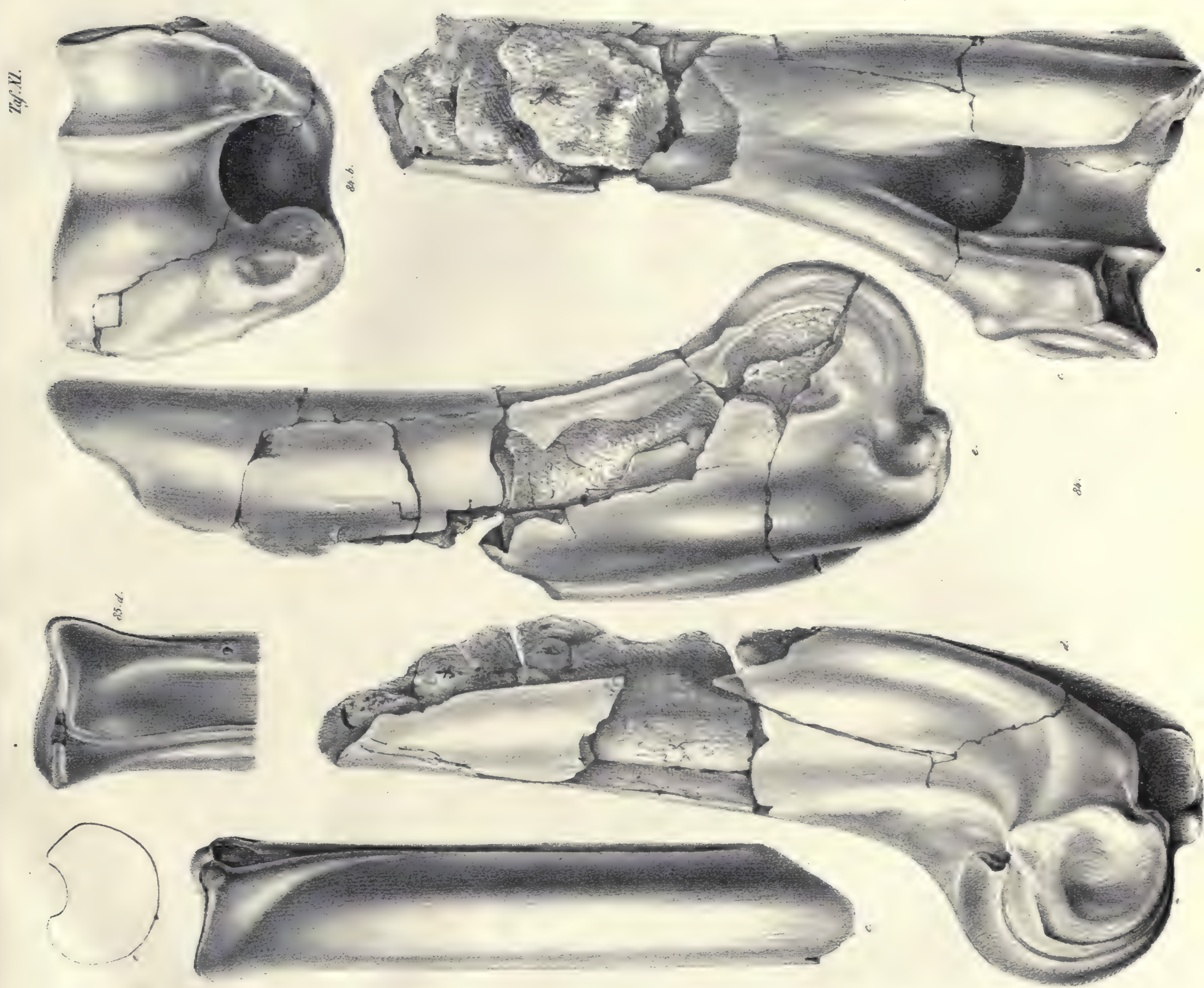

8
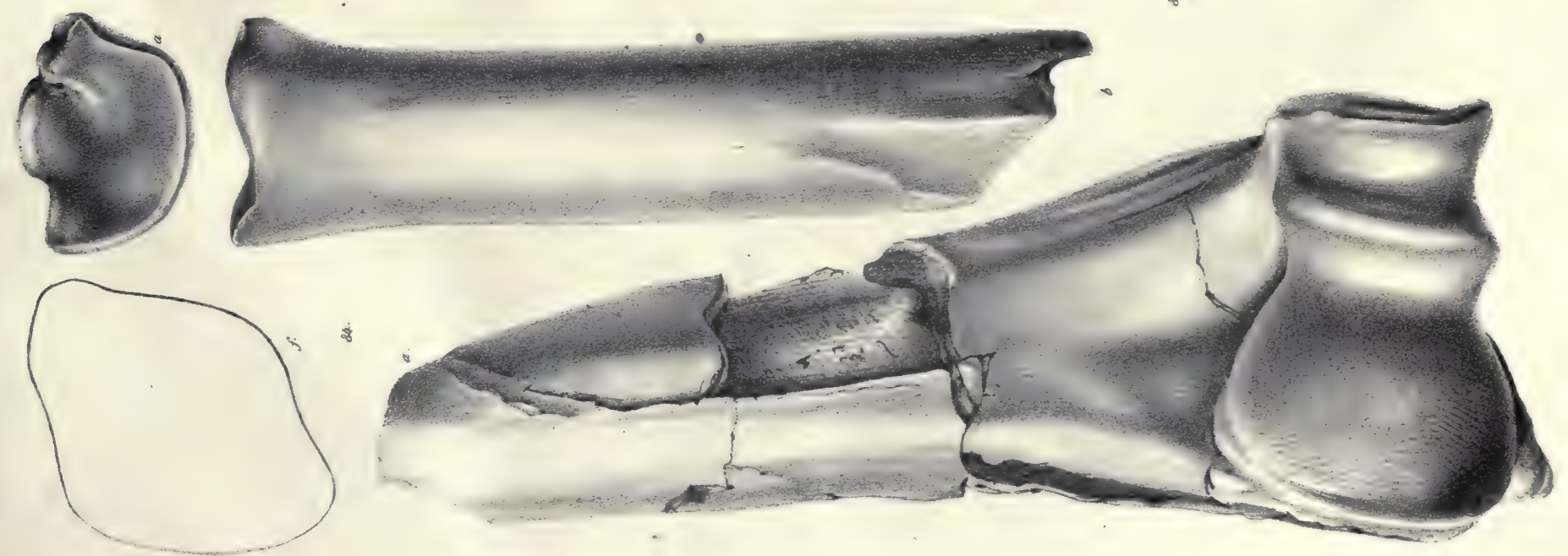



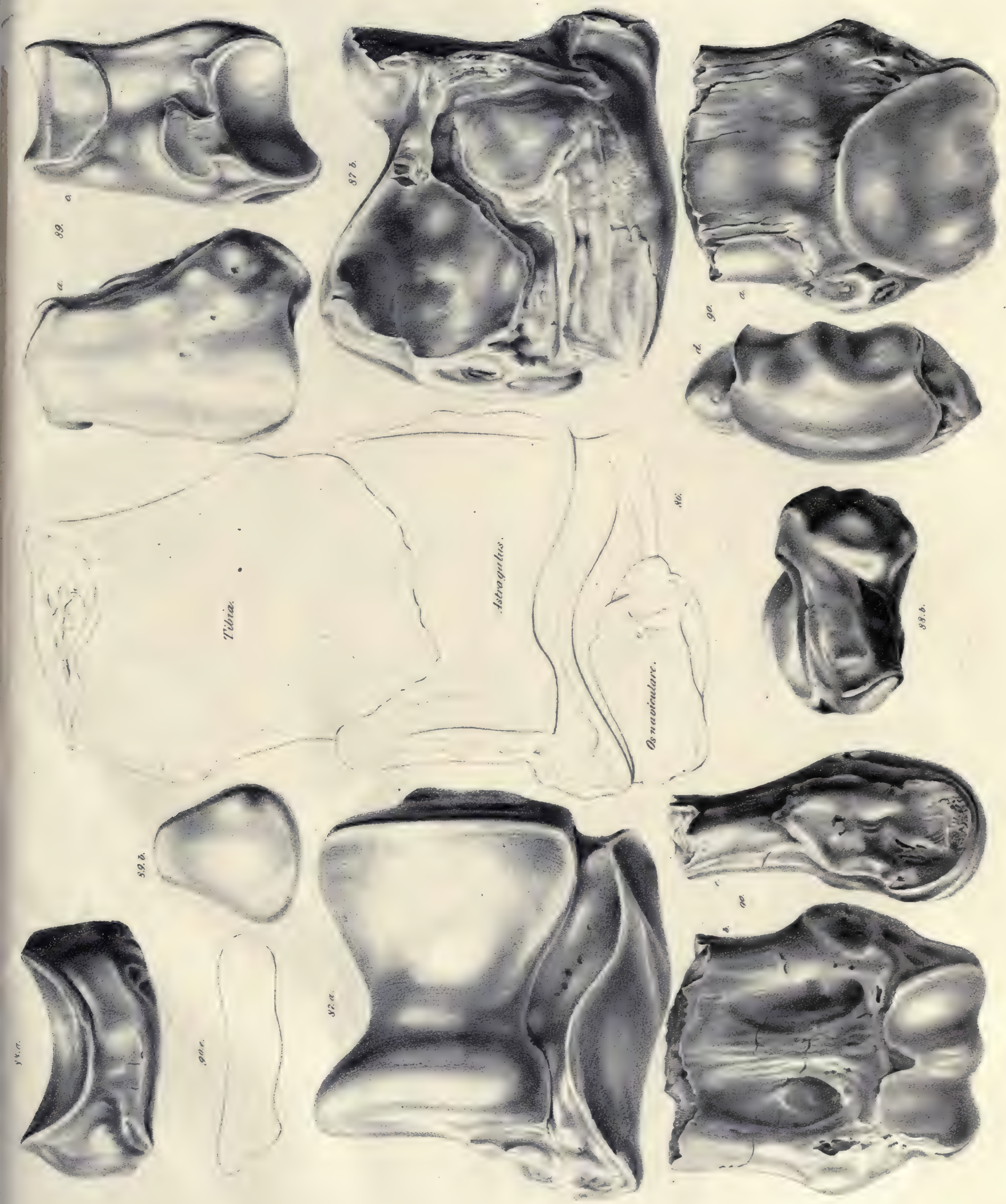





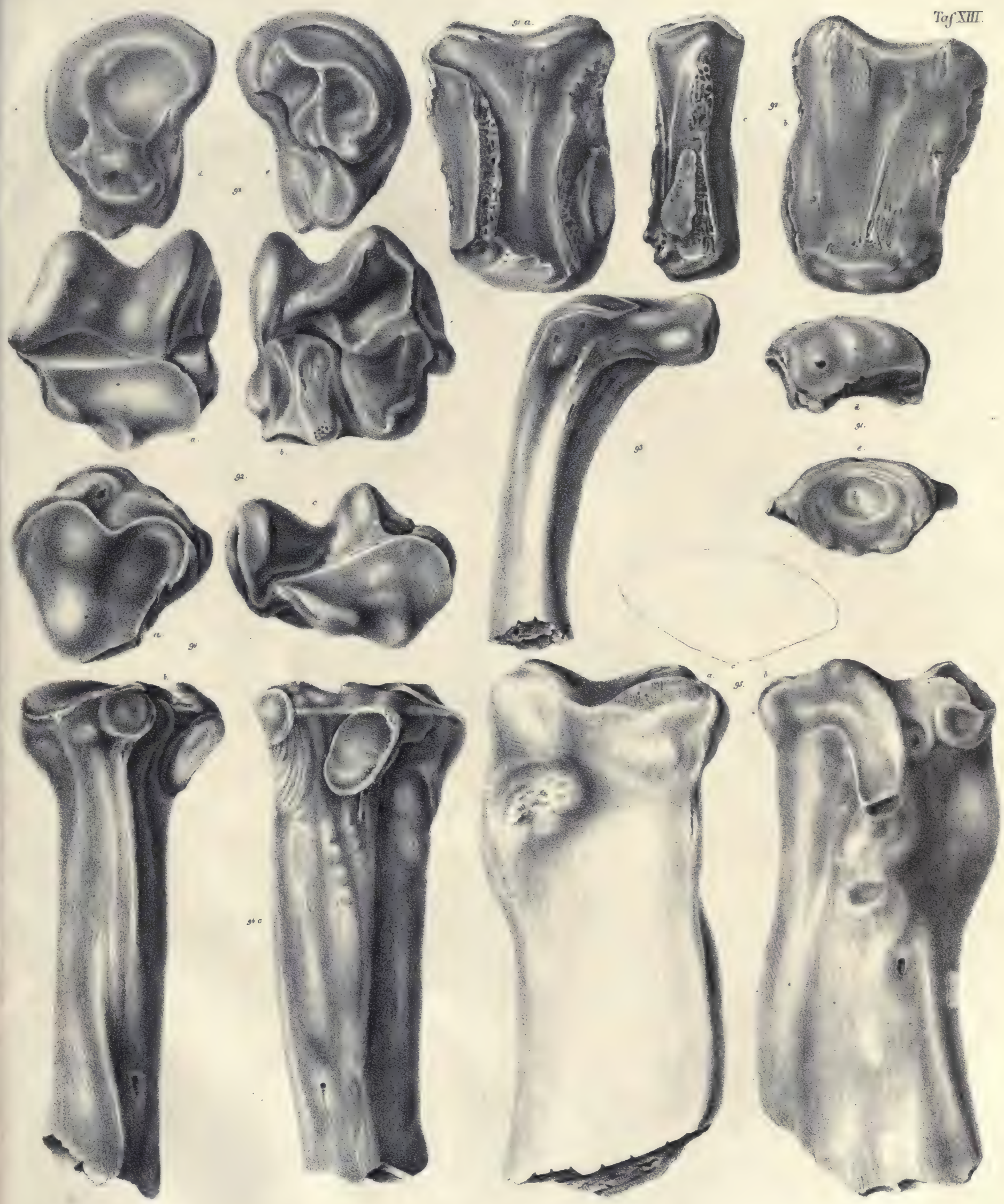





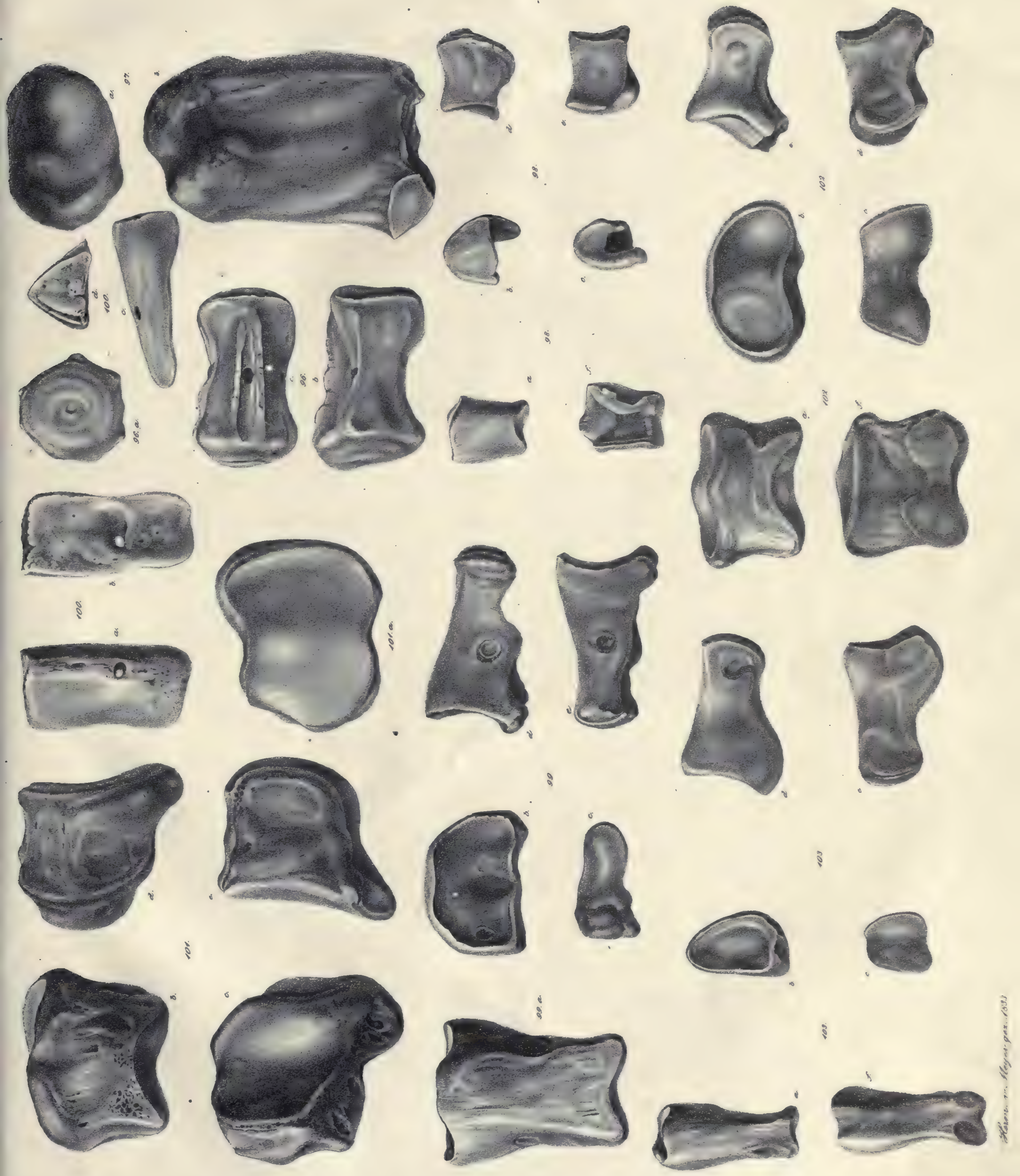




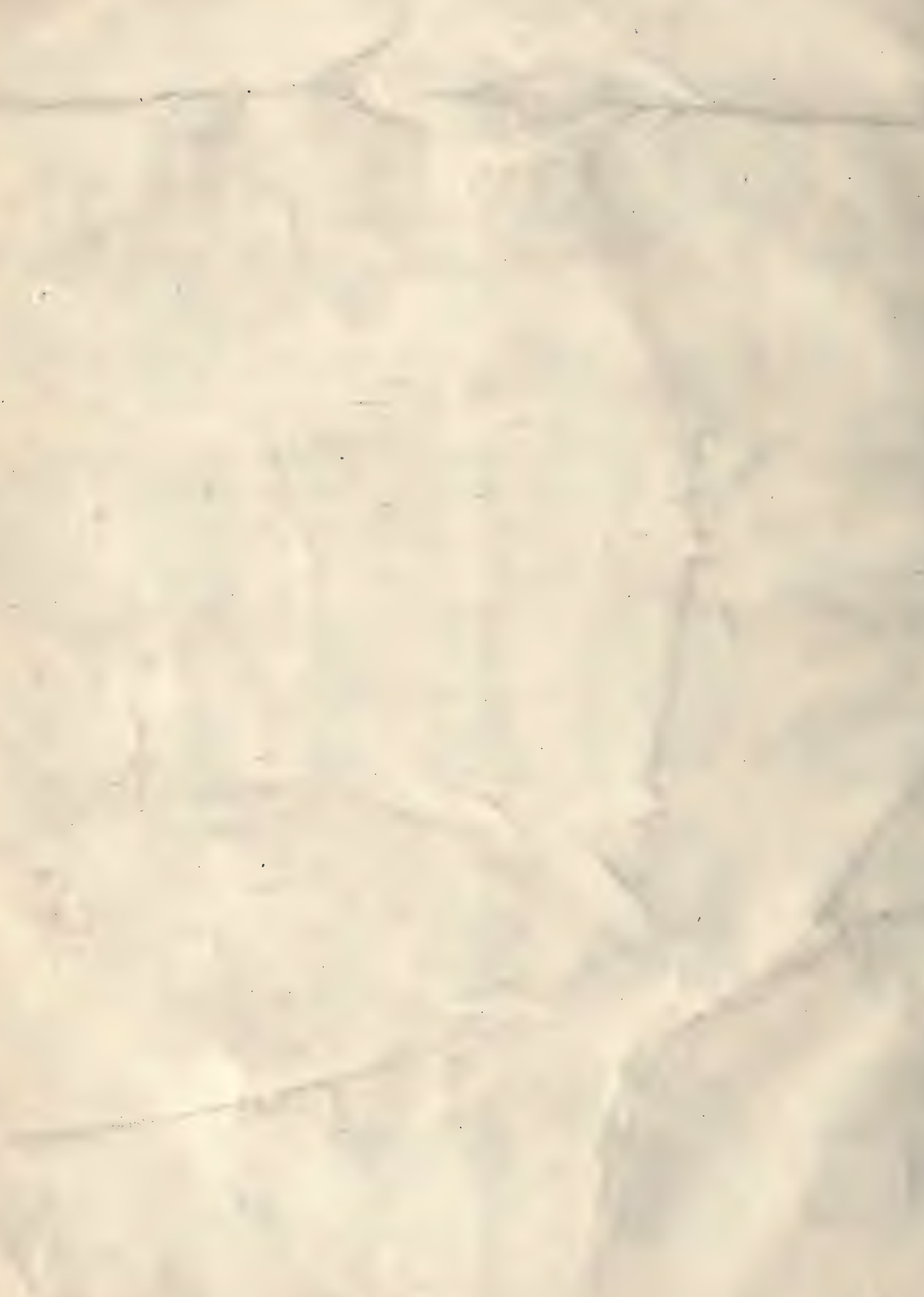




QE Meyer, Hermann von

755 Die fossilen Zähne und Knochen

G4M4 und ihre Ablagerung in der Gegend von Georgensgmind in P\&ASci Bayern. 1834.

PLEASE DO NOT REMOVE CARDS OR SLIPS FROM THIS POCKET UNIVERSITY OF TORONTO LIBRARY 


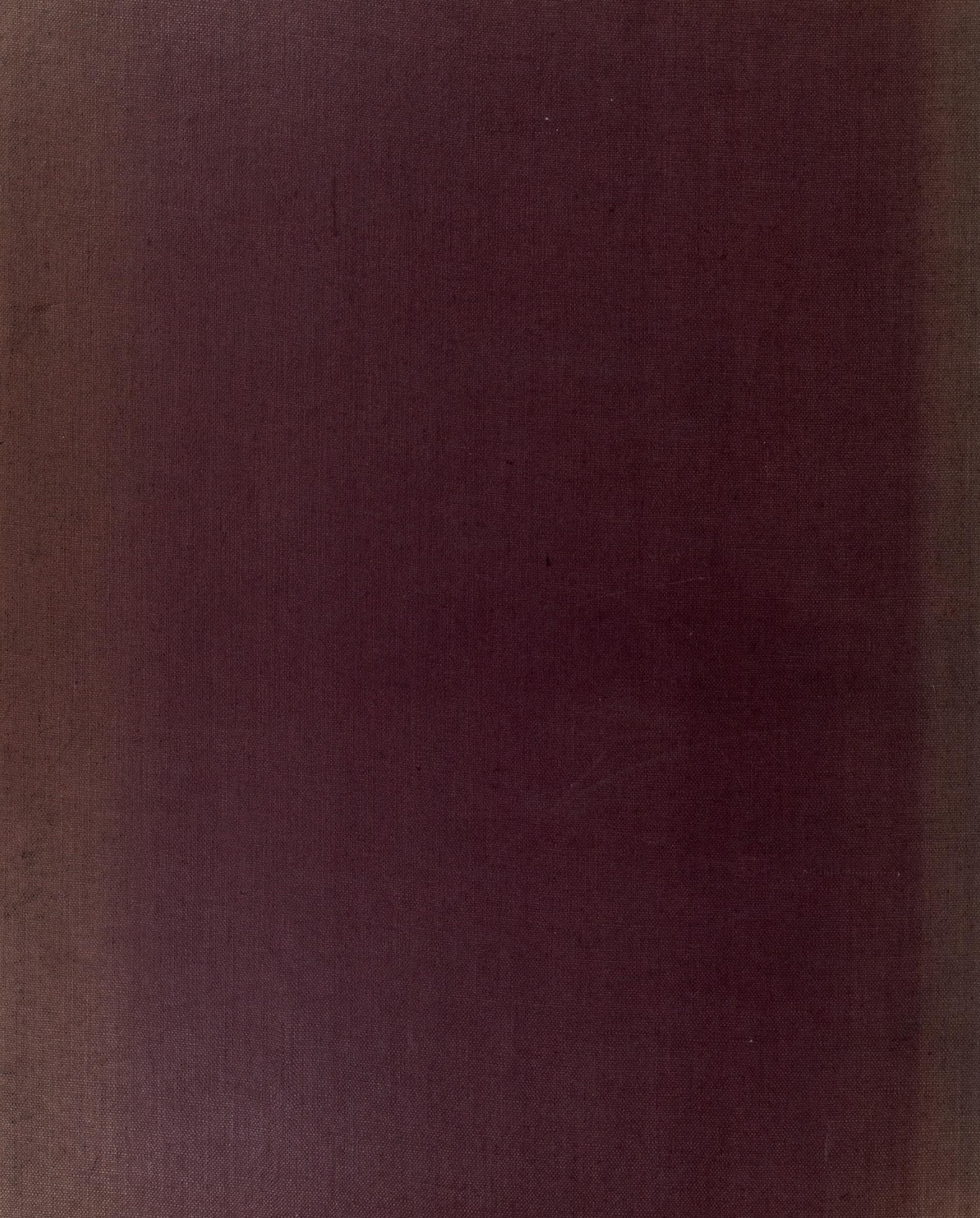

